Doctorado en Filosofía

Facultad de Humanidades y Ciencias de la Educación

Universidad Nacional de La Plata

\title{
Ecología y Praxis Ambiental
}

\author{
Una revisión de presupuestos
}

Doctoranda: Paula Gabriela Núñez

Dirección: Dra. María Luisa Femenías

Co-Dirección: Dr. Francisco Naishtat 


\section{Agradecimientos}

A María Luisa que me contuvo y orientó en uno de los procesos más difíciles de mi aprendizaje.

A Marcelo, quien sin saberlo resultó fundamental en este trabajo

A Daniel, interlocutor permanente y fuente de sentido común.

A Pedro, por facilitar la continuidad de mi reflexión, enriqueciéndola al permitirme, no sólo conocer nuevas ideas, sino trabajar con un equipo generoso y ameno.

A Olga y Mario, Beba y Bebe Dillon, Lucy, Pablo, Marisa, Martín, Carolina, Cecilia Por brindarme apoyo y honrarme al compartir sus ideas. 
Índice

Agradecimientos 2

Índice 3

Presentación preliminar $\quad 6$

- La elección del tema de estudio 8

- El contexto del problema 11

- Metodología 13

- Objetivos generales y específicos 18

- Hipótesis 19

- Breve esquema sobre la organización del escrito 20

Primera Sección: Los debates y sus límites

- Capitulo1: Ecología: Algunos aportes desde la epistemología 24

- Introducción 25

- La ecología en el mapa de las ciencias biológicas 26

- Los supuestos de la ecología en el marco de la 27 biología

- Ecología: Ciencia y Sociedad a lo largo del 28 tiempo

- La ecología en el tiempo

- I. Los primeros años 29

- II. La introducción de la experimentación 42

- $\quad$ III. Las dudas como estrategias de investigación 48

- Las reflexiones sobre ecología 55

- Consideraciones finales del capítulo 58

- Capitulo 2: Ecología: la arena de prácticas y debates 61

- Introducción 62

- Sociedad y Naturaleza en la modernidad 63

- Las reivindicaciones ambientalistas 81

- La ecología en disputa 85

- Naturaleza y reflexión política 91

- Repaso sobre las teorías políticas 101

- Consideraciones finales del capítulo 102 


\section{Segunda Sección: Los pilares de los "puntos ciegos"}

- Capítulo 3: Naturaleza: Jerarquía, Control, Dominio 105

- Introducción 106

- El orden de la naturaleza 107

- El origen aristotélico del orden jerárquico de la 108 naturaleza

- El orden taxonómico 112

- El ocultamiento de las tensiones 124

- Consecuencias empíricas de la pervivencia de 127 jerarquías

- El sostén de las jerarquías 133

- El desafío del reconocimiento 137

- Teoría de género 138

- El camino el ecofeminismo 140

- Consideraciones finales del capítulo 142

- Capítulo 4: Sociedad y Naturaleza, antagónicas, excluyentes y 144 exclusivas

- Introducción 145

- Filosofía de género y metáfora 147

- Las metáforas que homologan 148

- Inequidad estructural y mitos asociados 153

- El caballo como héroe, el humano como peligro 154 natural

- Ios ecofeminismos 161

- Las relaciones sociedad-naturaleza, con el acento 173 en la naturaleza

- Las relaciones sociedad-naturaleza, con el acento 181 en la humanidad

- Consideraciones finales del capítulo

\section{Tercera sección: El terreno de las prácticas}

- Capítulo 5: Praxis ambiental, el desafío pendiente 189

- Introducción 190

- Primeras aproximaciones teóricas 191

- El concepto de praxis 194 
- El desafío de la praxis ambiental 204

- El aporte antropológico 204

- La definición 207

- La praxis ambiental y las instituciones 209

- Praxis ambiental y ecología 218

- Praxis ambiental y producción de conocimiento 220

- Vínculos posibles, quiebres heredados 225

- Repensar la praxis desde la experiencia 226

- Consideraciones finales del capítulo 231

\section{Cuarta sección: Consideraciones finales 234}

- Recapitulación 235

- Conclusiones: temas pendientes y vías de reflexión

- I- El reconocimiento del marco desde el cual se elabora la reflexión: la globalización

- $\quad$ II- Los temas pendientes 248

- II - 1- La situación de la ciencia 248

- II - 2- La permanencia del dominio 252

- II - 2.1- La dialéctica hegeliana del amo y el 253 esclavo

- $\quad$ II - 2.2- Humanidad y Naturaleza ¿intereses 258 contrapuestos?

- II - 3- La naturaleza y la edificación de lo 260 normal

- Biología: Evolución y Ecología 271

- Filosofía e historia de la biología 275

- Filosofía e historia de las ciencias 281

- Teoría ambiental 284

- Teoría de género 288

- Obras de consulta en Filosofía y Lingüística 296

- Obras de consulta en Historia y Antropología 299

- Fuentes documentales y literarias 302 
Quien hoy elija por oficio el trabajo filosófico, ha de renunciar desde el comienzo mismo a la ilusión con que antes arrancaban los proyectos filosóficos: la de que sería posible aferrar la totalidad de lo real por la fuerza del pensamiento

Theodor Adorno Actualidad de la Filosofía

La investigación que desarrollo en esta tesis examina el plano de vinculaciones existente (y potencialmente edificables) entre las sociedades humanas y sus entornos. Desde aquí avanzo sobre la indagación de lazos que se encuentran mediados tanto por el conocimiento científico como por los supuestos sociales desde los cuales se consolida un determinado tipo de reconocimiento.

Esta tesis no ha adoptado las reflexiones éticas como herramientas de investigación, pero contiene inevitablemente implicancias éticas, porque el propio ejercicio de estudio que se realiza involucra valorizaciones sobre las diferentes alternativas posibles. El carácter de los compromisos que se asumen a partir de determinadas conceptualizaciones -y las actividades que se diseñan desde estas consideracioneslleva hacia el plano de los argumentos morales que reparan en el problemático vínculo actual entre seres humanos (en sus plurales circunstancias) y hacia seres no-humanos.

Los conceptos presentados bajo los términos "ecología" y "praxis ambiental" constituyen dos polos en tensión que están lejos de poder tomarse como expresiones lingüísticas aisladas. Por el contrario, son palabras que entiendo como expresiones referenciales, que remiten a sistemas de entidades, un marco en función del cual se edifica el sentido de cada una y a partir del que se pueda idear un plano de sentidos que 
las vinculen. Porque ecología y praxis ambiental, lejos de constituirse desde una red semántica y simbólica afín, aparecen en las prácticas como términos muchas veces antagónicos.

La oposición se edifica desde los dos ámbitos que disputan el sentido del término ecología: las ciencias naturales, por un lado, y sectores de movimientos ambientales, por el otro. Desde una conceptualización edificada desde perspectivas en muchos casos opuestas, y en otros ajenas, las praxis que se desarrollan avanzan en acciones con escasas interacciones, que raramente inciden en las reflexiones internas de cada uno de los ámbitos generadores de sentido.

Vivimos en un mundo afectado por una crisis ambiental sin parangones producto de las intervenciones humanas en el contexto de las prácticas productivas capitalistas. El reconocimiento del problema se complejiza a causa de la oposición que se establece entre las prácticas de los ámbitos dedicados a indagar en el tema (cienciaambientalismos). A fin de profundizar sobre el aparente antagonismo mencionado, y parafraseando a Celia Amorós (2008), esta tesis busca contrastar ciertas conceptualizaciones abstractas con los fenómenos concretos cuya contundencia se nos impone, a fin de revisar la oposición de los términos propuestos para avanzar en la constitución de posibles planos de consensos. Porque la hipótesis general que guía esta reflexión es que las diferenciaciones, que dan lugar a la mutua exclusión reconocida, se establecen a partir de asumir ciertas jerarquías y relaciones como naturales.

Entiendo que a partir de desmontar este carácter naturalizado es posible inaugurar modos de repensar vínculos ideados, no ya desde el antagonismo, sino desde una red semántica y simbólica solidaria, donde los términos se estabilicen mutuamente dando lugar a praxis diseñadas desde el conjunto de acuerdos antes que el de diferencias. Así, esta tesis estudia tanto la situación actual de relaciones como la posibilidad de establecer vínculos.

Uno de los ejes fundamentales con el que procedo a tal indagación es la definición de filosofía que adopto. En esta línea sigo la propuesta de la filósofa española Celia Amorós ya mencionada, quien indica que la filosofía es un contra-decir, decir en contra de las opiniones acríticamenter asentadas, de los prejuicios, entendiendo como tales a las ideas anteriores al esfuerzo intelectual. Se trata de afrontar una situación o una 
realidad como si fuera la tesis de alguien. En las palabras propias de la teórica "Filosofar es pensar el mundo contra ti y contigo" (Amorós 2008, 121).

Se trata de revisar conceptos a la luz de los prejuicios que los sostienen, no sólo hacia aquello que podría enmarcarse en la noción wittgensteniana "juego de lenguaje", sino a partir de las distancias que se instituyen en los diferentes "juegos de lenguaje" involucrados en la temática ambiental.

Dado que el problema a tratar involucra la reflexión sobre la utilización o relación con el entorno o naturaleza, sigo un camino que parte de la revisión de la ecología como disciplina científica, su articulación (o no) con los movimientos ambientalistas para, desde estos sitios de acción, investigación y movilización, avanzar sobre los temas que en ambos casos subyacen como problemas y que no terminan de explorarse desde estas perspectivas.

\section{La elección del tema de estudio}

El origen de este análisis se funda en motivos personales. Vivo en una localidad cuyo dinamismo está atravesado por tensiones vinculadas a la relación que se establece entre la sociedad y su entorno: San Carlos de Bariloche. El marco del Parque Nacional Nahuel Huapi es un fondo bello e imponente, pero su estética no impide que emerjan contradicciones. Se trata de un paisaje ajeno a gran parte de la población. La mayoría de los vecinos no ha podido visitar, por motivos económicos, los principales destinos turísticos de la localidad. Estos problemas, que podrían restringirse al terreno de las desigualdades sociales, se completan con otra situación: gran parte del paisaje local, el que se despliega hacia el sur, con cerros que se elevan sobre la región de estepa, con una belleza diferente (aunque no menor) a los bosques y los lagos, es un paisaje ignorado. Un sitio cuyo valor orgánico ha sido tan desestimado que incluso se ha establecido el vertedero municipal, un basurero a cielo abierto, fuente de contaminación permanente, que linda con barriadas caracterizadas por un acceso limitado a sus derechos (Fuentes y Núñez 2008).

Así, como contraste a la dimensión de la postal turística ampliamente reconocida, en esta ciudad se han edificado paisajes invisibles, poblados por habitantes ignorados 
(Núñez et al 2008). Al respecto entiendo que los acontecimientos locales cobran "forma y sentido" en función de esta paradoja de existencia y no-pertenencia, base de lo cotidiano de la ciudad.

Para completar el cuadro, en un vínculo que obliga a pensar en la desigual estructuración social, y a la luz del modo en que se conoce tanto el dinamismo social como el del entorno, Bariloche es una ciudad conocida por la excelencia de los científicos que la pueblan, sobre todo de aquellos vinculados a las ciencias naturales (mayormente especializados en áreas de física y biología). En esta ciudad se encuentra asentado uno de los principales laboratorios sudamericanos de ecología de bosques: el laboratorio de Ecotono. Un laboratorio que, a pesar de su excelencia, no termina de involucrarse activamente con el ámbito social que lo contiene espacialmente (Núñez 2008). No tanto por la apatía de los habitantes, profundamente sensibles a las temáticas ambientales sobre todo por la cercanía del Parque Nacional, sino por la propia dinámica de la producción de conocimiento.

He explorado esta tensión en el marco de la Maestría en Filosofía e Historia de las Ciencias, de la Universidad Nacional del Comahue. En el presente trabajo, a fin de evitar redundar en consideraciones ya realizadas, he buscado avanzar sobre las preguntas que, en esa primera investigación quedaron sin respuestas. Este camino, que parte de los puntos oscuros que se me presentaban como irresolubles desde el marco epistemológico que caracterizó mi trabajo inicial, me permitió indagar en alternativas que se presentaron a partir de los permisos que me otorgué para reflexionar desde lugares diferentes. Las “minorías sin voz” (Fox Keller 1991, Holland Cunz 1996) que indagan desde concepciones no dominantes de la noción de naturaleza, permiten poner de manifiesto el carácter construido de la misma. Desde estas consideraciones he buscado desmontar los compromisos que subyacen en las adscripciones conceptuales y las prácticas que se diseñan y naturalizan. Bárbara Holland Cunz, incluso, encuentra en la teoría política que las reflexiones que se permitieron avanzar a partir de problematizar el vínculo sociedad-naturaleza constituyeron, desde mediados del siglo XIX, la estructura interna de teorías de liberación antiburguesas, anticapitalistas y antipatriarcales. Esta tesis avanzó asumiendo que el escaso reconocimiento de estas líneas de análisis no debía eclipsar el potencial de cambio implícito en las mismas, y desde esta confianza he edificado la argumentación. 
En su forma original la presente investigación buscó explorar el tipo de conexiones que vinculan las ciencias naturales y las movilizaciones ambientalistas. La pregunta que guió mi reflexión se dirigía hacia los múltiples sentidos del término ecología que, inicialmente, esperaba resolver a través de la indagación de las tensiones internas de dos de los ámbitos discursivos más destacados para llenar de sentido el término: las ciencias biológicas y las reivindicaciones ambientales. La praxis ambiental, desde esta perspectiva, se definiría a partir de los puntos de encuentro que pudieran establecerse entre estos ámbitos.

La tesis de doctorado que se presenta trata de reproducir el camino histórico de mi propia indagación a lo largo de los desfíos teóricos que se presentaron. Fui incorporando elementos analíticos y horizontes referenciales en la medida que las perspectivas recorridas exponían limitaciones que trascendían los debates y problemas percibidos como propios. Así, por ejemplo, la revisión interna de las ciencias naturales, que en un primer momento esperaba se constituyera en la referencia obligada en la interpretación del mundo orgánico (o en contra de la cual se plantearan alternativas), abrió interrogantes que me llevaron a la búsqueda de nuevas herramientas de análisis. Se trataba de recurrentes "puntos ciegos", en los que irremediablemente caía al aproximarme desde una mirada acotada del problema.

Tras la ciencia y el ambientalismo emergía el mundo, cuyas crisis ambientales involucran dimensiones que no necesariamente se reconocían desde los ámbitos de análisis seleccionados, a pesar de operar como permanente fuente de tensión. Se trata de aspectos históricamente revisados en forma incompleta, que por cierto no son independientes a la desigualdad social e invisibilización de paisajes recurrente en mi ciudad.

Las preguntas que dirigieron el trabajo, entonces, se ampliaron hacia la indagación de las trabas que perturban el reconocimiento del carácter complejo de las tensiones involucradas en un tema que la ciencia no termina de abarcar y para el cual los ambientalismos, aún cuando han impactado en un mayor reconocimiento, no terminan de constituir alternativas materiales.

La ecología como término y práctica, puede indagarse desde los dos ámbitos definidos desde el inicio, pero la praxis ambiental involucra el reconocimiento de las tensiones de 
conjunto más amplio, con determinantes culturales y aspectos que obligan a la visualización de los modos concretos en que los habitantes de este mundo (humanos y no-humanos) nos vinculamos con nuestro propio entorno. Esto me obligó a ampliar el recorte temático establecido en un primer momento. De allí que haya sumado, no tanto prácticas nuevas en un listado inagotable, sino la revisión de las desigualdades implícitas en las formas de relación entre las partes. Desigualdades que implican jerarquías y formas de dominio, que subyacen en la permanencia de los "puntos ciegos" antes mencionados y que contienen a las prácticas científicas y ambientales con que inicié la presente reflexión.

\section{El contexto del problema}

El vínculo entre las sociedades y sus entornos es un tema que se presenta como objeto de estudio en un contexto específico: la globalización, como proceso de profundización del desarrollo capitalista propio de las sociedades occidentales modernas. Existen distintos conceptos utilizados para dar cuenta de la globalización como problemática de la vida contemporánea, elaborados desde diversos puntos de vista. Los mismos deben ser considerados como parte de un desarrollo histórico variable, contradictorio y multifacético (Fuentes 2004). En sentido estricto, corresponde a una etapa del capitalismo en la que los procesos de concentración y centralización del capital adquieren mayor fuerza, envergadura, alcance. Invaden ciudades, naciones y continentes, formas de trabajo y de vida, modos de ser y de pensar, producciones culturales y formas de imaginar (Ianni 1992).

La intervención y uso del medio ambiente se profundiza. La agricultura y ganadería industrializadas se incrementan con el avance de los monocultivos. Las prácticas productivas chocan cada vez más con los reclamos por la preservación de la biodiversidad. Los Estados Nación se debilitan, los derechos se retrotraen y, casi a modo de contraste, las diversidades buscan presentarse desde el derecho a ser distintos.

Esta tesis se presenta en contra de la tendencia a un pensamiento único, que sólo parece dejar lugar al incremento de prácticas coercitivas. Es un planteo de alternativas frente a un discurso hegemónico donde el "otro" emerge como un confundido que hay que esclarecer, un adversario que hay que combatir o un enemigo que hay que eliminar. En 
esta línea sigo la idea propuesta por Joseph Fontana a principios de la década de los noventa, quien afirmaba la necesidad de eliminar la vía única, para aprender a pensar el pasado en términos de encrucijadas a partir de las cuales eran posibles diversas opciones y que la triunfantemente impuesta no era la mejor ni la única que cabía (Fuentes 2004).

Esta tesis explora el pasado de la tradición occidental, a fin de exponer los modos en que históricamente se han edificado, tanto las prácticas en relación al uso del medioambiente (criticadas por los ambientalismos), como la producción del conocimiento científico, base legítima del saber reconocido desde nuestras sociedades occidentales. Aún cuando se haga mención a formas de vida no-humanas, o de culturas ajenas a la tradición moderna, esta tesis se sitúa sobre todo en las promesas incumplidas de la modernidad occidental, en la perspectiva a-moderna, que revisa las expectativas a la luz de los proyectos inconclusos.

La ecología, como disciplina científica, es el ámbito que permite explorar los límites de las confianzas, los mitos heredados y los ocultamientos de responsabilidades. Sobre los desarrollos inacabados reviso experiencias de los "perdedores" en el proceso de globalización neoliberal, los sujetos que plantean resistencias y alternativas. Indago estas resistencias, no tanto a la luz de las desigualdades económicas sino, sobre todo, desde las falencias de reconocimiento. En todos los planos de actividad pueden encontrarse sonoridades distintas en las voces de los grupos involucrados, grados de prestigio diferentes y reacciones frente a una desigualdad que no tiene mayor sustento que la aceptación acrítica de los involucrados en las prácticas.

A fin de poner a la luz aspectos que permitan repensar prácticas, en grandes líneas debo indicar que esta tesis avanza a partir de entender que la desigualdad social y la reproducción de esta desigualdad en las prácticas cotidianas no son independientes de los problemas ambientales.

El modo en que se ha edificado el saber occidental, sustentado en jerarquías que implican ejercicios de dominio, ha llevado a pensar a la sociedad y la naturaleza como estancos aislados e independientes. Y este modo de considerar el mundo también da lugar al contexto vigente, donde la reducción de mediambiente a recurso es cada vez más profunda. La ecología científica, heredera de esta tradición, se constituyó como un espacio particularmente sensible a estas contradicciones, y desde este lugar permite 
reflexionar sobre los vínculos que se establecen en la propia edificación del saber que trascienden al área de estudios que se toma como punto de partida.

Lejos de indagar en la situación particular de la vasta diversidad de los excluidos y silenciados, tomé como guía la problemática dualidad sobre la que se edificó el pensamiento y la praxis moderna ya mencionada, la escisión antagónica y excluyente entre sociedad y naturaleza, asociada a la idea del hombre como ser de máximo desarrollo, cuya cercanía a la razón permitiría justificar su dominio sobre todo lo nohumano, fundamento de la evaluación de lo diferente en términos peyorativos.

Exploro especialmente el modo en que "lo natural" se consideró como menos desarrollado, con potencialidades que sólo lograría en caso de estar dominado por un ser efectivamente desarrollado. Pueblos no occidentales, sectores económicos menos privilegiados y poblaciones femeninas son algunos de los grupos asociados a la idea de naturaleza. Dentro de los mismos, la situación femenina y el peso de la metáfora que liga a la mujer a la naturaleza ha sido particularmente observada, no sólo para dar cuenta de un problema sectorizado, sino para profundizar en el análisis de la constitución de las formas de dominio y la búsqueda de alternativas. Las mujeres, como señala Val Plumwood (2004) parecen estar mejor colocadas para resolver este antiguo dualismo, pueden hablar y razonar desde la posición de -y en solidaridad con- los que han sido considerados como 'la naturaleza'.

\section{Metodología}

La metodología de estudio siguió algunas premisas. La primera de ellas es que la edificación de las ideas es un proceso eminentemente histórico. Esto genera, por una parte, la revisión de ideas y actividades ligadas a la constitución de la noción de naturaleza en ámbitos variados $\mathrm{y}$, por otro, la adopción de una visión sobre la disciplina histórica.

En relación al primer tipo de revisión, esta tesis explora en la edificación de las ideas ecológicas a la luz de la tradición de las ideas biológicas modernas, cuyas raíces se rastrean fundamentalmente en el siglo XVII. Por otro lado se observa cómo se constituyeron los reclamos ambientales, que emergen claramente a partir de la segunda 
mitad del siglo XX. Estas referencias se complementan con acontecimientos históricos que permiten problematizar algunas de las formas en que se consolidó en la práctica la particular idea de naturaleza sobre la que se constituyeron los Estados Modernos. En esta línea exploro el proceso constitutivo de los Parques Nacionales y acontecimientos que se desprenden de la apropiación territorial que, desde fines del siglo XIX, se realiza por parte del Estado Argentino sobre un territorio descrito como virgen: la Patagonia.

Ahora bien, el relato histórico está lejos de ser un relato constitutivo de los conceptos que se problematizan. Más bien es el horizonte referencial sobre el cual hilvano las reflexiones que permiten acercarme a los conceptos que busco explorar. Este horizonte no implica una aceptación de los hechos como relato positivo de estilo rankeano. Por el contrario, son referencias que reconocen y aceptan las diferencias y los conflictos como elementos intrínsecos de grupos sociales con una historia viva e igualmente compleja. Se trata de un relato que busca involucrar a los actores del presente, que apela a los mismos como agentes históricos responsables, buscando referencias desde las cuales puedan presentar la experiencia personal como una cuestión a instalar en el espacio público para afianzar procesos de reclamos, auto reconocimiento y autogestión. En este sentido la revisión histórica es paso hacia acciones concretas hacia la unión de historia con memoria e historia con política (Fuentes y Núñez 2007).

Las fuentes documentales que se presentan a lo largo del relato no se reducen a las obras teóricas, de las que se puede inferir la estructura conceptual en disputa, sino que se complementa con obras literarias, memorias institucionales, relatos autobiográficos y entrevistas edificadas en el marco metodológico de la Historia Oral. ${ }^{1}$

En la historia que se presenta se revisa las tensiones globales impactando en procesos locales. La mirada sobre la incidencia de los compromisos conceptuales involucrados permite avanzar hacia un relato histórico que reconoce las tensiones y que explora procesos culturales, que no quedan reducidos a las visiones político-económicas de la disciplina histórica, ni a la revisión interna de las ideas, característica de la historia de las ciencias. La reflexión histórico-filosófica avanza, no desde hechos, sino desde la consideración de los conflictos que se desencadenan en relación a esos hechos.

\footnotetext{
${ }^{1}$ Algunas de las obras donde se puede consultar este marco, donde el problema de la constitución de la memoria es un desafío fundamental son D. Schwarzstein (1991), E.P. Thompson (1988), R. Fraser (1990), D. Hammer y A. Widavsky (1990), J.M. Marinas y C. Santamarina (1993).
} 
La segunda de las premisas que guía la metodología de análisis es que los conceptos, lejos de edificarse desde ejercicios abstractos, se constituyen en permanente vínculo con el plano de las prácticas. Esta premisa no es independiente de las reflexiones previas, porque los ejemplos concretos, con su carácter histórico y su particularidad, operan como recuerdos de las consecuencias que se desprenden de la adopción de ciertos conceptos y la omisión de ciertos procesos que quedan relegados a lo innominado. En este sentido sigo la propuesta de Kate Millet (1975), quien señala que conceptualizar es politizar, y busco avanzar en una idea fundamental, edificada desde preconceptos y ocultamientos: la naturaleza.

Esta noción me lleva a revisar tanto la propuesta aristotélica como las herencias aún vigentes del estarigita. En contra de las visiones que han fundamentado sobre una particular noción de naturaleza, la norma de lo "que debe ser", indago en propuestas que exponen el carácter constructivo de naturaleza y facilitan propuestas que desmontan gran parte de las normas jerarquizantes asociadas. Desde este sitio busco problematizar la constitución de los relatos históricos, porque los mismos se edifican desde una cierta concepción de naturaleza concebida como normal.

Entre los factores de mayor incidencia se cuenta la aceptación acrítica de un mundo jerárquico, donde la propia noción de naturaleza resulta apelada para justificar formas de dominio específicas. De hecho, a lo largo de la tesis, exploro formas y lógicas de dominio (en el sentido acuñado por Horkheimer y Adorno 1997) indagando en el modo en que se fue edificando el sistema de jerarquías en las sociedades modernas, que de forma casi circular me retornaron hacia el discurso biológico, que en el siglo XVII permitió recuperar la Escala de los Seres aristotélica, para situarla como referencia de los derechos naturales de uso de la naturaleza por parte de los hombres. Escribo hombres y no seres humanos, porque la particular idea de naturaleza edificada en la modernidad tiene implícito un recorte específico de lo que se considera humano, que paradójicamente deja fuera a gran parte de los habitantes del planeta.

"Naturaleza" y "norma" emergen como los conceptos desde los cuales se institucionalizan estrategias de reconocimiento y diferenciación. Por ello, en forma complementaria, esta tesis avanza sobre una red conceptual que apela a conceptos como desigualdad, ocultamiento, silencio, opresión o sometimiento, entre otros. 
A partir de los mismos exploro ciertos pares conceptuales que se han establecido como antagónicos, excluyentes, y exclusivos. Me refiero a las dicotomías SociedadNaturaleza, Cultura-Naturaleza, Humanidad-Naturaleza. Tres diferenciaciones, que aún tomando tres términos diferenciables: sociedad, cultura y humanidad, a partir de situarlos en oposición a la noción de naturaleza, permite el establecimiento de una red semántica y simbólica afín, solidaria, con dualidades que, como unidades conceptuales, se estabilizan mutuamente.

A lo largo del texto incorporo referencias a estas dualidades asumiendo el sentido compartido que se edifica desde su oposición. Estos pares antagónicos se encuentran formados por dos términos que no pueden considerarse como voces separadas, porque son expresiones referenciales, que remiten a sistemas de entidades, un marco en función del cual se edifica el sentido.

La tercera premisa que guía a la metodología es que en el fondo de la red simbólica antes mencionada se encuentra el paternalismo como diferenciación fundamental. Esto es la idea de hombre como dominador natural de lo no-humano, con una idea de hombre restringida a la noción de varón, blanco, occidental. Así reviso el universal masculino investido como lo humano, lo social y lo cultural para echar luz sobre esquemas de dominio, fundamentados bajo la idea de naturaleza y presentados en gran medida desde el lenguaje establecido por la biología.

Es, en definitiva, un esquema metodológico que me permitió redactar una tesis que, aún sin tener como objetivo la problematización desde reflexiones éticas, tiene consecuencias en este campo. La propia noción de praxis ambiental implica un compromiso con la idea de cambiar un mundo que, a la luz de lo expuesto, se puede evaluar como fundamentalmente injusto. Se trata de acciones que asumen a las prácticas vigentes como parte de un modo jerarquizante y opresivo, por ello desmontar la naturalización de esta jerarquía es politizar, es valorar éticamente y avanzar hacia un cambio que se presenta como posible.

A modo de esquema general, las herramientas adoptadas para analizar escenarios y elaborar reflexiones pueden resumirse en los siguientes puntos:

1) La indagación en las formas hegemónicas de discurso-dominio, tomando como punto de partida a la ciencia en una de sus prácticas más expuestas: la ecología. 
2) La revisión de la política pública en torno a la apropiación del espacio.

3) La apropiación de la perspectiva feminista como discurso contrahegemónico.

4) El retorno a lo local y la revisión de las formas específicas de dominio como clave reconstructiva.

5) El análisis de las prácticas instituidas, en las prácticas científicas y las esferas de gobierno, a la luz de modos alternativos que implican el reconocimiento de prácticas sociales y saberes edificados desde la experiencia.

Se trata, en definitiva, de reconocer los planos de conformación discursiva para buscar estrategias que permitan desmontar las principales trabas que, en la actualidad, operan como límites en la edificación de intercambios (como son los planos valorativos jerárquicos que llevan a ignorar las experiencias valoradas como no-expertas, la reproducción institucional de las desigualdades, formas de interacción que apelan al reclamo y rechazo antes que al diálogo, subestimación de lo diferente como irrelevante). El camino seguido me lleva a estudiar la producción de conocimiento científico como instancia reproductora de desigualdades, que no sólo impacta hacia fuera de la práctica científica, sino que al interior de la propia organización disciplinar introduce reconocimientos diferenciados.

Desde este camino busco escapar a las oposiciones de "unos" contra "otros", donde la mejora de la situación de los "otros" se resuelva a partir de la precarización de la situación de los unos. Por el contrario, expongo las contradicciones que para todos, desde cada situación particular, acarrea la pervivencia de jerarquías diferenciadas. Reviso las consecuencias de la mirada jerárquica que, por ejemplo, impide la revisión sobre el mundo orgánico desde estrategias que no supongan un uso destructivo, o que la propia humanidad se constituye en términos de recortes discriminatorios, y sobre todo analizo de qué manera el contexto globalizado profundiza las formas jerárquicas de intervención, parece imponer un alejamiento de la atención hacia estos fundamentos para constituir un discurso que legitima, cada vez más, formas totalitarias de organización. 


\section{Objetivos generales y específicos}

El objetivo inicial de este trabajo es indagar en la pluralidad de debates involucrados en la tematización -y apropiación- social de la naturaleza. En este sentido se trata de analizar y evaluar las teorías y prácticas que llenan de sentido y acciones que se conforman como tales a partir de una cierta consideración sobre el tema. Se trata, en definitiva, de avanzar en uno de los debates más tensionantes de la actualidad para diseñar posibles arenas comunes de debates y diseño de prácticas.

Desde este primer objetivo general se desprenden objetivos específicos:

- Repensar la teoría a la luz de las prácticas, indagando en las dinámicas mutuamente estructurantes.

- Ordenar el universo de sentidos con que se entiende la palabra ecología, a partir de estudiar aquellos que históricamente fue adoptando a la luz del modo de considerar la práctica científica.

- Explorar la pregunta por la naturaleza, su conocimiento y los modos de intervención y vinculación que se diseñan a partir de cierta conformación social.

- Avanzar en las consideraciones que actualmente se problematizan a partir del reconocimiento de la crisis ambiental presente en término de calentamiento global, sequías, tormentas, contaminación, entre otros.

- Vincular el sentido científico con las demandas ambientales que, precisamente refieren a limitaciones de la propia práctica científica.

- Examinar la pluralidad de sentidos sociales asociados al término ecología.

- Escrutar el plano de presupuestos conceptuales desde los cuales se edifican las teorías y constituyen las prácticas.

- Exponer el carácter fundamentalmente jerárquico de las perspectivas edificadas desde las reflexiones elaboradas en el marco de las sociedades occidentales capitalistas.

- Desmontar los fundamentos de la dualidad antagónica sociedad-naturaleza. 
- Abrir vías de reflexión que permitan pensar en la incorporación de cambios accesibles en relación a la consideración de la naturaleza y la evaluación del carácter de la humanidad.

- Exibir la responsabilidad implícita en la producción de conocimiento en general -y al de la ecología en particular- en relación al cambio que se propone.

- Criticar la dinámica existente, no tanto desde sus formas, sino a partir de las consecuencias que acarrea el concebirla como la única posible o legítima.

\section{Hipótesis}

Las hipótesis que guían este trabajo se desprenden de una hipótesis general: Las diferenciaciones que dan lugar a la mutua exclusión reconocida entre sociedad y naturaleza, se establecen a partir de asumir ciertas jerarquías y relaciones como naturales.

Esta diferenciación se complementa con la idea que los ladrillos que diferencian sociedad de naturaleza, en un modo jerárquico y antagónico, son los mismos que separan las ciencias sociales de las naturales.

Adopto como propia la idea que la sobrevaloración de la razón occidental se constituye en el origen de desigualdades y sometimiento en las acciones de intervención, así como en traba de las revisiones epistemológica de la ciencia.

Desde estas consideraciones entiendo, además, que los problemas ambientales, vistos a la luz de las tensiones que se ocasionan en base a las desigualdades, no son un tema propio de la ecología en tanto ciencia. Pero, a pesar de este recorte, la disciplina no logra escapar a permanentes referencias que incorporan las tensiones ambientales al horizonte desde el cual se demanda socialmente a esta área de estudios.

\section{Breve esquema sobre la organización del escrito}


El texto que se presenta se divide en cinco secciones. La primera sección indaga en los debates existentes en torno al tema ambiental, expuesto en los dos primeros capítulos.

En el primero introduzco los aportes constituidos desde la epistemología de las ciencias aplicada a la ecología y la filosofía de la biología y epistemología de la ecología. En esta línea exploro el sitio de la ecología en el concierto de las ciencias biológicas. Así presento los supuestos disciplinares, el recorte temático reconocido en el interior de esta área de estudios y la variabilidad de los compromisos disciplinares a lo largo del tiempo, establecidos en tres quiebres temporales: los primeros años, la introducción de la experimentación y la incorporación de las dudas como estrategias de investigación. Desde allí retorno hacia los modos en que se ha reflexionado sobre la ecología, las demandas que se reconocen y los límites en la capacidad de otorgar respuestas.

El segundo capítulo avanza en el vínculo entre las sociedades occidentales modernas y el recorte que se asume como naturaleza. En este apartado presento los condicionantes productivos que llevaron a la conformación de la ecología como disciplina científica. Expongo el modo en que se instituye una cierta forma de cuidado, vinculada a la política de los Parques Nacionales, que repite la escisión al dividir el planeta entre santuarios a preservar y espacios vividos y condenados. En este plano de reflexiones y políticas de intervención se presentan las reivindicaciones ambientalistas, explorando la disputa que se genera en torno al sentido que se otorga al término ecología, permitiendo mostrar que la capacidad crítica para denunciar problemas no termina de llevar a la edificación de alternativas. En este capítulo incorporo una revisión de las teorías políticas que han incorporado el tema de la naturaleza como un desafío desde el cual revisar las relaciones instituidas. Estas teorías, aún cuando no han sido adoptadas por las principales corrientes de pensamiento político, se consolidan en el siglo XIX como las principales teorías que desacreditan los privilegios burgueses, capitalistas y patriarcales (Holland Cunz 1996).

Desde este contexto de problemas que se reconocen y respuestas que no se concretan, en la segunda sección avanzo sobre los dos ejes que entiendo como fundamento de la pervivencia de las consideraciones desiguales del mundo.

En el tercer capítulo exploro el modo en que se fue edificando la idea de una naturaleza ordenada, cuyos orígenes pueden rastrearse en la propuesta aristotélica del mundo, que 
presenta esta noción de orden asociada indefectiblemente a una jerarquía sustentada en relaciones de dominio legitimadas desde la propia organización que se reconoce en el mundo natural. El impacto de estas nociones se percibe en la recuperación de la escala de los seres en el siglo XVII, en los albores de la biología moderna. La taxonomía racional aparece como consecuencia directa de un mundo ordenado en jerarquías. La reinstalación de formas de dominio instrumental, ligadas a un creciente desencanto del mundo, vinculadas a la creciente explotación capitalista, se redacto en sus orígenes con términos biológicos. La naturaleza jerárquica, cuyo destino es ser explotada al considerarse en términos de recurso, se asumía también como fija. Este último punto es el que se discute sobre todo a partir de la teoría darwiniana, pero las nociones de jerarquía y dominio, lejos de removerse, pasaron simplemente a omitirse. El tema se eclipsó al mismo tiempo que las prácticas legitimadas desde las ideas implícitas, se profundizaban. De aquí infiero que las jerarquías se sostienen, entonces, de los presupuestos que se naturalizan al no volver a problematizarse. A fin de remover esta confianza adopto la teoría de género, como marco cuyo objetivo es explorar y deponer los supuestos sobre los que se asientan las desigualdades, a partir de tomar como punto de partida la desigualdad entre varones y mujeres. Desde este amplio marco teórico adopto especialmente las líneas de reflexión ecofeministas, que revisan la constitución de desigualdades a partir de asumir asociadas la noción de mujer y la de naturaleza. Es decir, la naturaleza que se oponía a sociedad, cultura y humanidad, se presenta ligada al carácter femenino, de allí se desprende que tanto las mujeres como la naturaleza deben ser dominadas.

En otras palabras, el potencial teórico que incorporo desde la teoría de género, y en particular de los ecofeminismos, es su compromiso con la búsqueda de un cambio de un mundo que entienden como problemático y susceptible de modificarse. Desde allí avanzo, en el cuarto capítulo, en la indagación en la dualidad sociedad-naturaleza. En este apartado las metáforas que homologan la idea de naturaleza y la de mujer para exponer el carácter lábil del recorte entre humanidad y naturaleza que, paradójicamente, permite una separación que se propone como tajante. Desde estas consideraciones retorno hacia los ecofeminismos, reconociendo en los mismos las modificaciones que se proponen tanto en el reconocimiento del mundo no-humano, como en la propia consideración del carácter humano. 
En la tercera sección exploro el terreno de las prácticas y la noción de praxis ambiental a partir de problematizar el concepto de praxis (tanto en su acepción aristotélica como marxista), y a la luz de los desafíos reconocidos en los capítulos precedentes. En este apartado destaco especialmente el aporte antropológico sobre la noción de praxis, que permitió remover los compromisos occidentales del término, aún cuando se abandonara el carácter fundamentalmente revolucionario que Marx reconoce en esta noción.

Desde situaciones concretas que exponen el peso de la aceptación acrítica de las jerarquías, las desigualdades asociadas y el debilitamiento de reconocimiento, retomo la noción de praxis ambiental a fin de enmarcar acciones y reflexiones que se comprometan con el cambio, por un lado asumiendo como injusticias del desarrollo la reducción del otro-diferente a sujeto-sometido, y por otro, reconociendo la posibilidad de modificaciones sin necesidad de apelar a la destrucción absoluta de lo instituido, sino a partir de buscar la modificación de las formas a la luz del reconocimiento de las desigualdades que se reproducen en la medida que no se problematicen.

La cuarta sección de este trabajo contiene las reflexiones finales. Las mismas están divididas en dos partes, una recapitulación de las principales conclusiones de cada capítulo y una segunda parte destinada a avanzar en los temas pendientes y las vías de reflexión, espacio desde el cual retomo el problema de la globalización. En este apartado indago en la situación de la ciencia a la luz de las consideraciones sobre la ecología, no tanto por concebir que desde ésta área se contenga al universal de problemas, sino porque al ser una disciplina limitrofe, con temas y metodologías propias de las ciencias naturales pero con demandas indefectiblemente ligadas a los haceres humanos, contiene dentro de sí muchas de las paradojas sobre las que reflexioné a lo largo de la tesis. Otro punto fundamental de las conclusiones es la revisión de la permanencia del dominio, tema con el cual cierro este conjunto de reflexiones. A fin de avanzar en el tema de dominio retorno a uno de los fundamentos explicativos más recurrentes sobre las jerarquías humanas: la dialéctica hegeliana del amo y el esclavo. En la misma busco exponer cómo, a partir de remover la idea de naturaleza que subyace en la reflexión, puede discutirse que la única organización social posible sea jerárquica. Desde aquí argumento en contra de uno de los principales razonamientos totalitarios, la visión de los intereses de la naturaleza como opuestos a los humanos, destacando la necesidad de abandonar la dualidad para no llegar al consecuente incremento de formas 
opresivas. En el cierre desmonto el carácter construido de lo normal, desnaturalizo lo natural para repensarnos como seres humanos capaces de cambiar aquello que consideramos injusto.

La quinta y última sección es la bibliografía, que se destaca por estar ordenada en diferentes categorías que buscan englobar las tradiciones de análisis más importantes involucradas en la presente tesis. Las mismas son Biología: Evolución y Ecología, Filosofía e historia de la biología, Filosofía e historia de las ciencias, Teoría ambiental, Teoría de género, Obras de consulta en Filosofía y Lingüistica, Obras de consulta en Historia y Antropología y Fuentes documentales y literarias.

Esta organización es a fin de tener como referencia permanente el marco y contexto desde el cual escribe cada autor, así como el espacio teórico sobre el que buscó incidir con su obra. 


\title{
Primera Sección: Los debates y sus límites
}

\author{
Capítulo1:
}

Ecologia: Algunos aportes desde la epistemologia 


\section{Introducción}

El término ecología, previo a ser referencia de movimientos sociales que contemplan problemas ambientales, fue la denominación de una rama de la biología que surgió a fines del siglo $\mathrm{XIX}^{2}$ Con el correr del siglo XX, y asociado al modo en que se desarrolló esta disciplina, la idea a la que hacía referencia la expresión fue diversificándose en sentidos que cubren desde prácticas científicas hasta movilizaciones sociales, pasando por espacios de publicidad de la más variada índole.

Uno de los objetivos que persigue la presente tesis es organizar este universo de sentidos y prácticas asociadas. Por ello revisaré las diversas implicancias, potencialidades y limitaciones en dos de los ámbitos más influyentes para edificar el sentido social de la ecología, las ciencias biológicas -sobre todo la ecología- y los ambientalismos.

En este capítulo presento a la ecología como disciplina científica e indago en los compromisos epistemológicos adoptados por la misma a lo largo del tiempo. Entre los resultados de esta indagación destaco que estos compromisos, lejos de ser estables, fueron variando con el tiempo. En estas modificaciones operaron cambios de carácter ligados al modo en que la ecología fue respondiendo a los contextos y desafíos que se inauguraban.

A la luz de la historia de las ideas ecológicas, puede notarse que la revisión del plano de compromisos cobró un dinamismo particularmente notable desde fines del siglo XX, cuando un contexto ambiental particularmente crítico comenzó a demandar respuestas a la ecología (y a la ciencia en general), que pusieron en primer plano los límites y contradicciones que surgían de las formas modernas de apropiación de la naturaleza (entendida como naturaleza no humana). Proceso que está llevando cada vez más a revisar los cimientos sobre los que se ha desarrollado la disciplina.

\footnotetext{
${ }^{2}$ El término ecología fue acuñado Ernest Haekel en 1866 por con el objetivo de dar cuenta de los estudios de sus organismos y su medio. El biólogo unió los términos oikos (casa) y logos (estudio) para dar cuenta del área de estudio que reclamaba hacia el interior de las incipientes disciplinas biológicas. A fines del siglo XIX la denominación de la disciplina era oecología, una denominación que aún se presenta en publicaciones específicas.
} 


\section{La ecología en el mapa de las ciencias biológicas}

La ecología se distingue entre las disciplinas biológicas por estudiar las relaciones entre los organismos y sus ambientes. Esto significa que investiga los modos en que se vinculan los diversos organismos de un espacio, y no se detiene en indagar en las particularidades de los organismos que conforman las áreas analizadas. Por esto se trata de una disciplina donde la misma idea de descubrimiento cobra un carácter diferente a la acepción clásica. Como indican sus mismos practicantes

“... en ecología no vas a encontrar descubrimientos como en biología molecular que encontrás el gen..., no hay descubrimientos como una vacuna o ese tipo de cosas, en ese sentido de descubrimiento no hay, lo que son, son procesos, mecanismos que se van dilucidando, como que trae aparejado toda una cosa anterior, hay sí posturas, teorías nuevas, pero descubrimientos... no sé si se puede hablar de descubrimientos pero sí de ideas nuevas, que son muy pocas, hay avances...”(citado en Núñez, 2005)

Esta diferencia entre la ecología y otras ramas de la biología que reparan en los detalles de los organismos en cuestión (como las biologías taxonómicas o la genética), ha sido tomada como pretexto para presentar a la ecología como una disciplina "dependiente" de las ramas de la biología con las que se vincula, considerando al trabajo científico de la ecología como una proyección de las prácticas investigativas en otras ramas como la biología evolutiva, la genética o la botánica.

Yrjo Haila y Peter Taylor (2001) reconocen que esta visión ha trabado las reflexiones epistemológicas de la ecología, por considerarlas redundantes. Asimismo reclaman la necesidad de empezar a reparar en las problemáticas particulares en esta rama de la biología. La falta de reconocimiento, según estos autores, se debe a que existe un desinterés consciente en las reflexiones sobre ecología. A fin de sustentar esta aseveración presentan estudios bibliométricos que demuestran que, dentro de la filosofía de la biología, las reflexiones sobre ecología son casi inexistentes, y reclaman acciones y reflexiones para paliar esta falencia.

Desde una postura afín con Haila y Taylor (2001) considero que, en el estudio del proceso histórico que dio lugar a la ecología actual, pueden reconocerse tanto aspectos epistemológicos propios como indicios que permitirán problematizar la vinculación entre el conocimiento científico de los dinamismos naturales y la apropiación social de 
ese conocimiento, en el contexto de un mundo cuya situación ambiental se agrava progresivamente.

\section{Los supuestos de la ecología en el marco de la biología}

Durante el siglo XVIII los estudios sobre la vida se multiplicaron a un nivel sin precedente (Makinistian 2004). De hecho el término "biología" se acuña a principios del XIX para dar cuenta del conjunto de áreas de conocimiento que se inauguraban. ${ }^{3}$ Sin embargo las disciplinas biológicas, tal como se conocen en la actualidad, se encontraban en el siglo XIX en un estado embrionario.

No existían diferenciaciones claras en los campos de estudio (Makinistian 2004, Mayr 1988, Frezzatti 2003). Los naturalistas e investigadores tenían un amplio espectro de intereses que los llevaban a hacer aportes en diferentes áreas del conocimiento. Una característica de este período es el peso de los estudios amateurs, que se incorporaban y reconocían a la par de otros elaborados por profesionales (Alberti 2001). ${ }^{4}$ El contexto decimonónico de formación de los Estados Nacionales favoreció los intercambios locales al limitar, por motivos nacionalistas, el intercambio entre especialistas (Frezzatti 2003).

Pero más allá de estas tensiones, se observa que los estudios de laboratorio y las investigaciones de campo se multiplicaban dando lugar a dos tradiciones diferentes en las ramas de la biología, la experimental y la descriptiva. En este marco la ecología se fue gestando a fines del siglo XIX como un área de investigación descriptiva, ligada a la herencia de los exploradores e incorporando las propuestas de los teóricos evolucionistas.

Para aproximarnos al marco general de conocimiento que dio lugar a esta disciplina debe tenerse en cuenta que la ecología hunde sus raíces en disciplinas taxonómicas como la botánica o la zoología, sumando interrogantes provenientes de la química

\footnotetext{
${ }^{3}$ Como nota de color vale mencionar que tanto Lamarck como Treviranus presentan simultáneamente el neologismo "biología" a fin de aplicarlo al conjunto de trabajos que se dedicaban al estudio de las leyes de la vida. Este término fue empleado por primera vez en Francia en 1802, por Jean-Baptiste Lamarck en su tratado de Hidrogeología. El mismo año en que el naturalista alemán Treviranus introduce la palabra en una obra en seis tomos titulada Biología o Filosofía de la naturaleza viva.

${ }^{4}$ Muchos aportes que se publicaban en las revistas científicas de ese período provenían, por ejemplo, de sociedades de amantes de la naturaleza o desde clubes de observadores de aves y plantas (Alberti 2001).
} 
agrónoma, los estudios demográficos y fundamentalmente la teoría evolutiva (Mc Naugton y Wolf 1984).

Este variado marco teórico no fue, sin embargo, el motivo que llevó al surgimiento de esta nueva disciplina. La ecología se erige como área de estudios debido a problemas ambientales que hicieron necesario el diseño de una nueva perspectiva de estudio. Los límites productivos que se comenzaban a percibir en la agricultura del siglo XIX pusieron de manifiesto que la naturaleza no era una fuente inagotable de recursos y que sus dinamismos resultaban poco menos que desconocidos para los investigadores del período. Por esto se elaboraron políticas estatales que buscaban enfrentar la limitación de los recursos naturales. El punto de partida de las mismas fue el reconocimiento de la necesidad de adoptar una perspectiva integradora, que reparara en las interacciones de los organismos y sus ambientes.

Antonio Casares Serrano (2005) indica que en el contexto de la segunda revolución industrial hacía falta una racionalización económica de la explotación y la ecología fue la disciplina que se desarrolló para ello. Uno de los fundamentos de esta aseveración es que los estudios que dieron lugar a los primeros conceptos ecológicos fueron financiados por gabinetes gubernamentales (sobre todo Ministerios de Agricultura) y dirigidos a desarrollar y controlar medidas adecuadas para una explotación científica de los recursos naturales (Casares Serrano 2005). El trabajo de los primeros ecólogos se orientó, entre otros temas, al estudio y la erradicación de plagas, el aumento de la productividad y la lucha contra el agotamiento del suelo y la desertificación.

El creciente interés gubernamental, con el consecuente incremento de fondos para estas investigaciones, ayudaron a la conformación de la ecología como un área de problemas autónoma y diferenciada, que por estar atravesada por intereses que trascendían aquellos específicamente académicos, se conformó como síntesis de múltiples especialidades (Mc Naugthon y Wolf 1984).

\section{Ecología: Ciencia y Sociedad a lo largo del tiempo}

El creciente desarrollo académico de la ecología parece haberla alejado de la problemática relativa al manejo de los recursos (que quedó a cargo de áreas de mayor 
aplicación como la ingeniería forestal, entre otras) para centrarse en los debates teóricos sobre los dinamismos de la naturaleza.

En el proceso histórico de las ideas de esta disciplina pueden distinguirse tres períodos: el primero atravesado por una metodología descriptiva, que la caracterizó hasta la década de los cuarenta. En el segundo período, en cambio, se incorporan prácticas experimentales antes que descriptivas. Las mismas se sostienen en la confianza por arribar a procesos y patrones generalizables, la adopción del ecosistema como unidad de estudio y la aceptación de la competencia como relación estructurante de las comunidades de organismos.

El tercer período se distingue porque, aún adoptando la metodología experimental, inaugura una discusión en torno a la competencia como factor relacional preponderante y permite la introducción de dudas sobre la posibilidad de realizar generalizaciones. En este último período, las escalas de estudio se han diversificado y comienzan a discutirse fundamentos centrales de la disciplina.

En la actualidad, el tema ambiental vuelve a enfrentar a la ecología con los problemas de agotamiento de recursos que a mediados del siglo XIX llevaron al surgimiento de esta área de estudio. Sin embargo la complejidad que ha adoptado el tema, la globalidad del problema y, sobre todo, las reflexiones que apuntan contra la lógica misma de la producción científica, llevan a que se pongan en entredicho muchos de los consensos sobre los que se ha tejido la teoría ecológica. Para comprender la magnitud del desafío disciplinar tomaré como punto de partida la revisión del proceso histórico de la ecología como disciplina, hurgando en el tipo de preguntas y debates que fueron armando la estructura teórica que hoy se pone en entredicho.

\section{La ecología en el tiempo}

\section{Los primeros años}

La primera referencia al término ecología se ubica en 1866, cuando se presenta el vocablo oecología para designar el área de investigación que se estaba inaugurando. Esta denominación, que une los términos oikos y logos, fue propuesta por el naturalista alemán Ernest Haekel para especificar el estudio de las relaciones de los organismos 
con su medio físico y biológico y proyectar las propuestas darwinianas a escala de poblaciones. La propuesta original de la teoría evolutiva tenía referencias a nivel individual exclusivamente. La ecología, en cambio, buscaba profundizar en las poblaciones y comunidades a partir de revisar las interacciones de los organismos entre sí y con su ambiente.

El aporte de Haeckel se inscribe en un debate que se estaba llevando adelante entre diferentes propuestas evolutivas. El naturalista alemán era el principal seguidor de Darwin en su país (Makinistian 2004). Defendía la idea de selección natural introduciendo en esta defensa la noción que los organismos eran activos respecto del ambiente, tal como había sostenido Lamarck. Así la ecología se presentó como línea de investigación que destacaba la actividad y capacidad de cambio de los organismos frente al ambiente.

Esta propuesta se opuso a la idea de que los organismos fueran pasivos frente al contexto abiótico, esto es que los vínculos entre los seres vivos estuviesen determinados exclusivamente por el ambiente. ${ }^{5}$ Se inaugura así una perspectiva que reconoce la influencia mutua en la vinculación de factores bióticos y abióticos.

En los primeros años los debates que se inauguraban tuvieron desarrollos independientes. Los estudios ecológicos progresaron de forma diferenciada entre botánicos y zoólogos e incluso, dentro de ambas áreas de conocimiento, la ecología se desarrolló con itinerarios disímiles según los estudios se orientaran a ecología terrestre o acuática (Kingsland 1991).

En su origen, la ecología estuvo formada por cuatro vertientes de investigación, la ecología vegetal (o ecología botánica), la ecología animal (o ecología zoológica), la ecología de agua dulce (o limnología), la ecología marina (u oceanografía) (Deléage 1993). Dentro de ellas la ecología botánica fue la rama que contuvo al mayor número de especialistas, así como también a los debates más dinámicos.

La vinculación entre ecología y botánica se sustentó en los precedentes de la geografía de los paisajes, que habían sido estudiados principalmente en función de la vegetación (Humboldt, De Candolle, entre otros). Tal era el vínculo entre ecología y botánica que a

\footnotetext{
${ }^{5}$ En oposición a la pervivencia de las ideas desarrolladas por Geoffroy Saint Hilaire, quien sostenía que los organismos eran moldeados por el ambiente y no por los hábitos, el uso y desuso (Vila Valenti 1984, Malpartida y Lavanderos 1995, Rostand 1985).
} 
mediados del XIX los estudiosos de la vegetación planteaban que la ecología era estrictamente una rama de la botánica (Deléage 1993). Por otro lado la ecología de plantas resultaba más simple de desarrollar puesto que la descripción resultaba más accesible en los escenarios vegetales estables y fijos (Vila Valenti 1984). El principal antecedente de la ecología vegetal es el texto de E. Warming de 1895 La ecología de las plantas, que puede considerarse como un tratado de autoecología, en el sentido que Warming estudió las relaciones entre los organismos a partir de indagarlos individualmente.

En este caso se investigaron las relaciones de los organismos (en este caso vegetales) con los factores abióticos (luz, temperatura, humedad, nutrientes minerales, etc.). Esta investigación tuvo varios continuadores, entre los que se destacó A. F. W. Schimper, quien tres años más tarde defendió que el clima es el factor fundamental para explicar la vegetación (y con ello el poblamiento en general) de las regiones fitogeográficas del mundo.

Si bien la dimensión de los trabajos de ecología vegetal tuvo preponderancia en este primer período, debe reconocerse que existieron importantes avances en las otras perspectivas. En ecología animal la obra que puede considerarse como principal antecedente es el trabajo de Wallace, de 1876, en torno a la distribución geográfica de los animales. Estudio en el cual incorpora elementos relativos al ambiente. Tomando como base la zoología, la ecología animal se dedicó, entre otros aspectos, al estudio del comportamiento animal, los problemas de alimentación y distribución y la relación predador-presa (Deléage 1993).

La ecología acuática (limnología y oceanografía) inauguró los estudios de las comunidades vivientes que indagaban en la interacción entre vegetales y animales. Entre los aportes más significativos de los primeros años se encuentra el estudio de Moebius (1872) que acuña el término biocenosis, definiendo unívocamente a la comunidad de seres vivientes que habitan en un lugar determinado. También se destaca el trabajo de Forbes (1887) quien propone el estudio del lago como un microcosmos que opera como laboratorio natural. En una línea similar, Forel (1895) presentó un extenso detalle sobre el modo de llevar a delante las investigaciones en limnología en su estudio sobre el lago Lemman. 
Así, a finales del siglo XIX la ecología surgía como una ciencia biológica ocupada en el estudio de la pluralidad de organismos y sus ambientes. Estos primeros desarrollos pueden ser caracterizados como autoecología, porque se dedicaban a indagar el modo en que el ambiente afectaba a los organismos sin avanzar en el estudio de la dinámica de poblaciones o comunidades como conjunto. Otro aspecto que compartían, más allá de la diversidad temática que se abordaba, fue la adopción del método descriptivo como estrategia de investigación (Jaksic 2001, Deléage 1993, Kingsland 1991), la aceptación de la teoría evolutiva darwiniana y el conocimiento de los organismos provenientes de la botánica y zoología (Kingsland 1991, McNaugthon y Wolf 1984).

Asimismo los trabajos ecológicos desde sus formas más tempranas reconocieron aportes de perspectivas que hoy se pueden catalogar como fisiología, etología, epidemiología, geología, química, geografía, demografía humana, matemática, estadística, economía, (Margalef, 1977), climatología, física (Deléage, 1993), u otras áreas más aplicadas como pesquería, ingeniería forestal, agricultura, ganadería (Margalef, 1977), mostrando de esta forma una clara tendencia hacia el diálogo con otras especialidades que se inauguraban en el período.

Una de las primeras teorías que cruzan este campo de conocimiento, que llevó a reparar en la relación entre el crecimiento del manto verde con factores abióticos, fue la "ley de factores limitantes", que intentaba esclarecer el papel de los elementos químicos en los procesos vitales. Von Liebig (1840), investigando sobre plantas verdes, llegó a demostrar que los nutrientes son múltiples y que el desarrollo de las plantan no depende de que sobren ciertos elementos, sino en que no escaseen otros. Así consolida la idea que los elementos limitados de un espacio son los que regulan el crecimiento, viendo con ello la posibilidad de reactivar el desarrollo con el concurso de abonos químicos. También insistió en la importancia fundamental de la energía solar como motor de todo el ciclo vital de la naturaleza (McNaugton y Wolf, 1984).

Immanuel Wallerstein (1997) indica que la delimitación del conocimiento en un área de investigación debe considerar la revisión de tres planos: el intelectual, que focaliza el conjunto de saberes que se considera propio desde la disciplina; el organizacional, que revisa las estructuras que permiten el intercambio entre los científicos pertenecientes a la disciplina; y el cultural, que indaga en las comunidades de académicos que comparten premisas que los lleva a reconocerse contenidos en esa disciplina. 
Si se revisa la ecología en las primeras décadas del siglo XX se encuentra una confluencia en los tres planos propuestos por Wallerstein. Porque la identificación en torno a un recorte de problemas se asocia al establecimiento de un corpus teórico amplio, que se fue afianzando a partir de la organización de jornadas de encuentro, la formación de departamentos específicos en facultades de ciencias naturales de diversas universidades en Estados Unidos, Gran Bretaña, Alemania, Rusia, ente otros países. ${ }^{6}$ En relación a la modalidad de estudios debo indicar que cada una de las vertientes de la ecología se sustentó sobre un amplio conjunto de acuerdos pero tomó como foco recortes de la naturaleza que se consideraron de forma separada hasta los albores de la década del treinta.

Dentro de este primer período puede reconocerse un clivaje a partir de los años veinte, cuando comienzan a aparecer intentos tangenciales por articular las miradas botánica y zoológica en la ecología terrestre. Estos intentos llevaron, en 1939, a la edición de la obra Bio-ecology redactada entre un especialista en ecología vegetal, Frederic Clements, y un especialista en ecología animal, Shelford. Este texto introduce el término bioecología como referencia a los estudios conjuntos, que aún siendo minoritarios empezaban a ocupar un sitio cada vez más amplio. Una referencia aparte merece la ecología acuática, porque desde su inicio indagó en la relación entre plantas y animales, aunque sin articular sus resultados con estudios provenientes de la ecología terrestre. ${ }^{7}$

Pero más allá de los puntos de contacto en todo el corpus de conocimiento, si se revisa el entramado conceptual de cada rama de la ecología se pone en evidencia que los aportes teóricos de cada una de estas vertientes pueden diferenciarse. En la ecología animal, el nicho fue el concepto sobre el que se desarrollaron los principales aportes.

\footnotetext{
${ }^{6} \mathrm{La}$ institucionalización disciplinar se reconoce en todos los planos. Si se revisan las publicaciones se encuentra que a fines del siglo XIX los escritos ecológicos se presentaban en revistas de historia natural. Sin embargo a inicios del siglo XX ya se encuentran las primeras revistas especializadas que explícitamente incorporaban el término "ecología" para diferenciarse de otras revistas especializadas. Desde esta perspectiva puede considerarse a la ecología como ámbito de investigación autónomo desde este período.

${ }^{7}$ Vale destacar que en la ecología acuática también se desarrollaron debates sobre la vinculación entre los factores bióticos y abióticos. El apoyo estatal para el desarrollo de estos saberes fue fundamental, ya que los estudios de limnología y oceanografía se multiplicaron gracias al establecimiento de estaciones de investigación marítimas y lacustres, sobre todo en Estados Unidos y Alemania. Entre las estaciones marítimas destacaron las estadounidenses Scripp (fundada en 1903), en California, y Woods Hole (fundada en 1930), en la costa atlántica. El actual instituto de Limnología Max Planck, en Alemania, (fundado en 1895), fue uno de los más importantes centros de investigación de ecología acuática europeos, corroborando el papel privilegiado de los lagos y ríos como laboratorios naturales.
} 
La incorporación de nicho como término ecológico se originó cuando se investigaba la relación de los animales con su espacio de vida. En los primeros años la definición de nicho tuvo límites difusos y carácter abierto. Así J. Grinell (1917) lo incorporó para analizar la forma en que el medio ambiente regula la distribución de las especies mientras que C.S. Elton (1927) lo aplicó para ver cómo los organismos actúan en su medio.

M. Leibold y P. Gedes (2005) indican que este carácter dual del nicho -1) concepto para evaluar cómo los organismos son afectados por el medio ambiente y 2) concepto para evaluar cómo el medio es influido por los organismos- se mantuvo a lo largo de toda la historia del concepto, porque fue utilizada desde ambas perspectivas por distintos autores.

Es G.F. Gause quien en 1935 sistematiza el concepto de nicho y lo introduce como unidad de estudio a partir de los trabajos que desarrolla en la URSS. En una línea afín a la mirada de Grinell, Gause delimita el nicho a partir del principio de exclusión competitiva, según el cual dos especies que luchan por los mismos recursos no pueden coexistir. Este biólogo suponía a la competencia interespecífica -tomada de la teoría evolutiva- como factor fundamental de la estructuración de comunidades y la importancia otorgada a la misma fue la base de estos estudios que introdujeron además evaluaciones demográficas. ${ }^{8}$ El desarrollo de la propuesta de Gause se debilitó por motivos extra académicos que detuvieron su crecimiento y difusión. La política científica del estalinismo entendía a los aportes de la ecología como opuestos a los intereses gubernamentales, por ello acabó con este espacio de investigación, que era el más dinámico de la ecología animal (Deléage 1993). Las propuestas de Gause fueron recuperadas algunos años después, en un nuevo contexto disciplinar.

La ecología vegetal merece particular atención ya que tuvo un desarrollo comparativamente más complejo, posiblemente por haber sido el ámbito que contuvo el mayor número de especialistas. Se su desarrollo se destacó por encima del de otras ramas de estudio. En la ecología vegetal se presentó tempranamente una concepción que propuso superar estudios autoecológicos desarrollados en los primeros años. El ecólogo norteamericano F. Clements en 1905 definió a la ecología como la ciencia de las

\footnotetext{
${ }^{8}$ La competencia interesepecífica es la competencia de dos especies por los mismos recursos. La exclusión competitiva supone que especies con competencia interespecífica no pueden coexistir.
} 
comunidades y tomó a la comunidad vegetal como unidad de estudio privilegiado abandonando la indagación sobre los organismos individuales.

A principios del siglo XX los ecólogos de la vegetación entendían que el resto de las relaciones de los seres vivos se desprendía del modo en que se constituía la asociación de plantas y por ello los estudios elaborados en esta área adquirieron una relevancia mayor que el resto (Mayor 1958). En el contexto general de la ecología, el primer debate de alta repercusión se desarrolló entre ecólogos de plantas terrestres. El mismo versó sobre la forma de comprender las asociaciones y las sucesiones vegetales, que indagan el modo en que un tipo de flora es progresivamente remplazada por otra.

Este debate surge a partir de una nueva propuesta de Clements. En 1916 este ecólogo norteamericano definió la sucesión vegetal como una secuencia de reemplazo de comunidades de plantas, en un proceso unidireccional por el cual las comunidades vegetales convergían hacia un estado de equilibrio, cuyas características resultaban exclusivamente del clima regional. Clements basaba su marco teórico en las escuelas de fitogeografía alemana y sus trabajos se centraron en las estables comunidades vegetales del centro y este de los Estados Unidos (Bazzaz 1996). ${ }^{9}$

Clements presentó las asociaciones vegetales como "superorganismos", porque entendía que sus partes estaban integradas a un nivel tal que podía equipararse con las de un organismo vivo. Esta fue una mirada teleológica que suponía un destino prefijado. De esta metáfora se desprendía que las asociaciones vegetales "nacían" -por ejemplo como un conjunto de pastos determinados- y "crecían" hacia una forma preestablecida -por ejemplo un bosque.

Aquí vale un paréntesis que repare en la carga teleológica de los supuestos de Clements. La idea de una finalidad en la naturaleza es un lugar común de los estudios de la vida. En este punto puede encontrarse una referencia al pensamiento de Aristóteles como precursor de la idea que la naturaleza no hace (o produce) nada al azar o sin una finalidad, o en forma inversa, que todos los procesos tienden a un fin (Guthrie 1981). Aristóteles asumía la noción de cambio o progreso como progresando hacia algo, un final preestablecido y existente en un mundo ordenado jerárquicamente.

\footnotetext{
${ }^{9}$ La fitogeografía es el estudio de la distribución de plantas en la tierra.
} 
La hipótesis sobre la que Aristóteles desarrolla su trabajo, que la naturaleza es constructiva y sigue una finalidad, tuvo, a decir de W.K. Guthrie (1981), un enorme valor heurístico que introdujo avances notables en los estudios biológicos, aunque también llevó a importantes debates en torno al sustento intencional o no de la finalidad (que escapan al presente trabajo). Sin embargo Aristóteles no es el único filósofo que avanzó sobre el conocimiento de la naturaleza con la guía de la teleología. En el siglo XVIII Immanuel Kant recorrió un camino que lo llevó a conclusiones en el mismo sentido. En su incipiente obra Historia General de la Naturaleza y Teoría del Cielo, marca particularidades del mundo orgánico que resultan complejas de integrar a un mundo natural signado por leyes de causa y efecto. ${ }^{10}$ En sus propias palabras

"En mi doctrina (...) descubro la materia vinculada a ciertas leyes necesarias. En su total disolución y dispersión, veo comenzar el desarrollo por completo natural de un todo hermoso y ordenado. Esto no ocurre debido al azar o por casualidad; por el contrario se observa que factores naturales conducen necesariamente a ello... (:17)

Me parece que aquí se puede decir en cierta manera sin temeridad: Dadme materia y os construiré con ella un mundo, es decir: Dadme materia y os mostraré cómo un mundo ha de nacer de ella. Pues si existe materia dotada de una determinada fuerza de atracción, no es difícil determinar las causas que han podido contribuir a la formación del sistema universal (...) en cambio ¿podemos jactarnos de esta ventaja respecto de las más humildes plantas o insectos? ¿Podemos decir: dadme materia y os mostraré como se produce una oruga? ¿No quedamos paralizados desde el primer paso, por ignorar la verdadera naturaleza íntima del objeto y las complicadas diversidades que encierra? No debe, pues, extrañar a nadie si me atrevo a decir que la formación de todos los cuerpos siderales, la causa de sus movimientos, en fin, el origen de toda la actual constitución del Universo podrá ser comprendido con mayor facilidad que el nacimiento de una sola hierba”.

Kant busca una resolución al desafío de conocer la naturaleza viva en una de sus últimas obras Crítica del Juicio. ${ }^{11}$ En este texto toma la idea que somos conducidos a la idea de finalidad por un raciocinio necesario. Plantea que existe una armonía entre la sensibilidad y el entendimiento como facultades y cuando se produce este encuentro es

\footnotetext{
${ }^{10}$ Los datos bibliográficos de la obra consultada son Kant, I. (1969) [1755] Historia general de la naturaleza y teoría del cielo. Juárez Editor. Buenos Aires. Colección PAIDEUMA dirigida por Carlos Astrada y Alfredo Llanos. Traducción Jorge E. Lunqt.

${ }^{11}$ Los datos bibliográficos de la obra consultada son Kant, I. (2007) [1790] Crítica del Juicio, edición de Juan José García Norro y Rogelio Rovira, Editorial Tecnos. Madrid. Traducción de Manuel García Morente.
} 
que tenemos la experiencia de la belleza. Así la universalidad del juicio estético no pasa por principios, como en el caso de los juicios analíticos y sintéticos, sino que pasa por el acuerdo entre facultades. En esta línea plantea el idealismo estético, que aparece como el primer paso de presentación del juicio teleológico:

“... la finalidad no existe en la naturaleza... es un principio a priori que pone la conciencia en la creación o no en la contemplación de lo bello. La finalidad como Idea acerca el arte a los objetivos de la humanidad. De ahí que se califique a la belleza como símbolo de la moralidad." (§59)

Esto implica, tal como señala en el $\S 61$ de la Crítica del Juicio, que los límites reconocidos al conocimiento de la naturaleza orgánica se ligan a las características del juicio que se reconoce como válido para indagarla. No se trata de abandonar los juicios sintéticos y analíticos para el mundo orgánico, sino que las reflexiones desarrolladas para el mundo inorgánico no alcanzan para explicar los seres organizados. Esto lleva a un problema entre los límites posibles del conocimiento: la explicación mecánica surge de reconocer que las categorías son constitutivas de la experiencia. Así todos los fenómenos deben ser explicados en base a la causalidad mecánica pero esto no alcanza para el mundo orgánico.

En relación a los seres organizados Kant señala que el entendimiento sugiere un modo de comprender las causas corpóreas mientras que la razón propone otro. Y en este punto reconoce el enorme peso heurístico de la teleología. Kant indica que el conocimiento de los seres organizados ha sido posible por la aceptación general de fines en la naturaleza (§72). Pero esta suposición necesaria ha sido vista como real en sí y, basándose en la misma, se han generado reflexiones que se proyectan más allá de los límites reconocibles desde la filosofía.

Estas reflexiones sobre el modo de interpretar la teleología en el mundo orgánico, que desde todas las perspectivas se consideraba necesario de una u otra forma, influyó directamente sobre el modo de conocer. Entre las propuestas de mayor relevancia debe contarse la vertiente alemana de reflexión sobre la naturaleza denominada naturphilosophie (Maquinistan 2004, Gilson 1988). ${ }^{12}$ Desde la misma se sostenía un carácter tanto teleológico como jerárquico del mundo basado, sobre todo, en cuatro

\footnotetext{
${ }^{12}$ Algunos de los representantes más notables de esta propuesta son Johann F. Meckel(1781-1833); Johan W. Goethe(1749-1832); Lorenz Oken (1779-1851) y Étienne Geoffroy Saint-Hilaire (1772-1844)
} 
premisas: 1) La creencia en la unidad de la naturaleza y sus leyes, donde el hombre se reconocía como la más alta expresión de la materia sobre la tierra; 2) La creencia en la existencia en la naturaleza de una tendencia al desarrollo progresivo; 3) La postulación que todos los procesos naturales se mueven en una única dirección (entre ellos, desarrollo individual y progresión de especies); 4) La consideración que el desarrollo y la progresión son gobernados por las mismas leyes, dando lugar a una proyección biologicista sobre variables sociales.

En este marco de ideas no resulta extraño que se planteen concepciones teleológicas en el análisis sistemático de los dinamismos de los organismos vivos. Tampoco resulta sorprendente que estas ideas hayan generado atracción, porque resultaban facilitadoras al momento de comprender la enorme diversidad de un escenario natural.

Esta tendencia a introducir destinos no es exclusiva de la ecología. El filósofo de la biología e investigador Jacques Monod (1972) indicó que el postulado de objetividad sobre el que avanzó el conocimiento en los últimos tres siglos llevó a los biólogos a reconocer en los organismos vivos un carácter teleonómico, esto es, con una actividad orientada, coherente y constructiva. En este sentido la biología ha reconocido que los organismos, en su estructura y actuación, persiguen un fin y deciden de acuerdo con él. Para saltar esta "profunda contradicción epistemológica" (denominación otorgada por Monod), hizo falta la microbiología del siglo XX que mostró que "el puro azar, absolutamente libre pero ciego, está en la raíz del edificio de la evolución” (Monod 1972, 110)

En este contexto no sorprende que las propuestas de Clements que sostenían que el crecimiento de cada de cada clase de vegetación tendía a un equilibrio -el climax- que se podía predeterminar y se suponía inalterable en la medida que la asociación no enfrentara ningún cambio brusco externo, realizadas a principio del siglo $\mathrm{XX}$, tuvieran gran aceptación.

Clements indicó que el climax podía permanecer sin variaciones durante millones de años (Clements 1936). Si bien esta propuesta fue adoptada como base metodológica de gran parte de los ecólogos de Norteamérica y Europa (Deléage 1993), algunas voces se alzaron en contra. Los ecólogos vegetales adscribieron rápidamente a la idea clementsiana de privilegiar el estudio de comunidades en contra de la investigación de 
organismos aislados, pero dos estudiosos de la vegetación entendieron que de esta opción no se desprendía la noción teleológica propuesta.

El primer detractor de la teoría de climax fue Henry Gleason (1926). Formado en universidades norteamericanas, Gleason encontraba dificultades para aplicar las teorías de Clements en los conjuntos vegetales que él observaba. La principal crítica desarrollada por Gleason indicaba que no se podía pensar a una asociación vegetal como superorganismo porque no existen límites claros (como los que diferencian a un individuo de cualquier especie) ni espacial ni temporalmente. Los límites de una determinada asociación vegetal estaban dados, según Gleason, por criterios que tenían más que ver con el observador que con el conjunto de plantas. Este biólogo planteaba que las asociaciones vegetales eran simplemente la suma de las respuestas adaptativas de los organismos que las conformaban. Desde esta perspectiva individualista las asociaciones, lejos de ser superorganismos, eran epifenómenos de las acciones singulares. Las categorías planteadas por Clements eran, para Gleason, abstracciones desarrolladas por los investigadores con el propósito de describir, clasificar o manejar la vegetación.

El ecólogo británico Arthur Tansley (1935) también se opuso a la teoría de climax. Este biólogo discutió que el equilibrio de una asociación vegetal pudiera preestablecerse y contrapuso la noción de ecosistema a la idea de superorganismo. Tansley entendía que las asociaciones vegetales podían pensarse como un sistema integral, pero en un sentido físico, donde debía estudiarse el flujo de energía. Abandonó la presunción teleológica implícita en la propuesta de Clements a pesar de mantener una concepción holista. Según esta propuesta, las asociaciones vegetales no convergen necesariamente a estadíos preestablecidos sino que, en todo caso, llegan a distintos momentos de equilibrio imposibles de predecir. Tansley abandona las formas clásicas de concebir la naturaleza y busca las formas para acercar la ecología hacia otras ciencias naturales que, en estos primeros años del siglo XX, cobraban cada vez más reconocimiento.

A pesar de las impugnaciones de Tansley y Gleason la mayor parte de la comunidad de ecólogos adoptó las ideas de Clements hasta los años cuarenta. Sin embargo en la medida en que se fueron conociendo más sistemas naturales empezó a provocar dudas entre los investigadores la necesidad de suponer disturbios en los climax previamente supuestos para dar cuenta del tipo de comunidad observado (Barbour et al. 1996). 
A las alternativas de Tansley y Gleason ya conocidas, que permitían indagar las asociaciones de plantas desde otras perspectivas menos problemáticas se suma en los años cincuenta con la revisión de Whittaker $(1951,1967)$. Este investigador analiza los gradientes de las poblaciones vegetales y encuentra que las mismas no son más que coincidencias en las curvas de distribución de las especies de plantas. También demuestra, a través del estudio de los gradientes altitudinales, que las comunidades se integran continuamente y la competencia entre ellas no genera zonas de vegetación separada. De este modo quebró la posibilidad de equiparar a una comunidad con un organismo porque no es posible delimitar a un individuo.

La conclusión de Whittaker fortaleció la propuesta de Gleason, que entendía a las sucesiones vegetales como la suma de las respuestas individuales. Si bien el trabajo de Whittaker ha sido puesto en discusión en los últimos años (Wilson y Agnew 2004), a mediados del siglo XX sirvió para afianzar el abandono de la propuesta de Clements (Barbour et al. 1996). Los estudios alternativos, sustentados en las propuestas de Tansley y Gleason, cobraron cada vez más fuerza y la controversia se fue dirimiendo en la medida que más ecólogos adoptaban la nomenclatura de ecosistema de Tansley y la metodología individualista de Gleason para el estudio de los mismos.

Si se revisa el modo en que se ha escrito la historia de la ecología, que en su mayor parte han adoptado una perspectiva de análisis kuhniana, se encuentra que se reconoce en la propuesta de Clements al primer paradigma de la ecología (Simbreloff 1980, Wiens 1989) en el sentido kuhniano del término. Los autores que lo proponen entienden que a partir de la teoría de climax se dio un período de ciencia normal, porque fue adoptado por gran parte de la comunidad que dejó de discutir fundamentos y se propuso aplicar la metodología y teoría para avanzar en el conocimiento de los diversos sistemas naturales del mundo. Desde este primer paradigma Daniel Simberloff (1980) entiende que se sustentó una visión holística y teleológica en un sentido real y no heurístico, por ello denomina a este conjunto de acuerdos paradigma aristotélico de la ecología. El abandono de la propuesta clementsiana se presenta, desde esta perspectiva, como una suma de anomalías. Es decir, en la medida que los estudios se multiplicaron se propusieron fragmentaciones y periodizaciones cada vez más complejas que llevaron al cambio teórico. 
Sin embargo, la existencia de ramas de la ecología independientes, sumado a la presencia de divisiones en ecología vegetal en líneas de investigación alternativas y mutuamente excluyentes hacen difícil pensar en una aplicación estricta de la noción de paradigma en el sentido propuesto por Khun (1962). Esta no es la única dificultad para revisar la ecología a la luz de los postulados del autor de La estructura de las revoluciones cientificas. Tampoco parece poder aplicarse su modelo de cambio, porque el proceso de abandono de la teoría de climax no es resultado de una revolución paradigmática. Se trata más bien de una permutación progresiva de metáforas, donde trabajos como los de Lindeman $(1942)$ o Whittaker $(1951,1967)$ sirvieron para afianzar el cambio que, por otra parte, estuvo acompañado por una integración creciente con las otras ramas de la ecología.

La propuesta de Clements fue abandonada, entre otros factores, por la creciente complejidad que adoptaban las explicaciones basadas en el climax, sumado al creciente reconocimiento de propuestas mecanicistas, que posiblemente facilitaron la decadencia del modelo metafísico-teleológico, para justificar sucesiones de plantas que existían en diversos escenarios y que no se adecuaban a la propuesta original (Barbour et al., 1996). Sin embargo, en el proceso de abandono de los factores explicativos teleológicos, ninguna de las posiciones se mantuvo invariante por la importante incidencia del progresivo acercamiento entre las diferentes ramas de investigación y de cambios extradisciplinares.

Lejos de pensar en cambios de paradigmas kuhnianos, considero más apropiada una concepción de articulación progresiva, que en forma parcial fue rescatando parte de cada una de las teorías, inaugurándose en ese proceso una práctica que redundó en un cambio de carácter disciplinar, ya que en el cambio de los conceptos los estudios descriptivos fueron dejando cada vez más lugar a los estudios experimentales. Las vertientes originales de la ecología desdibujaron sus límites dando forma a lo que podría denominarse como el período clásico de la ecología.

\section{La introducción de la experimentación}

El acercamiento entre las diferentes vertientes de la ecología se fortalece a mediados de los años cuarenta, cuando comienza un proceso de cambio que afecta a toda la disciplina estableciendo a la ecología científica tal como se conoce hoy en día. Este 
cambio redundó en un nuevo carácter disciplinar, que de descriptivo pasó a experimental, y en la incorporación de teorías que vincularon las controversias de las diversas ramas de la ecología.

El desarrollo tecnológico de este período permitió nuevas estrategias de investigación con los correspondientes avances en el entramado teórico de la disciplina (Brown 1991). Esto generó una matematización creciente de las investigaciones ecológicas. ${ }^{13}$ Kingsland (1991) sintetiza este proceso al indicar que

"El origen de la ecología como ciencia comienza a mediados de siglo XX con la aplicación de los experimentos y los métodos matemáticos en el análisis de las relaciones de los organismos y sus ambientes" (Kingsland 1991,1).

Esta visión experimentalista de la historia de la ecología concuerda con los preceptos que se forjan desde los años cincuenta, donde resulta claro el abandono de la descripción como modo de investigación. Por ejemplo McArthur -uno de los ecólogos de mayor influencia desde mediados de siglo XX-señaló en 1971 que

“... no todos los naturalistas quieren hacer ciencia; muchos se refugian en la complejidad de la naturaleza y desde allí justifican su oposición a buscar patrones. Este libro está dedicado para aquellos que desean hacer ciencia" (McArthur, 1971: 9).

Mostrando una concepción diametralmente inversa a la reconocida por Alberti (2001) en relación al reconocimiento de los estudios amateurs en el siglo XIX, la idea de McArthur explicita la separación de la actividad de investigación respecto de la observación de la naturaleza. En la década de los cuarenta, al mismo tiempo que el concepto de climax y la metáfora de "superorganismo" perdían preponderancia, se incrementó la tendencia a buscar patrones relacionales a través de regularidades matemáticas. A partir de mediados de siglo XX hacer ecología fue buscar explicaciones

\footnotetext{
${ }^{13}$ Vale una aclaración sobre este punto, porque la modelización de los sistemas naturales tiene tempranos antecedentes en los estudios estadísticos de Raymond Pearl, quien descubrió en 1920 curvas de crecimiento de poblaciones (Pearl también encontró que otro matemático, el belga Pierre Verhulst había llegado a conclusiones similares un siglo antes aunque sus resultados no se dieron a conocer) así como en las ecuaciones del demógrafo norteamericano Lotka y el físico italiano Volterra, que modelaron procesos de competencia y predación en los primeros años del siglo XX. De la mano de Pearl se introdujeron en ecología estudios de curvas de crecimiento poblacional. En los `30 ya se encuentran análisis de las fluctuaciones en las poblaciones y su correspondiente modelización matemática (Cushing 1977), sin embargo el auge de estos estudios se reconoce a partir de los años cincuenta, cuando se incorpora el análisis poblacional estadístico en las diferentes especialidades existentes. Siguiendo esta concepción estadística en 1954 Andrewartha y Birch plantearon que la ecología era el estudio de la distribución y abundancia de los organismos.
} 
causales a partir de patrones estadísticos. En este proceso se incorporó un ideal de ciencia clásico, positivo y experimental (Roughgarden et al., 1989; de Laplante, 2004) que supone la existencia de patrones generales porque se aceptaba que existía un factor determinante en la estructuración de comunidades: la competencia interespecífica. El reconocimiento de esta regularidad permitía plantear la existencia de otras.

En la adopción de los valores clásicos de las ciencias naturales experimentales se incorporan supuestos que marcaron tanto las formas como los modos de interpretar el conocimiento que se produjo. Entre ellos se destaca el supuesto objetividad, que implica que el seguimiento de un método científico riguroso, de protocolos y técnicas estandarizados y la aplicación de métodos estadísticos y cuantitativos garantiza que las conclusiones científicas están libres de la influencia de la emoción y de la intención del/ la científico/a.

En el libro de R.H. Peters (1991) Crítica a la ecología se expone la importancia de la búsqueda de regularidades como base de cualquier teoría ecológica que se pretenda científica, y en sus propuestas se acerca a nociones vinculadas a la idea de objetividad más aceptada por las ciencias naturales, que ha sido la postulada por Karl Popper (1963). Quien entiende que la objetividad se da en la actitud honesta del/la científico/a que formula una conjetura y no acude a toda serie de argumentos no racionales para defender su propuesta y supone, en modo asociado, la trascendencia de condicionantes históricos y subjetivos.

Peters (1991) apela a un fortalecimiento de la matemática para sortear los ruidos y tensiones que provienen de las demandas extracientíficas, en ello reconoce un camino que permitirá consolidar las bases de lo que considera "buena ciencia", por ello señala "Sólo una comprensión basada en leyes de cobertura o modelos matemáticos generales pueden proveer explicaciones que posean estándares consistentes con el poder predictivo de la ciencia" (Peters 1991,177).

El objetivo de la investigación ecológica es, a los ojos de este autor, la búsqueda de las leyes generales de las cuales se desprendan deductivamente las consecuencias observables. Sagoff (2003) señala que bajo esta concepción filosófica, muchos ecólogos crearon modelos matemáticos y teorías que buscaban descubrir reglas y principios que gobernaran los fenómenos ecológicos. 
M. Sagoff sugiere que, si bien se ambicionaba la búsqueda de leyes generales que permitieran predecir, la complejidad de algunos modelos matemáticos ponía en discusión si éste era el camino. A modo de solución a este problema, donde la complejidad matemática parecía resultar mayor que la propia complejidad orgánica, Peters (1991) propuso un retorno a estrategias más inductivas aceptando que

“... ciertas regularidades bien confirmadas pueden eventualmente transformarse en explicaciones aceptables" (Peters 1991, 108) y asumiendo que “...los ecólogos deberían investigar preguntas y modelos simples... que conduzcan a mejores predicciones, en lugar de dedicarse a construir y analizar complejos modelos realistas para todo propósito" (Peters 1991, 114).

Al indagar en las prácticas y las reflexiones de investigadores/as se encuentra que la seriedad y ausencia de intenciones personales parece sortearse en la aplicación del método hipotético-deductivo (Núñez 2007). Por ello en los protocolos de investigación de esta disciplina se desarrollaron debates cuyo objetivo era analizar estrategias que ayudaran a adecuar la misma al ideal clásico de ciencias (Farji-Brenner 2003).

Junto a la objetividad se fue incorporando la idea de neutralidad, que plantea la existencia de verdades universales, esto es, al margen de consideraciones historicocontextuales o factores subjetivos, tales como preferencias, prejuicios, personalidad o valores que posean los/las investigadores. Este supuesto no está separado de la idea de objetividad pues la neutralidad valorativa se toma como garantía de la objetividad de la ciencia. Pero, como se desprende de las formas que adoptan los protocolos de investigación, la idea de una ciencia neutra no es, en sí misma, neutra; sino que sesga el modo en que se plantean las relaciones y reconocen otros ámbitos no académicos.

En este contexto uno de los desarrollos teóricos de mayor impacto fue la sistematización de la teoría de nicho, que había surgido en la ecología animal varios años antes. Aún cuando la idea de nicho resultaba inspiradora de muchos trabajos su formalización fue llevada adelante recién en 1957, cuando G.E. Hutchinson realizó su sistematización algebraica. Hutchinson postuló que cada variable medioambiental podía ser representada por un eje cartesiano. En cada eje se podía señalar un valor superior y un valor inferior donde se desarrolla la especie. El nicho fundamental era, desde esta perspectiva, el hipervolumen que resultaba de unir los distintos ejes conformando un hiperespacio de tantas dimensiones como variables se tomaran. La competencia 
interespecífica de dos especies o más podía incluso medirse, porque era equivalente a la intersección entre sus nichos.

Una de las consecuencias de esta propuesta fue que si los nichos de dos especies resultaban idénticos, las mismas no podrían co-ocurrir, es decir no podrían estar en el mismo espacio, por las limitaciones supuestas en la exclusión competitiva. Del mismo modo, si el nicho de una especie se encontraba dentro del de otra, la especie con el nicho más reducido se vería desplazada. La aceptación del nicho hutchinsoniano generó interés por el estudio de los límites del mismo y varios ecólogos se dedicaron a avanzar en esta línea de trabajo.

J.G. Kingsolver y R. Paine (1991) indican que la definición de nicho de Hutchinson ayudó a la clarificación de las relaciones entre particiones de las comunidades ecológicas, así como la interpretación de la coexistencia y evolución de los nichos dentro de las comunidades. Este proceso ayudó a incrementar la coherencia interna de la disciplina. Los aportes de Hutchinson resultaron de tal magnitud que existe un acuerdo general en reconocerlo como "padre fundador" de la ecología científica.

Otro de los aportes reconocidos a Hutchinson fue su estudio en torno a los factores que determinan la abundancia de especies (Hutchinson 1959). A fin de delinear procesos ecológicos de generación y limitación de la biodiversidad ambiental, Hutchinson elaboró la "Regla del 1,3". La misma postulaba que las especies de formas semejantes podían coexistir en la medida que la diferencia de tamaños fuera del treinta por ciento, esto es de 1,3 puntos; porque en ese caso utilizarían diferentes recursos o los mismos recursos de forma diferenciada. Desde allí Hutchinson postuló que en la medida que las especies poseyeran un tamaño diferente, aumentaría la posibilidad de coexistencia porque disminuiría la tensión competitiva. Este postulado llevó a muchos ecólogos a buscar este patrón entre los organismos vivos tomándolo como una ley organizadora de la estructura de las comunidades orgánicas.

La confianza en el poder explicativo de la competencia llegó a tal nivel que Hutchinson (1979) justifica porqué la competencia seguía siendo el factor fundamental aún en escenarios naturales donde la exclusión competitiva no parecía operar por la obvia convivencia de especies similares. ${ }^{14}$

\footnotetext{
${ }^{14}$ A modo de ejemplo cita trabajos como los de McArthur (1958) o Marshall (1960), donde la similitud y proximidad de las aves que estudiaban en cada caso hacía impensable que no compitieran por los recursos
} 
Durante este período se instala gradualmente el ecosistema como unidad de estudio, sobre todo a partir de la sistematización energética introducida por Lindeman en 1942. Brown (1991) plantea que la propuesta de Lindeman generó dos líneas de investigación contrapuestas: la ecología del ecosistema, -que indagaba el intercambio energético- y la ecología evolutiva -que reconocía en los sistemas naturales las fuerzas evolutivas. El biólogo norteamericano E.P. Odum $(1953,1969)$ buscó tender un puente sobre las alternativas explicativas explicando porqué estas líneas resultan necesariamente contrapuestas.

Odum utilizó las sucesiones de organismos para inferir los principios que gobiernan el dinamismo de los sistemas ecológicos. Así propuso una visión que articuló los procesos de energía con el crecimiento poblacional. J.H. Brown (1991), por su parte, señala que el estudio de los ecosistemas emerge como la rama unificadora de los estudios ecológicos, que supone la visión del ecosistema como un sistema físico y el reconocimiento de las fuerzas evolutivas actuando en el mismo. Los manuales de Ecología de la década de los cincuenta y aún posteriores, permiten reconocer que el ecosistema, como concepto, permitía un acercamiento reduccionista ya que suponía la posibilidad de un estudio escindido de sus partes. Porque se designa al ecosistema como la suma de las distintas comunidades (o biocenosis) y el biotopo (ambiente inerte) que ocupan. En esta definición los organismos o la comunidad, aparecen disociados del entorno, puesto que se define ecosistema por la suma de términos, siguiendo la propuesta individualista que Gleason desarrolla en su temprano debate con Clements.

Finalmente, entre las principales propuestas que inician nuevas vías de trabajo, también se destaca la desarrollada por R.H. McArthur y E.O. Wilson (1967) de biogeografía de islas. Estos ecólogos propusieron que las islas más grandes y cercanas al continente tendrían mayor número de especies que las islas más pequeñas y alejadas. Esta hipótesis, que se basó en numerosas observaciones y regularidades estadísticas, impactó en políticas de conservación de especies, porque de la misma se desprendía que el riesgo de extinción disminuye en poblaciones de mayor tamaño que habitan en un área extensa.

Esta sucinta descripción permite mostrar que los debates que se abrieron entre los años cincuenta y sesenta no muestran enfrentamientos o discusión en torno a los supuestos, a pesar de la co-existencia observada. Tanto McArthur como Marshall encontraron explicaciones ad hoc que salvaban el rol preponderante de la exclusión competitiva. 
porque tanto Hutchinson como MacArthur y Odum lograron fundamentar acuerdos generales sobre los que se llevó adelante la investigación. En este conjunto de acuerdos se acordó destacó el rol fundamental de la exclusión competitiva en la organización de las comunidades y se adoptó el ecosistema como unidad de estudio.

En este proceso, la articulación de la ecología con otras ciencias naturales se fue fortaleciendo, ya que la revisión de los múltiples factores presentes en los diversos ecosistemas demandaba aportes de otras especialidades como las ciencias de la tierra o la climatología.

Si bien existieron voces contrarias a algunas de las propuestas descriptas, las mismas fueron minoritarias o se circunscribieron a casos puntuales. A modo de ejemplo se puede citar el trabajo de C.S. Holling (1959), quien criticó la preponderancia adjudicada a priori a la competencia en todos los sistemas, postulando el peso de la predación en sus estudios sobre insectos. En el mismo sentido, R.T. Paine (1966) señaló procesos de predación que minimizan la incidencia de fenómenos competitivos sobre organismos que habitan en zonas afectadas por mareas. Pero muchos ecólogos investigaban la causa de que la competencia no apareciera claramente en algunos sistemas particulares, presuponiendo igualmente que era el principal factor estructurador. Desde esta perspectiva era razonable que casos que no parecían adecuarse a la regla general pudiesen, en el futuro, explicarse de tal forma que se salvaguardara el rol privilegiado de la competencia.

En general, se vio como un logro llegar a este conjunto de consensos ante el desafío disciplinar por encontrar reglas generales en un mundo orgánico tan complejo. Aún cuando se llamara la atención sobre otros factores (como el artículo de Andrewartha y Birch de 1954, que introdujo la importancia de reconocer factores dependientes de la densidad poblacional en la dinámica de una comunidad), logró remover la confianza en la preponderancia de la competencia interespecífica que se suponía operando de forma permanente e independiente del número de individuos de una comunidad.

Un aspecto a destacar de estos años es que no se reconocieron voces extradisciplinares en los debates, a pesar del incremento de movimientos ambientalistas y las implicancias indiscutibles de la ecología en temas de preservación ambiental. ${ }^{15} \mathrm{~K}$. de Laplante (2004)

\footnotetext{
${ }^{15}$ Vale mencionar que en 1948 se publica la obra de Aldo Leopold, quien indica que el problema ambiental no es un problema de conocimiento sino de ética. Este texto se reconoce como el inicio de los
} 
señala que a mediados de siglo $\mathrm{XX}$ las voces ambientalistas se reconocieron como ajenas a la disciplina, y la ecología buscó de forma creciente diferenciarse de los movimientos ecologistas que iban incrementándose, por ello se fortaleció una mirada introspectiva acorde a los criterios de ciencia clásica presentes en la disciplina.

\section{La incorporación de las dudas como estrategia de investigación}

Estos acuerdos se vieron trastocados cuando, desde el propio corazón de la ecología, se empezó a discutir la jerarquía explicativa de la competencia en la estructuración de comunidades orgánicas. El primer trabajo que buscó instalar una impugnación hacia la competencia fue presentado por Williams (1947). Este ecólogo reclamó la revisión del rol explicativo de la competencia al discutir la interpretación de uno de los principales patrones de competencia de esos años: el cociente $n^{o}$ de especies / $n^{\circ}$ de géneros.

Calculado tempranamente, este cociente permitía observar que la razón resultante en las islas era menor que en el continente del cual habrían migrado las especies. Los científicos que notaron esta característica debatieron sobre posibles explicaciones de este fenómeno y finalmente la interpretaron como un argumento a favor de la competencia, porque entendieron que la presión competitiva era mayor en las islas, por tener una superficie más reducida, con alto nivel de aislamiento y menor diversidad de habitats (Elton, 1946). En contra de esta visión, Williams $(1947,1964)$ sostuvo que esa diferencia se debía a un sesgo matemático producto del estudio de grandes grupos (en los continentes) comparado con el estudio de pequeños grupos (en las islas). De allí infería que la competencia no era parte necesaria la explicación. Sin embargo no logró persuadir a la comunidad científica de ello y su trabajo fue ignorado.

Con posterioridad Simberloff (1970) desarrolló un trabajo en la misma línea que había reclamado Williams. Este ecólogo supuso que el trabajo de su antecesor no había logrado mayor repercusión porque no había sido elaborado con herramientas matemáticas contundentes. Por ello Simberloff introdujo avances informáticos y programó modelos nulos. Esto es, elaboró matrices de datos que permitieron comparar los datos tomados en el campo con los datos que se obtendría si esas mismas

movimientos ambientalistas (Kwiatkowska e Issa 1998). En la ecología esto provocó rechazo, aunque tangencialmente se elaboraron líneas de investigación que buscaban trascender los límites de las ciencias naturales (ver p.e. Odum 1975) que adolecieron de continuidad. 
comunidades se distribuyeran de forma azarosa. En 1970 demostró que la capacidad explicativa a partir de la competencia era la misma que si se postulaba que las migraciones a las islas habían sido azarosas. Consideró que la conocida diferencia del cociente entre islas y continentes se podía explicar por el sesgo ya mencionado por Williams. Debe señalarse que en su trabajo, Simberloff denuncia que el análisis de Williams fue ignorado, pero ni la denuncia ni la explicación propuesta en 1970 lograron repercusión, a pesar de ser publicada en una de las principales revistas sobre ecología y que otros de trabajos suyos, habían impactado fuertemente en estos años en la comunidad científica.

El supuesto de la competencia como factor preponderante de la organización de los seres vivos seguía presente en la mayor parte de los estudios ecológicos. De hecho, en 1975 se publica el artículo más representativo sobre la adscripción a la idea de la competencia como la fuerza estructuradora omnipresente y determinante de los sistemas naturales: el texto de J. Diamond (1975) sobre el ensamble de las especies (Gotelli 2001).

La verificación del trabajo de Diamond favoreció de forma ineludible la revisión del valor explicativo otorgado a la competencia y llevó a la refutación de uno de los supuestos más importantes de la ecología en general. En 1979, Connor y Simberloff discuten las reglas de ensamblaje propuestas en 1975, contrastando los resultados de Diamond con modelos nulos. Esto es, la comparación de los datos obtenidos en el campo -y explicados en términos de competencia interespecífica- con los datos que se obtendrían si esas mismas comunidades se distribuyeran de forma aleatoria. Connor y Simberloff demostraron que los datos de Diamond también eran consistentes con una distribución azarosa de las especies. Esta constatación inició una discusión ampliada sobre la posibilidad de dudar de los supuestos establecidos. ${ }^{16}$

El escrito de Connor y Simberloff fue un desafío directo a la confianza en la competencia como factor preponderante al vincular esta confianza con el modo en que se establecieron las reglas de ensamblaje. La frase inaugural advertía: "En este trabajo mostramos que las reglas de ensamblaje cuando no son erróneas, son triviales" (Connor

\footnotetext{
${ }_{16}$ Vale aclarar que, matemáticamente, si los datos explicados en términos de competencia son consistentes (es decir, son igualmente explicados) con una explicación alternativa -el azar en este caso -significa que es equivalente pensar que las comunidades se estructuraron por competencia que por casualidad.
} 
y Simberloff 1979, 1132) y a lo largo del texto manifestaban que el error en las conclusiones provenía de la falta de búsqueda de explicaciones alternativas.

La aplicación de los modelos nulos permitió comparar la capacidad explicativa de la competencia con el supuesto de ausencia de factores estructurantes (esto es, el azar como fuerza imperante de la organización del mundo vivo). La falta de diferencia significativa en el porcentaje de datos explicados por ambos supuestos permitió inferir que la competencia no podía tomarse como factor determinante. De allí podía desprenderse que el peso de los diferentes factores podía variar junto con los escenarios orgánicos y que en este contexto resultaba discutible la posibilidad de generalizar patrones.

La revisión de supuestos provocó resquemores. Entre otras críticas, los denominados "nulistas" fueron acusados de abandonar los presupuestos biológicos que sustentaban los estudios ecológicos. Por ejemplo Levins y Lewontin (1982) señalaron que los nulistas no aportaban ninguna hipótesis biológica nueva y que esta revisión era contraproducente al avance de la disciplina. En ese mismo sentido, Roughgarden (1983) acusó a las hipótesis nulas de ser "empíricamente vacías" porque no incorporan procesos biológicos como las dispersiones o la extinción de poblaciones. La aleatoriedad, el mecanismo básico de los modelos nulos, no parecía concebible en el marco de las teorías ecológicas de la época. Tal es así, que Grant y Abbot (1982) rechazaron su aplicación porque entendían que asumían principios no evolutivos. Estos biólogos indicaron que al plantear una distribución en términos de azar se suponían propiedades fijas en las especies, que son las que determinarían la forma de estructuración de las comunidades.

Los defensores de los modelos nulos señalaban que reconocían esta heterogeneidad y que no estaban probando el azar. Muy por el contrario, lo que ponían en duda era el rol de la competencia en la explicación. A tales efectos se revisaron distintas investigaciones, siendo uno de los casos más movilizantes en este debate la revisión de la regla del 1,3 propuesta por Hutchinson.

Tanto los simpatizantes como los detractores de los modelos nulos fueron acercando posiciones. Los defensores de la competencia fueron aceptando la necesidad de revisar el valor de la misma en la estructuración de comunidades. La discusión sobre la 
legitimidad o no de revisar la competencia se reorientó hacia el modo en que los modelos nulos habían sido aplicados. Los cambios que se proponían tenían que ver con la programación de las matrices y las restricciones biológicas que se debían suponer.

Entre los aspectos que se destacan en la ecología de los últimos años se cuenta el incremento de la importancia de los estudios sobre el efecto de las interacciones positivas. Esto se encuentra, por ejemplo, en el trabajo de Bertness y Callaway (1994) que plantea la importancia de reflexionar sobre los mutualismos, así como en artículos que revisan mecanismos de invasión de las especies (Simberloff y Von Holle, 1999, Richardson, 2000) o que retoman la pregunta original de Hutchinson sobre el porqué de la diversidad de especies, pero a la luz de las interacciones positivas, como es el caso de Hacker y Gaines (1997). En la misma línea Bruno et al. (2003) reclaman por la necesidad de profundizar en torno a los impactos de los dinamismos facilitadores en ecología.

Actualmente en ecología no aparecen acuerdos generales claros, sino más bien diversas posiciones, acuerdos parciales e interpretaciones que abren nuevas temáticas a investigar que igualmente enriquecen la disciplina. Este proceso también ha dado lugar a miradas alternativas que parecen buscar extender el conjunto de acuerdos que sostiene la práctica a partir de dar prioridad a un cierto tipo de estudios sobre otros.

El ejemplo más claro es la propuesta inaugurada por la macroecología, que se fortalece a partir de diferenciarse de la ecología de comunidades. Esta especialidad se funda en las propuestas de la biogeografía de McArthur y Wilson (1967) o aerográficos de Rapoport (1975). A fines de la década de los años noventa, luego que se evidenció que los experimentos a escala local eran insuficientes para identificar los mecanismos que regulan la dinámica y persistencia de comunidades ecológicas (Maurer 1999, 2000), se propuso la macroecología, esto es una observación a escala de planeta y con tiempos evolutivos, como una perspectiva necesaria de estudios. El supuesto básico de todo análisis macroecológico, a cualquier nivel geográfico, es que los sistemas ecológicos no son colecciones de organismos interactuando al azar, sino que están organizados. Esta organización u orden se observa en características emergentes que tiene propiedades estadísticas (Brown, 1999). Puede decirse que la macroecología es la aplicación de un enfoque estadístico a la ecología por medio del cual se trató de identificar principios invariantes o leyes naturales subyacentes a la estructura y función de sistemas 
ecológicos (Blackburn \& Gaston 2002). Es el intento más fuerte por retornar a ideas de órdenes y leyes con las nuevas herramientas tecnológicas.

En los últimos años en esta línea de investigación se ha desarrollado una nueva perspectiva: la indagación a escala metabólica (Brown et al., 2003, 2004a, 2004b). Desde esta propuesta se explican patrones observados en la estructura y dinámica de sistemas ecológicos en términos de conexiones entre tasas metabólicas individuales, rangos en el flujo de energía dentro de poblaciones y partición de energía disponible entre especies en una comunidad. Así los procesos ecológicos aparecen como susceptibles de ser explicados en términos exclusivamente físicos y químicos (Brown et al. 2003, 2004'; Marquet 2002, Marquet et al. 2004).

Los teóricos de la ecología metabólica proponen privilegiar los estudios que resultan de analizar los organismos a escala metabólica porque desde allí se pueden deducir patrones a escala de planeta. En un intento por restablecer las jerarquías explicativas, estos autores sugieren que el resto de la ecología debería ser subsidiaria de esta propuesta, ya que se dedicaría a indagar en los fenómenos que no se adecuan completamente a los intervalos de confianza supuesto por los patrones que se encuentran a escala metabólica. O dicho en sus propios términos, el resto de la ecología se debería dedicar al análisis de la varianza residual de los procesos expuestos desde el análisis metabólico.

El reduccionismo de la teoría a escala metabólica se puede vincular a algunas de las propuestas que se encuentran en Crik (1966), que supone a todos los procesos biológicos como reducible a escala molecular. Caben aquí las críticas que Donna Haraway (2003) elabora en relación a la búsqueda genética del proyecto "genoma humano". La teórica norteamericana avanza en la pregunta acerca de quién es el humano que va a ser presentado de forma tan exhaustiva. Esto es sobre el criterio desde el cual se plantean los recortes de las observaciones. Estas discusiones provienen de una crítica que imputa a los genetistas una falencia de conocimiento en relación a la biología evolutiva y la genética de poblaciones introduciendo de forma inevitable una definición sesgada acerca de lo que es humano. Si esto se refiere a lo humano, queda aún mucho por revisar en cuanto a las consideraciones del fenómeno de la vida como conjunto desde esta perspectiva privilegiada. En el caso de la ecología es difícil que a los investigadores se les pueda criticar límites tanto en biología evolutiva y genética de 
poblaciones, porque este es el marco temático desde el cual se eleva la propuesta. El problema, más bien, es que en su adhesión a una perspectiva que contiene estas falencias, permiten la filtración de concepciones sesgadas, de la omisión de vínculos y relaciones como referencia de diálogo. De allí que sea posible (e igualmente falaz) la consideración de una escala como privilegiada en relación al resto de las escalas, que deben adaptarse a la forma de discusión establecida desde un sitio edificado sobre un recorte muy acotado.

Esta visión jerárquica sobre las posibles explicaciones ha generado un importante debate dentro de la propia ecología, así por ejemplo Simberloff (2004) y Sagoff (2003) discuten esta pretensión en ecología planteando que se privilegia la rigurosidad sobre la realidad y presentando dudas sobre la eficacia de esta mirada aislada para responder a los problemas ambientales vigentes. Esta no es la única impugnación que se realiza por este intento jerárquico de retornar al establecimiento de órdenes, Davis et al. (2005) y Lortie et al. (2004) marcan que tras estas pretensiones el único resultado es la fragmentación y la falta de diálogo entre las escalas de estudio. En este sentido acercan ejemplos que muestran la escisión del diálogo entre la ecología de comunidades y la macroecología en las definiciones de sucesión vegetal. También muestran los problemas que se desprenden de esta escisión, ya que en todas las escalas se presentan interrogantes que se vinculan con escalas diferentes.

El actual incremento de las diferencias entre perspectivas de análisis tiene consecuencias graves si tomamos en cuenta el actual contexto de emergencia ambiental. Porque el tipo de respuestas que se reclama a la ecología requieren la articulación de las diferentes escalas de análisis (Lortie et al. 2004) y la consideración de prácticas culturales y factores sociales (de Laplante 2004). Graham y Dayton (2002), por su parte, reconocen los problemas de la creciente especialización asociada a la pérdida de intercambio entre ellas En ese sentido, Lortie et al. (2005) muestran cómo cada mirada parcial lleva a respuestas incompletas e ineficaces y proponen eliminar la idea de tomar una perspectiva como privilegiada $\mathrm{u}$ orientadora intentando conformar arenas de diálogo en torno a problemáticas específicas que requieran de la participación de las distintas escalas de estudio.

Esta situación de falta de reconocimiento que se presenta, por ejemplo, entre la ecología de comunidades y la macroecología, se liga también a diferencias en el modo de 
concebir la disciplina. En la adopción de una determinada escala de estudio, se aceptan ciertos supuestos disciplinares que no se comparten necesariamente, como por ejemplo la aceptación o no de la reducción epistemológica (Núñez y Núñez 2006). En el escenario actual, la ecología parece quebrarse por la falta de intercambio entre las diferentes líneas de investigación (Graham y Dayton 2002) lo que redunda en un incremento de dilemas en la articulación de la producción científica e importantes limitantes para reconocer y dar repuestas a los desafíos que se inauguran en un proceso de creciente crisis ambiental.

La situación de incertidumbre de los últimos años (tanto en relación con la disciplina como en la vinculación con la sociedad que demanda conocimientos para resolver problemas ambientales), pone sobre el tapete la necesidad de revisar los supuestos, los objetivos y la vinculación de la ecología con otras ramas del conocimiento, trascendiendo al ideal de ciencia experimental, con reglas generales, con expresiones matemáticas, objetiva y predictiva que parece poco adecuado para responder a las tensiones que enfrenta esta disciplina.

Debe destacarse que recién en los últimos diez años los problemas de la ecología como área de conocimiento empiezan a reconocerse y a tratarse de forma sistemática desde perspectivas diferentes a la evaluación de la epistemología clásica (de Lapalante 2004), que como señalaban Haila y Taylor (2001) fue poco reconocida como espacio de interés filosófico en el período precedente. 


\section{Las reflexiones sobre ecología}

Si se observa el modo en que se ha reflexionado sobre la disciplina, se encuentra que las primeras reflexiones fueron esencialmente metodológicas (Clements 1905, Cowles 1899, Forel 1892). A mediados de siglo las reflexiones que se desarrollaron se orientaron a vincular las investigaciones en ecología con supuestos asociados a las ciencias naturales experimentales (Andrewartha y Birch 1954, Elton 1946, MacArthur 1971). A partir de esta adecuación muchas de las reflexiones sobre esta disciplina han tenido un carácter crítico.

Uno de los estigmas de la ecología fue el de ciencia inmadura. Estas referencias son recurrentes y se encuentran tanto en trabajos como los de Hagen (1989), Turchin (2001), Mahner y Bunge (1997), Hengeveld (1992) como en los de Marone y Gónzalez del Solar (2000). La prueba de esta inmadurez disciplinar se fundamenta en la vigencia de muchas de las principales controversias y se la vincula al supuesto de falta de autonomía. Sin embargo, este supuesto de dependencia también se pone en duda en la actualidad, cuando los límites de la ciencia en general para dar respuestas están llevando a pensar las dificultades fuera de un plano estrictamente epistemológico.

En el proceso de multiplicación de perspectivas y de proliferación de preguntas se están abriendo debates teóricos cada vez más álgidos. Uno de los modos más sugestivos para pensar la ecología desde principios del siglo XXI es reconocer en la misma un carácter dual, esto es natural y social, por estar ambos aspectos presentes en los temas a los que se aboca la ecología (Diegues 2005). En general, la ecología ha sido planteada como una ciencia de lo general, la búsqueda de patrones ha sido (y sigue siendo) uno de sus principales objetivos. El punto que se comienza a considerar desde fines del siglo XX es si esta búsqueda es necesariamente opuesta a la observación de particularidades, que resultan ineludibles en los sistemas específicos, que son contingentes y susceptibles de contener variables tanto naturales como sociales.

Existe un consenso general en que la ecología se enmarca metodológicamente en las ciencias biológicas, con las se vincula en los distintos escenarios que investiga. Sus observaciones y análisis siguen registros rigurosos. De hecho los puntos que resultan problemáticos para los investigadores a la hora de revisar su práctica son los mismos que llevaron a la revisión de la filosofía clásica de la ciencia y muchos de los principales 
debates son de carácter matemático (Núñez 2007). Sin embargo los problemas del foco ecológico también tienen factores sociales profundamente imbricados.

La literatura sobre ecología, según de Laplante (2004), puede dividirse en dos concepciones antagónicas: la ortodoxa y la expansiva. La primera reconoce a la ecología como una ciencia natural separada de las ciencias sociales. La segunda, la concibe como una ciencia afectada tanto por factores naturales como sociales. En su artículo, de Laplante menciona áreas de investigación que, según la concepción expansiva de la ecología, deberían entenderse como especialidades de la disciplina, como la economía ecológica, la psicología ecológica, la antropología ecológica, entre otras. Esta ampliación lleva a considerar a la ecología ya no como disciplina sino como ciencia interdisciplinar que toma aportes de diversas disciplinas como la física, las ciencias biológicas y las sociales (Keller y Golley 2000).

Este reconocimiento, que se ha desarrollado en la última década, no termina de incorporarse en la práctica. de Laplante (2004) señala que la mirada ortodoxa se fortaleció sobre todo en las décadas del sesenta y setenta, cuando los movimientos ambientalistas adoptaron el término "ecología" para reclamar aspectos ligados a la ética. En este contexto, los científicos adscribieron a una argumentación que los diferenciara de los "ecologistas", afirmando que la disciplina que ellos practicaban no implicaba un compromiso con el ambientalismo sino con el conocimiento. Esta opción fomentó la falta de consideración sobre variables sociales como interesantes para la investigación ecológica y los estudios que se generaron en un sentido contrario tuvieron un carácter marginal.

La revisión de la ecología en los últimos años parece reclamar la remoción de la visión ortodoxa, hecho que puede observarse en diferentes publicaciones pero con un impacto aún limitado en las principales líneas de investigación. Holling (1998) señala que el principal peligro de la concepción ortodoxa es tener respuestas exactas para preguntas erróneas, mientras que el problema de la concepción expansiva es hacer preguntas exactas que tienen respuestas inútiles. Estas dos perspectivas se diferencian, entre otros aspectos, en la forma de incorporar la incertidumbre, que en el primer caso se niega y en el segundo se asume. 
Volviendo a la disciplina, considero que la introducción de los interrogantes ambientales y la pregunta por el vínculo con factores sociales ha sido posible, entre otros aspectos, porque la ecología históricamente se ha vinculado con esferas extra disciplinares, que han impregnado el núcleo de la ecología con necesidades que trascendían la actividad científica. Por otro lado, las ciencias sociales se acercan hacia esta área de estudios biológicos porque desde hace varios años están incorporando cada vez más factores ambientales (Ferrete Sarriá, 1999), incorporando (aunque de forma acrítica) conceptos como ecosistema, habitat, etc. (Sagoff 2003).

Si bien la ecología no es la única disciplina afectada por este proceso de revisión que nace de la problemática ambiental, por el sitio que ocupa entre las ciencias naturales resulta especialmente sensible a estos reclamos (Núñez 2008). Sin embargo debemos considerar que al interior de la práctica científica el abandono de la mirada ortodoxa implica el alejamiento de la visión disciplinar que estructuró la práctica de la ecología en los últimos cincuenta años.

Y aquí debo retornar a la reflexión sobre la objetividad y neutralidad que, a mediados de siglo XX, se supuso sostenida por la matematización de la disciplina. En la práctica vigente, la idea de neutralidad se desliza desde la instancia de justificación hacia las instancias de elección de la pregunta científica y de aplicación del conocimiento generado, omitiendo que la ignorancia de la problemática ética no exime al/la científico/ a de su responsabilidad ética (Kitcher 2001). Los supuestos de objetividad y neutralidad se ligan a la idea que el avance del saber no implica un compromiso moral, y todo lo relacionado con este avance queda fuera de cualquier juicio social. La ciencia se separa de sus usos, la legitimación de desigualdades se aleja de los temas de debates disciplinares y en este proceso se evita o disminuye la responsabilidad socio-ética de aquello que se presenta como cientifico.

El supuesto de objetividad, asociado al supuesto que la razón lógica impera sobre los procesos científicos y elimina las contradicciones, llevó a considerar que el "contexto de justificación", que es donde opera la racionalidad al establecer con conexiones lógicas las razones sobre las que se justifica una determinada teoría, es un ámbito separado del "contexto de descubrimiento" o sea, el ámbito donde surgen las preguntas, las intuiciones, la presunción de ciertas conexiones causales sin un fundamento racional (Reichenbach 1938). Desde la epistemología clásica se considera que el primero 
pertenece al dominio de la razón mientras que el segundo aparece inscripto en la intuición e irracionalidad. Por lo tanto, las consideraciones de Popper sobre objetividad no abarcan el planteo de preguntas y al no problematizar esta práctica, se deja lugar a la introducción imperceptible de intereses.

También se ha discutido que los contextos de descubrimiento y de justificación estén lógicamente separados (Hanson 1958), pues ni la metodología ni la lógica que se utilicen permiten superar las contradicciones que emergen de las preguntas e intuiciones adoptadas al iniciar una investigación (Menna 2004). En este punto los debates actuales sobre el ambiente, que no son ajenos ni ignoran los intereses y utilizaciones que se hace del mismo, choca de plano con la pervivencia de estos supuestos. Porque si justificación y descubrimiento no son ámbitos separados y las tensiones de unos se trasladan a los otros, no hay metodología suficientemente poderosa como para superar la intencionalidad que da origen a un tipo de estudio.

Aún cuando se reconozca como necesidad replantear la escisión ciencia / sociedad, que resulta insostenible desde las demandas que se inauguran creo importante tener en cuenta que el avance sobre esta dicotomía no sólo enfrenta una práctica de 50 años sino, y sobre todo, la larga tradición científica que ha dado forma a las ciencias naturales. La misma noción de naturaleza se pone en juego en el escenario que se inaugura y, con ello, se filtran preguntas que apuntan a revisar el modo en que la sociedad se relaciona con la naturaleza.

\section{Consideraciones finales del capítulo}

En las páginas precedentes he recorrido la historia de las ideas ecológicas mostrando, sobre todo, las limitantes internas actuales, que se enclavan en "trampas epistemológicas" que no permiten resolver las preguntas que se plantean a una de las disciplinas biológicas que más presiones recibe (Holling 1998). Entre los supuestos de neutralidad y objetividad se eclipsa que la ciencia es, como indica Lewontin (1992) una actividad productiva influida por el resto de las instituciones sociales, y como el resto de las actividades humanas desarrolladas por las formas modernas de cultura, insume tiempo y dinero, y por lo tanto, son guiadas y dirigidas al menos en parte, por las fuerzas del mundo que tienen control sobre el tiempo y el dinero. 
Pero los debates científicos y los ambientales no pueden considerarse de forma aislada, porque aún pretendiendo cerrar la disciplina a los reclamos surgidos de movimientos ambientalistas (como se hizo en nuestro denominado "período clásico de la ecología"), los interrogantes que se desarrollan en la actualidad son cada vez más sensibles a un mundo que cambia de forma cada vez más acelerada por el accionar de la humanidad. En estos debates tampoco debe perderse de vista que, junto al reconocimiento sobre el modo de conocer se incorporan preguntas relativas a la responsabilidad de los/as investigadores/as.

En esta reflexión debe tenerse presente que en el mismo período en que se desarrollaron los debates internos más cerrados a voces extradisciplinarias, la ecología, como palabra, fue adoptando múltiples significados, reflejando tal vez las contradicciones y tensiones que se desencadenaban en un mundo que no terminaba de ser comprendido por el corpus de conocimiento que se diseñó y financió para tal fin.

La paradoja que se plantea desde algunas revisiones es que la ecología, como la ciencia en general, se desarrolló sobre la misma lógica que da lugar a los problemas que se intentan resolver y por ello resulta ingenuo plantear que las problemáticas internas se resuelven exclusivamente desde la indagación de los debates.

El rastreo histórico de este capítulo muestra que la ecología es una disciplina cercana a los problemas ambientales, a situaciones concretas, con debates abiertos que no impiden crecimiento disciplinar y con múltiples perspectivas que, en la actualidad, no terminan de articularse. La revisión histórica del entramado de teorías ecológicas permite una mayor comprensión de las preguntas que se consideran como propias de la disciplina, observando a su vez, la lejanía histórica adoptada en relación a los problemas sociales. Por ello resulta tan contrastante el proceso actual, en que los principales problemas de la ecología no provienen tanto del desarrollo teórico sino que muchas de sus tensiones surgen en escenarios ajenos a la disciplina, a problemas concretos que exponen seres humanos y no humanos interactuando entre sí, con presencia de factores abióticos y con urgencias cuyas soluciones dependen de una profunda comprensión del complejo sistema en general.

Hay compromisos epistemológicos clásicos (el supuesto de escisión naturaleza/sociedad o el compromiso de objetividad y neutralidad) que traban cierto nivel de revisión 
interna. Aunque resulta ineludible el reconocimiento de actores no científicos que, más allá de estas trabas, operan en este complejo escenario. Creo que en función de comprender la complejidad implícita en los diversos discursos y prácticas se podrá diseñar una perspectiva que permita comprender y actuar sobre los desafíos que se inauguran para la ecología y para cada uno de quienes se comprometen con el avance del conocimiento. 
Primera Sección: Los debates y sus límites

Capítulo 2:

Ecología: la arena de prácticas y debates 


\section{Introducción}

En este capítulo exploro el problema de la ecología desde las impugnaciones ambientalistas, esto es los reclamos por un cuidado ambiental que se desarrolla tanto en la arena de la movilización social como en el de la teoría. Los ambientalismos, aún cuando surgen con posterioridad a la disciplina científica, adoptan el término ecología como representativo de sus actividades. Prácticas y debates no se pueden considerar por separado, ya que ciertas definiciones teóricas son las que abren las puertas a determinadas formas de acción. Asimismo trato de explorar de qué modo la ciencia, que se instituye como sinónimo de conocimiento, pierde su sentido de referente en términos como cuidado y respeto.

Este capítulo se divide en tres partes. En la primera presento las formas en que se consideran los vínculos entre sociedad y naturaleza en el contexto moderno, revisando especialmente algunas referencias de la ecología como disciplina científica atravesada por las tensiones provocadas por la permanente crisis ambiental.

La segunda parte de este capítulo apunta a revisar el plano de las reivindicaciones ambientalistas. En este complejo escenario de propuestas profundizo los fundamentos desde los cuales se sostienen las diversas posturas, el modo de reconocer los problemas $\mathrm{y}$, en particular, examino los motivos por los que la ecología, como término y como actividad aparece, desde diferentes miradas, comprendida en sentidos antagónicos.

En la tercera y última parte repaso las posibilidades históricas que se presentaron como propuestas edificadoras de cambios. Es decir, examino las concepciones políticas vinculadas a la temática ambiental, que repararon en los problemas relativos a la desigualdad implícita en el sistema capitalista.

Al igual que en el capítulo precedente, en este caso tomo referencias históricas como guía $\mathrm{y}$, en la medida que el relato lo permite, busco señalar las referencias temporales que permitan vincular estos debates con la conformación de la ecología como disciplina científica. 


\section{Sociedad y Naturaleza en la modernidad}

Sociedad y naturaleza suelen presentarse como un par antagónico desde las visiones que toman como referencia las sociedades occidentales modernas. Un antagonismo que parece establecerse desde una tautología, porque parte de suponer que ambos hacen referencia a conjuntos de elementos mutuamente excluyentes. La sociedad, en tanto complejo de actividades humanas, actúa o interviene en un espacio que, precisamente por estar habitado por humanos, no se reconoce como naturaleza. Desde estas consideraciones la idea de naturaleza parece remitirnos a aquello que no es humano, que no se inscribe en las pautas culturales de las civilizaciones. Por ello la oposición sociedad/naturaleza puede tomarse en el mismo sentido que la dualidad cultura/naturaleza o humanidad/naturaleza. Todos los antagonismos presentan la naturaleza como ese otro excluido de las definiciones, y tal vez por esta exclusión que fuerza diferencias es que la idea de naturaleza emerge como un concepto particularmente esquivo cuando se trata de definirlo.

Los términos que hacen referencia a lo humano (o lo cultural o lo social) pueden establecer recortes más o menos amplios, pero la naturaleza es ese sitio del que somos ajenos. Donna Haraway (1999) ha trabajado con especial profundidad sobre este problema de definición.

\footnotetext{
"Atrozmente conscientes de la constitución discursiva de la naturaleza como «otro» en las historias del colonialismo, del racismo, del sexismo y de la dominación de clase del tipo que sea, sin embargo encontramos en este concepto móvil, problemático, etnoespecífico y de larga tradición algo de lo que no podemos prescindir, pero que nunca podemos « tener»." (Haraway 1999,122)
}

La bióloga y filósofa norteamericana recorre las consideraciones que han tomado a la naturaleza como tema desmontando una larga lista de confianzas. Entiende que la naturaleza que ha edificado el discurso no es un lugar físico, tampoco un tesoro que se pueda guardar, no es una esencia. No está oculta, no puede desvelarse, no es un texto que puede leerse en códigos matemáticos, no es una mujer por lo cual no cumple roles de madre o enfermera o esclava, no es matriz, ni recurso, ni herramienta al servicio de la humanidad. Es decir, para Haraway (1999) no es nada de aquello que hasta el presente ha sido la base sobre la que se han diseñado intervenciones y establecido relaciones. 
En contra de estas consideraciones argumenta a favor de que la naturaleza es un topos, esto es, un lugar retórico o un tópico a tener en cuenta en lugares comunes. Haraway nos dice que “... la naturaleza es el lugar sobre el que reconstruir la cultura pública” (Haraway 1999, 122), donde ordenamos nuestro discurso y nuestra memoria. Es el tópico del discurso público en torno al cual giran todas las cosas, puede pensarse que es la referencia fundamental.

Resulta provocativa esta idea de la Naturaleza como aquello que se define como tal y en torno a lo cual se sitúan todas las cosas, porque sitúa la consideración de sociedad y naturaleza en un plano diferente, y ya no son fuente de explicaciones sino resultantes históricas del movimiento de lo colectivo (Latour 1990). Desde aquí no se pierde la referencia a lo material sino la ilusión de que se puede conocer esa materia de forma trascendente. A modo de salida al discurso que presenta a la naturaleza como artefacto, opuesto a la sociedad, Haraway (1999) argumenta a favor de dos giros relacionados entre sí:

“1) despojarnos de las historias rituales de la historia de la ciencia y la tecnología como paradigma del racionalismo y 2) repensar los actores implicados en la construcción de las categorías etnoespecíficas de naturaleza y cultura" (Haraway 1999, 123), donde los actores no son exclusivamente humanos, u orgánicos o tecnológicos.

Aún cuando adhiero a esta visión sobre la naturaleza, debo señalar que el sentido que se presenta en el texto es diametralmente opuesto. Como asumo que el modo de entender esta referencia está local y culturalmente determinado, introduzco el sentido de naturaleza que en ciertos contextos desarrollaron diferentes actores. Ahora bien, aunque la mayor parte de las menciones haga alusión a la idea de naturaleza como oposición a lo humano, no debe perderse de vista la idea de naturalidad asociada en la cultura occidental. Una herencia aristotélica según la cual naturaleza también apela a un ideal regulativo, una normativa implícita que advierte que es deseable para el bien de todas las partes (Femenías 1996)

Así tomo la propuesta de la teórica norteamericana, asumiendo que el trabajo que se desarrolla apunta a avanzar sobre los dos ejes propuestos por la filósofa, aún cuando no siga escolarmente los pasos propuestos por la autora. Sin embargo voy a tomar estas reflexiones como parte del horizonte referencial de las ideas que se vayan a desarrollar a lo largo del trabajo, donde el carácter construido y fundacional de la noción de 
Naturaleza (y por ende sociedad) facilitará desmontar muchas de las consideraciones asumidas como certezas.

Si bien no es el objeto de esta tesis profundizar en la teoría elaborada por Haraway, existe un punto que resulta difícil de omitir: el modo en que la filósofa norteamericana reconoce a la modernidad. Nuestra autora asume como lo moderno a "la mentalidad racional ilustrada que procede realmente de un método objetivo y persigue representaciones adecuadas, en ecuaciones matemáticas si es posible, del mundo-objeto (esto es natural)" (Haraway 1999, 155). Entiendo, con esta pensadora, en la falacia de investir a la modernidad con estos reconocimientos. Por el contrario, en adelante (y también en relación a lo precedente) las referencias a la modernidad deben considerarse desde la connotación histórica por la cual se asume como referencia a las sociedades que se desarrollaron en el proceso europeo-occidental del siglo XVII que consolida el abandono de las formas gubernamentales definidas como antiguo régimen (Anderson 1989, 1993) enmarcadas en la tradición feudal.

Indagar desde las instituciones científicas, propias de la modernidad, ha implicado en muchas ocasiones asumir de forma aproblemática la oposición sociedad/naturaleza. Un tema que resultó especialmente contradictorio en la antropología, donde los investigadores se enfrentaban en sus prácticas a cosmovisiones que no necesariamente reproducían la concepción dual. P. Descola y G. Palsson (2001) reconocen esta tensión que entienden como una limitante de la remoción de esta una dicotomía más, la escisión entre la naturaleza y la sociedad marca el origen mismo de la modernidad, y abandonar una es abandonar la promesa de la otra.

Estos autores necesitan exponer esta tensión porque asumen las variables ambientales como factores ineludibles para comprender los diversos procesos que afectan a la humanidad no-occidental. Esto no implica un retorno a los determinismos geográficos, porque el actual estado de los debates lleva a problematizar la naturaleza como concepto constituyente y constitutivo del mundo social en una idea afín a la propuesta mencionada de Haraway. Es por esto que reclaman la redefinición del mundo teórico y académico, donde las fronteras disciplinares entre las ciencias naturales y sociales deben desmantelarse para edificar un ámbito desde el cual dar cuenta de los vínculos (Descola y Palsson 2001, 26). 
Esto nos lleva a una de las hipótesis que guían el trabajo que se desarrolla en esta tesis: los ladrillos con los que se edificó la frontera entre las ciencias sociales y las ciencias naturales están hechos con el mismo material que la muralla que propone separar naturaleza y sociedad. En forma vinculada a la cristalización de la separación entre naturaleza y sociedad, o naturaleza y cultura, se alejó la producción de conocimiento científico del plano de valores vinculados a este mismo conocimiento. ${ }^{17}$

Como resultado de estas distancias el entorno fue comprendiéndose como separado de los procesos sociales y, desde allí, resultaba esperable que las limitaciones éticas que se discutían sobre el "mundo humano" pudiesen proyectarse sobre la apropiación (en el sentido de explotación) del mundo "no-humano". La naturaleza, reducida a una concepción de "recurso", se consideraba al servicio del concepto de desarrollo que se tomaba como destino ineludible de la humanidad.

El modo de conocer ligado a la idea de naturaleza-recurso ha sido puesto en tela de juicio desde variadas perspectivas, que en general reproducen al menos en parte, las consideraciones que M. Horkheimer y T. Adorno elaboraron al respecto. Estos autores en su reflexión remiten a un proceso dialéctico, material e histórico. Nada más lejos de este planteo que las definiciones lógico-empíricas de la ciencia positiva, que reducen la multiplicidad de lo dado a una unidad identificante. Desde esta última perspectiva, todas las proposiciones deben poder reducirse a proposiciones básicas o atómicas, y por ello deben referirse en último sentido a definiciones lógicas dentro de un sistema o a los hechos. En contra de esta concepción, para Adorno el concepto no debe proceder en forma escalonada y jerárquica de concepto en concepto superior, sino a través de constelaciones, formando parte de un entramado de conceptos que intenten superar la intención de subsumir, o determinar a priori, lo heterogéneo.

Los autores frankfurtonianos sostienen que el modo positivo de conocimiento no sólo es falaz, sino que responde a una lógica de dominio o lógica iluminista (término que acuñan), que fundamenta diferencias, desigualdades y ejercicios de control. ${ }^{18}$ En contra

\footnotetext{
${ }^{17} \mathrm{El}$ detalle sobre este punto se va a trabajar en el capítulo tres.

${ }^{18}$ Nestor García Canclini (1984) reflexiona sobre una tensión que está en la base de la revisión de las ideas de dominio. Se trata de la dicotomía en las reflexiones de raíz marxista que escinde los estudios del dominio (basados mayormente en la escuela de Frankfurt), de las investigaciones sobre hegemonía (sustentadas sobre todo en los escritos de Gramsci). La dicotomía se presenta en la medida que se describen los mecanismos supuestamente omnipotentes de la dominación o se exaltan en forma exclusiva la capacidad de resistencia política de los oprimidos. Desde esta tensión vale aclarar que si bien el presente trabajo avanza sobre la noción de lógicas de dominio, ello no implica que asuma esta dualidad.
} 
de Marx sostienen que si desapareciera la propiedad privada la desigualdad se volvería a ejercer, porque el problema no está en la potestad de las cosas, sino en la lógica desde la cual se edifican las vinculaciones (Abbagnano 1993). La conformación de esta lógica se consolida, a decir de estos autores, a partir de asumir la escisión entre sociedad y naturaleza. Porque en esta diferenciación reconocen el fundamento del control, o como los filósofos lo denominan "la autoafirmación egoísta del hombre frente a la realidad". Desde estas reflexiones se desprende que los supuestos de neutralidad y objetividad permitieron al empirismo lógico omitir estas referencias y avanzar en la ilusión de edificar un conocimiento ajeno a la desigualdad social imperante.

Carolyn Merchant (1983) y Vandana Shiva (1988) incorporan a este conjunto de reflexiones la revisión sobre el modo en que la base de las diferencias se constituyó desde un mundo concebido en términos de jerarquía. En esta línea exploran cómo la razón del hombre-varón se constituyó en la medida fundamental para establecer la graduación de una escala que asumía un orden desde lo menos hacia lo más perfecto. Merchant (1983) señala que, a diferencia de la dicotomía cartesiana que sostiene a la ciencia moderna, en los siglos XVI y XVII la imagen del cosmos era orgánica, visualizado como una mujer viva, una madre nutricia cuyo cuidado estaba en directa relación a la "suerte" de sus habitantes. Con la modernidad, se fue perdiendo el carácter de "naturaleza viva" del mundo en la medida que la visión mecánica impuso una noción de naturaleza "muerta" o pasiva, susceptible de ser dominada y controlada por los seres humanos. Esta autora señala que en el método experimental que se fue gestando, se introdujo una metáfora sexista, porque la aceptación de la situación de dominio que se postulaba sobre la naturaleza tiene permanentes referencias a la visión que entiende a la naturaleza como mujer a ser sometida. Susan Bordo (1986) avanza sobre esta idea exponiendo el modo en que la mirada cartesiana removió el carácter femenino del mundo, que se había consolidado en la Edad Media y el Renacimiento. Para esta autora, el objetivismo cartesiano es una respuesta que se opone a esta noción, una agresión intelectual que arrasa lo femenino simplemente al confiar en el ideal positivo de la

La ecología avanza sobre una red de tensiones donde, por una parte, forma parte de lo que podría denominarse discurso hegemónico, pero por facilitar la visualización de aspectos (dentro y fuera de la disciplina) sobre los que se sostienen diversos actores que presentan discusiones a partir de reconocerse en un sitio subalterno y discutir la naturaleza del mismo. Así la idea de dominio, lejos de ser tomada como determinante absoluto se presenta como el marco a desmontar, con fisuras internas, ataques externos, y también fortalezas que se incrementan en el actual proceso de globalización. 
nueva epistemología. Así el cartesianismo refunda y reimagina el conocimiento y el mundo como masculino. ${ }^{19}$

En esta línea resultó fundamental la separación ontológica de lo humano y lo natural en dos sustancias diferentes - la espiritual y la corpórea- que no comparten cualidades, que interactúan pero que no se mezclan, y se definen precisamente una en oposición a la otra. La exclusión mutua de la res extensa y la res cogitans permitió conceptualizar al intelecto como trascendente del cuerpo, que quedó atado a las sensaciones y conmociones que provocan confusión o distracción. El cuerpo, desde Descartes, es en sí la mayor traba para la objetividad.

Lo masculino, entonces, no hace referencia a un carácter biológico sino a un estilo cognitivo. Es justamente esta masculinización la que permite asumir el despegue de lo intelectual respecto de lo emocional, de las particularidades del tiempo y el espacio (Bordo 1986); lo femenino es lo que queda relegado y sobre lo cual se proyectan los controles que se edifican desde una masculinización de los estilos de apropiación. El dominio hacia lo femenino, separado de la res cogitans, se incrementa y profundiza desde Descartes.

La reflexión de Bordo es uno de los ejemplos más claros para visualizar cómo, desde la conformidad sobre el derecho de control como natural, se fue presentando como neutral una práctica que oculta que la comprobación de hipótesis, las manipulaciones controladas de la naturaleza y la repetición de las experiencias se basan en metáforas que suponen jerarquías de dominio. ${ }^{20}$

Shiva adhiere a esta concepción al señalar, en acuerdo con Merchant que "Para conceptuar la naturaleza y la investigación se tomaron como modelo la violación y la

\footnotetext{
${ }_{19}$ Vale mencionar en este punto el aporte fundamental de Luce Irigaray (1978) para dar cuenta del vínculo racionalidad-masculinidad. La filósofa denuncia esta complicidad al indicar que toda teoría del sujeto se ha adecuado siempre a lo masculino. Sometiéndose a ello, la mujer renuncia sin saberlo a la especificidad de su relación con lo imaginario. Y se coloca una vez más en situación de ser objetivada por el discurso en cuanto femenino. En él se re-objetiva a sí misma cuando pretende identificarse como un sujeto masculino. El énfasis de esta pensadora en torno a la diferencia sexual, como una manera de afirmar la subjetividad femenina, apela a la ruptura de la tríada masculinidad-racionalidad-universalidad, que aplica a su relectura de la historia de la filosofía occidental y puede proyectarse hacia la edificación de conocimiento en general.

${ }^{20}$ J. Haila y P. Taylor (2001) acercan otra impugnación hacia la mirada cartesiana. Estos ecólogos sostienen que el problema por adquirir un conocimiento adecuado sobre el mundo es una necesidad que compartimos con otros organismos, y al respecto se preguntan porqué asumimos el modelo cartesiano de organización del mundo no-humano, si sabemos que al menos para los humanos, como parte de los organismos que vivimos en el planeta, no resulta adecuado.
} 
tortura... y ese modelo se presenta como una razón para valorar la ciencia. Según Bacon... el conocimiento científico y las invenciones a las que conduce no 'ejercen solamente una guía sobre el curso de la naturaleza; tienen el poder de conquistarla y subyugarla, de sacudirla en sus cimientos'..." (Shiva 1988, 47)

Merchant muestra cómo el cambio de reconocimiento hacia la naturaleza, que de madre nutricia se deslizó a la idea de materia inerte, resultó funcional a la explotación capitalista naciente. Esta legitimación de la explotación irrestricta de recursos es la que ha llevado a la crisis ambiental que hoy pone en jaque a la ecología, que enfrenta preguntas que socavan la confianza en los fundamentos más profundos de la ciencia.

Shiva (1988) señala que el suponer que la ciencia es neutra respecto del punto de vista de clase, cultura y género, oculta que tanto la ciencia como el desarrollo son proyectos que dieron lugar a un "ilimitado apetito de explotación de recursos", donde la ciencia moderna proporcionó la licencia ética y congnoscitiva para que dicha explotación fuera posible, aceptable y deseable. Dentro de las actividades de explotación, la agricultura extensiva tiene un sitio destacado entre las iniciativas de más alto impacto en la destrucción de paisajes, por ello no debe sorprender que las preguntas que dieron origen a la ecología como disciplina se fundaran, como mencionamos en el capítulo precedente, en los límites que se reconocían en las plantaciones.

A la luz de estas consideraciones, no puede sostenerse que las ciencias naturales sean un ámbito exclusivo respecto de las sociales. Creo que, sin embargo no se trata de una omisión ingenua. La pervivencia del supuesto de distancia y diferencia favorece la omisión hacia los vínculos existentes, diluyendo las reflexiones que apuntan a la responsabilidad en la pervivencia de los supuestos peyorativos que se reproducen desde prácticas acríticas que se asumen neutras. Una reflexión que no sólo cabe para las ciencias naturales, porque las reflexiones éticas también se han visto afectadas por una visión que reconoce a la naturaleza "claramente discontinua u ontológicamente dividida de la esfera humana" (Plumwood 1998).

Para revisar este punto la filósofa australiana Val Plumwood reconoce que una de las claves de esta discontinuidad es la supremacía otorgada a una razón, construida oposicionalmente a la emoción y a lo particular, fundamento del antropocentrismo de la tradición occidental. La dualidad se filtra porque en este marco las preocupaciones éticas se proyectan sobre pretensiones universalistas, sostenidas sobre abstracciones que 
permiten el desentendimiento de las emociones y los vínculos espaciales. Así, al perder de vista las relaciones, $\mathrm{y}$ en forma asociada justificar el alejamiento, la escisión se presenta como el único sitio desde el cual se puede reflexionar.

En contra del "yo" indiferenciado, Plumwood defiende una visión del "yo" en relación, que evita el atomismo a la vez que hace posible el reconocimiento de la interdependencia, que reconoce tanto la continuidad como la diferencia y quiebra así la "falsa dicotomía planteada culturalmente entre intereses egoístas y altruistas" (Plumwood 1998, 253).

Desde esta perspectiva, el problema que debe asumir cualquier teoría de conocimiento, y a su vez cualquier disciplina en particular, es el reconocimiento de las diferencias y particularidades de nuestras características como seres humanos respecto del mundo nohumano sin perder de vista las relaciones y las continuidades existentes. Algunos indicios de estas formas de reflexión se encuentran en aportes que se han originado en sociedades no occidentales, que usualmente han sido evaluadas como menos valiosas respecto a las propuestas occidentales (fundadas en prácticas capitalistas y ligadas a concepciones dualistas).

El estudio de la naturaleza "sin hombres" propuesta por la biología es un retorno al antropocentrismo (y un punto de referencia del androcentrismo). El problema que enfrenta la ecología es, justamente, responder a problemas que se originaron en una visión de jerarquías y dominio, que la propia disciplina contiene desde la conformación de sus conceptos y prácticas.

Debe destacarse que en la segunda mitad del siglo XX se encuentran referencias parciales que llaman la atención sobre modos de incorporar al ser humano en los sistemas que se estudian (Odum 1975), y también que a partir de los años ochenta estas reflexiones se multiplican, aunque no terminan de salir de los límites de la mirada ecológica que incorpora al ser humano con un organismo susceptible de ser esquematizado de la misma forma que los ecosistemas. Un ejemplo de esto es el gráfíco que propone Jorge Morello (1984) para sistematizar el modo en que, hasta ese momento, se había reflexionado entre las sociedades humanas y la naturaleza desde la ecología en un artículo que busca incidir en el plano político y jurídico. ${ }^{21}$

\footnotetext{
${ }^{21}$ Jorge Morello se desempeñaba como Presidente de la Administración de Parques Nacionales en el período en que escribe este artículo (Morello 1984,23)
} 
En este artículo el autor reconoce "al hombre como el elemento más relevante del ecosistema" (Morello 1984, 29) pero, como se puede observar en el gráfico $\mathrm{n}^{\circ} 1$, no se incorporan referencias a las tensiones sociales, a la diversidad, a las relaciones no necesariamente causales. O sea, se dejan de lado las tensiones propias de las organizaciones humanas.

En este artículo los conceptos para revisar los vínculos reconocen categorías homogeniezantes como "las acciones humanas" sin mayores referencias cultuales, que se observan en incidencias puntuales de actividades específicas (ver también Gallopin 1983, 1981a , 1981b, 1982). El gráfico que esquematiza los vínculos que se reconocen pone de manifiesto el carácter equivalente entre las variables sociales y las ecológicas. Es un diagrama de flujos energéticos, con preguntas equivalentes a ambos planos. La similitud del esquema en ambos planos permite preguntar incluso sobre el porqué de la división. Las preguntas desde las que se recorre cada espacio de análisis “¿cómo afecta?”, “¿qué?”, “¿a quién?”, “¿por qué?”, dan cuenta de un supuesto que admite respuestas puntuales y definitivas. No hay sitios para configuraciones laxas, cultural (antes que absolutamente) determinadas.

El análisis de lo social se reduce al modo de indagar lo ecológico. La naturaleza cosificada vuelve a instalarse como norma. La equiparación se establece por la negativa a admitir la particularidad. Sería difícil imaginar en este gráfico el sitio de las perspectivas diferenciadas, los compromisos subjetivos o incluso los preconceptos desde los que se establecen los vínculos que se busca estudiar.

\section{Grafico no 1}

Esquema de la incidencia de los factores sociales y los sistemas ecológicos 


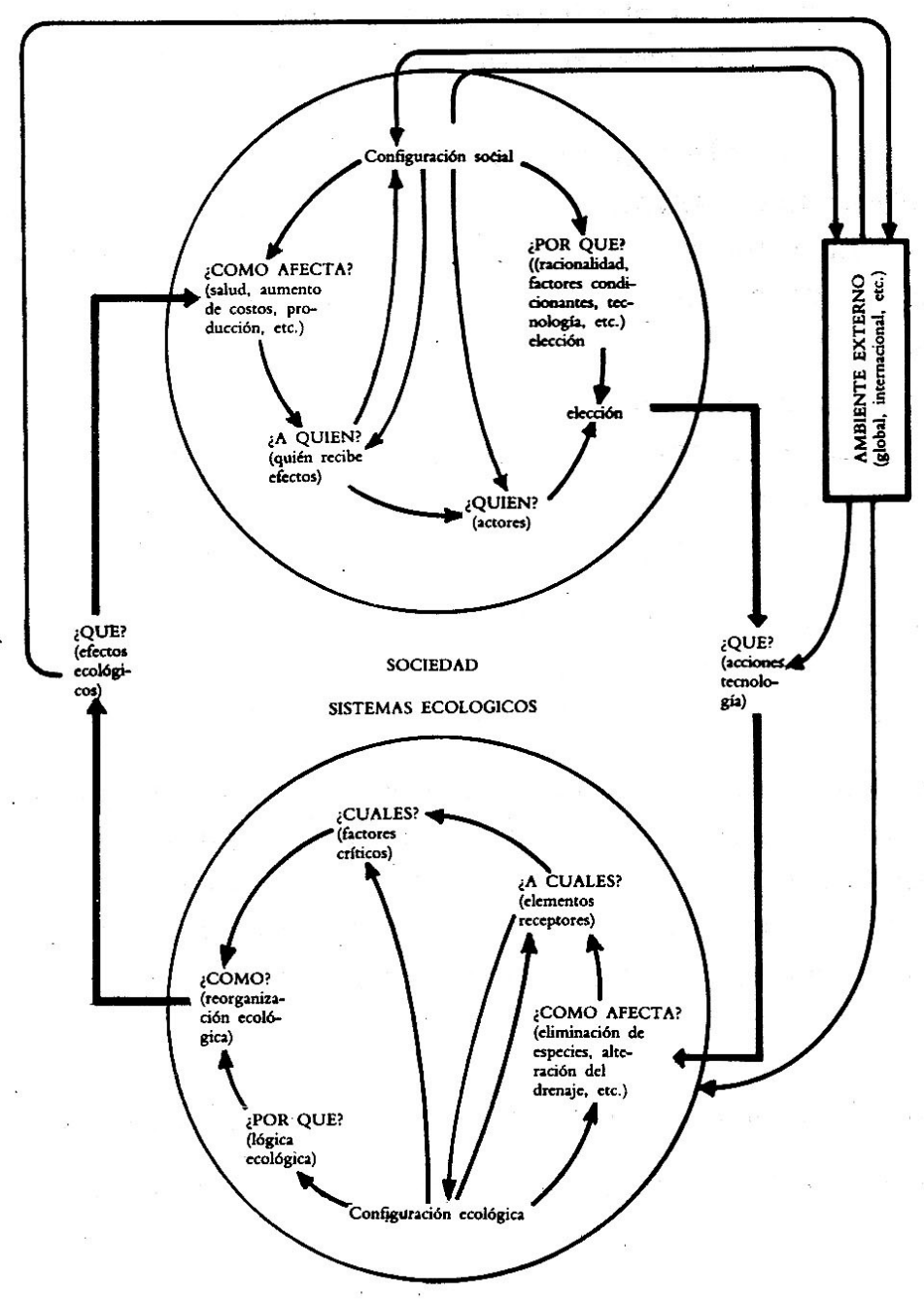

Morello

1984, 31

Un punto enriquecedor para llegar a comprender los planos de complejidad que se enfrentan en los problemas que se intentan abarcar son las referencias prácticas. A las reflexiones sobre impacto de la producción de conocimiento agrego, entonces, una mención a las "lógicas del cuidado" que se establecieron a fines del siglo XIX y principios del siglo XX.

Debo aclarar que incorporo esta noción de lógicas de cuidado teniendo, en algún punto, como horizonte de referencia la propuesta de Michel Foucault (2000) sobre el biopoder. Este autor sostiene que en la modernidad se llevó adelante un cambio fundamental, donde el poder dejó de referenciarse en su capacidad de dar castigo a los cuerpos, para redefinirse a partir de su capacidad de cuidar la vida. Las lógicas de cuidado no resultan independientes de las de dominio, puede pensarse incluso que son la forma pública en que se explicitan. Las asocio a las políticas de salubridad pública, desde las cuales se 
fue planteando un ordenamiento social que se instaló hasta en la cotidianeidad más privada de las personas.

El filósofo francés indica que la legitimidad y el poder del Estado Moderno abandonaron la dinámica previa de mostrar poder al someter los cuerpos, trasladando el reconocimiento hacia su capacidad de cuidar la vida. Entiende que en la modernidad la soberanía pasa de cuidar la muerte a cuidar la vida, el disciplinamiento que hasta el siglo XVIII se aplicó al cuerpo del individuo pasa, en el siglo XIX, a aplicarse a la sociedad como conjunto. La política dirigida a la anatomía, cambió su destino hacia la especie. Se pasó de una anatomopolítica que se mostraba en los cuerpos, a una biopolítica que se dirigía a cuidar la vida (Foucault 2000).

Esta biopolítica se orientó a aplicaciones que incidieran en ciertas referencias estadísticas, como la tasa de nacimiento, de mortandad, de reproducción, etc., donde se medía el éxito o el fracaso de las acciones. El poder se presenta como biopoder. Desde el siglo XIX la medicina pasa a tomar un rol central como fundamento de políticas públicas de higiene que atraviesan indiscriminadamente ámbitos públicos y privados, ya que el ser humano, en tanto organismo vivo, encuentra su propia supervivencia cada vez más asegurada como una cuestión de Estado. Por ello es coherente que los primeros cuidados sobre las limitaciones ambientales surjan del Estado y en directa vinculación al cuidado de los individuos y del cuerpo social en su conjunto.

Este esquema resulta de interés para el tema que me ocupa, porque el cuidado se proyectó hacia todas las esferas. Los modos que se establecen para preservar la naturaleza debe considerarse en el marco de esta biopolítica. El caso que tomo como paradigmático es la constitución de los Parques Nacionales, que temporalmente cubren las instancias de formación de la ecología como disciplina científica. Al mismo tiempo que la ecología empezaba a ser reconocida desde los ámbitos académicos tanto en Europa como en Estados Unidos, a fines del siglo XIX, desde diferentes sectores se comenzó a llamar la atención sobre la necesidad de cuidar los recursos naturales. Se hacía particular mención a la necesidad de preservar ciertas áreas de particular belleza. La primera respuesta a estas propuestas estuvo en Estados Unidos. Este ejemplo resulta útil, además, porque temporalmente cubre el período fundacional de la ecología, donde tanto funcionarios como científicos se encontraban cubiertos por dependencias nacionales antes que por universidades. 
El país que diseña las primeras políticas de cuidado y acuña el término de "Parques Nacionales" es Estados Unidos. Las definiciones y propuestas que se determinan en este país fueron reproducidas casi literalmente en el resto del mundo. El hito fundacional de este modo de cuidado es la decisión de crear en 1872 la primera gran reserva natural protegida del mundo en las montañas Rocosas: el Parque Nacional de Yellowstone, un territorio de casi 900.000 hectáreas de los estados de Wyoming, Montana e Idaho se reserva como espacio virgen "para el goce del pueblo". ${ }^{22}$

Este caso facilita el reconocimiento de las tensiones implícitas en las formas de controlcuidado que se establecen, donde las definiciones se enmarcan en consideraciones cambiantes. Como la mencionada por Norberto Fortunato (2005) quien expone que los Parques Nacionales asumen un proyecto de cuidado aunque no existe una acepción unívoca acerca de la idea de conservación de la naturaleza, porque para las ciencias biológicas significa "asegurar aquellas condiciones necesarias para la evolución de una comunidad natural", mientras que en las ciencias económicas, que impactan en el establecimiento material del espacio, prevalece la noción de "limitar el uso de los recursos naturales hoy para disponer de ellos mañana" (Oelschlaeger 1991, 419 y 420).

Sin embargo, y esto es lo que resulta más provocativo del trabajo de Fortunato, estas ideas de conservación que en la actualidad se toman como referencia no constituyeron la preocupación central durante la etapa fundacional de los parques nacionales. Con estos espacios se buscaba cuidar la vida, pero en las definiciones que operaron bajo las primeras consideraciones emerge el sentido móvil que la idea de vida tiene en el contexto del biopoder.

Volviendo al hito de 1872, cuando el gobierno de Estados Unidos de América creaba el primer parque nacional del mundo en la región del río Yellowstone dio inicio a una serie de políticas vinculadas. En el transcurso de las tres décadas siguientes, otras diez porciones territoriales del "far west" habían sido conservadas bajo igual denominación. Fortunato (2005) pone a la luz la intencionalidad de la adjetivación usada por los norteamericanos. Los parques fueron llamados "nacionales" y no federales (por su ámbito de dependencia administrativa), ni naturales, silvestres, salvajes o de una manera análoga (según su fase de desarrollo distintivo). Se quería cuidar la vida, pero no de

\footnotetext{
${ }^{22}$ Ley de fundación del Parque Nacional de Yellowstone.
} 
determinados organismos específicos en forma aislada, sino la vida en el marco de un esquema de control, cuya existencia quedaba mutuamente ligada.

La conservación del Yellowstone estuvo caracterizada, como en tantos otros Parques Nacionales, por la intervención de sujetos e instituciones vinculados principalmente a intereses territoriales. Fortunato reconoce tres principios que dieron su forma original a la figura jurídico-espacial: la propiedad pública federal de las tierras involucradas, la valoración estética de paisajes considerados singulares y la estrecha relación establecida entre el territorio puesto a resguardo y el ámbito geográfico e histórico de conformación de la identidad de la nación. Y este es el punto que quisiera destacar en relación al biopoder: al revisar la intervención en ámbitos no-humanos, lo que se encuentra es la vida ligada a la identidad de nación. Se trata entonces de una invención social antes que una innovación ecológica.

El proyecto norteamericano estuvo dirigido a la conservación del "wilderness", ambiente considerado escenario fundacional del carácter nacional, representado por la figura del pioneer y sus cualidades arquetípicas como hombre de frontera (Nelson, Needham y Mann 1978). Se cuidaba la vida y la nación como si estuviesen indiscutiblemente asociados, esta fue la base del argumento que fue cobrando sustancia gracias a la ardua labor de un grupo de referentes sociales, dedicados a persuadir a la opinión pública. Porque en la sociedad norteamericana, legitimadora del modo de producción capitalista y defensora de la propiedad privada, deben plantear que el mejor aprovechamiento social del espacio de Yellowstone se lograba a partir de que ninguna porción del mismo fuese apropiada por un particular.

Y aquí vale una aclaración más. Con los Parques Nacionales se preservaba el Estado y el modo de aprovechamiento de los recursos que se establecía. Porque lejos de impugnar el modo en que se explota el espacio, la lógica de apropiación y uso queda liberada porque el desgaste que se observa en unos sitios se compensa por el cuidado de otros.

Treinta años después la noción de preservación fue potenciada durante la administración de Theodore Roosevelt. En ese gobierno se promovió el manejo de áreas naturales y explotadas a través de la Dirección de Estudios Biológicos. ${ }^{23}$ Esta dependencia llevó

\footnotetext{
${ }^{23}$ Esta dependencia estuvo fundada y dirigida por Hart Merriam Merriam, quien llevó adelante todos los proyectos desde 1886 hasta 1910. Debe indicarse que esta dependencia estaba contenida en la división de
} 
adelante iniciativas que vuelven a poner a la luz la consideración antrópica en lo que se refiere a las políticas de cuidado, porque antes que fundamentar desde observaciones biológicas, el diseño de las actividades descansó en los intereses de productores, como la promoción de inversiones estatales para la exterminación de plagas. Así, por ejemplo, se desarrolló un intervencionismo radical que justificaba y organizaba la matanza de aves, lobos y coyotes, considerados plagas de la agricultura y la ganadería (Casares Serrano 2005).

En forma opuesta al espacio habitado por seres humanos, los parques nacionales eran vistos como santuarios. Porque se entendía que la capacidad destructiva de los humanos condenaba a la destrucción a todo espacio que habitara. En este contexto la naturaleza, aún cambiante, era una naturaleza condenada en la mayor parte del planeta. Esta sentencia en sí misma fundamentaba la necesidad de institucionalizar espacios de reserva y políticas de cuidado e intangibilidad. La ecología generaba el conocimiento necesario para la preservación. ${ }^{24}$

Como señalaba, la construcción norteamericana de los Parques Nacionales signó la estructura de cuidado de ciertas regiones consideradas santuarios en gran parte del planeta. No es objetivo del presente trabajo relevar el modo en que, alrededor del mundo, se fueron constituyendo estos lugares, pero vale la pena al menos una mención sobre el espacio argentino.

La idea del cuidado de los espacios en Argentina sigue directamente las líneas elaboradas en Estados Unidos. El primer parque nacional de Argentina se conforma en base a la donación de tierras realizada por Francisco Pascasio Moreno el 6 de noviembre de 1903, quien recibe estos territorios como parte del pago por su trabajo en la comisión de estudio de límites en la región patagónica entre Argentina y Chile durante los primeros años del siglo XX.

ornitología y mamíferos del Departamento de Agricultura de los EEUU, que fue denominada como División de Estudios Biológicos en 1890. Desde esta dependencia se realizaron estudios que permitieron, por ejemplo, clasificar a la mayor parte de los mamíferos mexicanos (Guevara-Chumacero et al. 2001).

${ }^{24}$ Esta noción de preservación se reconoce en todo el mundo. Por ejemplo en 1883 se establece en Paris el primer acuerdo sobre la protección de focas en el mar de Bering, y en 1895 se celebra en la ciudad de Sena el primer Congreso Internacional sobre la protección de las aves beneficiosas para la agricultura. Ya en el siglo XX se celebró el Primer Congreso Internacional para la preservación de la Naturaleza, que se realizó en París en 1923, donde se debatió sobre la problemática relación entre las sociedades industriales y el ambiente. 
La diferencia de criterios entre el espacio cuidado y el espacio habitado puede reconocerse en que, algunas leguas al sur (en la región circundante a la actual localidad de El Bolsón), el mismo Moreno en 1907 facilita la entrega de tierras a la familia Martínez de Hoz, quienes venden estos territorios a la empresa de capitales chilenos "Cochamó" y, a partir de esa compra, reivindican el derecho de Chile a controlar territorios de la patagonia argentina y avanzar con explotaciones madereras y ganaderas, iniciándose uno de los tantos conflictos de frontera que tuvo su origen en un intento de nacionalizar un espacio legalmente reconocido como argentino (Hosne 1998). El conflicto sobre los bosques sureños se refería a qué país tenía el derecho de explotación y no tanto al modo en que se explotaba.

El espacio vivido, que además se sometía al pastoreo de ovinos y a la tala de árboles, era arena de conflictos sociales. El espacio cuidado era un ámbito que, en contraposición, se debía mantener ajeno a estas dificultades. Se deslizó la idea que lo humano era ajeno a las áreas cuidadas, así como la naturaleza perdía tal carácter en las áreas vividas.

La forma específica en que se consolidan los parques nacionales en Argentina se encuentra varios años más tarde, el 8 de abril de 1922, cuando se crea el Parque Nacional del Sud en la región aledaña al lago Nahuel Huapi, en pleno auge de la explotación maderera y ganadera en la zona (Méndez e Iwanow 2001). Sobre este proceso debe hacerse notar que fue una creación esencialmente simbólica, ya que no se destinaron grandes partidas de fondos para asegurar formas de cuidado específicas que limitaran las talas que ya se llevaban adelante en la zona (Núñez 2007), aunque vale la mención de una relación que puede encontrarse con el desarrollo que se estaba delineando sobre el manejo, ya que la dependencia que controló este primer parque nacional fue el Ministerio de Agricultura, una esfera similar a la que en Estados Unidos daba lugar al inicio de los estudios ecológicos.

En el decreto de creación del Parque Nacional del Sur se destaca "Artículo 5: Encomiéndese la vigilancia y dirección provisional del Parque Nacional el Sur al ingeniero geógrafo de la Dirección General de Tierras, don Emilio Frey, quien elevará al Ministerio de Agricultura el proyecto de reglamentación necesario para el cuidado y la vigilancia del parque...”. 
Esta referencia nos remite hacia la influencia del pensamiento que se gestaba en Estados Unidos, ya que en la zona del Nahuel Huapi Emilio Frey fue el principal colaborador del ingeniero norteamericano Bailey Willis, quien dirigió en 1911 la Comisión de Estudios Hidrológicos, destinada a crear un documento que planteara los modos en que se debía desarrollar la zona norpatagónica y en particular la región del Nahuel Huapi. ${ }^{25}$

El informe Bailey Willys está atravesado por una idea de industrializar la región, pero aún cuando se reconoce, por ejemplo, la necesidad de contar con ganadería y explotación maderera, en escritos posteriores se plantea límites y organización de estas actividades presentando al turismo como una alternativa posible. ${ }^{26}$ Una alternativa posible medida desde un potencial especulado antes que desde un marco material existente. ${ }^{27}$ De hecho en este primer parque nacional el turismo se presenta como una actividad conciliatoria ya que los seres humanos están de paso en una región que es ajena (Bustillo 1971).

Esta práctica de apropiación y concepción diferenciada del espacio resultaba acorde a la elaboración de ideas biológicas. Desde la ecología incorporaba y legitimaba la sociedad separada de la naturaleza en el mismo proceso de edificación de teorías. Tansley presenta uno de los ejemplos más claros cuando reflexionó sobre el modo de comprender las asociaciones vegetales y propone al ecosistema como unidad de estudio. En este proceso de construcción de las principales nociones ecológicas también se destinan párrafos para explicitar el sitio que la humanidad tendría en este marco de investigación.

"Es obvio que el hombre civilizado moderno altera en enorme escala los 'ecosistemas naturales' o 'comunidades bióticas'. Pero sería difícil, por no decir imposible, trazar una frontera natural entre las actividades de las tribus humanas que presumiblemente

\footnotetext{
${ }^{25}$ En 1906, el Ministerio de Obras Públicas inicia un programa destinado a la construcción de ferrovías, en el marco de este programa se organizó en 1911 la Comisión de Estudios Hidrológicos, con el fin de realizar estudios que permitieran conocer las características geológicas, topográficas y económicas de regiones en los territorios prácticamente desconocidas para el Estado Nacional. Si bien el gobierno nacional ligaba el poder político y el económico a través del voto censitario, el propio sector dominante no era homogéneo. En medio de una mayoría terrateniente, un sector planteaba la necesidad de desarrollar un plan de industrialización; la principal referencia era el ministro de Obras Públicas: Ramos Mejía. Los resultados de este estudio se encuentran en Willis, B. "El norte de la Patagonia" Eudeba. Argentina. 1988

${ }^{26}$ Estas reflexiones son expuestas en trabajos presentados en los Anales de Estudios Geográficos, durante la década del veinte.

${ }^{27}$ Hay referencias a la existencia de turistas desde los primeros años del siglo XX, sin embargo los visitantes llegaban en una cantidad muy limitada y la infraestructura del poblado difícilmente contaba con los servicios mínimos (Vallmitjana 1993; Nuñez 2003)
} 
encajen en las comunidades bióticas y formen parte de ella y las actividades humanas destructivas del mundo moderno ¿Es el hombre parte de la naturaleza o no?... Considerada factor biótico excepcionalmente poderoso que altere de modo creciente el equilibrio de los ecosistemas preexistentes y finalmente los destruye, formando otros de índole muy diferente al mismo tiempo, la actividad humana encuentra su lugar propio en la ecología" (Tansley 1935, 303).

Desde esta posición hay un deslizamiento entre la primera frase "el hombre civilizado moderno" hacia la humanidad en general con que se cierra el párrafo en la última línea "la actividad humana encuentra su lugar propio en la ecología". Desde este deslizamiento la humanidad aparece reducida al "hombre", blanco y occidental. Las poblaciones humanas, aún siendo reconocidas como parte de la naturaleza, necesariamente terminan destruyéndola, tal vez porque en el período en que escribe Tansley había una fuerte tendencia que suponía que la "evolución social" converge necesariamente en formas capitalistas y occidentales de organización. La capacidad humana para utilizar recursos era un argumento de suficiente peso para concebir un sitio para la humanidad diferenciado al resto de los organismos.

El "lugar propio" deviene en "sitio ajeno" a la luz del recorte temático de la disciplina. Es decir, la actividad social se consideró fuera del alcance analítico de la ecología, así naturaleza y sociedad se consolidaron como esferas de estudio separadas. La ciencia ecológica se circunscribió al análisis de un "mundo natural" donde la humanidad (reducida a "el hombre") era un factor externo, fuente de disturbios. ${ }^{28}$

Esta presentación resulta casi opuesta a los objetivos que dieron inicio a la ecología como actividad de investigación, puesto que, como señalábamos en el primer capítulo, la ecología surge de las preguntas que emergen de prácticas de producción agrícolas. Podríamos pensar que, dado que de la mano de la teoría de ecosistemas la ecología fue adoptando un carácter científico cada vez más experimental, en la medida en que se fue fortaleciendo la práctica ecológica como práctica científica enmarcada en la visión ortodoxa de las ciencias naturales (Makinistan 2004), la sociedad como parte de los ecosistemas fue alejándose de las preguntas y focos de interés temático. ${ }^{29}$

\footnotetext{
${ }^{28}$ La referencia a la humanidad como factor biótico especialmente poderoso parece equiparar la actividad humana a una catástrofe climatológica antes que al desarrollo de un conjunto de organismos.

${ }^{29}$ Vale la mención a la excepción que se reconoce en los trabajos de E. Odum, quien buscó estrategias para acercar la reflexión ecológica al análisis social.
} 
En los últimos años encontramos una tendencia inversa, el desgaste ambiental es un proceso que ha sido denunciado claramente a partir de los años setenta, aunque existen importantes obras previas. Los estudios ecológicos y el resto de las iniciativas ideadas para asegurar el crecimiento económico no alcanzaron para evitar el desgaste de recursos naturales y el deterioro ambiental fue en aumento. Frente a los límites en la reflexión y de la acción, a mediados de siglo XX surgieron cada vez más voces reclamando una vuelta al equilibrio de la naturaleza, que invistieron al término "ecología" con un nuevo sentido.

En este punto resultan de interés las reflexiones que revisan la propia noción de biopoder, que utilicé en la base de los análisis precedentes. Porque en la actualidad no sólo el desgaste ambiental, el incremento de la tecnología y el marco de un mundo globalizado, son referencia de las limitaciones para la evaluación de los modos históricos de dar cuenta de la situación, tanto en las ciencias naturales como en las sociales. Los límites y desafíos quedan explícitos a partir del reconocimiento de sujetos emergentes cuya situación no termina de ser comprendida desde el marco foucoltiano, que según la crítica de Rosi Braidotti (2000) y Donna Haraway (2007), nombra una forma de poder en el momento mismo de su implosión, pero no cubre la complejidad que adopta el poder con el tiempo y, sobre todo, se pierde en el contexto vigente. ${ }^{30}$

Tanto Braidotti como Haraway se alejan de la visión de biopoder mencionada, al reconocer que el poder contemporáneo ya no opera mediante una heterogeneidad normalizada, sino que más bien lo hace tendiendo redes, mediante la comunicación y las interconexiones múltiples. Celia Amorós (2008) reconoce que en este contexto "la visibilidad virtual se extiende más allá del panóptico”.

Los límites históricos se desdibujan en los sujetos emergentes. Naturaleza, tecnología, humanidad se mezclan en el cyborg de Haraway (2007). Frente a estos sujetos, las formas de cuidado establecidas en concordancia con la idea de biopoder, se presentan no sólo inadecuadas sino también contraproducentes. El cambio de reconocimiento que

\footnotetext{
${ }^{30}$ Braidotti (2000), a partir de reflexionar sobre la situación femenina, repara en que los términos de ciudadanía y subjetivación han sido históricamente definidos por los varones y constituyen un a priori histórico. Es por esto que demanda que las mujeres se construyan como sujetos nómadas, que se evite la ontologización negada y estereotipada. Se trata de desarticular los sistemas filosóficos modernos y posmodernos en un proceso de des-ocultamiento, para habitar y trascender tanto los lugares como las envolturas de la identidad, y transitando todos los lugares que siempre le fueron expropiados. En este reconocerse cambiante, Braidotti se acerca a una ontologización que discute el modo en que se reconoció y constituyó el mundo: la propuesta de Haraway (2007) sobre la ontología cyborg.
} 
se plantea desde estas perspectivas implica necesariamente una modificación en términos políticos, una revisión de responsabilidades y una reelaboración del conocimiento que se piense como adecuado. Los límites de la ecología para dar respuestas, se profundizan si se incorpora la noción que las entidades que debe reconocer, habitan en un mundo donde las identidades y vinculaciones se funden. Desde la misma perspectiva, puede pensarse que la pervivencia de la noción dualista de Parques Nacionales, con la idea de naturaleza asociada a un Eden orgánico y virginal, ajeno incluso a sus propios habitantes originarios, se presenta como anclaje de la organización social, que parafraseando a Braidotti y Haraway, cristaliza una forma establecida en el momento mismo de su implosión. La sociedad continúa separada de la “naturaleza en una vitrina", para el disfrute de los pocos que tengan acceso.

El marco de un mundo con circunstancias que avanzan sobre la capacidad de reconocimiento institucional, posiblemente profundiza el reclamo ambiental, en el sentido de exponer falencias para dar cuenta (y respuesta) a los problemas desde los sitios oficiales de contención. La idea de una naturaleza ajena habilita la concepción de mantenerla intacta en algún espacio puntual. La contradicción emerge cuando se reconoce que, para emerger intacta, esta naturaleza reconstruida en función de un ideal, requiere de las armas avanzadas, las patentes existentes, los viajes transoceánicos, la conservación de los alimentos, las redes ferroviarias, las autoridades burocráticas, la acumulación del capital, las sociedades filantrópicas entre otros elementos (Haraway 1999). La ilusión se desprende al reconocer que la vida de la naturaleza descansa en los mismos elementos que esferas organizativas de la sociedad occidental. En este contexto de globalización, que profundiza las desigualdades al mismo tiempo que incrementa la usurpación de recursos, no debe sorprender que los reclamos se multipliquen y diversifiquen.

\section{Las reivindicaciones ambientalistas}

Los límites a las consideraciones ambientales provenientes de instituciones oficiales fueron expuestos tempranamente. La obra fundante de las reflexiones ambientalistas en las sociedades occidentales es el escrito de Aldo Leopold (1948) A Sand Cunty Almanac, and Sketches here and There. Desde este texto el naturalista abogaba por una nueva ética, ya que entendía que el problema ambiental se reconocía a partir de los valores asociados al entorno natural y no al conocimiento científico que se tuviera sobre 
un espacio (Kwiatkowska e Issa, 1998). Leopold, desde su propia experiencia como investigador, apelaba al reconocimiento de trabas que no se podían sortear desde las actividades reconocidas como válidas en los espacios institucionales.

Algunos científicos se sintieron atraídos por esta visión que los comprometía con un nuevo concepto de preservación que traspasaba los límites de las reservas. Así, por ejemplo, Rachel Carson en 1962 expuso en su libro "La primavera silenciosa" los problemas que acarrea el uso indiscriminado de pesticidas en las zonas de cultivo. Las especies a cuidar ya no fueron exclusivamente las que benefician al hombre de forma directa. A partir de la segunda mitad del siglo XX se hizo cada vez más fuerte el reconocimiento de la dependencia entre todos los seres vivos y ello se asoció a un planteo por el derecho de vida de todos los organismos vivos.

En la década del setenta puede encontrarse un clivaje que lleva a las referencias sobre el cuidado ambiental de las manos exclusivas de los Estados Nacionales hacia organismos no gubernamentales. Estos últimos se erigieron como los abanderados públicos de los reclamos ambientales. Organizaciones de la sociedad civil trascienden sus reclamos como ciudadanos particulares y se erigen como grupo que discute los valores sobre los que se desarrollan las actividades. ${ }^{31}$ Los movimientos ambientalistas toman como deber moral el cuidado de la naturaleza y este deber pasa a denominarse "ecología". Así los ambientalismos resignificaron el término que previamente aludía a la ciencia. La ecología pasó de hacer referencia a un cierto tipo de estudios en biología a entenderse como una reivindicación y militancia en la preservación de la naturaleza.

En esta escisión de sentidos los movimientos ambientales tuvieron particular éxito en la difusión pública de su acepción del término "ecología", que quedó entonces asociado a un compromiso moral. La ecología como actividad científica no perdió su referencia en el contexto académico, pero se desvaneció en la apropiación pública de la palabra.

La palabra ecología aparece ligada a un vasto conjunto de acciones que se han tomado incluso como base de muchas campañas comerciales. No es motivo de la presente tesis profundizar en el sentido público del término ecología, sino tener como horizonte la complejidad del mismo para comprender que hay una oposición entre el sentido científico y el sentido coloquial del término, lo cual puede llevar tanto a confusiones

\footnotetext{
${ }^{31}$ Para una diferenciación entre ciudadanía y sociedad civil en el sentido que se toma en este texto revisar Ocham (2004).
} 
como al incremento de las distancias entre los actores interesados en un problema común.

A modo de esbozo, los movimientos ambientalistas pueden diferenciarse según se aboquen a reclamos que se vinculen directamente con el cuidado de individuos (el caso paradigmático es el reclamo por determinada especie en extinción), o si actúan en defensa de la naturaleza como conjunto (Tafalla 2004, Attfield 2005). Si bien puede pensarse que la defensa de cada organismo independiente puede sumar al cuidado de la naturaleza en general, existen críticas que sostienen que la defensa de una determinada especie carismática quita atención sobre los problemas que están llevando al desgaste ambiental en su conjunto (Leff 2001). ${ }^{32}$

Los movimientos ambientalistas lejos de ser un ámbito homogéneo se presentan con notables diferencias. Si bien tienen en común la valoración de la naturaleza no-humana, se diferencian de acuerdo al argumento con el que fundamentan este valor. A grandes rasgos se pueden distinguir dos visiones, que aunque no terminan de exponer la pluralidad de perspectivas de los debates reivindicatorios, sí presentan posiciones que se plantean como antagónicas. La primera posición se reconoce como antropocéntrica, en tanto el motivo que lleva a bogar por el cuidado de la naturaleza es la preservación de la humanidad como especie. La segunda posición se presenta como biocéntrica y sostiene que el cuidado de la naturaleza se justifica en la naturaleza misma (Tafalla 2005).

Estas dos visiones están en conflicto. Quienes critican el antropocentrismo sostienen que esta posición lleva a reducir la naturaleza a la idea de hábitat, la fuente de recursos, materiales, energías u objetos de estudio, y la razón para protegerla es, entonces, egoísta y no termina de escapar a la lógica que provocó el desgaste de los espacios vividos. Desde el biocentrismo se busca superar este egoísmo, pero el riesgo es que se llega rápidamente a legitimar ciertas formas de violencia, como la caza, considerada natural (Reagan 1981). Asimismo, si los intereses de la biosfera están por encima de la humanidad, debería aceptarse la inmediata disminución de la población humana que está sobredimensionada respecto del resto de las especies (Tafalla 2005). En este sentido el riesgo de una teoría holística tan vasta es su acercamiento al totalitarismo

\footnotetext{
${ }^{32}$ Estas líneas de reflexión se cruzan, por ejemplo, con la revisión de estructuras de dominio que han silenciado el valor de la diversidad, no sólo ambiental sino también cultural o sexual, dando lugar a los ecofeminismos (Cavana et al 2004, Puleo 2000, Shiva 1988) o ecoindigenismos (Leff 1998, 2001, Guerra y Aranzazu 2005).
} 
(Light y Rolston 2003). El modo en que se concreta la vinculación entre los movimientos ambientales y la ciencia no es generalizable ya que depende, entre otros factores, de la perspectiva ambiental con que se busque dialogar.

La noción de naturaleza está en disputa, porque se edifica y referencia desde marcos antagónicos. En la medida en que no se aclare la serie de compromisos ligados a cada modo de considerar la misma es difícil que se pueda encontrar una arena de debates comunes.

Un aspecto a rescatar de las movilizaciones ambientalistas es que, desde sus particulares reivindicaciones, tratan de impactar en la conciencia social. Son actividades que juegan en los escenarios públicos, buscando la mayor trascendencia en los medios de prensa. Se trata de golpes de efecto que, con mayor o menor carga de violencia, buscan el reconocimiento del problema. Puede pensarse que estas actividades han resultado exitosas, ya que la cuestión ambiental se consolida como parte ineludible de la agenda pública, aun cuando no se terminan de concretar acuerdos generales sobre los principales procesos de desgastes como lo exponen las negativas de los principales países industrializados a adherir al protocolo de Kioto sobre el cambio climático establecido en $1997 .{ }^{33}$

Quiero destacar que los ambientalistas, al igual que los científicos, operan desde y hacia los ámbitos públicos entendiendo que en este proceso también se traspasan las barreras hacia el ámbito privado. No se trata sólo que los principales países industriales limiten sus emanaciones de gas, se trata de lograr que en cada hogar se separe la basura, se midan los recursos no renovables o se limite el consumo. Algunas las iniciativas de cuidado se concretan desde el aparato represivo estatal (colocación de multas en la cuestión relativa al manejo e basura o costos de servicios muy altos), pero el cambio de conciencia al que se apela en la constitución de sociedades sustentables todavía aparece lejano, por no decir inaccesible. $\mathrm{Y}$ en esto, creo, un punto no menor es el modo en que se han arraigado en las sociedades modernas los supuestos legitimadores del conocimiento científico, que son los mismos que permiten y justifican la explotación ilimitada. Estos principios también operan en el nivel privado, estando fuertemente

\footnotetext{
${ }^{33}$ El principal compromiso del protocolo de Kioto es la reducción de las emisiones de seis gases provocadores del calentamiento global: los gases industriales dióxido de carbono $\left(\mathrm{CO}_{2}\right)$, gas metano $\left(\mathrm{CH}_{4}\right)$ y óxido nitroso $\left(\mathrm{N}_{2} \mathrm{O}\right)$, además de tres gases industriales fluorados: Hidrofluorocarbonos (HFC), Perfluorocarbonos (PFC) y Hexafluoruro de azufre $\left(\mathrm{SF}_{6}\right)$, en un porcentaje aproximado de un $5 \%$, dentro del periodo que va desde el año 2008 al 2012.
} 
arraigados en prácticas cotidianas, ese tópico que Haraway (1999) reconoce tras la idea de naturaleza.

En la variedad de sentidos que adopta la ecología, así como en las discusiones que se han establecido en torno a las formas capitalistas de producción pueden encontrarse indicios sobre las trabas que continúan operando.

\section{La ecología en disputa}

Dentro del ámbito de la producción de conocimiento, Barbara Holland Cunz (1996) considera que existe un riesgo a considerar en las lecturas y demandas que se están realizando desde las diversas disciplinas. Esta filósofa reconoce que en la discusión sociológica actual se incorporan cada vez más referencias a la "cuestión de la naturaleza", aún antes de haber sido perfilada desde el punto de vista de la teoría social. Estas referencias se originan en las opiniones de diferentes gremios de expertos que desde las disciplinas más variadas se ven atraídos por el posible barniz ecológico de cada área de estudio (Mayer- Tasch 1985). Este atractivo opera aún cuando, como menciona Holland Cunz, este carácter permanece hasta hoy totalmente difuso

“... hay que temer que la 'ecologización' de la teoría social siga manteniéndose como un ideal, aún antes de que se haya intentado proceder siquiera a una revisión sistemática" (Holland Cunz 1996, 58)

Un primer aspecto a tener en cuenta es que las necesidades que dan sentido al atractivo de la ecologización se sostienen desde el reconocimiento social del incremento de la polución, la desaparición de especies, el incremento de las desigualdades sociales vinculadas a la disminución de recursos, entre otros fenómenos igualmente trágicos. Es decir, el atractivo del carácter ambiental de las teorías que se elaboran se sostiene sobre problemas concretos que reclaman por el abandono de la dicotomía sociedad / naturaleza.

Pero el abandono de esta dicotomía, el reclamo por tornar a la naturaleza "menos ajena", históricamente no se ha originado en una reflexión teórica, sino que se ha edificado sobre años de reclamos de movimientos que se consideraron como tangenciales a la producción académica. Una tangencialidad que, debo señalar, ha 
tenido matices. En el caso particular de la ecología, atravesada por la dicotomía ciencia/ ambientalismo, se encuentra que la diferencia cobra reconocimientos variados según sea la concepción ambiental desde la que se evalúe la actividad científica. La consideración de esta pluralidad servirá más adelante para reflexionar sobre posibles puentes de diálogo.

El caso extremo de separación entre ciencia y ambientalismos se presenta en la ecología profunda (deep ecology en adelante), que se asume como máximo ejemplo de biocentrismo (Kwiatkowska e Issa 1998). Esta vertiente del ambientalismo postula la necesidad de repensar la naturaleza más allá del conocimiento científico, esto es de forma independiente al mismo. El principal referente del movimiento, Arne Naess, señala en un artículo de 1986 que los ecólogos profesionales, aún cuando estén involucrados en problemas de conservación, sólo se permiten desarrollar soluciones de corto alcance. Este "ecósofo" reconoce que, de otra forma, se discutirían compromisos sociales, económicos e incluso epistemológicos que van en detrimento de su propia práctica $\mathrm{y}$, sobre todo, de la valoración de su trabajo. ${ }^{34}$ Desde esta perspectiva la relación de este movimiento con la ciencia se presenta como posible en el futuro, cuando la propia práctica científica cambie los valores sobre los que se desarrolla actualmente.

Un aspecto general de las revisiones sobre la naturaleza provenientes de tradiciones nocientíficas es que el reconocimiento de los problemas suele tener una profundidad y solvencia mayor que las propuestas que se presentan como alternativa al problema que se reconoce. La deep ecology es un ejemplo en este sentido, porque, si bien las dificultades con la ciencia pueden acordarse desde múltiples perspectivas, su idea de generar alternativas a partir de asumir sin mediaciones la continuidad entre todos los organismos no puede tomarse tan a la ligera.

La posición de Naess, y de la deep ecology en general, ha sido criticada por Val Plumwood (1998) quien argumenta en contra de la posibilidad de distinguir entre el “yo" humano y la naturaleza (Naess 1986, Fox 1984). Plumwood (1998) señala que el abandono de la mirada del ser humano actuando en el medio ambiente, adoptando una visión holística, no sólo disuelve el concepto de "lo humano" sino a toda cosa compacta en el entorno. La falacia que reconoce la filósofa australiana en esta propuesta es que

\footnotetext{
${ }^{34}$ Naess se autodenomina "ecósofo", denominación que reúne los términos ecólogo y filósofo.
} 
avanza en la indistinguibilidad; proponiendo abandonar la dualidad sin reparar en los orígenes de la misma, que continúan operando en las prácticas precisamente por no haber sido analizados.

El problema de la ecología profunda es el problema de todas las visiones que, en cada plano, proponen abandonar la dualidad antes que indagar en los factores sobre los que se identificó. Plumwood (1998) reconoce que esta confusión se basa en la que dualidad se ha confundido con atomismo. La indistinguibilidad es la oposición al atomismo pero no necesariamente a la dualidad. En el plano ético, uno de los problemas que puede reconocerse es el de la visión de los humanos como "metafísicamente unificados a un todo cósmico será igualmente verdadera cualquiera sea la relación que los humanos mantengan con la naturaleza" (Plumwood 1998, 242).

La pensadora australiana señala que esta corriente propone una indiferenciación que lleva al ocultamiento de tensiones y diferencias y, con ello, a la pervivencia de las mismas. Por ello propone el reconocimiento de relaciones y dependencias que permita la exposición vincular como método fundamental para tener en consideración la diversidad de aristas en el problema.

Yendo hacia otras propuestas se encuentra una modificación respecto de la vinculación que se plantean con el conocimiento científico. Entre las concepciones que marcan diferencias vale mencionar la propuesta del ambientalista J. B. Callicott. Este pensador sostiene que la ciencia es uno de los puntos fundamentales para avanzar en estrategias de conservación. Comparte con el resto de los movimientos ambientales el reclamo por una nueva ética que valore la vida sin las barreras del antropocentrismo, pero plantea que este cambio debe estar acompañado por el conocimiento ecológico (Callicott 1989). Así postula que la concepción de la sociedad como ecosistemas ayudará a la instauración de un nuevo paradigma (en el sentido de visión el mundo) que potencie la transformación de la visión del mundo vigente.

Vale mencionar que es usual que en muchas reflexiones ligadas a movimientos conservacionistas se mencione que en la ecología se encuentran las herramientas teóricas desde las cuales se realizará un viraje en las ciencias y en la sociedad en general, para volverla más adecuada a las necesidades ambientales. A modo de ejemplo, que se suma a la propuesta antes mencionada de Callicott, A. Campillo (2000) entiende 
la constitución de la ecología como un entramado interdisciplinar de ciencias muy diversas. Postula que este desarrollo de la ecología se inscribe en el marco de una profunda transformación epistemológica que ha afectado al conjunto de las ciencias naturales y que ha puesto en cuestión el viejo paradigma mecanicista. ${ }^{35}$

En contra de estas confianzas adhiero a las impugnaciones de Bruno Latour (2004) quien señala que algunos movimientos ambientalistas no toman en cuenta los problemas asociados a la elaboración de conocimiento, y que de hecho entienden los resultados científicos como "espejos de la naturaleza", esto es, desde una perspectiva realista casi ingenua. En el caso que se indaga se reconoce que debería revisarse la confianza expresada en el potencial del entramado teórico de la ecología para cambiar la visión del mundo y con ello la relación entre la sociedad y su entorno. Si se toman en cuenta los reclamos ambientales y el cambio que proponen en relación al manejo de los recursos, no es tan obvio que la ecología como rama de la ciencia se encuentre a la vanguardia de estos reclamos. ${ }^{36}$ Tampoco es claro que esta rama de la biología contenga los conceptos necesarios para discutir la explotación capitalista de la naturaleza o que aceleren el cambio en la ética. La ecología, como ámbito de producción de conocimiento, acompaña el proceso de toma de conciencia de los problemas ambientales. Pero, si se toma en cuenta la elaboración del conocimiento que se produce a la luz de la exposición en el capítulo previo, más bien podría decirse que lo acompaña desde sus límites y compromisos con la visión clásica de las ciencias y no necesariamente desde su potencial de ruptura con la misma.

La convocatoria que se realiza a partir de un problema ambiental usualmente se dirige a una amplia audiencia y en general se desarrolla en ámbitos de debates fragmentados, abocados a problemas específicos, donde cada sector -científico natural, científico social, gubernamental, preservacionista, $u$ otro- incorpora un modo de razonamiento y un esquema de valores particular que llevan a reconocer al resto de los interlocutores desde un cierto conjunto de preconceptos peyorativos.

\footnotetext{
${ }^{35}$ Vale aclarar que Campillo, al igual que Callicott, entienden Paradigma como visiones del mundo, alejándose de la visión disciplinar de la propuesta kuhniana, Volviendo a las reflexiones del teórico ambiental debo indicar que, entre otras reflexiones, menciona que como resultado de esta transformación epistemológica, se ha modificado radicalmente nuestra idea de la naturaleza y de sus relaciones con aquello que parece ser su opuesto: el artificio, la cultura, la historia, es decir, de la sociedad humana en su conjunto.

${ }^{36}$ Aún cuando se cuente con reflexiones que abogan por una concepción integral de la ecología como Holling 1998 o de Laplante, 2004, las mismas continúan siendo tangenciales y los principales trabajos ecológicos se enmarcan en la visión disciplinar desarrollada a mediados del siglo XX.
} 
Observando en la historia del reconocimiento de los temas ambientales puede reconocerse que el clivaje de los años setenta sacó el debate ambiental de las esferas gubernamentales. A partir de estos años, y en función del reconocimiento de obras fundamentales como la de Aldo Leopold, el tema ambiental comenzó progresivamente a transitar por los carriles de la moralidad, la ética y a ampliarse desde procesos de movilización específicos. El debate ético, que tocaba en profundidad el accionar humano, no se incorporó a las ciencias naturales. La ecología como parte de las ciencias naturales realizó análisis que no se vincularon a compromisos morales de tipo preservacionista. Incluso los actuales vínculos de la ecología con ramas de las ciencias sociales también resultan problemáticos y aún no se terminan de conformar de manera sistemática. De hecho, la diferenciación que la ecología-disciplina científica, fue planteando respecto de los ambientalismos desde los años setenta (Holling 1998) operó en términos de quiebre en las posibilidades de diálogo. Los científicos que reflexionaron sobre el tema ambiental (donde se destacan Aldo Leopold o Rachel Carson entre otros) lo hacen, según se interpreta, desde sus motivaciones personales y no desde sus compromisos como investigadores. Ciencia y cuidado se perciben, desde la ciencia, como espacios diferentes y sin mayores estrategias de intercambio. ${ }^{37}$

La ecología mantiene aún su carácter introspectivo. Esto se reconoce a partir de observar la concepción ortodoxa que permanece en los libros de textos que, en gran parte, se utilizan actualmente en las facultades (de Laplante 2004). Aún presentándose como una disciplina plural desde algunas perspectivas, para la mayor parte de los practicantes, la ecología se dedica a explicar y a predecir patrones y cambios en la distribución y abundancia de especies. La ecología, desde esta concepción, es una ciencia de procesos demográficos (Begon et.al. 1990, Krebs 2001) que aún no deja puertas abiertas a las variables sociales.

Hay un sitio de alternativas que escapa a todas las partes. La cuestión sobre la naturaleza no termina de resolverse ni en las diferentes demandas ni en las distintas propuestas, el carácter esquivo del término emerge de los debates. La ecología científica no termina de dar respuesta desde su consideración de la naturaleza como ajena. Pero las propuestas ambientales tampoco arriban a mejor puerto. Para revisar este último

\footnotetext{
${ }^{37}$ Esta actitud permanece en los laboratorios de ecología argentinos, donde una parte importante de los discursos de los/las científicos/as que presentan su trabajo se dirige a explicar la diferenciación de su tarea respecto de los ambientalismos a los que consideran ajenos a sus tareas. Datos presentados en Núñez (2008)
} 
punto Plumwood (1998), como ya se mencionó, recorre el compromiso ético de la deep ecology. Pero también revisa éticas de inspiración racionalista que se proyectan sobre los temas ambientales, sobre todo en relación a los derechos de los animales. La filósofa australiana objeta que las mismas resultan contraproducentes para llegar a las preguntas que surgen de los reconocimientos prácticos, por no terminar de problematizar la tensión sobre la que se erigen los debates éticos, y en este ignorar reproducen las contradicciones.

El trabajo de Paul Taylor (1986) puede ser comprendido desde esta crítica. El defensor de los derechos de los animales argumenta a favor de tomar a los mismos como merecedores de cuidado por derecho propio. En esta línea formula una ética biocéntrica que intenta insertar en un marco ético kantiano, que distancia la acción moral de la emoción y el afecto. Una escisión criticada desde varias perspectivas. Porque la distancia vuelve a permitir la intromisión de perjuicios y re-fortalece la dualidad al separar de forma tajante la razón pública de la emotividad privada (Benhabid 1987, Blum 1980, Gilligan 1982, Lloyd 1983).

Holland Cunz (1996) analiza que la complejidad de los problemas asociados a esta dualidad no termina de reconocerse porque la razón anclada en la naturaleza y comprensiva constituye todavía hoy una minoría sin voz (concepto tomado de Keller 1991) en el corpus general de teorías.

La filósofa alemana retoma así la pregunta por el sentido del término ecología, mencionando que en torno al mismo se superponen, sin que se mencionen, varios niveles de significado: ecología son, por un lado, las ciencias naturales aplicadas a los ecosistemas, y en su forma adjetiva (crisis ecológica, cuestión ecológica, modernización ecológica, etc.). Pero también "ecología es frecuentemente el comodín de todo el complejo de relaciones humanas respecto a la naturaleza: La forma difusa en que se determinan y utilizan los conceptos tanto ecológicos como sociales caracteriza de forma drástica el balbuceo de las ciencias naturales ante las cuestiones sociales" (Holland Cunz 1996, 26). Un comodín donde los sentidos se diluyen.

Pero esta dilución no debe hacer perder de vista que tanto las teorías ambientalistas como los supuestos científicos edifican y argumentan a favor de una idea de naturaleza 
desde preconceptos e intereses. Es decir, nunca han sido neutrales hacia la naturaleza. Por esto acuerdo con la filósofa alemana cuando alega que

"La crisis ecológica, los efectos de la actuación humana y social sobre la naturaleza extrahumana plantean a la teoría social el problema de tener que integrar "algo" que no estaba previsto en el estudio: el, hablando en términos de la teoría de los sistemas, entorno no social del sistema social, es decir, la naturaleza" (Holland Cunz 1996, 57)

Agregando que en la ciencia ecológica acontece un problema similar. Sólo que ese "algo" que se agrega es la humanidad desde su carácter diverso.

\section{Naturaleza y reflexión política}

A diferencia de la ecología, que en su incorporación de ese "algo" externo, la humanidad, reprodujo el esquema interpretativo cercenando referencias a patrones culturales y revisando los procesos en términos energéticos, en la teoría social la incorporación de lo externo, la naturaleza, se propuso desde formas variadas que tuvieron más o menos continuidad.

Holland Cunz revisa, dentro de las teorías políticas, lo que entiende como minorías sin voz, esto es las concepciones no dominantes de la naturaleza, dentro de las teorías de la liberación. En las mismas observa la capacidad para romper el marco antropocéntrico de la teoría política. Desde estas reflexiones buscaremos continuar las líneas de estas rupturas y proyectarlas hacia la reflexión sobre la ciencia.

Un punto a destacar es que las reflexiones de la teoría política sobre la naturaleza han sido escasas, precisamente porque se trazó una línea tajante entre la sociedad y la naturaleza, que ha llevado, desde la mayor parte de las teorías, a considerar como notematizable a la naturaleza. Sin embargo existieron teorías que de una forma $\mathrm{u}$ otra tomaron el tema por considerar elementos autónomos, que aún estando incluidos en las determinaciones sociales no se presentaban como reductibles a las mismas (Beer 1990). Holland Cunz llama la atención a la importancia de indagar sobre estas líneas, sobre todo porque constituyeron, desde mediados del siglo XIX, "la estructura interna de teorías de liberación antiburguesas, anticapitalistas y antipatriarcales" (Hollanz Cunz 1996, 81). 
Estos conceptos se asocian a la idea de que las formas de dominio sobre la naturaleza tienen características propias, puesto que la autonomía de elementos sobre el que se ejerce el dominio resultan irreductibles a nociones como clase o sexo. Pero cuya presentación como elementos ajenos ha generado que aún no existan conceptualizaciones que permitan intuir categorías en este sentido (Holland Cunz 1996).

Para explorar las líneas que han realizado algún avance sobre este problema Cunz toma, en primer lugar, teorías histórico-marxistas. En relación al tema de la naturaleza rescata en Alison Jaggar (1983) la idea que la epistemología clásica marxista concibe una interacción dialéctica entre la humanidad y la naturaleza, tal como se observa en la introducción de la "ideología alemana". Elmar Altvater (2006) señala que algunos ecologistas le reprochan a Marx una cierta desatención al valor de la naturaleza en el proceso de generación de valores (por ejemplo: Immler y Schmied 1984, Deléage 1989). En contra de estas críticas, el autor argumenta que esta visión es solamente relevante con respecto al proceso de trabajo. Así señala que el concepto marxista de naturaleza es que la naturaleza es indiscutiblemente productiva, la evolución de las especies en la historia del planeta y su tremenda diversidad y variedad lo demuestran. Pero la naturaleza no produce mercancías para vender en el mercado. No hay mercado en la naturaleza. El mercado es una construcción social y económica y ese es el punto que problematiza Marx.

Holland Cunz (1996) advierte que entre las perspectivas más enriquecedoras del debate actual debe mencionarse la propuesta de James O`Connor (1988). Este autor introduce la noción de "segunda contradicción del capitalismo", que se proyecta sobre las fuerzas de producción y no sobre las relaciones de producción. O`Connor parte de reconocer en la naturaleza de los bienes públicos que, aún cuando no son producidos en forma capitalista son utilizados como mercancía. En este proceso donde hay formas de regulación explícitas, el Estado se instala entre la sociedad y la naturaleza mediando y politizando las relaciones.

Los actores que politizan el tema económico de la provisión de bienes públicos o de las condiciones generales de producción son, en primer lugar, el estado representado por el gobierno, los partidos políticos, la administración, etc. Seguidamente, los capitalistas y los representantes de corporaciones o asociaciones de empleados. Finalmente, los gremios; las organizaciones no gubernamentales y los nuevos movimientos sociales. 
Sobre este punto O Connor destaca que los conflictos sociales y las luchas discursivas se centran no sólo alrededor de la estructura de clases, el conflicto de clases y los intereses de las clases en una sociedad capitalista, sino también en torno a la relación social entre humanidad y naturaleza, el medio ambiente construido, las condiciones generales de producción, y el tema de la calidad y cantidad de la provisión de bienes públicos, por ello reclama por una teorización ecológica en el marxismo que, desde los teóricos marxistas se discute aunque no terminan de encontrar aportes significativos que agreguen una variable diferente a la propuesta original de Marx (Altvater 2006). ${ }^{38}$

Sobre este punto Holland Cunz (1996) reconoce un aporte en Beer (1990), ya que esta autora incorpora la naturaleza a las fuerzas productivas reconociendo en la misma "una lógica de desarrollo que es muy diferente y diferenciable de la lógica humana" (Holland Cunz, 82). Sin embargo, a pesar de este aporte, Holland Cunz advierte que desde todas las perspectivas la naturaleza sigue quedando sujeta a lo social "amoldándose bien a modo de condición de producción bien como fuerza de producción" (Holland Cunz 1996, 83). La naturaleza sigue considerándose desde un punto de vista económico. Sigue concibiéndose en términos de relaciones hacia y no con la naturaleza y menos aún de la naturaleza hacia sí misma.

Es interesante destacar los límites que se encuentran en las teorías que, aún cuando han avanzado en la teorización de la naturaleza, no terminan de presentarla fuera de las formas humanas de sociedad. Al respecto Holland Cunz señala que "la estructura interna de las teorías críticas, su forma de pensar en relaciones sociales de dominio, dificulta el intento de determinar por lógica interna", sobre todo porque las teorías marxistas no dejan de focalizar el tema de la producción (Mies1989).

James O’Connor (1989) llamaba la atención sobre este punto al señalar

"los seres humanos transforman la naturaleza: mientras tanto, la naturaleza se transforma a si misma y transforma el terreno sobre el que se desarrolla la historia humana. Este parece ser un camino que tendrá que tomar toda revisión o ampliación del marxismo o del materialismo histórico" (O’Connor 1989, 8).

\footnotetext{
${ }^{38}$ En este trabajo no vamos a ingresar a una revisión profunda de la teoría marxista, sino que incorporamos esta referencia para dar cuenta del modo en que se están desarrollando los debates. Para ver una ampliación del debate puede consultarse en Leff 1998; Kaul et.al. 2003, Altvater 1993, MartinezAlier 1987.
} 
En concordancia con este pensador, entiendo que este es el camino que deberían tomar todas las teorías que intentan afrontar esta problemática, reconociendo la riqueza de perspectivas que se abrieron en las diversas teorías de liberación que, aún cuando quedaron circunscriptas a las minorías sin voz, no deberían perderse de vista a la hora de indagar sobre este punto.

En este sentido es interesante revisar la herencia de los denominados "socialismos utópicos" que, sobre todo en la obra de Charles Fourier, repararon sobre este punto. Holland Cunz (1996) reconoce tres componentes en la obra de Fourier que permiten profundizar en estos aspectos

"la imagen de la naturaleza histórica, la estrecha relación entre la historia natural y la historia social... y una concepción teleológico-histórica que incluye a la naturaleza" (Holland Cunz 1996, 137)

Ya en 1808 Fourier planteaba que la naturaleza interna y externa, así como la organización social están sometidas a las mismas formas lógicas de orden. Asumía la armonía como horizonte de expectativas, contraponiendo los efectos de la industrialización que entendía como caos. Tanto Fourier como los denominados "utopistas" reconocían el desorden de las sociedades industriales en todos los planos, en lo económico, lo moral, lo social, lo espacial y urbano, en la salud. Cada desorden con sus consecuencias, hacinamientos, violencia, crisis, prostitución, disolución de familias, mortalidad; era revisada a la luz de propuestas que se presentaban como superadoras. José Sierra Álvarez (1984) señala que aún cuando las propuestas eran diferentes, todas obedecían a una percepción similar de los datos.

El ambiente fue un tema central de estas reflexiones, porque entendían que una sociedad nueva debía construirse cuidando al ambiente que rodeaba a todos los habitantes. En este sentido los utopistas estaban comprometidos con las bases de la ilustración. La ciencia, el conocimiento, se presenta como una herramienta de emancipación en un contexto de ideas atravesado por los principios de las ciencias físicas y naturales (biológicas).

En este sentido los socialistas utópicos buscaron hacer una historia natural de lo social, siendo Fourier el mayor exponente en este sentido, 
"Muy pronto me di cuenta de que las leyes de la atracción apasionada correspondían plenamente a las de la atracción material, explicadas por Newton y Leibnitz, y que existía una unidad del sistema de movimiento en el mundo material y espiritual" (Fourier 1972[1808], 62).

Mirilla Larizza (1970) pone en evidencia que

"Fourier participa de la concepción iluminista de la naturaleza como mecanismo autorregulatorio que incluye en el propio seno su principio organizador" (Larissa 1970, 12-13), llegando en el uso de sus argumentos a ejemplos altamente criticados como la idea que el "sabor como a limón del agua marina es el sabor de la armonía ascendente".

Pero más allá de las metáforas o concepciones criticables vale señalar que, fundamentalmente, no escapa de la mirada teleológica ya reconocida en el corpus de conocimientos biológicos en general, dando lugar a una mirada apoyada en la escisión entre el conocimiento y las prácticas de aplicación, aún cuando fuesen importantes críticos de esas mismas prácticas.

Walter Benjamín (1987) es uno de los teóricos que toma la obra de Fourier como una ventana hacia el optimismo. Las "fantasías" de Fourier, ridiculizadas por los marxistas científicos posteriores, eran en cambio para Benjamín propuestas que resolvían una visión del trabajo que al mismo tiempo satisfacía necesidades humanas y reconciliaba a la humanidad con la naturaleza. Hector Alimonda (2002) recupera las reflexiones de Benjamín junto a otras perspectivas que reclaman una nueva lectura sobre los denominados "socialistas utópicos". Una lectura que, sin embargo, no deja de reconocer las limitantes propias del contexto en que fueron planteadas, como la teleología o el antropocentrismo.

Algo equivalente ocurre con las obras de Marx y Engels, aún reconociendo una cierta desatención del "valor de la naturaleza" en el proceso de generación de valores (Immler y Schmied-Kowarzik 1984, Bunker 1985, Deléage 1989), hay autores que reclaman una revisión de las obras originales, en las que reconocen un potencial de emancipación que debería tenerse en cuenta en el proceso de reflexión sobre una sociedad más justa y con un vínculo sustentable con la naturaleza. Altvater (2006) resume los argumentos en este sentido al intentar responder a los críticos de Marx sosteniendo que, el autor de $E l$ 
Capital, lejos de desconocer el valor productivo de la naturaleza, el punto que resalta es que estos valores no se venden en el mercado, porque el mercado es una construcción social y económica. Y en este punto hace una distinción, indicando que no es el trabajo en sí mismo, el trabajo sans phrase, el que logra la metamorfosis de la naturaleza en mercancía, sino la fuerza de trabajo consumida bajo la forma social del capitalismo y bajo la condición social de estar subyugada al proceso capitalista de producción de valor y plusvalía (Altvater 1993, Burkett 1996).

Altvater no hace mayor énfasis en la falta de atención a la dinámica propia de la naturaleza, sino que destaca la vinculación que Marx y Engels plantearon a partir de problematizar el trabajo. Debo mencionar que en este otorgamiento de pesos diferenciados se introducen sesgos, y resulta criticable, por ejemplo, la aceptación directa de la homologación de trabajo a la idea de padre y de tierra a la idea de madre sin reparar en la desigualdad de género implícita.

En general puede decirse que Marx, en su revisión del sistema, no escapa a la idea de la supremacía de la razón, ni a la consideración de roles fijos en términos de género. Pero estas barreras, que deben explicitarse en las lecturas de sus obras, no impiden reconocer, como hace Elmer Altvater (2006), el valor de Marx por marcar límites y problemas de crecimiento que se vinculan con la lógica misma de apropiación.

En este sentido se destaca que el proceso del trabajo muestra al mismo tiempo efectos productivos y destructivos, porque en el proceso productivo no sólo se producen valores de cambio y plusvalía, sino que también se transforman materia y energía. Desde esta perspectiva la entropía necesariamente crece (Prigogine y Stenger 1986) y por ello resultaba fundamental pensar en los modos de desarrollo de las fuerzas productivas. Marx entendía que el desarrollo de las fuerzas productivas resultaba positivo para la humanidad, porque eran la base de una sociedad redistributiva que reparaba en las necesidades de cada persona. Por esto Altvater entiende que,

“... dado que los hombres y sus necesidades son parte del ciclo de reproducción natural, la nueva formación social que distribuye riqueza de acuerdo con las necesidades humanas es también pensada como una sociedad de reconciliación del hombre con la naturaleza" (Altvater 2006, 348). 
El proceso de producción, como contraparte, es necesariamente destructivo en cuanto al modo en que se lleva adelante desde el capitalismo. No sólo porque no repara en la relación con la naturaleza, sino porque al focalizar sus referencias en el capital (y no en la pervivencia del sistema) socava los medios de autorreproducción social y natural. Al producir valores de uso que potencialmente satisfacen necesidades humanas, produce también, inevitablemente, deshechos y malos gastos. La acumulación capitalista, desde esta perspectiva, no sólo produce desigualdades sociales sino que se basa en una lógica de gasto que resulta insostenible.

En Marx y Engels el medio ambiente aparece mayoritariamente como el medio ambiente construido en un sentido material antes que discursivo, es decir producido o provocado por el hombre (el masculino no es casual), la naturaleza queda pasiva e incluso indiferenciada. El medioambiente es concebido como la provisión de bienes públicos, que incluyen no sólo los bienes culturales y naturales sino también la infraestructura material e inmaterial producida.

Por esto Elmer Altvater (2006) y James O’Connor (1988) argumentan que la categoría del medio ambiente construido es capaz de relacionar la dinámica de la acumulación capitalista con el papel del medio ambiente, dando así lugar a lo que denominan "marxismo ecológico"

En esta línea sostienen que el concepto marxista de relación naturaleza-hombre es más apropiado que otros conceptos para comprender las contradicciones y la dinámica de la relación social entre ser humano y naturaleza. El potencial de este concepto es que permite concebir al ser humano trabajador como alguien que transforma la naturaleza y, por lo tanto, está incluido en un metabolismo de naturaleza-hombre que, por un lado, obedece a leyes de la naturaleza cuasi-eternas y, por el otro, está regulado por la dinámica de la formación social capitalista.

Una crítica que puede hacerse es que no reconocen problemas en que las "leyes de la naturaleza cuasi eternas" estuviesen siendo analizadas desde un espacio aislado a estos debates, la ciencia, y mucho menos cruzan esta idea con el debate actual que pone en duda la existencia misma de "leyes naturales", en el sentido en que se entendían en el siglo XIX, dando cada vez más lugar a los fenómenos aleatorios en todas las escalas de 
análisis. Otra, que el conjunto de interacciones posibles reducidas a la estricta noción de trabajo resulta cuanto menos problemática.

Esto no implica desmerecer los aportes que se hayan elaborado cuando en el siglo XIX se planteaba la idea del problema de la naturaleza asociado a un sistema que se valoraba como injusto. Vale repasar, por ejemplo la idea que Fourier sostiene respecto de la forma humana/social de trabajar la naturaleza, que entiende como dependiente del estado intrasocial y de la calidad de la libertad de la naturaleza humana. ${ }^{39}$ Un concepto retomado por Engels muchos años más tarde (1875), cuando en su Dialéctica de la naturaleza reconoce que las leyes de la dialéctica se abstraen tanto de la historia de la naturaleza como de la sociedad humana.

Ambos autores comparten que la historicidad no es igual para la naturaleza y para la sociedad, aún cuando están afectados por las mismas leyes. Esto se debe, a decir de Fourier y Engels, a que los seres humanos, a diferencia del resto de los seres vivos, afectan su propia historia, construyendo intencionalmente un devenir. Siguiendo a Engels "la historia del ser humano... surge de y con el trabajo; la historia del animal de y con su origen" (citado en Holland Cunz 1996, 148)

Podemos resumir que trabajo y origen, se constituyen en las claves fundamentales para comprender la historicidad y su direccionalidad desde las propuestas socialistas en sus diversas variantes. Ambas perspectivas comparten un carácter teleológico (propio de todas las reflexiones que reparaban sobre los seres vivos en el período), así como el reconocimiento de un final sin vida, una certeza que se sostenía desde el conocimiento científico de la época pero tan lejano que igualmente resultaba más accesible la imagen de un cambio posible.

Una crítica, heredera de estas reflexiones pero con aportes propios, es la que proviene de Max Horkheimer y Theodore Adorno, quienes desde su obra socavan la confianza hacia los principios que sostenía el iluminismo. Estos autores entienden que el iluminismo, como proceso histórico, dio un impulso de autoafirmación egoísta del hombre frente a la realidad. Por esto manifiestan que el iluminismo ha perseguido la idea de sacar el temor del hombre y situarlo como padrino del mundo que lo rodea. En

\footnotetext{
${ }^{39}$ Otro aspecto destacable de su teleología es que el fin final no es la concreción definitiva de la armonía, sino que postula un largo proceso involutivo que expira con el fin de la vida animal y vegetal.
} 
la base del iluminismo está la separación del hombre y del ser y la consecuente ruptura entre el hombre y la naturaleza (Abbagnano 1993).

Horkheimer y Adorno sostienen que, uniendo la ciencia a la técnica, entendiendo a la naturaleza como campo de disfrute del hombre, se ha ligado el destino de la ciencia al de la burguesía. Así el saber científico-tecnológico aparece como un componente integral del proceso de la iluminación de conquista del mundo, donde no se escapa ninguna de las ciencias (naturales o sociales, aunque marcan alguna expectativa en torno a ciertas revisiones filosóficas). Los autores de la Escuela de Frankfurt entienden que la esclavitud de la naturaleza se transformará en esclavitud del hombre en tanto el hombre no sepa comprender su propia razón en el proceso que la ha creado.

En general, la filosofía de Horkeimer tiende a "desenmascarar" el sistema de pensamiento puesto al servicio de la lógica de dominio. En este sentido discuten con Marx que la principal causa de alienación no reside en el antagonismo entre una clase que usufructúa y otra que es usufructuada. Para Horkheimer la lógica del domino se fundamenta en la razón instrumental.

Otro punto fundamental que este autor discute con Marx es que el progreso de la humanidad no necesariamente implica el dominio de la naturaleza y el crecimiento ilimitado de la fuerza productiva, del cual son parte integrante la ciencia y la técnica. Para Adorno y Horkheimer el dominio continuo sobre la naturaleza implica un incremento de la ciencia y la técnica que redundan en un dominio creciente sobre el hombre. $\mathrm{Y}$ en este sentido suman reflexiones que ilustran la necesidad de abandonar las dicotomías, se trata de comprender a la humanidad y su contexto desde las relaciones que se establecen, como por ejemplo cuando señalan "Los seres faltos de razón han podido experimentar siempre la razón... en el matadero" (Horkheimer y Adorno 1997, 295).

En sus escritos reconocen en la ilustración un nuevo género de barbarie. Una que puede pensarse oculta tras un conocimiento científico que da la ilusión de civilización, pero que antes que resolver, eclipsan las contradicciones. Horkheimer y Adorno sostienen que la herramienta fundamental de este ocultamiento es el modo reduccionista de elaborar conocimiento. Conocer es, por tanto, asimilar la diversidad a la unidad; es decir, conocemos cuando logramos identificar bajo un concepto una pluralidad de 
manifestaciones. Por tanto, el conocimiento implica un proceso de reducción de la multiplicidad sensible a una unidad conceptual. El camino que, como se presentó en el capítulo previo, intentan seguir ciertas líneas de la ecología. Hegel ha mostrado que esta reducción supone, al mismo tiempo, una negación. Así la identidad conceptual anula el carácter real de la multiplicidad sensible, y lo real pasa a ser sólo el concepto.

Desde la forma que adopta el conocimiento legítimo lo diverso carece de realidad más allá de su síntesis en un concepto. En este sentido, el conocimiento a través de conceptos supone dos operaciones simultáneas: la reducción de la multiplicidad de lo sensible y la negación de la realidad de lo sensible (o del carácter individual), que se completan con una tercera operación: la superación de la negación en la identidad del concepto.

A partir de reconocer esta operatividad en el proceso constitutivo del conocimiento, Adorno y Horkheimer señalan que éste no se limita a ser un conjunto de operaciones teóricas sino que también se encuentra en la base de las operaciones prácticas de la racionalidad instrumental. Volviendo a los procesos de producción en serie, en ellos se trata de reducir la diversidad de una materia prima dada para la obtención de un producto genérico, en torno del cual se identifican las diversas materias prima, pero a través de la negación de su propia realidad individual, y vuelve a nosotros la imagen del matadero como la aplicación de la razón sobre los seres “carentes de razón”.

El carácter genérico de los productos así obtenidos los vuelve intercambiables y superfluos en cuanto a su singularidad. El sistema se afirma en un proceso que relega a la negatividad a los individuos y adquiere identidad a través de la reducción de la diversidad, que supone poner al individuo al servicio del sistema. De este modo, la afirmación del sistema se presenta como absoluta dominación.

"El iluminismo se relaciona con las cosas como el dictador con los hombres, pues el dictador sabe cuál es la medida en que puede manipular a éstos. El hombre de ciencia como el dictador conoce las cosas en la medida en que puede hacerlas. De tal suerte el en-sí de éstas se convierte en para-él. En la transformación la esencia de las cosas se revela cada vez como la misma: como fundamento de dominio. Esta identidad funda y constituye la unidad de la naturaleza [...] Es la identidad del espíritu y su correlato, la unidad de la naturaleza, ante la cual sucumbe la multitud de las cualidades" (Horkheimer y Adorno 1997, 22-23). 
Otra característica de la dominante sociedad tecnológica que se ha construido es, según Horkheimer y Adorno, que este desarrollo del aparato de dominio no sólo se sostiene desde la ciencia, sino también desde el gigantesco aparato de la industria cultural. El mismo es un instrumento de manipulación de la conciencia. Y en este punto marcan que no se trata tanto del problema de la técnica como del espíritu en que la técnica se desarrolla. La velocidad actual de las comunicaciones no es neutral. Los medios masivos de comunicación no sólo transmiten ideología, son ideología. Lo mismo el cine, las propagandas y las diversiones modernas. Son las que permiten eclipsar contradicciones y con ello la construcción de conciencia que demande un cambio efectivo. La mirada de estos autores, que con aguda percepción profundizaron en las contradicciones y limitaciones del sistema, es claramente pesimista.

\section{Repaso sobre las teorías políticas}

A modo de cierre sobre los aportes de las revisiones políticas en torno a la apropiación de la naturaleza debe destacarse que, a pesar de plantear el problema de la relación sociedad - naturaleza, los límites de las teorías marxista y socialista se plantean en que, aún reconociendo el problema, tanto Fourier como Engels y Marx presentan una naturaleza que no termina de reconocerse con lógica propia. En Fourier, porque la pone en relación con la actividad humana. En Engels y Marx, porque queda atrapada en la fuerza del trabajo. De este modo, a pesar de reconocer una historicidad propia en la naturaleza no escapan de las trampas del antropocentrismo (Holland Cunz, 149), facilitando procesos de indiferenciación antes que sostener propuestas que indaguen en la dinámica relacional entre partes que han sido consideradas como ajenas.

Los aportes de la Escuela de Frankfurt suman reconocimiento en este sentido, pero dado que el peso sobre la crítica está sobredeterminado en relación a la alternativa, dejan una visión pesimista como resultado de sus análisis

Las disciplinas biológicas, donde se enmarca la ecología, parecen tener una debilidad similar en el análisis, pero en un sentido diametralmente opuesto. La naturaleza, en donde se reconoce el impacto de las actividades humanas, se observa como ajena a estas actividades y los procesos sociales se conciben como ajenos a los procesos que los involucran. 
Este camino de revisiones truncadas y estudios parciales está siendo discutido a la luz de la actual situación de crisis ambiental. En acuerdo con Holland Cunz (1996), entiendo que el concepto de crisis ecológica se utiliza con énfasis desde la arena pública sólo desde hace un par de décadas, con lo cual no necesariamente la cuestión ambiental se ha tomado como eje de los análisis críticos sobre el sistema. Si bien es posible rastrear importantes raíces críticas en referencia al estado de la relación social industrial hacia la naturaleza, coincido con Plumwood cuando reconoce una supremacía otorgada a una razón, perdiendo en esta perspectiva la edificación de alternativas posibles que reparen en visiones que contemplen la emoción y lo particular.

En la actualidad nos encontramos con debates que hacen poner en duda la eficiencia del esquema cultural que buscó reducir lo puntual a lo general, y en este sentido resulta interesante revisar las propuestas que analizan los ámbitos relegados como noconocimiento: el ámbito privado, las esferas emocionales, las situaciones particulares de las sociedades no occidentales, entre otros.

\section{Consideraciones finales del capítulo}

A la luz de lo expuesto hasta este punto podemos suponer que, en el siglo XIX, la respuesta de los gobiernos (comprometidos con la forma de producción capitalista), frente a los límites que empezaban a reconocerse en la naturaleza, fue la producción de conocimiento científico, entre el que he destacado la producción de conocimiento ecológico porque la apertura de este nuevo campo de estudios sería el ámbito por excelencia para encontrar respuestas.

En este proceso se filtraron nociones precedentes, que sustentaban la ciencia moderna, como las discriminaciones de género (Merchant 1983) o la escisión sociedad/naturaleza (Descola y Palsson 2001). Es interesante el modo en que estos preceptos se filtran hacia prácticas de conservación, donde los Parques Nacionales se erigen como ejemplo de lo que se debe cuidar y diferenciar, en un claro ejercicio distintivo hacia el resto del espacio que aparecía condenado por el mero uso humano.

En un período acorde al del surgimiento de la ecología, y a partir del reconocimiento de problemas similares, los socialismos intentaron problematizar el vínculo 
sociedad/naturaleza, dando varias pistas en torno a los problemas y riesgos de las prácticas capitalistas, pero sin quebrar con los preceptos teleológicos ni con la confianza en la mirada científica.

Así, ni el debate científico ni el debate político terminaron de erigirse como alternativas. No es extraño entonces que desde lógicas diferentes se comenzaran a elaborar discursos y prácticas tendientes a llamar la atención hacia el problema ambiental. La dificultad que se encuentra en estos reclamos es, por un lado, su diversidad que hace discutible el reconocimiento de una reivindicación común, y por otro, la pervivencia de ciertas dificultades que tampoco han facilitado reflexiones tendientes a cambios definitivos en las sociedades actuales.

Como contracara se cuenta con un reconocimiento cada vez más profundo del problema ambiental y de las trabas del sistema productivo para facilitar la constitución de alternativas. Ahora bien, resulta claro que el mero conocimiento no produce los cambios $\mathrm{y}$, de hecho, muchas de las reflexiones nos llevan al reconocimiento de un esquema disciplinador tan vasto que hasta resulta discutible la posible implementación de cambios.

Por ello, a fin de avanzar en esta reflexión, tomo como paso siguiente la revisión del ámbito final sobre el que se desea establecer el cambio: el espacio privado.

En el reconocimiento de la enorme desigualdad que se ha incrementado con el desarrollo del capitalismo, el impacto de la crisis y el desgaste en los sectores más frágiles de la sociedad (pueblos del tercer mundo, mujeres, ancianos), muchas veces nos lleva a imaginar un horizonte apocalíptico, donde la destrucción aparece más cercana que la posibilidad de cambio, en contra de la intuición de Fourier y Engels. Esta noción se fortalece si se tiene en cuenta que los mismos movimientos ambientales han resultado mucho más eficientes en términos de denuncia que de búsqueda de alternativas.

Sin embargo, en contra de esta visión que puede llevar a posturas inmovilizantes, seguiré una línea de reflexión que abandona los procesos generales de las sociedades occidentales e indaga en debates de espacios históricamente no reconocidos, los que se desplegaron en ámbitos privados. 
Se trata de repensar la cotidianeidad como sitio al cual debe llegar el cambio, la nueva sociedad, pero ya no como resultante final de una estructura disciplinadora determinante inexorablemente, sino como fuente eficiente y efectiva de cambio en si misma. 
Segunda Sección: Los pilares de los "puntos ciegos"

Capitulo 3

Naturaleza: Jerarquía, Control, Dominio 


\section{Introducción}

Las discusiones entre científicos y ambientalistas parecen desplegarse en una confrontación sin solución, a tal nivel que los propios científicos reconocen que su compromiso ético se circunscribe a su vida privada no-profesional (Núñez 2008). En un ámbito más distante, las reflexiones dan cuenta del desconocimiento entre unas y otras posturas, tal vez por idealizarlas, tal vez por ignorarlas. Aparentemente las capacidades, entrenamientos y saberes adquiridos en un ámbito resultan ajenos al otro.

Si bien dentro de la ciencia existen las revisiones que llaman la atención sobre el problema de la necesaria vinculación de las sociedades humanas y su entorno, que reclaman la apertura temática de la ecología como disciplina científica (Holling 1998, de Laplante 2004), el nivel de debates, y la historia de los mismos, permite postular que el problema ambiental difícilmente se reduzca a un mayor conocimiento académico del mundo natural. Es un problema que, sin perder las necesarias referencias a los saberes biológicos, demanda de la incorporación de referencias ligadas a prácticas y valores humanos.

La actividad científica habilita formas relacionales entre las sociedades y sus entornos. Se trata de vinculaciones asimétricas que permiten fundamentar modos de dominio y control específicos que se proyectan desde ciertos segmentos sociales hacia el entorno y hacia muchos de sus pares (Horkheimer y Adorno 1997). Como consecuencia vivimos en un mundo construido a la medida de unos pocos, edificado sobre una arena de prejuicios y supuestos que no pueden desmontarse si no se revisan. En las páginas que siguen voy a recorrer el fundamento biológico de este dominio; esto es, el modo en que desde la biología se fue legitimando la forma de control a partir de supuestos extracientíficos que, en el proceso constitutivo de las ciencias modernas, se fueron eclipsando de los debates específicos de esta área de estudios.

En este sentido voy a revisar uno de los supuestos fundamentales sobre los que han normado las desigualdades del mundo moderno: las jerarquías naturales que se asumen a lo largo de la historia de la biología como disciplina científica. Voy a recorrer los órdenes que se han asumido, haciendo referencias a la articulación evaluativo-valorativa que, desde estas concepciones, se han proyectado en la comprensión de la organización social, siguiendo la idea desarrollada por María Luisa Femenías (1996) que "las 
jerarquías políticas remiten, como fundamento 'extrapolítico', al discurso biológico" (Amorós 1996,15)

La modernidad que se inaugura en el siglo XVII consolida una visión jerárquica a partir de sostener una organización cimentada en la escala de los seres. Vale mencionar que aún cuando la ciencia moderna ha abandonado esta noción, permanecen supuestos de dominio y control que se encontraban en la base de esta idea. La hipótesis que guía esta revisión es que la continuidad de los supuestos se vincula a una imposibilidad estructural por removerlos. Se generaron desde un cierto ámbito de conocimiento y se sostienen desde otro. El debate se ha deslizado hacia una arena que no toca sus fundamentos, en un ejercicio que naturaliza formas de explotación propias de las sociedades occidentales modernas. De este modo se conforma un sentido jerárquico que trasciende las referencias ontológicas específicas para situarse en el plano relacional.

\section{El orden de la naturaleza}

La idea de una naturaleza organizada resulta, sin duda, tranquilizadora frente al desafío de interpretar la complejidad de la vida. Objetivo postulado, a diferentes escalas y alcances, en las diversas disciplinas biológicas. Frente a la complejidad de procesos que el joven Kant apreciaba casi incomprensibles- la biología fue respondiendo con observaciones y teorías que buscan explicar la situación y el devenir de individuos y comunidades en las más diversas escalas de observación. Estas explicaciones se sustentan, como la ciencia moderna, en supuestos en torno a la presencia de leyes, patrones, organizaciones básicas, formas de interacción privilegiadas, entre tantos otros elementos que, diseñados a través de la matematización y la experimentación, han dado lugar al desarrollo de las diversas ramas de la ecología en el último siglo.

La estructura teórica que resulta de este desarrollo científico se encuentra sustentada sobre un conjunto de supuestos que deben revisarse junto a las teorías correspondientes para dar cuenta, no sólo de los postulados, sino de los modos en que las propuestas teóricas impactan en la sociedad que, en diferentes formas, se apropia de este conocimiento. Modos que no son independientes del propio saber científico, porque, como indica R. C. Lewontin (1992), el conocimiento científico provee los modos para 
manipular el mundo material al tiempo que diseña las explicaciones para fundamentar porqué las cosas son como son.

La noción de jerarquía -que subyace a la idea de orden- organiza el conocimiento consolidando un reconocimiento diferenciado. Para revisar este aspecto indagaré la valoración privilegiada que fundamenta el dominio de una de las partes hacia la/s otra/s. Desde los estamentos establecidos en las ciencias de la vida revisaré la articulación entre los conceptos teóricos y las prácticas sociales, hurgando en las formas legitimadoras, por ejemplo, del dominio de la humanidad (occidental) sobre la naturaleza, o de unos seres humanos sobre otros (mujeres, esclavos, no-humanos, etc.).

\section{El origen aristotélico del orden jerárquico de la naturaleza}

La ciencia moderna tiene sus antecedentes más directos en las propuestas de los filósofos griegos de la antigüedad clásica, a pesar de manifestar su rechazo hacia ellos. ${ }^{40}$ En este contexto, y en relación al conocimiento del mundo vivo, se concede a las observaciones y propuestas elaboradas por Aristóteles la validez de un orden natural, una norma de lo que es naturalmente correcto.

El filósofo estagirita, particularmente dedicado a indagar sobre organismos vivos (Guthrie 1981, Lloyd 1977), encuentra en ellos el principal justificativo para fundamentar la idea de orden asociada a la teleología. En Sobre las partes de los animales sostiene

"En las obras de la naturaleza se comprueba particularmente la ausencia del azar y el servicio de finalidades. Y el fin para el cual han sido construidas o han llegado a ser pertenece a la categoría de lo bello" (citado en Lloyd 1977, 157).

Aristóteles ordenó los seres vivos de acuerdo con su grado de organización, señalando que la naturaleza progresa desde los seres más simples hasta los más complejos, dando lugar a las llamadas escalas naturales (Maquinistan 2004).

\footnotetext{
${ }^{40}$ Vale aclarar que, a pesar de las continuidades de las jerarquías y estructuras categoriales aristotélicas en la modernidad que se reconocen en este capítulo, tal como reconoce Merchant (1980) la Ilustración moderna produce un giro en la cosmovisión de la técnica, cuya dimensión baconiana será decisiva para las consecuencias sobre la problemática focal de la tesis.
} 
La propia noción de naturaleza es vista por el filósofo como el origen y finalidad de los seres, porque, a decir del estagirita, permite dar cuenta tanto de lo que crece como de su principio constitutivo.

"Naturaleza... es la materia primera... y también la forma y la ousía /la causa formal, lo que es ser esto/, es decir, el fin de la generación... la materia es naturaleza por el hecho de recibir en sí misma a la naturaleza... Y ella es el principio del movimiento de los seres naturales, en cierto modo inherente, sea que existan en potencia sea que existan en actividad" (Met. V. 1015a)

En la propuesta aristotélica se sostiene que todos los seres se mueven naturalmente hacia su fin, que es su propia perfección. Dentro de su doctrina de las cuatro causas, la causa final es la que permite justificar la existencia y valoración diferenciada de un cierto ente o fenómeno. Porque a los ojos de Aristóteles, todo lo creado por la naturaleza -o por el hombre- tiene un fin, una función particular que explica su existencia y determina su generación, que se establece en un universo continuo y ordenado.

En su Historia de los Animales, Aristóteles se dedica particularmente a subrayar la continuidad entre el mundo inanimado y el orgánico indicando que

"La naturaleza avanza poco a poco desde lo inanimado hasta la vida animal, de una manera que es imposible determinar exactamente, cuál es el límite de demarcación, ni a qué grupo podrían pertenecer las formas intermedias" (Historia de los Animales. VIII. $588 b)$.

Una continuidad que, sin embargo no impide valorar las diferencias. Porque la continuidad entre los seres no impide catalogarlos en relación a un orden de perfección. La propuesta aristotélica conecta la noción de finalidad con la de orden universal. Porque el filósofo entiende que cada parte del ser vivo se ha desarrollado a partir de sus partes más pequeñas hasta formar partes más complejas, con vistas a cumplir una finalidad en un cuerpo, que a su vez cumple una finalidad en el Universo.

Ahora bien, estas finalidades se establecen en función de jerarquías de dominio y control, porque las plantas existen para los animales, y éstos para el servicio del hombre, porque es el género humano el que se destaca por valerse de la técnica y del 
raciocinio (Met. I. 981a). La jerarquía que se establece permite incluso una valoración diferenciada,

“...los animales domesticados valen naturalmente más que los animales salvajes, siendo para ellos una gran ventaja, si se considera su propia seguridad, el estar sometidos al hombre" (Pol. I.2).

La continuidad entre los seres no traba un ejercicio de dominio diferenciado, donde uno de los animales -el hombre- rige sobre todo el conjunto de seres, animados o no.

"Así, el hombre puede domesticar a los animales para que le provean de alimento y vestido. La naturaleza, que no hace nada en vano, ha hecho a todos los animales para provecho del hombre. Esta es una clara aplicación del supuesto teleológico que guía toda la investigación social y biológica del Estagirita. La estructura jerárquica de la naturaleza fundamenta la organización de la sociedad civil que la reproduce”. (Femenías 1991, 88)

De esta escala natural (en el doble sentido asumido por el filósofo de Estagira) forman parte todos los seres vivos bajo el supuesto de que el ordenamiento se orienta a la perfección del todo. Es una pirámide que se orienta en función de todas las fuerzas propias que deben convertirse en acto. Seguir este orden, esta teleología, es respetar la naturaleza, el orden virtuoso establecido, desde aquí dejarse utilizar y usar, a o por, otros seres, es legítimo en tanto se respeten las finalidades y las tendencias hacia la perfección. Por oposición las deformaciones y monstruosidad provienen de las cosas y seres que no actúan de acuerdo con este concepto del Orden Universal.

Ahora bien, el mundo de Aristóteles no sólo es ordenado sino que también es fijo. Desde esta visión se entiende que los seres vivos no pueden transformarse a través de las sucesivas reproducciones (Cecchi et al. 2001). Los seres vivos son, en su concepto, entes naturales finitos cuya generación adviene por absoluta necesidad. La reproducción es entonces el modo de eternizar lo finito. La existencia se funda en un propósito final que precede y determina la génesis. La teleología trasciende entonces cualquiera de las manifestaciones materiales de la vida. 
En este esquema, el orden que se reconoce no sólo implica una estructura explicativa sino también una cierta forma de dominio y control entre las partes. En las primeras referencias mencionadas sobre el orden Aristotélico, María Luisa Femenías (1996) señalaba que "La estructura jerárquica de la naturaleza fundamenta la organización de la sociedad civil que la reproduce", una sociedad civil que permite ilustrar la dimensión del dominio que se supone como vínculo del orden universal instituido. Aristóteles sostiene que la obediencia y la autoridad es parte fundamental del orden. La presencia de ambos

"es una condición que la naturaleza impone a todos los seres animados, y algunos rastros de este principio podrían fácilmente descubrirse en los objetos sin vida: tal es, por ejemplo, la armonía en los sonidos" (Pol. I.2).

La autoridad y la obediencia son reconocidas por el estagirita dentro de los seres donde el alma manda al cuerpo- y proyectada en toda la organización. Cualquier tendencia a la igualdad o dislocación de poder es evaluada como contranatura para todas las partes implicadas. En la relación del amo y el esclavo, entre el hombre y los demás animales, en la relación de los sexos; el uno es considerado superior al otro. "Éste está hecho para mandar, aquél para obedecer" (Pol. I.2).

El fundamento último del control es el ejercicio de la razón, potestad del alma de los hombres-varones. La jerarquía de Aristóteles se funda en una teleología inapelable, por la cual algunos seres desde el momento de nacer están destinados a obedecer y otros a mandar. La fuerza de la autoridad, sin embargo, no se reconoce sustentada desde la violencia, ya que el propio Aristóteles discute la legitimidad de tomar como esclavos a los perdedores de las guerras. Las formas de dominio aristotélicas están basadas en el consenso. El filósofo insiste en que la situación óptima de las partes se obtiene cuando actúan en forma coordinada respetando los sitios jerárquicos diferenciados, donde el ejercicio de la razón de unos es suficiente motivo para que asuman el gobierno, control y propiedad de los otros. Así, aún separándose de las formas más directas de control a partir de la violencia, se legitima la utilización de estrategias coercitivas para sostener el orden que se considera legítimo. Desde este esquema, las resistencias al orden pueden ser vistas como incomprensiones de las mentes menos favorecidas, cuyo ejercicio de rechazo puede fundamentar el acto de dominio. 
La discriminación en general se cubre bajo la imagen de protección, el ejercicio de poder diferenciado es lo mejor para todas las partes. Así por ejemplo la relación entre el marido y la esposa es caracterizada por Aristóteles como "Amistad entre desiguales" (Femenías, 1996, 50). Aristóteles sostiene que las mujeres son inferiores a los varones como regularidad que se proyecta sobre toda la humanidad, aunque la relación entre varones y mujeres se caracteriza por involucrar afecto y placer, que por ser asimétricos no dejan de estar presentes. Esta es una diferencia respecto a las situaciones entre los amos y los esclavos, porque los esclavos no dejan de ser más que propiedades vivientes, son personas que no se pertenecen a sí mismos, que se ven beneficiados por pertenecer a otro. Ese otro, el varón de la pareja, el amo del esclavo, quien detenta la razón, quien tiende al máximo grado de perfección de la humanidad.

Desde la mirada de Aristóteles, las diferencias en las jerarquías entre los seres del mundo se establecen tomando como medida a la razón. En el capítulo precedente expuse, desde los escritos de Bordo (1986), Shiva (1988) y Merchant (1980) los sesgos que se incorporan en la sobre valorización de esta razón androcéntrica y excluyente. En la presente exposición resulta aún más evidente que es el ejercicio de la razón la característica que se asume como distintiva de lo humano, y sobre la cual se fundamenta el ejercicio del dominio. Se apela a que los seres sobre los que se ejerce la autoridad son, en algún grado, menos perfectos y se benefician más en la obediencia que en la libertad.

La pregunta que permanece en el horizonte se refiere a la ciencia ecológica. Porque el mapa de conocimiento biológico que favoreció la conformación de determinados modos de dominio, está lejos de haber permanecido fijo. Sin embargo no es necesariamente claro que tanto dominio como jerarquía, edificados en la antigüedad clásica desde observaciones biológicas, se hayan removido totalmente del conjunto de supuestos sobre los que se erige la disciplina moderna. Por ello me remitiré a los cambios que se introducen en los conocimientos de la vida a partir del siglo XVII, base directa de las ciencias biológicas actuales.

\section{El orden taxonómico}

Carolyn Merchant (1983) explora el contexto histórico del período en que se asientan las bases de la ciencia moderna. Su trabajo explicita la mutación de las metáforas en 
relación con la naturaleza, imágenes que en sí conceptualizan el cambio de vínculos que se constituyeron en el período reconocido como Revolución Científica. La autora señala que entre los siglos XVII y XVIII la imagen de un cosmos orgánico, que en su centro tenía la imagen de una "madre" tierra, femenina y viva, fue dando lugar a una perspectiva mecanicista del mundo, donde la naturaleza fue reconstruida como muerta, pasiva, destinada a ser dominada y controlada por los seres humanos. Con la revolución científica se introduce la idea de "control" sobre la naturaleza y con esta incorporación se modificaron actitudes y comportamientos humanos respecto de la tierra, avanzándose en el proceso de comercialización e industrialización, que dependen de actividades que alteran la tierra.

En este contexto de cambio de imágenes y metáforas, de desmitificación, en biología se recupera la scala naturae aristotélica. La incorporación de esta idea, que ubica todos los cuerpos orgánicos e inorgánicos de la naturaleza en una escala ascendente que va desde las rocas hasta el hombre, en una jerarquía que lejos de presentarse sólo como esquema operativo, involucra evaluaciones valorativas, porque se asume que la también denominada Gran Cadena de los Seres fundada por Aristóteles, recorre los organismos en una escala de perfección ascendente. Perfección que se define a partir de la Razón humana, que por ser medida de jerarquía es, de forma asociada, el fundamento del dominio. John Locke, en su Ensayo sobre el entendimiento humano comienza la obra con las siguientes palabras "Puesto que es el entendimiento lo que coloca al hombre sobre el resto de los seres sensibles y le proporciona dominio sobre ellos, constituye por su nobleza un tema merecedor de ser investigado", una visión que se reproduce más o menos explícitamente en pensadores del período Buffon, Anderson, Linneo, entre otros.

La Gran Escala de los Seres es el planteo material de la idea, siendo el naturalista francés Charles Bonnet, uno de los observadores más preocupados por dar forma tangible al concepto. En su Tratado de la Naturaleza (1765) ubica a todos los cuerpos orgánicos e inorgánicos en la naturaleza en una escala ascendente que va desde las rocas hasta el hombre (ver gráfico 2). Siguiendo la conocida expresión del filósofo alemán Leibnitz "Natura non faict saltum", Bonnet sostuvo que estas escalas de seres eran absolutamente graduales. El objetivo de los naturalistas, desde esta perspectiva, sería dar cuenta del total de organismos existentes a fin de completar los pasos intermedios 
entre los diversos grupos, y a ello se abocaron muchos de los estudiosos de la naturaleza del período.

La escala de Bonnet, que se reproduce en la Figura 1, presenta la continuidad jerárquica desde la tierra hasta el hombre, pasando por las diferentes especies de seres vivos, también ordenadas por rango. A grandes trazos esta organización, de menor a mayor presenta a minerales, vegetales, animales inferiores (invertebrados), animales superiores (mamíferos), que también se subdividen para llegar al reconocimiento de ser humano como el ser con mayor grado de desarrollo, y por ello el soberano natural del mundo.

De este modo, la escala de Bonnet no sólo plantea un orden con fines investigativos, también presupone una cierta vinculación. El mayor grado de desarrollo implica el derecho a usar a los seres asumidos como menos desarrollados.

\section{Gráfico No 2}

La Gran Escala de los Seres presentada por Bonnet 


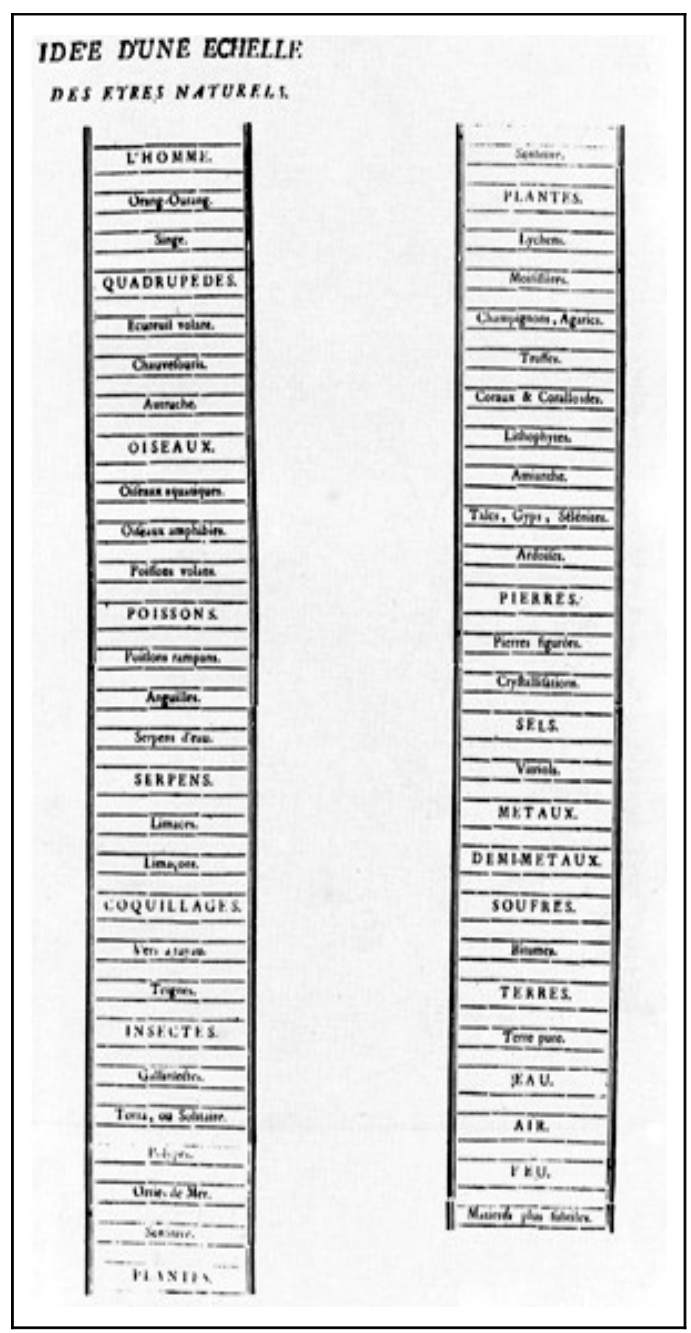

En general la idea de continuidad era compartida por los naturalistas de la época. Esta escala, que además presenta un orden que se entiende como inmutable, representó para la mayor parte de los naturalistas el reconocimiento de un plan cuya organización permite reconocer una intención divina. Esta escala era reconocida como fundamento de las principales reflexiones biológicas de la época (Maquinistian 2004). De hecho, tanto la escala como la continuidad formaron parte de los fundamentos del padre de la taxonomía moderna, Carl von Linné más conocido como Linneo, naturalista sueco que se guió por el objetivo de demostrar la grandeza de Dios.

Linneo se preocupó especialmente por el modo de organizar a los seres. La clasificación de los seres era una deuda pendiente, y en general las colecciones respondían a criterios reconocidos como arbitrarios. En Aristóteles no existió una clasificación absoluta, ya que en sus diferentes trabajos organiza a los seres vivos a partir de distintas características funcionales (Cecchi et.al. 2001). Las categorías se superponen, tal como lo indica el propio estagirita, muchas veces se solapan los géneros, pues ni los bípedos 
son todos vivíparos u ovíparos -ya que las aves y los seres humanos son bípedos-; ni los cuadrúpedos son todos ovíparos o vivíparos -pues caballos, vacas y lagartos pertenecen a esta categoría (Aristóteles Tratados breves de historia natural).

El naturalista sueco Linneo compartió con la herencia aristotélica que lo precede que las especies son entidades de existencia real en la naturaleza, señalando en su Philosophia botanica (1751) que "hay tantas especies como formas diferentes ha producido desde el principio el Ser Supremo". Para el estudioso sueco, el trabajo de los naturalistas era reconocer todas las especies creadas, dándole nombre para luego registrarlas, describirlas y, finalmente, clasificarlas. De este modo asume una naturaleza fija, organizada y susceptible de ser explicada en función de caracteres esenciales.

Como su estudio se inicia con la observación de plantas, los primeros criterios clasificatorios los toma en este terreno. Linneo entiende que los órganos sexuales de las plantas (estambres y pistilos) son fundamentales en las plantas, y los toma como referencia absoluta del orden que plantea, sobre valorándolos respecto de los demás órganos (Maquinistian 2004). A pesar de su compromiso continuista, plantea la división de los seres en tres grandes reinos discretos: mineral, vegetal y animal. Una división que resultó problemática, por ejemplo, para el caso de los infusorios, que en las primeras organizaciones se encuentran entre los vegetales y las revisiones posteriores los ubica entre los animales (Osorio 2007). Es de destacar que el continuismo del botánico sueco no le impidió formalizar una categorización con separaciones absolutas.

El orden planteado por Linneo signó el desarrollo de la biología, que sostuvo el criterio organizativo en el interior mismo de las categorías, establecidas en función de ciertos órganos que se tomaron como fundamentales. Desde estas consideraciones Linneo estableció el sistema de nomenclatura binaria (que se utiliza hasta el día de hoy), que consiste en denominar a todo ser vivo con dos nombres: el primero, que indica el género y el segundo, que nombra a la especie.

Ahora bien, a pesar de que el continuismo y la jerarquía no se discutían, la posibilidad de categorizar a partir de ciertos aspectos fijos sí tenía detractores. Por ejemplo, Michael Adanson, botánico francés del siglo XVIII, también reflexionó sobre las posibles clasificaciones. En relación al tema reconocía que las formas de ordenar a los seres vivos se dividían entre artificiales y naturales. Los modos artificiales eran los que 
tomaban un carácter como "distintivo", como contrapartida las clasificaciones naturales surgían al considerar al conjunto de caracteres. Consecuentemente Adanson entendía que la clasificación de Linneo era artificial. A esto agregaba que la confianza del sueco en relación a la existencia de las especies también debía discutirse, ya que -desde una posición nominalista- entendía que los géneros y especies son categorizaciones impuestas por los observadores y no entidades per se. En este sentido, Adanson puede vincularse con las reflexiones de Locke, quien en su Ensayo sobre el entendimiento humano (1690) señala

“... la naturaleza elabora muchas cosas particulares que concuerdan unas con otras en muchas cualidades sensibles, probablemente también en su constitución interna; pero no es esta esencia real lo que la distingue en especies; son los hombres quienes, fundándose en las cualidades que hallan unidad...las ordenan como bajo una enseña $[\ldots]$

No niego la naturaleza [...] pero considero que los límites de las especies por los cuales los hombres las ordenan son hechos por los hombres" (Libro III, cap.III "de las palabras", 149-150)

Georges Luis Leclerc o Buffon, atacó con particular énfasis las ideas de Linneo, con argumentos similares a los de Adanson (Maquinistian 2004). Este naturalista (considerado como antecedente a la teoría evolutiva), menciona la existencia de especies desaparecidas y el impacto del tiempo. En su Dégénération des animaux (1766) indica

"no es ni el número ni la colección de individuos parecidos lo que hace a la especie, sino la secesión y la renovación ininterrumpida de los individuos que la constituyen... La especie es una palabra cuyo referente no existe en la realidad más que considerando la naturaleza en la sucesión de los tiempos" (citado en Maquinistian 2004, 50).

Buffon suponía una degradación continua, considerando que las formas actuales presentaban caracteres degenerados respecto de la forma que los seres habían adquirido en el origen de los tiempos. Estas observaciones retornaban al naturalista francés a postular que lo que observamos no son más que individuos, y cualquier organización o agrupamiento de los mismos es una incorporación artificial. 
Estas impugnaciones, sin embargo, no generaron mayores respuestas de Linneo, cuyo sistema binario fue progresivamente incorporando más adeptos, llegando a ser valorado como la inauguración del sistema racional de clasificación (Guyénot 1956). Es decir, la razón en la que se basa la biología asume jerarquías y formas de control fundantes. Así la organización del mundo natural, en sus orígenes racionales, admite las diferencias y legitima el dominio.

Uno de los ejemplos más claros en este sentido proviene de las reflexiones de los naturalistas alemanes, en la naturphilosophie, que se diferenciaron de los franceses por privilegiar los estudios zoológicos sobre los botánicos. ${ }^{41}$ Desde una notable impronta kantiana, los alemanes se interesaron particularmente por las actividades de la mente humana y plantearon que cada organismo era simplemente la modificación de un plan único, un arquetipo (Maquinistan 2004).

Desde esta visión, que se reconoce mayormente desde las revisiones de la historia de la teoría evolutiva, se ha privilegiado el reconocimiento que la naturphilosophie otorga a las modificaciones que el tiempo introduce al arquetipo. Menos atención ha recibido la forma de control que se asume, cuyos principios pueden resumirse en cuatro puntos (Hartman 1960, Gilson 1980)

- La unidad de la naturaleza y sus leyes. El hombre como la más alta expresión de la materia sobre la tierra.

- La existencia en la naturaleza de una tendencia al desarrollo progresivo.

- Los procesos naturales desplegándose en una única dirección (entre ellos, desarrollo individual y progresión de especies).

- Considerar que el desarrollo y la progresión son gobernados por las mismas leyes, dando lugar a una proyección biologicista sobre variables sociales.

Estas referencias hacia el modo de concebir la naturaleza, resultan claves a la hora de indagar en el cómo se ha comprendido a la sociedad. Porque las principales corrientes de las ciencias sociales, e incluso gran parte de las corrientes críticas, compartían una idea de progreso necesario y continuo, propio del proyecto iluminista, en el sentido que Max Horkheimer y Theodor Adorno (1997) lo presentan.

\footnotetext{
${ }^{41}$ Ver capítulo uno.
} 
Volviendo a la biología como disciplina científica, debo señalar que la teoría fundamental de la biología moderna, esto es la teoría evolutiva, revisa y discute profundamente el fijismo, pero no asume como parte de los presupuestos a las nociones de jerarquía, sobre todo en lo que se refiere al predominio de la razón instrumental como fundamento del conocimiento y del dominio asociado. En este sentido resulta interesante indagar en el modo en que se introdujo el debate en relación al fijismo, analizando los supuestos que se remueven en el mismo.

En el siglo XVIII tanto en Francia como en Alemania, desde distintas perspectivas, degeneración o arquetipo, se comenzaba a pensar en el tiempo como artífice de cambios que llevaron a las especies a sus formas actuales. Sobre este debate se incorporó otro, menos conocido, en relación a la idea de seres superiores e inferiores, ambos debates fueron inaugurados con claridad por Jean Baptiste Pierre Antonie de Monet, más conocido como Lamark. Una de las figuras menos reconocidas en su tiempo y en la historia de la biología (Guyénot 1956, Senet 1971, Núñez 1990).

Lamark compiló, sobre todo, las ideas de naturalistas franceses como Adanson, Buffon, Bonnet, Robbinet, entre otros. Defendió acérrimamente la idea de cambio en las especies, provocando un notable controversia con Georges Cuvier, quien argumentaba que las diferencias entre las especies actuales y aquellas que poblaron la tierra se debió a catástrofes naturales que provocaron sucesivas creaciones. En su época las ideas de Couvier triunfaron sobre las de Lamark, siendo este último reconocido posteriormente como antecesor de Darwin.

Sin embargo, en el tema que nos ocupa, el trabajo de Lamark resulta de interés por sus reflexiones en relación a la escala de los seres. En la introducción a su obra Filosofía zoológica, el naturalista francés reconoce en el estudio de los "objetos pequeños que ofrece la naturaleza" los fundamentos para las leyes. Al respecto llama la atención sobre el estudio de los seres que define como invertebrados que reconoce, han sido poco menos que ignorados en los estudios naturales. Reclama que los observadores de la naturaleza, desde sus orígenes, se abocaron a la indagación de los seres vertebrados en parte, según Lamark, porque los seres sin vértebras se caracterizan por tener facultades limitadas y poseer órganos con escasa analogía a los humanos. 
Antes de Lamark los ahora invertebrados eran conocidos como seres inferiores, en directa alusión al sitio de reconocimiento que tenían en la jerarquía implícita en los estudios. Esta referencia merece ser observada a la luz de la propuesta de Donna Haraway (1999). La filósofa norteamericana propone tener en cuenta a la naturaleza como construida "como ficción y como hecho" en el sentido que si se trata de reflexionar sobre organismos, se debe tener en cuenta que los mismos "... no nacen; los hacen determinados actores colectivos en determinados tiempos y espacios con las prácticas tecnocientíficas de un mundo sometido al cambio constante." (Haraway 1999, 123). Esta mención resulta particularmente provocadora en el contexto nominativo sobre el que se instala Lamark, los seres inferiores no sólo eran biológicamente más simples, también eran más susceptibles de ser usados o destruidos por los seres más complejos o superiores. Siguendo a Haraway, no se trata exclusivamente de discutir al organismo biológico por separado sino a la multiplicidad de relaciones que se establecen con el mismo a partir de su construcción social como ser vivo.

Pero las consecuencias de esta construcción no sólo se establecen en términos de dominio. Lamark llama la atención sobre las confusiones a las que llevó la sobreestimación de los caracteres humanos. Asume, como los naturalistas de la época que el humano es el organismo vivo de mayor complejidad, por lo cual asocia la idea de perfección a la figura humana. Pero discute que efectivamente sirva de referencia a las causas de la vida, que entiende se encontrarán con mayor claridad en los seres más sencillos.

En este sentido menciona que para la producción del sentimiento, la característica que según Lamark diferencia a la humanidad del resto de los seres vivos, es necesario que el sistema nervioso esté ya muy perfeccionado, y más aún para poder dar lugar a los fenómenos de la inteligencia que reconoce sobre todo en los humanos. ${ }^{42}$ Asimismo indica que, esta referencia compleja ha llevado a ignorar, por ejemplo, que los seres invertebrados

" $1^{\circ}$ resultan mucho más numerosos en la naturaleza que los animales vertebrados. $2^{\circ}$ siendo más numerosos resultan más variados naturalmente, $3^{\circ}$ las variaciones en su organización son mucho más grandes, más marcadas y más singulares, y $4^{\circ}$ el orden que emplea la Naturaleza para formar sucesivamente los diferentes órganos de los animales,

\footnotetext{
${ }^{42}$ Vale destacar que Lamark se aleja de la idea de Razón como medida de la diferencia. La inteligencia es producto de la complejidad del sistema nervioso, que se manifiesta desde los sentimientos.
} 
se encuentra mejor expresado en las imitaciones que estos órganos sufren en los invertebrados y hace su estudio mucho más propio para hacernos descubrir... el origen mismo de su organización" (Lamark, Introducción, XIX y XX)

Lamark reclama en contra de esta mirada antrópica que indaga tomando un modelo que oculta particularidades. El argumento, sin embargo, no discute la supremacía humana en función de la razón, sino que argumenta desde esa misma razón. Se opone a buscar las causas de la vida en las causas de un carácter propio de la especie humana, el sentimiento. El naturalista francés, desde su estudio de los invertebrados, argumenta que no todos los seres vivos detentan sensibilidad, pero asumir como medida ineludible lo humano, conlleva necesariamente referencias hacia este elemento específico. Incluso propone una indagación en un sentido contrario para dar cuenta de las particularidades de la humanidad, que entiende asociadas tanto a lo físico como a lo moral, porque para el naturalista francés "En su origen lo físico y lo moral constituyen sin duda la misma cosa" (Lamark, Introducción, XV). Fundamentó así la idea de la dependencia orgánica de los fenómenos psíquicos (Cupani 2006) y argumentó hacia una estrategia de indagación que partiera de los organismos más simples, reclamando el estudio de la sensibilidad como fenómeno particular de algunos organismos vivos entre los que se destaca el hombre.

Más allá de las fuerzas que Lamark reconoce para el cambio en las especies -el clima y las circunstancias- en el presente escrito el trabajo del naturalista francés da cuenta de la creciente incorporación de seres vivos desde sus particularidades, rebatiendo que el estudio deba partir de consideraciones antropocéntricas, pero sin discutir el sitio de mando que se reconoce a los seres humanos sobre el resto de los organismos vivos. Tal es así que entre las variables que Lamark postula para lograr la posición erguida del ser humano está "la necesidad de dominar, de ver a lo largo y a lo ancho" (Lamark, 234-235). Es en el deseo de control y dominio, nos indica Lamark en su capítulo Algunas consideraciones relativas al hombre, donde los seres humanos fueron adquiriendo las particularidades que los distinguen sobre el resto de los seres vivos, como su organización social, la difusión de ideas y el habla. ${ }^{43}$

\footnotetext{
${ }^{43}$ No debe perderse de vista en la indagación sobre la vida, el marco de ideas sobre los que se desarrollan los estudios biológicos. Voy a retomar una mención muy somera del caso de Linneo en que se hacía referencia a su propuesta como parte de la búsqueda de la glorificación de Dios. El marco de creencias cristianas es un horizonte ineludible en los debates científicos, y la idea de dominio no sólo está atravesada por el conjunto de observaciones sobre el mundo, sino desde el mismo Génesis bíblico, en que en el mismo proceso de creación, Dios le otorga al hombre (macho y hembra) derecho sobre todos los seres vivos, plantas y animales, para cumplir con el mandato crecer, multiplicarse, poblar la tierra y
} 
Escapa a las pretensiones del presente escrito el revisar las reflexiones relativas a las teorías evolutivas. De allí que omitiré mayores reflexiones sobre la edificación de las teorías biológicas, saltando a la figura fundamental de la teoría evolutiva: Charles Darwin. El objetivo de la presente reflexión no es explicar el modo en que se fue constituyendo la biología como disciplina sino dar cuenta del modo en que se fue naturalizando la visión jerárquica. Desde fines del siglo XVIII y principios del XIX encontramos cada vez con mayor claridad que el dominio, que se fundamentaba en la actualidad desde las observaciones biológicas, es un supuesto que se asume. Ernet Haeckel, biólogo que incorpora el término ecología en la biología a mediados del siglo XIX, encuentra en la obra de Lamark la idea de hombres inferiores o primitivos, que se elevan por sobre el resto de sus pares al erguirse, una posición desde la cual mejoran sus actividades intelectuales. Haeckel se diferencia de Lamark en que no considera tanto al sentimiento como a la razón la característica distintiva de la humanidad y a la posición erguida el fundamento biológico de la misma. Una idea que puede considerarse como herencia de Galeno, ya que el médico griego tomaba a la postura erecta como símbolo del dominio sobre la naturaleza (Peset 1983).

La validez jerárquica no se discute. La biología, que fundamenta en sus orígenes la diferencia, asume la desigualdad en el control como parte de los vínculos naturales, abandona progresivamente el tema en la medida en que se va constituyendo como disciplina científica moderna. Desde este relato encontramos que la ciencia se fundamenta y edifica a partir de preconcebir un mundo jerárquico, la razón humana se constituye, como indicaron Horkheimer y Adorno (1997), en la naturalización del dominio occidental moderno. Las ciencias biológicas abandonan el tema del dominio humano como parte del recorte erotético disciplinar; una omisión que está lejos de ser ingenua, porque al desconocer el tema evitan su remoción conceptual, naturalizando las formas jerárquicas de relación entre la humanidad y su entorno.

Así, en los orígenes de la biología moderna, en el siglo XVII, se encuentran supuestos explícitos en términos de control y jerarquía que ya en el siglo XX se omiten. El proceso de omisión eclipsa las referencias pero no necesariamente las pierde. De hecho considero que tanto dominio como jerarquía están presentes a lo largo de las observaciones naturales del siglo XIX aunque en un modo diferente respecto del XVII. Las referencias ya no abordan el conjunto de los seres vivos, que se toman al servicio de someterla. 
las producciones humanas sin mayores problematizaciones. Sino que los debates sobre las distinciones se profundizan en torno a las características de los seres humanos como especie. La biología como área de estudios se fue especializando en ramas disciplinares específicas que perdieron de vista el tema de la organización jerárquica general. La explicita antropología física, abocada al estudio de los caracteres humanos observables. Puede pensarse que en este deslizamiento de áreas de estudio, que de naturales se trasladan a sociales, el tema de las jerarquías, las desigualdades y los dominios se desliza hacia un plano que en sí mismo no contiene los fundamentos.

Pero la pregunta por la jerarquía no dejó de instituir formas de relación desiguales, con consecuencias críticas en las relaciones humanas. En función de las diferencias observables entre las personas se legitimó el control de uno sobre otros. Idea que no es muy diferente al antiguo planteo de Aristóteles, pero que contribuyó a legitimar otras jerarquías, por ejemplo, la basada en el color de la piel.

Esta fundamentación se opuso, sobre todo, a reflexiones precedentes que hacían alusión al derecho a la libertad de todos los seres humanos. A fines del siglo XVIII en Estados Unidos era usual la referencia hacia la igualdad teórica entre las razas humanas. Esta perspectiva hacía cada vez más discutible la esclavitud y en el período cercano a la independencia de este país los alegatos en este sentido cobraban cada vez más lugar (Peset, 1983). Sin embargo, ya entrado el siglo XIX, la ciencia se toma como fundamento de la existencia de esclavos al argumentar sobre el origen diverso de las razas a partir de los estudios de cráneos. Samuel George Morton publica en 1842 Brief Remarks on the Diversities of the Human Species, en el cual no sólo argumenta a favor de la diversidad de orígenes humanos, sino sobre la imposibilidad de mejorar las razas inferiores (Peset 1983). El fundamento que subyace a la idea de dominio es el de las capacidades intelectuales. Morton, entre otros autores como William Frederick van Amringe o John van Evrie, avanzan sobre la idea de que tanto los cerebros de los animales (no-humanos), como los de las razas inferiores, son menores a los del hombrevarón-blanco. Los motivos son fundamentalmente ambientales: las zonas que habitó, el clima que enfrentó y el escenario al cual se adaptó. Desde estas consideraciones se concluía que este hombre tenía como ser vivo el lugar de conquistador del mundo. Un dominio, que no sólo se proyecta hacia la naturaleza y otros grupos humanos, sino que asume a las mujeres como naturalmente dependientes, incorporando la desigualdad 
hacia el interior de cada grupo étnico, donde la población femenina se reconoce como subordinada a la masculina.

La visión regente a mediados del siglo XIX refunda un mundo organizado desde la idea de dominio, donde las luchas $-\mathrm{y}$ no los acuerdos- se entienden como determinantes de las relaciones que se viven en el mundo. Esta perspectiva impacta entre las vinculaciones que se reconocen entre los organismos, destacándose la obra de Charles Darwin El origen de las especies, donde argumenta a favor de la competencia por los recursos como motor de la evolución. Las interacciones entre los organismos, a pesar de conocerse en sus formas cooperativa (interacciones positivas), como de enfrentamiento (interacciones negativas) se reconocen como fundamentales cuando adoptan la segunda modalidad (como también se observa en la historia de la ecología expuesta en el primer capítulo). Tal vez la adopción de las interacciones negativas permite asumir de forma más directa las jerarquías y la naturalización de las formas de dominio.

El privilegio otorgado a las interacciones negativas se fue incrementando en paralelo a la especialización biológica. A fines del siglo XIX encontramos la profesionalización de diferentes ramas de estudio, que progresivamente se fueron separando de los temas humanos. El problema es que, aún cuando posteriormente se demostraron que las evidencias cientificas que justificaban el esclavismo o el reconocimiento de las mujeres como menores de edad, carecían del sustento racional del que habían sido investidos en su origen, las formas de dominio que se habían legitimado no necesariamente se removieron.

Hoy en día sería discutible que un científico sostuviera, como Galeno o Lamark, que la posición erguida justifica el dominio sobre la naturaleza. Pero también sería discutible que un científico natural asumiera como tema disciplinar el problema del dominio, aún cuando su propia disciplina ayudó a edificarlo en períodos que, tal como muestra Carolyn Merchant (1980), se presentaban visiones y metáforas que se oponían a la cosificación de la naturaleza y dominio exclusivo de una de las partes

\section{El ocultamiento de las tensiones}


Ahora bien, con los cambios acontecidos en las diferentes ramas de la biología ¿podemos pensar que esta amplia área de estudios aún sostiene diferencias vinculadas a las que ayudó a construir en sus orígenes? Más específicamente, la ecología ¿acompaña en la actualidad el sitio de dominio reconocido a la humanidad? Si esto es así, ¿qué desafíos afronta la ecología por su particular recorte temático?

Para responder estos interrogantes debemos tomar en consideración a la historia disciplinar pero también a la apropiación social del saber producido. Como observábamos en el primer capítulo, la historia de la ecología está profundamente imbricada con la de la teoría evolutiva aún cuando no resulte reducible a la misma (Haila y Taylor 2001). En ambas áreas de investigación biológica han acontecido enormes cambios. Pero si se avanza sobre el análisis estricto de las modificaciones teórico-metodológicas, aun perviven los ecos de fundamentos jerárquicos. Las ciencias biológicas, y la ecología en particular, se alejan de su sitio legitimador de formas de dominio, pero antes que desmontarlo, lo ocultan.

La primacía del conocimiento científico se fue fortaleciendo en modo paralelo a la problematización de las jerarquías en el mundo orgánico pero, y en esto es fundamental la referencia a la historia de ecología, sin revisar el determinismo de las interacciones negativas. El dominio, la lucha por el control, siguió siendo la explicación fundamental del porqué el mundo es como es. La filosofía de la biología se asumió como la de la teoría evolutiva (Ruse, 1990) y la vinculación entre los organismos se focalizó en términos de competencia. En este proceso, donde una interacción se asumió como válida y fundamental, la revisión de la escala de los seres no implicó la revisión de los vínculos de uso que se establecieron. Desde la ciencia no se retomaron las metáforas organicistas que en el siglo XVII disputaban el orden del mundo que se planteaba en la escala de los seres, pero ello no impidió que se levantaran otras argumentaciones. Desde los diversos ambientalismos empezaron a discutir el discurso científico, tal como se observó en el capítulo dos.

Por otro lado, la ecología, como las ciencias naturales en general, ha visto incrementar su reconocimiento al mismo tiempo que se ha asumido como metodología fundamental la reducción de la complejidad observada en el mundo orgánico a un cierto número finito de preceptos, edificados a través de patrones y análisis estadístico; proceso de indagación que en adelante denominaremos reduccionismo. En este proceso la 
reducción no sólo es ontológica sino también epistemológica. Este segundo modo trata de asumir marcos teóricos de una disciplina como un recorte de otra que se presenta como ontológica y teóricamente más básica. Un esquema que fue guiando el desarrollo disciplinar de la ecología. El enorme impacto logrado desde la física nuclear y la biología molecular se presentaron como fundamento para plantear la prioridad de ciertas perspectivas metodológicas y escalas de estudio (Brown et al. 2003, 2004a, 2004b). Reflexiones que traen ecos de las palabras de Francis Crick (uno de los descubridores de la doble hélice), quien en 1996 sostenía que toda la complejidad y dinamismo de la vida (humana y no-humana) podía explicarse desde la biología molecular.

Las variables biológicas (no humanas) se presentaron como determinantes. Así, las ciencias sociales se presentaban reducibles a los factores biológicos, estos a los químicos que a su vez se contenían en los físicos (Caponi 2004). En esta línea tanto los temas ambientales como los sociales se fueron asumiendo como subsidiarios de disciplinas que se presentaban como fundamentales.

La jerarquía del conocimiento se fue estableciendo con reconocimientos diferenciados, cuidando la relevancia de las ciencias naturales, en cuya cima la física se consolidaba como modelo (Nudler 1999). En el sucesivo recorte de aspectos fundamentales otros tantos se perdieron de vista, tales como los condicionantes materiales y formas específicas de apropiación social del espacio que incide en los procesos biológicos (Marglin 1988). Los temas que siguen la vía de lo biológico ligado a lo social no escaparon de su carácter tangencial en los debates científicos (de Laplante 2004).

La desigualdad estructural se refleja y fortalece desde la ciencia con nuevas estrategias. La jerarquía en los seres se deslizó hacia el fortalecimiento en el reconocimiento del saber científico, que en si mismo contiene escalas. En este proceso la vocación dirigida a la observación fue girando hacia la experimentación y matematización. Las observaciones descriptivas perdieron valor como conocimiento científico (McArthur 1971) y los debates, en el caso de la ecología, se focalizaron en las estructuraciones de las comunidades de los ecosistemas.

En este deslizamiento de jerarquía de entidades a jerarquía de saberes se oculta el fundamento de dominio. Porque la ciencia, que avanza con la tecnología, escinde lo social de lo natural, desconociendo como problema el desarmar el esquema desigual que 
ayudó a edificar. La ciencia no se desarrolla en forma aislada respecto del campo del conocimiento y la cultura (Haraway 1999), aunque la dualidad humanidad/naturaleza permite eludir responsabilidades. Pero las teorías científicas atraviesan ineludiblemente el mapa del conocimiento social reconocido, formando parte de lo que Horkheimer y Adorno denominaron industria cultural. Desde este concepto los filósofos de la Escuela de Frankfurt revisaron, precisamente, los modos de ocultamiento de las diferencias y las desigualdades; al respecto señalan:

"Los interesados en la industria cultural gustan explicarla en términos tecnológicos. La participación en ella de millones de personas impondría el uso de técnicas de reproducción que, a su vez, harían inevitable que, en innumerables lugares, las mismas necesidades sean satisfechas con bienes estándares... los estándares habrían surgido en un comienzo de las necesidades de los consumidores: de ahí que fueran aceptados sin oposición. Y, en realidad, es en el circulo de la manipulación y de la necesidad que la refuerza donde la unidad del sistema se afianza cada vez más. Pero en todo ello se silencia que el terreno sobre el que la técnica adquiere poder sobre la sociedad es el poder de los económicamente mas fuertes... la racionalidad técnica es hoy la racionalidad del dominio mismo" (Horkheimer y Adorno 1997,166)

Para estos autores, el mismo proceso que oculta las diferencias inaugura la puerta a los privilegios. El ocultamiento no es independiente de intereses sectoriales. En esta línea argumentan que, uniendo la ciencia a la técnica y entendiendo a la naturaleza como campo de disfrute del hombre, se ha unido el destino de la ciencia al de la burguesía. El saber científico-tecnológico aparece como un componente integral del proceso de la iluminación de conquista del mundo (Abbagnano 1993). Una conquista que, a la hora de interpretar el mundo, parece privilegiar los factores biológicos sobre los sociales en una jerarquización solapada, pero fundada en presupuestos que no parecen tan alejados a aquellos de los albores disciplinares. Horkheimer, avanzando sobre esta línea de reflexión, entiende que la filosofía que presenta vincula la reflexión social con la comprensión de la naturaleza y de la historia. Por ello argumenta que la esclavitud de la naturaleza se transformará en esclavitud del hombre en tanto el hombre no sepa comprender su propia razón en el proceso que la ha creado (Abbagnano 1993).

Acuerdo con Donna Haraway (1999) en el carácter autoevidente de la ciencia como cultura, afectada por los procesos descriptos. Acompañada y sostenida desde una tecnología global que en un grado cada vez más importante parece desnaturalizar todo, 
edificando un determinado sentido de naturaleza, que presenta cualquier cosa como maleable a través de decisiones estratégicas y susceptibles de adecuarse a procesos de producción y reproducción móviles (Hayles 1990). La pervivencia de las jerarquías se sostiene desde esta desnaturalización o visión particular, a través de dinamismos que exploraremos en el siguiente apartado.

\section{Consecuencias empíricas de la pervivencia de jerarquías}

El problema de las jerarquías en el conocimiento no sólo se vincula al uso irresponsable o no sustentable de los recursos naturales, sino también al modo en que se evalúa la situación ambiental y las soluciones que se proponen. En esta línea Héctor Poggiese (2001) y Gustavo Lins Riveiro (2006) señalan que una de las grandes dificultades en la resolución de los problemas ambientales es la sobredimensión de los factores biológicos en los análisis, que dejan en un segundo plano los aspectos sociales implícitos. Como consecuencia de este sesgo analítico, los grupos humanos que resultan más perjudicados por las condiciones ambientales son los menos tenidos en cuenta, porque sus experiencias son prácticamente omitidas en las consideraciones. Las poblaciones pertenecientes a los países menos desarrollados (desde la lógica capitalista), en los sitios más alejados o pertenecientes a los sectores más vulnerables, se constituyen como grupos sociales con los mayores riesgos pero sin derecho a voz, o sin derechos en general, porque su propia subsistencia no se encuentra garantizada.

Un paréntesis particular merece, en este punto, la situación de la población femenina de estos grupos, que a las opresiones de clase o etnia suma la discriminación de género (Perez Nasser 1999, Lagarde 1993, Vazquez García 2007). El desconocimiento y la omisión de la particularidad del sector femenino en cada caso ha llevado a que buena parte de los programas que se suponen desarrollados para mujeres en función de un desarrollo planificado convergen en el incremento del trabajo para las mujeres (Joekes et.al. 2004), ignorando el conocimiento que ellas tienen sobre los recursos (Rocheleau 1995).

Acerbi y Barrenechea (1997), encuentran que las consideraciones ambientales que fundamentan sus conclusiones en procesos biológicos, ignoran deliberadamente los factores socioculturales de las poblaciones que habitan los espacios estudiados. Esto se 
vincula a que implementan acciones que incrementan las desigualdades sociales, a la vez que diseñan soluciones costosas e ineficientes. Las limitaciones provienen, justamente, de la falta de reconocimiento a la imbicación de elementos que no resultan reducibles a lo biológico o a lo social.

Jorge Riechmann (2004) incorpora un elemento que se presenta como ineludible en el análisis ambiental: la demografía humana. Este ambientalista, a partir de su noción de mundo lleno, coloca sobre el tapete la necesaria incorporación de los factores humanos en las consideraciones. En esta línea argumenta que, por la actual demografía, y sobre todo por la forma en que gran parte de esa población busca vivir, se ha llegado a un particular nivel de apropiación de los espacios de modo tal que no existen áreas que se puedan considerar como ajenas o indemnes a la actividad humana. Una nota de color sobre este punto se encuentra, precisamente, en el modo en que fue incorporado el estudio de la forma en que vive la mayor parte de la población, porque la mención de Riechmann tiene en vista los modos occidentales de intervención en la naturaleza. Formas que, paradójicamente, fueron el fundamento de Arthur Tansley (1935) para separar a los seres humanos de los estudios sobre los ecosistemas. ${ }^{44}$

Eduardo Rapoport (1975) incorpora un dato llamativo a esta reflexión; este ecólogo demuestra que si se calculara el volumen de todos los organismos vivos y se comparara el espacio que ocupan los seres vivos, los seres humanos superan a los seres vivos salvajes en un orden de magnitud. Los únicos animales que se extienden en una dimensión mayor a la de los humanos es la de aquellos que se utilizan para subsistencia (por ejemplo vaca, oveja), o aquellos que encuentran un sitio de desarrollo favorable en el entorno humano (por ejemplo ratones). Al comparar peso y volumen Rapoport reflexiona "los seres humanos somos muy pesados y aplastamos al resto de los seres" (Entrevista 2006, inédita).

La ecología como disciplina científica, a lo largo su historia ha recorrido el particular recorte de interacción entre las sociedades y su entorno, y en este punto resulta de interés para nuestra indagación. El problema de la incorporación de la humanidad ha sido admitido desde distintas perspectivas, aun cuando las principales teorías que atraviesan esta área de estudios reproduce la escisión propuesta en los años treinta por Arthur Tansley. En forma paralela, han existido puntos de vista que buscaron avanzar

\footnotetext{
${ }^{44}$ Ver capítulo uno.
} 
sobre la dicotomía sociedad/naturaleza que se presentaba como ineludible. Richard Levins (1973), por ejemplo, desarrolla un trabajo que apunta, precisamente, a llamar la atención sobre este aspecto, generando una propuesta para entender la ecología tomando en consideración los factores sociales. Este biólogo señala que lejos de iniciar su trabajo desde preguntas, toma como presupuesto la complejidad ambiental, y de allí se interroga sobre las preguntas que debían ser resueltas (Levins 1968). En contra del privilegio de las variables genéticas, Levins critica que la genética de poblaciones supone un medio ecológico constante. Frente a esta concepción estática, el ecólogo modelizó una situación en la que la evolución tiene lugar en un entorno permanentemente cambiante y donde las variables sociales quedan inexorablemente imbricadas (Haila y Taylor 2004).

Existen varias publicaciones que dan cuenta de la incidencia de esta perspectiva en los estudios ecológicos, así por ejemplo Jukka Jokela y Erkki Haukioja (2000) evaluaron la vinculación entre los organismos y su ambiente a partir de analizar la evolución de las estrategias presentes en las historias de vida de los seres que estudiaban, alejándose de los modos clásicos de los estudios evolutivos e incorporando variables que colocaban en un primer plano a las experiencias. Otro ejemplo es el de Peter Taylor (2000), quien elabora una estrategia de estudio levinsiana a partir del diseño de un modelo para identificar los variados sitios de sociabilidad, que fueron modelados desde decisiones y no determinados por la naturaleza. En una línea similar Haila y Levins (1992) desarrollan uno de los ejemplos más ilustrativos sobre el tema, cuando reclaman que las tareas de un ecólogo deben incluir el estudio de los dinamismos humano-naturales combinados. Argumentan que resulta ineludible, por ejemplo, para comprender la fluctuación de las poblaciones de peces en el tiempo, su articulación con el valor de la carne de los mismos que el mercado.

Esto sin embargo no debe llevar a olvidar que, más allá de estos esfuerzos, los trabajos que históricamente se desarrollaron en la disciplina en torno a los estudios poblacionales siguieron las formas tradicionales de análisis estadísticas, desarrolladas según el modelo Lotka-Volterra que omitían referencia a los contextos y sus cambios. ${ }^{45}$ Sobre ellos, los ecosistemas fueron conceptualizados desde la idea de flujos de energía, ligada a la metáfora física que da lugar a la propia conceptualización de ecosistema. Frente a estas dos perspectivas, que podemos pensar en pugna (ya que el reclamo por

\footnotetext{
${ }^{45}$ Ver capítuo1, nota 8.
} 
superar la histórica dicotomía sociedad/naturaleza apunta a las limitaciones de la mirada tradicional), la propuesta por la complejidad quedó en un segundo plano en cuanto al impacto sobre los protocolos de investigación que se establecieron (Holling 1998). Y en este punto debemos volver al problema de las jerarquías, porque siguiendo la argumentación de Irjo Haila y Peter Taylor (2004), la diferencia de reconocimiento, antes que en potencial de investigación, ha descansado sobre supuestos que asumen como prioritarios los factores genéticos, situando a priori en un sitio desigual al reclamo por la revisión de la complejidad.

Haila y Taylor recorren la filosofía de la biología poniendo de manifiesto el escaso sitio que ha tenido la reflexión sobre la ecología. Retomando ideas del primer capítulo, rescato que estos autores argumentan que la filosofía ha sido sorda a las particularidades de la ecología, fundamentalmente, porque la entiende como redundante en el concierto de las reflexiones sobre la ecología. Podemos pensar que, en una línea similar al encubrimiento que se plantea desde los modos occidentales denunciados por Horkheimer y Adorno (1997), en el caso de esta disciplina la invisibilización de las particularidades de la ecología se producen a través de la homogeneización, que en el caso de la disciplina biológica se vincula al modelo de la unidad de las ciencias, supuesto fundamental del programa de investigación del empirismo lógico o concepción heredada para las ciencias naturales (Menna 2004).

La unidad a la que se apela desde esta concepción del conocimiento lleva, por ejemplo, a asumir que los procesos naturales son adecuadamente representados a partir de su localización unificada en un sistema matemático de coordenadas cartesianonewtonianas. De este modo se omiten los sesgos propios de esta mirada (Bordo 1986), así como el carácter filosófico e histórico sobre el que se edificó el compromiso hacia esta forma de reconocer el mundo (Grene 1985, Dear 1995). En este punto podemos reconocer un nuevo eco hacia el reclamo frankfurtoniano sobre la lógica de dominio, porque en la repetición de las formas de invisibilización se descubre un esquema de ocultamiento que opera silenciando todo lo que introduzca impugnaciones al esquema de jerarquías establecidos. El argumento hacia la ecología vuelve a ser, como en el resto de los planos, desde un criterio de autoridad, tomando como referencia dimensiones que se consideran fundamentales como la genética. 
Haila y Taylor (2004) mencionan otro problema ligado a la unidad de las ciencias y su incidencia en la mirada sobre la ecología, el requerimiento de una razón universal desde la cual edificar las conclusiones y sobre la cual contrastar la corrección de las metodologías. Una razón que se escapa, a decir de estos autores, al mundo desde el cual los seres humanos dirigimos nuestras propias vidas, en los contextos desde los cuales edificamos nuestros razonamientos. Una razón ajena a las raíces históricas de la vida práctica. De allí que, en contra de lo que denominan sagrados ideales de la ciencia moderna, como la objetividad o la evidencia reclamen que se abandone el compromiso acrítico, porque tanto la razón como los procesos naturales sólo puede entenderse como social e históricamente situados (Longino 1990).

Más allá de la filosofía de la ciencia, resulta interesante destacar que en este privilegio reduccionista se eclipsa la particularidad de la ecología en su especial situación de estar en medio de tensiones que no terminan de acotarse a lo biológico o a lo social. Tal es así que no alcanza con el enorme prestigio de muchos/as de los/as científicos/as que discuten la dualidad. Las intenciones no terminan de articularse más que como programas secundarios. En la práctica, los protocolos de investigación más usuales omiten esta problemática (Núñez 2008), en una ausencia que tampoco es homogénea, porque se acentúa en los laboratorios expuestos a las situaciones más desiguales. Y en este sentido vuelve a introducirse un sesgo, porque los laboratorios que entiendo como dependientes suelen hacer ciencia de excelencia pero en el marco de prácticas que Pablo Kreimer (2000, 2001), apelando al marco kuhniano, ha descrito como hipernormales, esto es, avanzan en líneas de investigación previamente establecidas, cuyos detalles se profundizan pero cuya estructura no se discute.

$\mathrm{Si}$ cruzamos esta situación con el reconocimiento de situaciones ambientales especialmente graves en los espacios más vulnerables del mundo, donde difícilmente se establezca un laboratorio más que desde esta lógica hipernormal, enfrentamos una nueva paradoja. Los espacios donde las desigualdades se incrementan y las consecuencias se agravan ni siquiera cuentan claramente con formas de conocimiento que permitan avanzar sobre esas desigualdades.

Las tensiones que acarrea la pervivencia de jerarquías diferenciadas se proyectan en prácticas locales de diversas formas, pero en general puede pensarse que afectan la percepción de los problemas y la equifonía de las voces involucradas, donde la poca 
recepción de algunas propuestas puede tener que ver con la menor sonoridad pero también con la escasa audibilidad, en el sentido del escaso reconocimiento social respecto de ciertas voces que pueden llegar a ser altamente sonoras. Bina Agarwal (1998) reconoce en los problemas medioambientales de la India que

"La cuestión... es el proceso por el cual lo que se considera como "conocimiento científico" se genera y aplica, y cómo se distribuyen los frutos de esta aplicación”. Así señala "Dentro de la jerarquía del conocimiento, el que se adquiere mediante las formas tradicionales de interacción con la naturaleza tiende a ser considerado menos valioso" (Agarwal 1998, 203).

En general la praxis de investigación opera como traba al reconocimiento de la artificialidad de las jerarquías supuestas, un punto que exploraré en mayor detalle en el capítulo cinco.

Los problemas ambientales, vistos a la luz de las tensiones que se ocasionan en base a las desigualdades, no son un tema propio de la ecología. Las dificultades se originan al reconocer que, a pesar de no pertenecer al recorte temático disciplinar, continúan retornando al horizonte de tensiones. La ecología se encuentra en un sitio complicado, donde las tensiones de una dualidad -insostenible desde la teoría y fundamental para la práctica- de una u otra manera llevan a sus practicantes a tomar una opción frente al tema. La falta de continuidad respecto una búsqueda de alternativas pone de manifiesto un compromiso fundamental, el esquema de edificación de conocimiento y revisión teórica reproduce (y legitima) una forma jerárquica de vinculación hacia el interior de las prácticas científicas. Los propios términos de la ecología se construyeron asumiendo como ajenos los planos desde los cuales en la actualidad se demanda respuesta. La traba principal no se encuentra tanto en la metodología, sino el escaso reconocimiento a su particularidad que facilita el eclipsamiento del desafío ambiental, que frente a los ojos de la genética se desdibuja.

En otras palabras, las jerarquías se sostienen desde determinadas políticas de reconocimiento que trascienden la propia disciplina ecológica, y en esta línea avanzaré con mi reflexión. 


\section{El sostén de las jerarquías}

A grandes líneas podemos decir que el problema de las jerarquías se ha deslizado desde las fundamentaciones biológicas hacia debates ético-políticos. La remoción de las pseudoevidencias biológicas que sustentaron las ideas como el esclavismo o la desigualdad de género no alcanzaron para desmontar la estructura de las desigualdades. El tema del dominio, como práctica social, quedó fuera del recorte de temas sobre los cuales buscaba incidir la biología moderna. $\mathrm{Y}$ en este proceso, de deslizamiento y ocultamiento, las formas de dominio lejos de revisarse, se fortalecieron.

Hoy en día, la desnaturalización de las jerarquías de disputa en otros planos. Siguiendo las afirmaciones de María Luisa Femenías (2007), se trata de crear condiciones para que las personas (y seres) históricamente perjudicadas(os) en el reconocimiento $\mathrm{y}$ consecuentemente en el usufructo de derechos comiencen a ser visibles en un número cada vez mayor porque, como señala la autora "los cambios cuantitativos dan lugar a cambios cualitativos en la condición de las personas" (Femenías 2007, 20). Se trata de explorar los modos en que se busca discutir la valoración de lo diferente como inferior para afrontar los desafíos de la situación presente desde un sitio que permita remover desigualdades.

Se trata de destituir presupuestos que contienen ecos de las miradas establecidas en la Grecia clásica. En contra de los supuestos aristotélicos, hoy consideramos que las diferencias no son naturales y la desigualdad no beneficia al conjunto, sino sólo a una de las partes. Este privilegio es, sin embargo, invisible a los ojos de los sectores con prerrogativas. Porque en general la población beneficiada difícilmente aprecia sus ventajas en términos de privilegios. Femenías (2007) toma de Iris Young la idea de la insuficiencia de las políticas basadas en el principio de no-discriminación. Al respecto señala que:

"Históricamente ningún grupo materialmente excluido de los beneficios de la igualdad la obtuvo por "graciosa concesión", sino tras movilizaciones y luchas significativas: las del movimiento obrero y el sufragismo marcaron el siglo XIX, la de los derechos civiles de los negros, en los Estados Unidos o en Sudáfrica el siglo XX” (Femenías 2007, 126)

Son muchos años de una mirada que escinde, separa y permite el ejercicio del control y la explotación. Como contracara, los privilegios se constituyeron naturalizando 
injusticias de sectores que, además fueron omitidos desde su particularidad, forzándolos a adecuaciones normativas establecidas desde los sectores privilegiados. Pero la realidad no es inmutable, y en este tema acompaño la idea de Ernst Bloch (1983) al reflexionar sobre la forma dialéctica que reconoce en todos los fenómenos. Este filósofo frankfurtoniano señala que "En el mundo hecho por el hombre la propia dialéctica es una relación sujeto-objeto, y no otra cosa: una subjetividad que trabaja y que siempre de nuevo rebasa y se esfuerza por romper la objetivación y la objetivación que se le presenta" (Bloch 1983, 474). En los últimos años diferentes movimientos de reivindicaciones han generado reflexiones que dan cuenta del carácter artificial de esta edificación de diferencias, la emergencia de grupos históricamente invisibles, con identidades culturales en tensión, ha inaugurado revisiones que impactan, por ejemplo, en la reivindicación de diferencias (Femenías 2007).

El análisis sobre los ejercicios reivindicativos ha llevado a reconocer limitaciones tanto en los conceptos de justicia distributiva como en la propuesta marxista, tal como explora Femenías (2007) tomando de Iris Young la revisión del concepto de opresión. La filósofa norteamericana reconoció cinco aspectos desde los cuales revisar este ejercicio de diferencia: la explotación económica, la marginación social, la carencia de poder y de representatividad, el imperialismo cultural y la violencia. Femenías reconoce que todos estos aspectos implican estructuras sociales, pero comparte con la norteamericana que si bien el primer aspecto de la opresión, la explotación económica, puede revertirse, el proceso opresivo va más allá. En el caso que tratamos no debemos perder de vista que nos encontramos frente a ejercicio de reclamos que trascienden el pedido de una mejor distribución y se erigen desde un sitio que busca una mejor representatividad. La marginación no se reduce a factores económicos y en esta línea se levantan muchos de los aspectos vinculados a la problemática ambiental, no sólo por la normatividad opresiva que se plantea en el uso industrial del entorno (que choca con muchas visiones de las más diversas culturas), sino porque las diferentes situaciones ambientales establecen condiciones de marginalidad. Por ejemplo, no es lo mismo vivir cerca o lejos de un vertedero de basura que periódicamente se incendia, aún cuando se tengan resueltas todos los condicionamientos económicos del grupo humano que allí habita. La visión de la diversidad es el desafío que se abre para desmontar la conceptualización jerárquica del mundo. 
En relación a este tema Rita Segato (2007) llama la atención sobre los riesgos de privilegiar un cierto tipo de reivindicaciones omitiendo las referencias al conjunto de opresiones que operan en una situación. Al respecto revisa el proceso de politización de identidades, que tomó el lugar de las luchas setentistas (que denomina clásicas) focalizadas en la revisión de estructuras económicas y situaciones de explotación. Muestra cómo, en nombre de identidades retocadas o construidas al servicio de una demanda, el reclamo por la identidad permitió ocultar diferencias y tensiones enraizadas en aspectos, por ejemplo, económicos y en este ocultamiento las formas de jerarquía y opresión lejos de removerse, se desdibujan y fortalecen.

“... Luchas en apariencia étnicas simplemente encubren o distraen de la existencia de un enemigo mayor, que permanece ileso, oculto y estable a lo largo de los avatares de las últimas décadas...” (Segato 2007, 16).

Un nivel similar de ocultamiento puede encontrarse si se revisan los reclamos por los derechos de los animales. La normativización, como base de los juicios que se establecen, emerge continuamente en las diversas reflexiones que paradójicamente buscan consolidar modos alternativos de vinculación con la naturaleza. Val Plumwood (1996) explora las tensiones entre la teoría ética animalista y la filosofía ecológica. Esta tensión se presenta, por ejemplo, frente a la propuesta de una teoría ética biocéntrica elaborada por Paul Taylor (1986), quien a pesar de abogar por una mirada alternativa continúa sosteniendo la primacía otorgada a la razón. Las formas jerárquicas se sostienen en la propuesta de Taylor dado que asume como única razón válida la cognitiva, desmereciendo argumentaciones desde consideraciones emocionales $\mathrm{o}$ estéticas.

Un poco más sutil es el caso del conocido defensor de los derechos de los animales Tom Reagan, quien toma como punto de partida la noción de derecho sustentado en la teoría de Stuart Mill. Esto es, "si un ser tiene un derecho a algo no sólo debería él o ella (o ello) tener tal cosa sino que los demás están obligados a intervenir para asegurarlo" (Plumwood 1996, 40). Una noción que parte de una visión de derecho establecida desde prácticas sociales y humanas, que desde estos argumentos busca ampliarse sobre todo hacia los animales domésticos o primates mayores, y que comienza a mostrar fisuras en cuanto se explora su proyección hacia los espacios salvajes. La asimetría parte de que la posibilidad de intervención no es general hacia todos los seres, sino que es potestad 
humana, de allí que el ejercicio del derecho retorna a la humanidad. Bajo la manta de la responsabilidad se vuelve a establecer la lógica jerárquica y la noción de control como base de vinculación.

El derecho a las diferencias se eclipsa en estos intentos de revisión en la relación de los humanos hacia los otros animales. Las teorías recientes de derechos de los animales y vegano/vegetarianas tienden a consolidar perspectivas individuales que excluyen otros modos de considerar la vida enraizadas, por ejemplo, en culturas no occidentales. Plumwood (2004) señala que estos movimientos, al postular que sólo los animales (nohumanos) cuentan éticamente, repiten a decir de la autora australiana, el dualismo cartesiano en el plano moral. La sobredeterminación cultural, fundamentada desde un cierto ejercicio de derechos que se considera legítimo, vuelve a incorporar formas opresivas como naturaleza de vinculación.

Frente a estas posiciones, los ambientalismos en general suelen naturalizar a los seres humanos como predadores del medio. Provocando desde esta situación un enfrentamiento ineludible con los defensores de los derechos animales, que condenan esta posición de los humanos, proponiendo medidas para eliminarla (Stage 1997, Sapontzis 1987) o simplemente deplorándola (Singer 1980). En medio operan argumentaciones que retornan fundamentos de control y de dominio, que buscan incidir incluso en las cotidianas costumbres culinarias reivindicando una adscripción forzada al modelo occidental vegano (que se opone al consumo de alimentos de origen animal, al uso de ropas con partes animales, al empleo de elementos que impliquen testeos en animales y al rechazo a las formas de ocio que involucren animales), reincidiendo en evaluaciones que toman como norma a lo humano, porque los seres que se reclama no consumir (y cuidar) son aquellos que tienen el mayor parecido o cercanía a las sociedades occidentales.

Estas dimensiones del ocultamiento permiten considerar la dimensión y pluralidad de las estructuras a desmontar. El sostén de las jerarquías es la no consideración de las mismas como problema.

A fin de sortear esta traba, avanzaré en el problema del reconocimiento y las jerarquías de la mano de las reflexiones feministas, que desde diferentes miradas han buscado rebatir la tendencia a la homogenización y ocultamiento, dando cuenta de los aspectos 
diferenciales que se han establecido a partir de la fundamental separación varón/mujer, que a decir de Luce Irigaray (1974) es la diferencia primaria que constituye el principio de inteligibilidad de la cultura occidental.

En esta línea sigo la propuesta de Celia Amorós (2008), quien rescata el valor de la complejidad adoptada por el pensamiento feminista, desde sus variados frentes y referentes polémicos. Es una tradición que se opone a los sistemas duales de raíz socialista, según los cuales el capitalismo y el patriarcado son analíticamente diferentes. Se trata de una visión que permite la relectura de desde un sitio original, basada en la experiencia de la reflexión desde la desigualdad, y que se ha propuesto dar respuesta a muchos de los desafíos que se inauguran en el contexto de globalización que ha promovido esta tesis. La filósofa española sostiene que

“... sólo la identificación del patriarcado como realidad sistemática puede dar cuenta de la sistemáticamente fraudulenta usurpación de lo universal por parte de una particularidad, una identidad facciosa: la constituida, muy precisamente, por el conjunto de quienes detentan el poder" (Amorós 2008, 61)

\section{El desafío del reconocimiento}

Muchas de las más importantes teorías feministas han avanzado en su análisis sobre el reconocimiento a partir de considerar las dificultades en la toma de consciencia. Al respecto cabe recordar que la consciencia no es estática ni se configura a sí misma, sino que se constituye en relación a otra consciencia. El problema a considerar es que la lógica del reconocimiento, desde la cual desde uno se constituye al otro, implica necesariamente relaciones asimétricas, siguiendo a Hegel en la dialéctica amo-esclavo. ${ }^{46}$ En el proceso de reconocimiento la conciencia del amo necesita de la del esclavo, porque a partir de ser percibida desde esa diferencia asegura su libertad. Como contracara la conciencia del esclavo, por temor a la muerte, abandona la pretensión de independencia. Es en esta vinculación donde opera la dialéctica, porque en el ejercicio de reconocimientos hay una circulación, una inversión de formas de la conciencia, viéndose que no hay una conciencia que domina en forma independiente, sino que más bien, ambas son convertibles la una en la otra. El amo necesita del esclavo, y en esta necesidad pierde su independencia, y el esclavo, al ser puesto por el mismo amo como

\footnotetext{
${ }^{46}$ La dialéctica hegeliana del amo y el esclavo será problematizada desde la lectura de Kojeve, en las conclusiones, a la luz de las reflexiones del conjunto de los capítulos.
} 
esencial, pierde su condición de "prescindible", quedando como lo más necesario. La base desigual está en el fundamento del reconocimiento.

En el siglo XX, el problema del reconocimiento comienza a ser explorado en profundidad a partir del trabajo de Simone de Beauvoir (1949), un hito fundamental del pensamiento feminista. Esta autora interpreta que la dialéctica amo-esclavo se resuelve en una dialéctica varón-mujer (Femenías 2007). La filósofa francesa indica que, aún cuando en las diferenciaciones entre grupos humanos el concepto de "otro" funciona como concepto relativo y recíproco al grupo que se nombra, esto no ocurre entre los sexos. La reciprocidad se pierde porque uno de los términos se afirma como el único esencial. Los feminismos han buscado desandar esta visión en función de sortear el problema del reconocimiento. Por ello seguiremos las líneas de reflexión que inauguran el capítulo cuatro y así retornar al problema fundamental de la situación ambiental: la dualidad sociedad/naturaleza.

\section{Teoría de género}

Los reclamos que se desprendieron en un primer momento de estas reflexiones apuntaron a hacer visible -e incluso denominar- situaciones de dominio y violencia como el acoso o la violación conyugal. Las voces en torno a la igualdad de derechos se incrementaron desde esta perspectiva. En este proceso se discutió, por ejemplo, que lo que se obtenía gracias a los procesos de lucha no eran concesiones. Sino que cada uno de los logros daba cuenta de la histórica negación de derechos y la gravedad de la situación construida a partir de naturalizar estas negaciones (Rosenthal 1973).

El análisis de las feministas que reclamaban la igualdad se articuló con los principios liberales que se habían sostenido desde el movimiento sufragista, desde el cual se reivindicaron las ideas ilustradas de igualdad de derechos así como la incorporación de las mujeres en la esfera pública. Sin embargo, en la década del setenta las/os pensadores que reparaban en estos temas empezaron a reconocer que la igualdad de derechos no terminaba de concretarse en igualdad de facto (Phillips 1996). Esta revisión de teorías no dejó de reparar en el pensamiento de Beauvoir, planteando que, más allá de todas las rupturas que buscó afrontar, la pensadora francesa no logró evitar la pervivencia de dualidades fundamentales en su propuesta (Butler 1986). 
La teoría de género se inaugura por el reconocimiento de estas limitaciones en el cuerpo de la mirada feminista. En la permanencia de dualidades se perdía parte del carácter construido de la idea de mujer. Judith Butler (1986), comprometida con las propuestas del giro lingüístico, señala que Beauvoir mantiene la diferenciación entre ontología y lenguaje y desde este marco binario no se puede lograr desarticular las estructuras que se plantea revisar. Desde la perspectiva feminista original se entendía que sobre los biomorfismos sexuales, sobre los cuerpos, se edifica el género. En este plano los modelos sociales operan como mandatos que se aceptan, discuten, incorporan o rechazan. Pero la noción de género comenzó a independizarse del modelo ilustrado que subyace en las ideas de Beauvoir y se acerca a un modelo más vinculado con la identidad. Butler desarrolló una postura donde no buscaba negar de plano la desigualdad a partir de su declamación o denuncia, sino que propuso desmontar la forma en que han sido armadas las estructuras en discusión. Esta perspectiva la lleva a argumentar desde las formas usuales de redacción hasta reconocer que el sexo y la sexualidad lejos de ser algo natural son, como el género, algo construido. La noción de natural pierde sentido desde esta perspectiva, quedando atada a la trama discursiva que se entiende como la densidad del ejercicio del poder.

La atractiva teoría de Butler hizo hincapié en la revisión de las estructuras psíquicas, políticas y sociales que han establecido el campo de lo humano, demarcando por defecto el ámbito no-humano. Estos aportes, que enriquecen la revisión en torno a las estructuras naturalizadoras de la sociedad occidental no profundizan, sin embargo, en las posibilidades de acción revisadas a partir del reconocimiento de las limitantes materiales sustentadas desde las diferencias sociales, un aspecto ineludible del conjunto de opresiones presentes en la temática ambiental. Una crítica que Nancy Fraser (1989) desarrolla. El aporte de Fraser se presenta como reclamo a la teoría del discurso. Que, a decir de la autora, no sólo -o centralmente- debe buscar las referencias de la construcción (o desarme de las identidades sexuales), sino que debe avanzar hacia una concepción del discurso que ayude a comprender cómo las identidades sociales de las personas se modelan y se alteran a través del tiempo.

En este sentido se trata de desarrollar una teoría que dé cuenta, en condiciones de desigualdad, de cómo los grupos sociales se integran y se desintegran. Que pueda aclarar cómo la hegemonía cultural de los grupos dominantes en una sociedad se 
asegura y se enfrenta, una reflexión que a decir de la autora, debería iluminar las perspectivas de cambio social emancipatorio y de práctica política.

Fraser abre la posibilidad de cambio al discutir que los sujetos hablantes sólo pueden reproducir el orden simbólico existente. Porque desde este supuesto no se puede, siquiera, formular la cuestión de la hegemonía cultural. La autora llama la atención hacia las teorías, porque les demanda el cuidar lugares que permitan reconocer agentes que disputan los significados sociales hegemónicos, aún desde prácticas cotidianas. Así reclama a las teorías feministas formas de compresión que permitan reconocer que no se es siempre mujer en el mismo grado; porque como señala, en algunos contextos la condición de mujer (womanhood) es central en el conjunto de descripciones bajo las cuales se actúa; pero en otros, es periférica o latente. Y es desde este lugar que vamos a presentar la perspectiva que se toma para hurgar en las tensiones fundadas en las más profundas consideraciones biológicas.

\section{El camino del ecofeminismo}

En forma asociada a las problemáticas denunciadas por el feminismo -aborto, acoso, violencia doméstica, doble o triple jornada de trabajo, control sobre el cuerpo y la sexualidad, entre otros- se fueron configurando nuevas categorías de análisis que llevaron a revisar el marco de conocimiento que explicaba los procesos sociales. Así las reflexiones caracterizadas por abstracciones teóricas se reconfiguraron para incluir la textura de lo cotidiano y, a causa de ese acercamiento, las referencias empíricas pasaron a incorporarse como elemento ineludible de las reflexiones (Vazquez García 2007). En este camino una metáfora comenzó a percibirse estructuradora de desigualdades y articulaciones naturalizadas. A partir de su reconocimiento, el desmontarla fue un objetivo claro. La desigualdad social y la reproducción de esta desigualdad en las prácticas cotidianas, no son independientes de los problemas ambientales. El modo en que se ha edificado el saber moderno, sustentado en jerarquías, ha llevado a pensar que sociedad y naturaleza son estancos aislados e independientes. Pero la imposibilidad de responder a las demandas orienta la atención, precisamente, hacia su necesaria vinculación. 
La metáfora que se problematiza es la que liga a las mujeres (como conjunto) a la naturaleza (con un carácter igualmente homogéneo). Las cualidades desde las que se edifica el vínculo apelan a términos como pasiva, irracional, caprichosa, dependiente y demandante de un control que en sí misma no encuentra. Esta idea de mujer reforzó, a su vez, la noción de naturaleza que se iba edificando en la modernidad. La revisión de esta simetría construida, que justifica dominios y desigualdades que trascienden este punto en particular, es un punto de encuentro de los planteos ecofeministas, que como señala Val Plumwood (2004) “...parecen estar mejor colocadas para resolver este antiguo dualismo porque pueden hablar y razonar desde la posición de -y en solidaridad con- los que han sido considerados como 'la naturaleza'” (Plumwood 2004, 54).

Hay otro aspecto que permite vincular la reflexión ambiental con la condición femenina: las principales víctimas de las desigualdades tanto materiales como ambientales son las mujeres, de allí que las reflexiones que toman en consideración al sector más vulnerable son las que reparan con mayor detalle en la lógica de las formas de dominio y reproducción de la desigualdad (del Valle 1997). A esto se agrega que uno de los orígenes de la actitud hacia lo natural como ajeno a lo social descansa en la internalización de ciertos dualismos oposicionales como naturaleza/cultura, público/privado, trabajo/ocio, etc. El género es una categoría analítica clave para comprender por qué esos dualismos han alcanzado los objetivos de quienes lo promovieron (Segales Kirzner 2006).

La imagen de la mujer pasiva tiene enormes contactos con la concepción de la tierra que se ara, y aún cuando desde el ecofeminismo se busca desmontar la idea, no dejan de ser reflexiones "silenciadas" (Holland Cunz 1989) que apuntan a la cuestión de la desigualdad de las sociedades que han dado lugar a esta particular forma de utilización del entorno, reducido en gran parte a un concepto de recurso susceptible de ser aprovechado. En este sentido adhiero a la reflexión de Barbara Holland Cunz (1996), quien explora los vacíos en torno al modo en que se han desarrollado las reflexiones que reparan en las vinculaciones sociedad-naturaleza. Al respecto indica

"[...] la razón aferrada a la naturaleza comprensiva, que busca sortear la dualidad, constituye todavía hoy una "minoría sin voz" dentro de las ciencias sociales consideradas normal science, que siguen avanzando sin inmutarse y en las cuales operan los esquemas de percepción selectivos, al parecer no sólo en los márgenes, sino 
también en el centro de la corriente principal... la reflexión teórico-social se encuentra muy por detrás de la realidad 'ecológica' y social.”(Holland Cunz, 15-16).

\section{Consideraciones finales del capítulo}

En este capítulo recorrimos una paradoja: la biología que fundamentó los cimientos de una sociedad desigual es practicada por científicos que no se reconocen como agentes de esa desigualdad que continúan reproduciendo en sus prácticas, precisamente por no revisarla. La historia de la consolidación del manejo jerárquico y dominante del mundo, en el sentido de relaciones hacia la sociedad o el entorno, expone los fundamentos biológicos que sostuvieron la idea de dominio, en un contexto donde esta misma idea era debatida.

El punto que queda a la luz con el relato histórico es que los organismos que se tomaban como ejemplo del establecimiento de diferencias trascendentales, continuaron siendo parte de los estudios biológicos. Pero la instalación de la jerarquía de análisis, que se proyectaba hacia el derecho al control, fue eclipsándose progresivamente en el desarrollo de las ciencias de lo vivo.

En la creciente especialización se perdieron de vista los compromisos fundacionales. La parcialización de los debates científicos ayudó a perder de vista el fundamento del dominio como parte de la estructura teórica de esta área de estudios en sus orígenes. Apelando a una metáfora organicista, puede pensarse que las raíces de la jerarquía, sobre la que crecen las desigualdades, se plantan en el territorio de la biología para crecer en el ámbito extra científico de las prácticas sociales.

El velo de ocultamiento que traba este reconocimiento parece repetir herramientas y estrategias: homogeneización, universalización, reduccionismo. Las estructuras que operan como invisibilizadoras del carácter artificial de las jerarquías están en sí mismas edificadas con esta lógica desigual. El desafío que se abre desde este examen es el modo de remoción de estas estructuras, tanto porque legitiman determinados usos como porque acotan las formas de evaluar las situaciones.

Para ello se adopta una línea de estudios que inauguró la revisión de la situación varón/ mujer, porque esta vinculación desigual ha dado lugar a la indagación general sobre el 
conjunto de situaciones opresivas y argumento a favor de tomar los ecofeminsmos para explorar la dualidad sociedad/naturaleza tomando en cuenta el conjunto general de desigualdades vinculadas a la pervivencia de este antagonismo. 


\section{Segunda Sección: Los pilares de los "puntos ciegos"}

Capítulo 4:

Sociedad y Naturaleza

Antagónicas, excluyentes y exclusivas 


\section{Introducción}

En las secciones anteriores he revisado el potencial y las limitaciones de las reflexiones epistemológicas en ecología y los debates ambientalistas. En el capítulo precedente he avanzado en las trabas que se desprenden a partir de la adopción de un reconocimiento jerárquico del mundo. Por ello he indagado el problema de la desigualdad y la falta de reconocimiento de experiencias que se abate sobre amplias poblaciones no tomadas en consideración.

En los capítulos previos también he mostrado que los límites para las respuestas se fundamentan en los supuestos de las ciencias naturales en general, que entienden el estudio del mundo natural como un mundo no-humano, ajeno o escindido de las variables sociales. Tras reparar en los modos de describir la naturaleza he buscado reconocer el carácter artificial de cada una de las metáforas que se toman como base de las definiciones de las acciones que se despliegan en la interacción con el mundo.

Pero más allá de este carácter, al revisar el modo específico y sesgado en que la ecología asume el estudio de la naturaleza, evidencio que por esta escisión se han desdibujado las referencias a las consecuencias de las acciones que se legitiman desde la mirada adoptada. De hecho el hilo que me ha llevado a revisar estos puntos se origina en la visualización de una problemática ambiental que parece desafiar con interrogantes de una disciplina que, con sus herramientas analíticas, no termina de encontrar respuestas definitivas.

Frente a esta problemática se erigieron, sobre todo en la segunda mitad del siglo XX, discursos (y movilizaciones) ambientales. Las denuncias focalizaban, sobre todo, un uso indiscriminado de los recursos y una falta de referencia hacia el plano ético involucrado. En el proceso que da cuenta de los límites cada vez más claros de las posibilidades de explotación, el sector social más expuesto a los problemas ambientales ha sido el más frágil, el de menores recursos económicos. Así, como señalan Silvio Funtowicz y Jerome Ravetz (1993), los problemas que no se han resuelto han sido el desgaste ambiental y la distribución de la riqueza. Estos problemas no están separados, aún cuando no resulte obvio el modo en que se vinculan. En una línea similar María José Guerra Palmero (2006) vincula la globalización económica y la situación devastadora para el sur del planeta y el medioambiente. La pobreza, asegura la pensadora española, 
no puede pensarse en forma ajena al deterioro y la expropiación de los recursos naturales. Frente a estos lazos considero que las trabas para la problematización de estos vínculos provienen, entre otros factores, del modo en que se constituye el conocimiento biológico y el reconocimiento social del mismo.

En los capítulos previos recorrí el modo en que el discurso biológico, que contiene las potencialidades que aporta un ejercicio de observaciones minuciosas, matemáticamente analizadas, que para el caso de la ecología tiende al reconocimiento de patrones en las diversas escalas de estudio. Pero bajo la confianza que genera la utilización de una metodología consensuada, la elaboración de conocimiento se encuentra atravesada por limitantes que emergen del plano de supuestos no problematizados. La constitución misma del conocimiento está sesgada por consideraciones jerárquicas que naturalizan desigualdades sociales como las de género (Merchant 1980; Bordo 1986); así como un uso y dominio ilimitados sobre lo que se presenta como no-humano (Horkheimer y Adorno 1997; Holland Cunz 1996).

Estos sesgos se suman, además, a los propios límites que impone la práctica científica. Como señala Manuel Castells (1999), en su intento por ordenar el universo de sentidos con que fue tomada la noción de paradigma kuhniana, podemos entender paradigma como un modelo conceptual que proporciona un modelo estándar de selección de interpretaciones. Como todos, el paradigma de la ecología, con todas sus definiciones y variantes, ha establecido que describir, interpretar o explicar, para que se acepte como pertinente en la retícula conceptual que implica la adopción de este conjunto de acuerdos. Como se muestra en el capítulo dos (y se amplia en este apartado), en este recorte la pregunta por lo social quedó afuera, al igual que la preocupación por la situación ambiental.

Estas limitantes operan, además, como traba para el reconocimiento de experiencias productivas no-capitalistas. Para ello adopté un marco teórico particularmente sensible para los sectores invisibilizados y la gestión de organizaciones alternativas: la filosofía de género, que ha profundizado especialmente en los modos solapados de dominio y la naturalización (en el sentido de aceptación aproblemática) de formas de relación desiguales. Desde la misma indagaré en un par conceptual que ha acompañado a modo de horizonte referencial el presente escrito: la dualidad sociedad/naturaleza. La adopción de esta perspectiva se debe, además, a que a través de la historia del 
pensamiento puede reconocerse un imaginario patriarcal según el cual las mujeres aparecemos como seres fronterizos, situadas entre lo humano y lo animal, entre la naturaleza y la cultura. Una situación de reconocimiento especialmente rica, cuando se problematiza, para dar cuenta del carácter artificial de las dualidades que antes que pares antagónicos edificaron pares desiguales.

\section{Filosofía de género y metáfora ${ }^{47}$}

El variado marco de la filosofía de género se encuentra atravesado por profundas discusiones internas. ${ }^{48}$ Dentro de las mismas, existe una rama especialmente dedicada a reflexionar sobre la relación entre la sociedad y naturaleza: los ecofeminismos. El plural se debe a que tampoco se trata de una teoría homogénea, sino que cubre a una vasta amplitud de reflexiones, que tienen importantes puntos en común en cuanto al reconocimiento de los problemas, pero que se bifurcan en un abanico de alternativas en el proceso de interpretación sobre motivos y alternativas.

Desde los ecofeminismos exploro el proceso histórico y metafórico desde el cuál se fijaron situaciones de dominio hacia las mujeres. Estas metáforas constituyeron la base a una cierta lógica de dominio (en el sentido presentado por Horkheimer y Adorno 1997), reconocida como única y fundamental, dado que a partir de las mismas se naturalizaron y proyectaron estrategias de control y sometimiento hacia cualquier forma que se considerara como diferente, sea la población femenina, una cultura, una religión o cualquier otro organismo o elemento.

Uno de los fundamentos de esta situación de privilegios, de una de las partes en cuestión (la masculina, occidental y blanca), es el reconocimiento de una razón regente, que separa los caracteres humanos de los no-humanos. Esta escisión atravesó la

\footnotetext{
${ }^{47}$ El sentido en que tomo el término metáfora es el propuesto por E.F. Kittay (1987), quien argumenta que las unidades metafóricas son las oraciones, no las palabras. En esa unidad metafórica existen dos polos en tensión. Para comprender la metáfora estos dos polos deben ser considerados como un sistema porque el sentido de la metáfora opera en la interrelación. Kittay incluso señala que el significado de la metáfora es irreducible y tiene contenido cognitivo. Los polos no deben considerarse como expresiones lingüísticas aisladas sino expresiones referenciales, que remiten a sistemas de entidades, un marco en función del cual se edifica el sentido. La idea básica sobre el funcionamiento de la metáfora es que consiste en la aplicación al foco de un sistema de implicaciones ligado al marco de la metáfora (de Bustos 2000).

${ }^{48}$ Ver capítulo tres.
} 
organización de la modernidad en todas las escalas y esferas, e impuso una estructura relacional sostenida desde jerarquías de sometimiento.

Horkheimer y Adorno (1997) señalan que esta razón, potestad de unos pocos, se erigió fortaleciéndose la promesa de un camino de progreso continuo y asociando a la capacidad de conocer a través de esta misma razón. El sitio del hombre se aceptó como el de amo de eso que conocía. Estos autores exploran tanto la promesa incumplida como las contradicciones a las que se llega desde la aceptación de estos preceptos.

En el tema que nos ocupa adhiero a la noción que esta forma de razón occidental fue la base de legitimación de construcción histórica de las diferencias. Es por ello que, expuesta a la luz de las contradicciones, que generaron el establecimiento de relaciones constituidas desde este proceso, permite establecer vínculos entre la situación femenina y la situación de la naturaleza. Como señala la filósofa australiana Val Plumwood (1996)

“...Gran parte del problema (tanto para las mujeres como para la naturaleza) yace en concepciones racionalistas o derivadas del racionalismo acerca del yo y de qué es esencial y valorable en el carácter humano. Es en nombre de la razón tal que a esas otras cosas -lo femenino, lo emocional, lo meramente corporal o lo meramente animal, y el mundo natural mismo - se les ha negado su virtud y se les ha acordado una posición inferior y meramente instrumental" (Plumwood 1996, 38)

Esta razón, tan valorada desde la forma clásica de saber, es fuente de desigualdades en acciones de intervención y trabas en las revisiones científicas. Por ello, dado el sitio privilegiado con que fue investida, resulta prioritario revisarla y removerla desde su sitial de reconocimientos.

\section{Las metáforas que homologan}

La unión entre feminismo y ecología fue reconocida por primera vez en los años en que la reivindicación ambiental empezó a cobrar fuerza. La denominación de ecofeminismos fue presentada por Françoise D`Eaubonne en 1974 (Agra Romero 1998, 5), quien expuso que en la lógica de dominio que las feministas denunciaban desde 
hacía tantos años, no resultaba ajena al dominio extremo que se proyectaba sobre la naturaleza.

La vinculación entre la mujer y la naturaleza tiene referencias de larga data. Las formas paternalistas han caracterizado ambas nociones como equiparables, donde formas de dominio similar pueden encontrarse en ambos lados de este par. En contra del hombrevarón, asociado a la razón, la mujer se presentaba con una cercanía particular a los animales-no humanos y las plantas, más vinculada a la reproducción y la subsistencia. En contra de la razón, la mujer se manejaba por instinto y sentimientos.

El dominio se justifica desde allí, porque el paternalismo antes de presentarse como una actitud opresiva, es descrito como un modo de cuidado. Los seres caracterizados como menos racionales -mujeres, hombres de culturas no occidentales, animales no humanos- son observados con limitaciones para decidir sobre su propio beneficio. La naturaleza, presentada como el ámbito no-humano, irracional, caprichosa, contiene en su seno a ese conjunto de seres jerárquicamente prejuzgados, que toma referencias descriptivas de lo considerado femenino de la cultura moderna occidental.

La noción de la mujer cercana a la naturaleza se sostuvo sobre metáforas que, de forma permanente, presentaban a la naturaleza como femenina, aún desde imágenes opuestas como las indagadas por Merchant (1980) de naturaleza-madre que se oponía a la de naturaleza-mujer a dominar. Los escritos del siglo XIX permiten recorrer las formas en que se plasman estas metáforas, e incluso reconocer ecos de frases que resultan recurrentes en las descripciones usuales de la literatura.

William Hudson escribió en 1870 Días de ocio en la Patagonia, allí relata la experiencia de un retiro obligado en los rincones más inhóspitos de un territorio poco explorado por visitantes incorporados a la cultura occidental. Las reflexiones de este naturalista son por demás elocuentes en relación a esta metáfora mujer-naturaleza. Cito

"Es duro vivir en el seno de una Naturaleza indomada o sometida a medias, pero hay en ello una maravillosa fascinación. Desde nuestro confortable hogar en Inglaterra, la Naturaleza nos parece una paciente trabajadora, obedeciendo siempre sin quejarse, sin rebelarse nunca y sin murmurar contra el hombre que le impone sus tareas; así puede cumplir la labor asignada, aunque algunas veces las fuerzas le fallen. ¡Qué extraño resulta ver esta naturaleza, insensible e inmutable, transformada más allá de los mares 
en una cosa inconstante y caprichosa, difícil de gobernar; una hermosa y cruel ondina que maravilla por su originalidad y que parece más amable cuanto más nos atormenta...

A veces es presa del furor que le causan las indignidades a que la sujeta el hombre podando sus plantas, levantando su suelo blando, pisoteando sus flores y su hierba. Entonces adopta su más negro y temible aspecto, y como una mujer hermosa que en su furia no tiene en cuenta su belleza, arranca de raíz los más nobles árboles y levanta la tierra esparciéndola por las alturas..." (Hudson 1997, 78-79).

La naturaleza no sólo es mujer, sino, dependiendo del espacio que se trate, puede verse como una mujer más o menos sometida. Aunque el dominio se presenta como un destino ineludible para la tierra (y para la mujer), que sólo en su juventud o en la mitología puede dar cuenta de un carácter rebelde, que no deja de leerse como caprichoso e irracional. Lo razonable y seguro, desde esta perspectiva, es el dominio y control de tanta irracionalidad e incertidumbre.

La idea de la naturaleza como una mujer indómita a la que hay que someter es, precisamente, la imagen que Merchant (1980) reconoce en los escritos de Bacon, en lo que podría denominarse como la fundamentación simbólica de la ciencia moderna y experimentación. Es esta incorporación de sometimiento, ultraje y silenciamiento como destino ineludible, el punto que se discute desde los escritos feministas y el tema que se resignifica en la teoría ecofeminista.

La idea de naturaleza se toma como referencia en disputa. Como se menciona en el capítulo dos, ésta es una noción esquiva (Haraway 1999). Pero antes que definirla resulta de interés exponer cómo se entiende en las menciones que equiparan mujer y naturaleza. Puede decirse que, con sus distintas variantes, siguen la línea trazada por Aristóteles según la cual la naturalidad implica un ideal regulativo, una normativa implícita que advierte que es lo deseable para el bien de todas las partes (Femenías 1996). Naturaleza es para Aristóteles materia y potencia, una potencia que ordena lo material en un mundo jerárquico, con dominios y finalidades preestablecidas. Lo natural es el respeto al orden establecido: que los varones sean superiores y las mujeres inferiores, que los varones dominen y la naturaleza se someta. Lo antinatural es antológicamente no deseable, va en prejuicio del conjunto. 
Los ecofeminismos, por su parte, refutan esta idea de naturaleza. Se trata de propuestas teóricas que apuntan a desnaturalizar lo natural al poner en evidencia el carácter artificial y peyorativo de los supuestos sobre los que se funda esta mirada. Rebate la visión dicotómica de relaciones asimétricas que se presentan con la forma dominador/dominado. Civilización/barbarie, amo/esclavo, varón/mujer, son algunos de los pares antagónicos en los que, como para el caso sociedad/naturaleza, la desigualdad implica derechos de dominio.

Los ecofeminismos rescatan, precisamente, las voces asumidas como menores; abren la posibilidad de reconocer la complejidad de la parte dominada del par y desde allí iniciar la refutación del modo desigual desde el que se vincula. Recorren autonomías y resistencia de quienes se presentan como pasivos, poniendo en evidencia la injusticia fundamental sobre la que se edificó la diferenciación. Desde el feminismo en general se reclama el repensar las historias y las trayectorias, tal como argumenta Femenías (2007).

"Porque la experiencia es la historia de un sujeto y el lenguaje el sitio donde representa su historia; donde lo personal y lo social se imbrican y son variables, donde la experiencia debe ser desnaturalizada para convertirse en crítica, donde la palabra disputada y contingente genere análisis y produzca relaciones transferenciales" (Femenías 2007, 102-103).

Ahora bien, estas consideraciones de cercanía a la naturaleza y alejamiento de la razón no se han proyectado en forma exclusiva hacia la condición femenina, sino se establecen como carácter de lo diferente, que al ser reconocido sobre todo desde esta particularidad, se presenta como conjunto homogéneo. Estas nociones se repiten en las descripciones que presentan a los sectores menos favorecidos de la sociedad occidental, así como también a los pobladores no-occidentales, donde se destacan las evaluaciones hacia los pueblos originarios de América o la población africana.

Los escritos decimonónicos son particularmente ricos en referencias a estas diferenciaciones, en gran parte por estar influenciados desde las consideraciones de la antropología física, que se destacó como fundamento de las más importantes discriminaciones del período. ${ }^{49}$ Para ilustrar esta idea pueden recorrerse las letras del escritor argentino Eugenio Cambaceres, quien en 1887 escribe una novela cuyo relato

\footnotetext{
${ }^{49}$ Ver capítulo tres.
} 
supone estos prejuicios, que se titula En la sangre. En esta novela presenta las desventuras de un personaje que, limitado por el origen social y las características de sus padres a la Razón, no termina de resignarse a su destino hasta el final de la obra. Este escrito se inicia con las siguientes frases:

"De cabeza grande, de facciones chatas, ganchuda la nariz, saliente el labio inferior, en la expresión aviesa de sus ojos chicos y sumidos, una rapacidad de buitre se acusaba.

Llevaba un traje raído de pana gris, un sombrero redondo de alas anchas, un aro de oro en la oreja; la doble suela claveteada de sus zapatos marcaba el ritmo de su andar pesado y trabajoso sobre las piedras desiguales de la calle.

De vez en cuando, lentamente paseaba la mirada en torno suyo, daba un golpe -uno solo- al llamador de alguna puerta y, encorvado bajo el peso de la carga que soportaban sus hombros: «tachero»... gritaba con voz gangosa, «¿componi calderi, tachi, siñora?»

Un momento, alargando el cuello, hundía la vista en el zaguán. Continuaba luego su camino entre ruidos de latón y fierro viejo. Había en su paso una resignación de buey”. (Cambaceres 1887, 5-6)

El modo de dar cuenta de las limitaciones en el acceso a la Razón se establecen desde similitudes con animales no-humanos. En este caso no se trata de un personaje femenino, sino de un varón. La idea de destino ineludible vuelve al primer plano en la población de los sectores populares, cuyas limitantes al desarrollo no descansan en formas desiguales de distribución y organización, sino en los condicionantes internos de estas poblaciones. Desde el relato, tanto la población como su descendencia están condenadas.

La propuesta de la novela no escapa a nociones filosóficas que entienden la diferencia como interiorización. La homogeneización de lo diferente hacia sectores tomados como modelo lleva, como se expone en el tercer capítulo, a la aceptación acrítica del juicio peyorativo desde el cual, en una falacia tautológica, se legitima la propia homologación.

El reconocimiento de la diferencia es un desafío cada vez más resonante en las reflexiones sobre la desigualdad. Siguiendo a Femenías (2007) se encuentran dos momentos en el proceso de diferenciación: la heterodesignación y la autodesignación. El primero, la heterodesignación, es una referencia a aquello que distingue, el lugar, nombre, rasgo, o la diferencia desde la cual un grupo se reconoce en el espacio público. 
En otras palabras "el momento de heterodesignación es el momento de exclusión del campo de los "iguales"” (Femenías 2007, 74). Este primer proceso está asociado a la edificación que el otro hegemónico haya realizado sobre el grupo que se diferencia. Que en general focaliza un rasgo investido con un carácter negativo para referenciar la distancia del grupo en cuestión respecto del hegemónico que se auto-asume como modelo. El discurso hegemónico es un discurso normativo.

En este contexto de limitaciones, la posibilidad de encontrar un espacio propio y salir de la disparidad-inferioridad edificada desde la mirada hegemónica, se genera a partir del segundo momento del proceso de diferenciación: la autodesignación. Entendiendo que se trata de reconocer el sitio de diferencia establecido por el otro, para desde allí establecer la autodesignación de un modo que escape a los sesgos displicentes.

En el caso del tema ambiental, los sesgos se vinculan a un modo particular de comprender la naturaleza, y en ello quisiera retomar la idea de Haraway (1999) de asumir la naturaleza como topos, como referencia desde la cual se edifica lo cotidiano. Tomaré la idea de cotidiano para explorar tanto la conformación de desigualdades como la edificación de la naturaleza a partir de revisar algunos mitos (en el sentido otorgado por Eliade 1972, 1992) desde los cuales se han proporcionado modelos de conducta.

\section{Inequidad estructural y mitos asociados}

La idea de mito que tomo en esta reflexión parte de la elaborada por Mircea Eliade (1972), que analiza sociedades donde el mito se reconoce como "vivo" en el sentido de proporcionar modelos a la conducta humana y conferir por eso mismo significación y valor a la existencia. En estos contextos el mito designa una "historia verdadera" sagrada, ejemplar y significativa. La sociedad que voy a tomar como base de reflexiones no es una sociedad arcaica, sino un asentamiento de pobladores galeses que a mediados del siglo XIX arribaron a las costas patagónicas, para asentarse en la región cordillerana a finales de esa misma centuria en la localidad que hoy se conoce con el nombre de Trevelin. La adopción de este caso se fundamenta en el tema de este trabajo; esta población reconoce como uno de sus principales héroes a un caballo, el Malacara, figura fundamental del relato de origen del asentamiento (Evans 1994). 
Claude Levi- Strauss (1996) elabora un punto de vista que también debe considerarse en este contexto de disputas territoriales. El antropólogo francés señala que todo mito diceen-contra de otro y no puede ser entendido sino a la luz de su referente polémico. El mito de origen de los galeses, se opone al de los pueblos originarios, necesariamente debe omitir el derecho a estar y habitar de estos pobladores.

Tal es la necesidad de este recurso de ocultamiento que la "historia ejemplar" de Trevelin adopta a un no-humano como par de los colonos, al mismo tiempo que enmudece a otros humanos (los pobladores originales), que quedan relegados en la figura de catástrofe natural. Este caso resulta especialmente paradigmático, por el modo en que se consolida el relato, que permite reconocer prejuicios y presupuestos que ponen en evidencia la condición lábil de la separación que se establece entre sociedad y naturaleza que busco explorar.

\section{El caballo como héroe, el humano como peligro natural}

Trevelin es una localidad fundada por colonos galeses a fines del siglo XIX. El arribo de los galeses a esas tierras estuvo plagado de peripecias. Los primeros asentamientos se concretan sobre la costa chubutense y, desde allí, fueron remontando el río Chubut hasta establecerse en el paraje cordillerano. En uno de los viajes de exploración un grupo de galeses fue atacado por un grupo de indígenas.

La simple idea de ataque obliga a una reflexión sobre los motivos. Porque en el trasfondo de este encuentro se presenta un Estado Nacional Argentino que estaba llevando adelante la denominada "Campaña del Desierto". Esta situación permite reflexionar sobre las tensiones que operan detrás de la noción de reconocimiento, porque en el caso de los pobladores originarios, que el estado los reconociera como habitantes de la Patagonia era sinónimo de convalidar el derecho sobre el uso y ocupación de la tierra. Esto resultaba opuesto a los intereses argentinos que, precisamente buscaban avanzar sobre los territorios de pueblos originarios para incorporarlos al esquema económico que se estaba edificando (Halperin Dongui 1992). En este proceso los habitantes de los territorios fueron caracterizados como “extranjeros" y forzados a mudarse a los terrenos más agrestes o a centros de detención que hoy podrían caracterizarse como “campos de concentración” (Navarro Floria 2004). 
Las definiciones que se establecieron desde el Estado Nacional no sólo impactaron en el vínculo entre el estamento gubernamental y los pueblos originarios, también incidieron en las relaciones entre el conjunto de actores humanos que se presentaba en el territorio de conquista. Volviendo al relato de Evans (1994) se encuentra que, al momento de asentarse en las costas patagónicas, los galeses reciben una importante ayuda de los pobladores originarios, a una escala que los lleva a valorar que sin este acompañamiento la posibilidad de subsistencia hubiese sido nula. Sin embargo, varios años después, los mismos galeses asumen a los pobladores originarios como peligro, como una traba a sortear en su deseo de concretar la ocupación de un determinado territorio.

Vale aclarar que si bien los exploradores galeses no formaban parte de los avances del ejército argentino, tenían vinculaciones con el gobierno que visualizaba en estos inmigrantes europeos una población culturalmente más apropiada para el desarrollo de una nación moderna. Raza y cultura aparecen como sinónimo y fundamento de la apropiación espacial.

El orden simbólico desde el cual se subestimaba a los pueblos originarios tuvo siempre el horizonte de la cultura occidental como modelo. Un pasaje del escrito de Hudson es particularmente claro al respecto.

"Durante esta investigación traté algunas veces de imaginarme algo referente a la vida espiritual y material de los habitantes desaparecidos hacía tanto tiempo. Los pieles rojas de hoy pueden pertenecer a la misma raza y tener la misma sangre; en una palabra: pueden ser los descendientes directos de los que trabajaban piedras en Patagonia; pero, sin duda, están tan cambiados y han perdido a tal extremo sus características que sus progenitores no los reconocerían ni los aceptarían como sus parientes. Allí, como en la América del Norte, el contacto con una raza superior los ha rebajado... Algo de su sangre salvaje continuará corriendo por las venas de los que han tomado su lugar; pero como raza tendrán que desaparecer de la tierra" (Hudson, 42)

La raza, como sitio de reconocimiento propio y desde los otros, se diluye en tanto se desdibujan creencias y costumbres. Pero en este eclipsamiento de la pertenencia los actores no quedan necesariamente inscriptos en la cultura que se toma como modelo y desde la cual se desestructura la identidad de los otros. $\mathrm{O}$ al menos no quedan inscriptos en el sitio del amo de la dialéctica hegeliana. Siguen describiéndose con rasgos que se 
entienden como limitantes para el acceso a la razón, en el sitio de la dependencia o del esclavo.

Los galeses que llegaron a Chubut en el siglo XIX no escaparon a estas tensiones, y se enfrentaron a que los habitantes que oficialmente se debían someter. Los perseguidos no compartían estros criterios de razón y lo desmostraban desde formas tan violentas como las que se utilizaban para someterlos. Por este motivo fueron atacados por los nativos.

Aquí nace el mito del caballo-héroe, porque sólo uno de los exploradores se salvó, el que logró escapar porque su caballo, el Malacara, saltó hacia el fondo de un barranco al que lo habían llevado los indígenas con la esperanza de acorralarlo. La capacidad física del caballo, no sólo le permitió saltar, sino caer sin mayores lastimaduras, reincorporarse y emprender la huida con su jinete sin que los indígenas tuviesen oportunidad de bajar hacia donde se encontraba. El jinete proyectó en la acción del caballo su propia intención por sobrevivir, y desde allí fundamentó un vínculo de amistad con el animal que lo invistió con un carácter de par antes que de animal.

Esta consideración sobre el caballo cobra un sentido social, porque el escape permite salvar la vida de quien sería el fundador de la colonia galesa en la cordillera. De allí que se lo presente como actor fundamental de la historia que se cuenta y se le levante un monumento. ${ }^{50}$

En el largo proceso de establecimiento de los galeses se van presentando dificultades, como un posible ataque de los indígenas (a los que se condena por su intención de recuperar las tierras), la depredación de los pumas, o las inclemencias climáticas. En el relato los pumas y los indígenas aparecen como un riesgo latente. Incluso se cuenta un evento (cuyos detalles se amplían en el museo local) en que un puma mata un niño y se organiza una cacería, porque resulta inconcebible la convivencia con un animal que asume a un ser humano como su presa.

Este relato permite mostrar un caso en que el "otro" ajeno, evaluado como riesgoso, susceptible de ser dominado, no necesariamente se asume como animal-no-humano. De hecho, el caballo Malacara se presenta como más próximo y similar a los galeses que

\footnotetext{
${ }^{50}$ Poco tiempo después del ataque en las márgenes del río Chubut, y gracias al relato del único superviviente que facilitó el encarcelamiento de los indígenas que poblaban la cordillera; los exploradores galeses fueron reclutados en los viajes de reconocimiento que el ejército argentino organiza hacia la cordillera, contando en estas exploraciones con el Malacara y su jinete. En este camino conocen el valle que actualmente ocupa Trevelin, la riqueza de la tierra, los arroyos que lo riegan, y deciden establecerse.
} 
los indígenas, que pocos años antes los habían ayudado a sobrevivir en la agreste costa chubutense.

La separación entre lo humano y lo natural no se presenta, entonces, como un problema relativo a ser o no humano (en un sentido biológico estricto), sino de la relación que se establece con la cultura que se presenta como dominante. Los animales más próximos se reconocen con una espiritualidad tal que permite presentarlos como amigos. En este reconocimiento no se pierde ni el carácter humano del explorador galés, ni el carácter caballuno del Malacara, pero fue justificativo suficiente como para erigir un monumento a la memoria del caballo, tal como puede observarse en la localidad chubutense.

Los indígenas no son humanos en un sentido equivalente, porque no tienen derechos a la ocupación de la tierra, a la pervivencia de sus costumbres o incluso a su supervivencia. Limitantes que se establecen hacia ellos aún siendo humanos, aún estableciéndose diálogos, e incluso habiendo facilitando intercambios de comida y estrategias de supervivencia en la región para los inmigrantes europeos llegados unas décadas antes. La imagen que el relato galés transmite de estos pobladores originarios los reduce a los riesgos del paisaje, casi como parte de las alimañas que hay que sacar para asegurar un modo de vida digno (es decir occidental). Todo lo que amenace la vida humana (entendiendo como humano a galés en este caso), debe ser alejado de la zona o aniquilado, sea un puma o sea un poblador originario.

Entonces ¿cuál es el límite entre la humanidad y la naturaleza?

A la luz de los debates, y considerando un ejemplo donde el límite entre la humanidad y la naturaleza deja de un lado galeses y caballos, y coloca del otro a pueblos originarios y pumas, podemos pensar que es un límite cambiante, cuyo sentido se encuentra, como menciona Plumwood (1996, 2004) en las relaciones que se establecen antes que en las esencias. Cada espacio, cada lugar, da lugar a ciertos ejercicios de relación (Hall 1973), que no están determinados ni por condicionantes geográficos o culturales, sino que resultan de la pluralidad de variables, materiales y simbólicas que convergen en ese lugar en particular.

Viajando nuevamente hacia fines del siglo XIX, y a la luz de las primeras reuniones que tratan el tema del cuidado del ambiente vale recordar el encuentro de 1895, celebrado en 
la ciudad de Sena, que se conoce como el primer Congreso Internacional sobre la protección de las aves beneficiosas para la agricultura. Es decir, no se piensa en la protección de otras aves, o en la importancia general de los animales, se trata de aquellas aves con las cuales establecemos relaciones desde las prácticas culturales.

La aceptación acrítica de la cultura occidental como medida (y fin preestablecido) de todas las culturas, acarrea confusiones que tienen similitudes con las impugnaciones que Lamark estableció en su discusión sobre el hombre como medida y modelo de los seres vivos. En el terreno de las formas culturales es la antropología la que permite llegar hacia los casos que ponen de manifiesto que los límites entre la sociedad y la naturaleza son, en definitiva, acuerdos y construcciones sociales. Vale mencionar, a modo de ilustración, las referencias con que Philippe Descola (1996) describe a los achuar (pobladores de la selva amazónica también conocidos como jíbaros). Los mismos, al momento de diseñar una cacería, se percibían como familiares de los animales que cazaban o de las plantas que cultivaban. Esto no les impedía cazar o comer, pero en el proceso de cacería el cazador "se convertía" en el animal que buscaba, y desde una situación de iguales, se presentaba el ataque. Descola reflexiona que a él le llevó un tiempo comprender que aquello que desde las sociedades occidentales se asume como actividad productiva, para los achuar era un modo de relación. ${ }^{51}$

Otro elemento fundamental para el reconocimiento, que varía en función de las culturas, es el relato histórico desde el que se configuran identidades. El vínculo con el pasado, al

${ }^{51}$ El antropólogo francés avanza sobre este problema de reconocimiento de límites entre sociedad y naturaleza e investiga las diversas formas en que las culturas conciben la relación con la naturaleza, presentando la escisión de las sociedades occidentales como una más entre las variadas posibilidades. Aunque es, tal como se reconoce desde la pluralidad de escritos presentados, la visión desde la cual se ha dado lugar a la mayor expoliación.

A modo ilustrativo debo señalar que Descola (2005) distingue cuatro modos de identificación entre la humanidad y la naturaleza. 1-EI naturalismo -cuyo mayor exponente es la cultura occidental- se basa en la idea de que sólo los humanos están dotados de vida interior. Los demás "existentes" -plantas, piedras, animales- están privados de ella. En el plano orgánico, los hombres no tienen nada de singular, ya que están gobernados por las mismas leyes físicas que los no humanos. 2- El animismo, donde los no humanos están dotados de la misma vida interior que los humanos y tienen una vida social y cultural. Donde las actividades que desde la cultura occidental podrían catalogarse como productivas (la caza, la jardinería, la pesca) son actos de sociabilidad. 3- El totemismo, donde los humanos y los no humanos comparten propiedades físicas y morales que los clasifican juntos según diferentes categorías: puede ser el color de la piel, la morfología (ser "redondo" o "anguloso") u otras características particulares (ser lento o nervioso). Un hombre podrá decir que un canguro es exactamente igual a él basándose en un principio común del cual ambos descenderían (la vivacidad, por ejemplo). 4- El analogismo, que caracteriza un mundo percibido como una infinidad de singularidades, todas diferentes entre sí. Es el ejemplo chino de un mundo compuesto por 10.000 esencias. El pensador francés destaca que el analogismo fue el modelo más común en el mundo, sobre todo en Asia, África del Oeste y en las sociedades andinas, antes de que se impusiera el naturalismo. 
igual que el vínculo con la naturaleza, no está predeterminado de forma trascendente. Un ejemplo sobre este punto acerca nuevamente las referencias patagónicas. Adrián Moyano (2007), revisando la relación entre los mapuche y su historia, reconoce en la figura del weupife mapuche una cierta similitud con los historiadores occidentales. El weupife es el encargado de transmitir el pasado, sus herramientas no son tinta y papel sino la palabra y la memoria. Pero no sólo las herramientas, el vínculo con el pasado cambia.

"Entre los mapuche los weupife son historiadores. Pero sus relatos no están desprendidos de un significado comunitario y tampoco carecen de un sentido espiritual. Cuando cumple su cometido, el weupife lleva a cabo una ceremonia. Canta, gime, dramatiza, se mete en la piel del héroe cuya epopeya relata, grita, se desespera, muere y vuelve a la vida. Revive el pasado que cuenta" (Moyano 2007,23)

El pasado, para los mapuche tiene la posibilidad de tornarse presente. Puede pensarse que estas referencias tienen un cierto grado de similitud con la propuesta de Robin G. Collingwood (1981), quien señala que la historia debe desarrollarse como una 'reactualización' (“re-enactment”) de experiencia pasada, donde la tarea el historiador es penetrar en el pensamiento de los agentes cuyo acto estudia siendo tan imprescindible la sensibilidad como la erudición. Pero la propuesta del pensador británico se encuentra lejos de la costumbre mapuche referida, porque la noción de Collingwood no deja de ser una experiencia mental, aún cuando se presente como un cambio frente a la historia positiva que el británico discute. Sin embargo, aún cuando a la luz de las comparaciones culturales se perciba como un cambio pequeño, es un cambio poco adoptado, porque las reflexiones de Collingwood, como señala Joseph Fontana (2006), pese a haber sido ampliamente leído por los historiadores, ha influido muy poco en su práctica.

Estas referencias permiten dimensionar el desafío que se presenta desde el reclamo por traducir la conciencia ambiental en acciones $-\mathrm{O}$ en particular en acciones de conocimiento como se propone esta tesis. A partir de reconocer las necesidades de cambiar la vinculación sociedad-naturaleza (o cultura-naturaleza), implícitamente se insertan modificaciones tanto en la relación con el mundo como con las explicaciones que hemos asumido como válidas.

Nos enfrentamos a poner en entredicho la constitución misma de lo cotidiano, los modos occidentales de vincularnos con el entorno, y en forma asociada, con la propia 
forma de edificar nuestra identidad. Así retornamos al mismo punto en que nos dejó la revisión de la concepción de la naturaleza: la pregunta por la posibilidad de avanzar en un conocimiento con valores diametralmente opuestos a los que han sostenido el saber occidental. Que no sólo nos permiten una forma de relación, sino que han resultado constitutivos tanto a nivel individual como social.

Es decir, nos enfrentamos a prácticas y valores que sostienen nuestra cotidianeidad, nos enfrentamos a nuestra propia historia e incluso a preceptos que afectan nuestra propia identidad. Pero tal vez, antes que abandonar los modos occidentales como conjunto, se trate de rescatar o reparar en las formas de referencia que no necesariamente se exponen con el mayor énfasis en la arena pública. Tal vez las propias voces menores den pistas sobre modos alternativos de pensar el vínculo sociedad/naturaleza, que no sólo se despliegan en culturas diferentes, sino que se encuentran en ámbitos no reconocidos como conocimiento, dentro de la propia cultura occidental. En esta línea puede encontrarse, por ejemplo, a los poemas, que no necesitaron de mayores reflexiones para asumir a animales no-humanos como pares de los animales-humanos, pero no como principio general sino a partir de la vinculación que se establecía entre determinado animal y determinada persona. ${ }^{52}$

\section{Los ecofeminismos}

El problema de la dualidad sociedad/naturaleza es explorado con especial profundidad desde los ecofeminismos. Las reflexiones que suman a la teoría de género los debates de la ética ambiental parten de discutir la metáfora mujer-naturaleza como fundamento de formas de dominio y control. Esto se suma al reconocimiento de que la desigualdad que se proyecta sobre amplios sectores sociales, no opera con igual peso entre los diversos

\footnotetext{
${ }^{52}$ Valen como imagen los versos de Atahualpa Yupanqui “...

En el fondo del abismo, ni una voz para nombrarlo. Solito se fue muriendo, mi caballo, mi caballo.

En una horqueta de un tala hay un morral solitario, y hay un corral sin relinchos, mi alazán te estoy nombrando.

Si es como dicen algunos, que hay cielos pal' buen caballo, por ahí andará mi flete, galopando, galopando..." (El alazán)
} 
actores afectados. En las poblaciones ligadas a procesos de expoliación, las mujeres son las que sufren los mayores ejercicios de sometimiento (Boserup 1970, Shiva 1988, Del Valle 1997), de allí que la vinculación de las reflexiones en torno al sometimiento de esta naturaleza (concebida como antinómica de la civilización), y la condición femenina da pistas en torno a una lógica de dominio que trasciende a las mujeres como género y nos pone de frente a un ejercicio de desigualdad más amplio.

El debate sobre esta vinculación mujer-naturaleza ha permitido aglomerar este conjunto de perspectivas en base a una serie de tesis, sistematizadas por Karen Warren (1987) y compartidas por todas sus corrientes ecofeministas.

a) Existe una relación entre la opresión experimentada por las mujeres y la sufrida por la Naturaleza

b) No puede entenderse en profundidad ni la opresión de sexo ni la de la Naturaleza si no se tiene en cuenta su relación

c) El feminismo en teoría y praxis, debe incluir una perspectiva ecológica

d) A su vez, las propuestas frente a los programas ecológicos deben asumir las reivindicaciones feministas.

En las teorías ecofeministas también se encuentran algunos elementos reiterados

a) La crítica a los dualismos (mente/ cuerpo; naturaleza/cultura; varón/mujer, etc)

b) Afirmación de la existencia de correspondencias entre todas las formas de opresión (sexismo, racismo, dominación de clase, de la naturaleza y del tercer mundo se hallarían íntimamente relacionados)

c) Internacionalismo, actitud anti-institucional y ética política de democracia de bases

d) Importancia concedida a las vivencias y a la práctica política de las mujeres

e) Reivindicación de la utopía

f) Sensación de sobrevivir en condiciones patriarcales enemigas de la vida. 
Los ecofeminismos se presentaron en su versión original o clásica, hilvanando conceptos como maternidad, pacifismo y ecología. En este sentido se propuso como una reflexión que asumía condicionantes esencialistas en la mujer como globalidad, sosteniendo que esta misma esencia era la que la posicionaba en una situación diferente, dada sus limitantes a la agresividad y su sensibilidad (también esencial) hacia los seres vivos (Puleo 2005).

La idea de la mujer como cercana a la naturaleza llevó a pensar, a partir de tomar conciencia sobre la finitud y el deterioro del planeta, en la condición femenina como clave para encontrar alternativas en el desafío de la conservación (Braidotti 1994). Esta noción, fundamentada en muchos casos en la concepción esencialista antes mencionada, ha tenido, sin embargo, limitantes en su aplicación, porque, como menciona Verónica Vazquez García (2007), muchos de los programas ambientales diseñados desde la perspectiva clásica de desarrollo sólo aumenta la carga de trabajo de las mujeres, sin aportarles mayores beneficios. Dianne Rocheleau (1995) señala, en una línea similar a la de Bina Aragwal y al capítulo tres en general, que uno de los principales problemas estriba en que no se toma como punto de partida los conocimientos que ellas tienen sobre los recursos, porque no se los considera como conocimiento equiparable a saberes técnicos específicos, y simplemente se avanza sobre lo que se considera mejor para ellas.

Vandana Shiva (1988), una de las pensadoras más reconocidas del ecofeminismo clásico, señala que esta falta de reconocimiento no sólo se debe a una vocación por ignorar a determinadas voces, sino que los movimiento ecológicos, los pacifistas y los feministas se constituyen como una fuerza de oposición que desafía las "categorías dominantes del patriarcado occidental que hoy dirige el mundo en nombre del desarrollo y el progreso aunque estén destruyendo la naturaleza y amenazando la vida de culturas y comunidades enteras" (Shiva 1988, 27)

La pensadora india recorre en detalle los aspectos ambientalmente más problemáticos del crecimiento capitalista. En esta línea señala que el desarrollo se redujo a ser la continuación del proceso de colonización, prolongando los condicionantes de dominio establecidos en relación a esos "otros", que no se adecuaban al ideal de varón-occidental que detentaba el conocimiento y la voz de mando. 
En este punto Shiva incorpora una característica sutil pero significativa, la idea de producción no se mide tanto a partir de la cuantificación efectiva sino en función de la incidencia de la actividad humana en el cambio del paisaje. Así sostiene que desde la visión occidental la naturaleza, en su forma original, es improductiva. Esa naturaleza salvaje, tan románticamente descripta por Hudson, no entrega frutos. Así quedan fuera del esquema comprendido como eficiente la agricultura orgánica (basada en ciclos naturales), o las estrategias desarrolladas desde sociedades no occidentales. Shiva señala que no existe una prueba definitiva que permita reconocer que desde formas cooperativas se producen menos bienes, sino que más bien la producción se restringe a la incorporación de técnicas, aún cuando éstas impliquen un desgaste irreversible. "Según esta opinión, un río estable y limpio no es un recurso productivo: es necesario desarrollarlo con represas..." (Shiva 1988, 32-33)

La pensadora india entiende que la aceptación sesgada del concepto de producción es la base de sustento de una lógica de dominio, porque al comprender los procesos de la naturaleza-no-humana como desligados de la supervivencia humana se evitan cuestionamientos que discutan las formas establecidas de expoliación. Desde las estrategias legítimas de "apropiación de recursos" se cercenan las capacidades de acción de grupos con organizaciones no-occidentales, porque se limitan los recursos a los que tienen acceso Pero esto se torna invisible porque no se problematiza el creciente control sobre los recursos naturales. Es un círculo vicioso que fortalece un proceso de dominio y desigualdad.

Entre las estrategias de invisibilización que denuncia Shiva se cuenta que este círculo vicioso no se reconoce porque, desde las sociedades occidentales, se evalúa en forma peyorativa a las formas organizativas alternativas como "pobreza". Desde esta perspectiva sostiene que la pobreza concebida (y reconocida) desde ciertos patrones culturales (que incluyen formas de domino específicas) no necesariamente implica limitaciones materiales. Así evalúa que las economías de subsistencia, aún cuando cubran las necesidades básicas, son consideradas como "pobres" porque no participan claramente en la economía de mercado.

Desde este reconocimiento Shiva propone una alternativa basada en lo que denomina la "recuperación del principio femenino", el cual entiende como desplazado cuando la ciencia moderna reduccionista se asume como forma legítima y única de conocimiento. 
En contra de esta propuesta Shiva sostiene la necesidad de recuperar el "principio femenino" - o el Shakti en la cosmología brahamánica - basado en las concepciones de mundo de antiguas civilizaciones, que desde los mitos que presenta asume una continuidad ontológica entre la sociedad y la naturaleza. Para Shiva, siguiendo a María Mies, las sociedades de subsistencia contienen el principio femenino porque en su trabajo se consolidaron como productores de vida de un modo tal que crearon una relación especial de las mujeres con la naturaleza.

Las críticas a Shiva se refieren, precisamente, a este punto, donde las apelaciones al cambio reconocen un vínculo esencial y generalizable. Regina Cochrane (2006), por ejemplo, reconoce la descripción del problema elaborada por Shiva, pero critica su propuesta de solución, que implica un rechazo total al desarrollo. Cochrane (2006) discute esta visión, donde la única alternativa que se plantea es el retorno a las economías de subsistencia señalando que, en el círculo vicioso donde la lógica que produce las desigualdades no puede tomarse como base de ninguna salida, el cambio que propone Shiva parece reducido a un retorno al pasado. Este ejercicio de idealización de las organizaciones no-capitalistas, que en el trabajo de Shiva también se presenta en la reivindicación de una esencia femenina especialmente vinculada a la naturaleza, impide el reconocimiento de contradicciones en los escenarios que se toman como ejemplo o como vía de desarrollo alternativa.

La falta de examen hacia las tensiones internas impide tomar en cuenta una impugnación práctica: las economías de subsistencia no cubrieron (y aún no cubren) todas las necesidades nutricionales de sus miembros al nivel biológico adecuado para mantener sus capacidades básicas. Cocharne profundiza esta idea al indicar que las "necesidades básicas" que las economías de subsistencia satisfacen no incluyen educación (escolarizada), autonomía personal, libertad de pensamiento, entre otras capacidades, con lo cual pone en duda los beneficios mencionados por Shiva.

Otro punto que se discute es la necesaria referencia al "principio femenino". Entre las autoras más destacadas que impugnan las posiciones que toman como centro el aspecto espiritual como mediador de la relación sociedad/naturaleza, y desde esta oposición generan perspectivas alternativas, se destaca Bina Agrawal (1998, 2002, 2003). Esta autora (también india) ha revisado las posturas espiritualistas o esencialistas extremas indicando que, si bien el vínculo mujer-naturaleza resulta enriquecedor para revisar las 
contradicciones en las relaciones que socialmente se plantean con el entorno, esto no se apoya en una esencia femenina que la acerca a la naturaleza, sino que se sostiene en la base material específica y cotidiana de cada situación (1998).

Agarwal nos llama la atención sobre las formas específicas de interacción, que deben tenerse como horizonte permanente en esta reflexión sobre humanidad y ambiente (o entorno, o naturaleza). Al respecto reitera la importancia de reflexionar sobre la inequidad de género, no sólo desde su particularidad sino, y sobre todo, a partir de los vínculos que pueden establecerse con otras formas de desigualdad (2003). En una línea similar, Verónica Vazquez García (2007) reconoce, a partir del caso de pescadoras mejicanas, la necesidad por conocer los distintos factores materiales que determinan el acceso y control de varones y mujeres a los recursos, así como los intereses que pudieran tener en la conservación ambiental. ${ }^{53}$

Las diferencias que estas autores introducen en el análisis es que las variables observadas, que son en un grado importante variables económicas, dejan de circunscribirse a las relaciones públicas, indagándose espacios usualmente poco problematizados, como son las relaciones al interior de los hogares.

En esta línea Agarwal (2003) reflexiona en torno a los estudios sobre las instituciones gubernamentales señalando que, gran parte de las investigaciones, caen en las falacias que caracterizaron a las evaluaciones hogareñas que tomaron como ajenas a este ámbito las tensiones generadas por las instituciones sociales. Así indica que estos estudios suelen reconocer a las desigualdades como factores macro, pero que no las consideran como condicionantes internos, haciendo caso omiso a las desigualdades creadas o arraigadas en el interior y la cotidianeidad de la organización familiar.

En este camino de revisión de particularidades Agarwal critica a Shiva por entender a las mujeres del tercer mundo como un grupo homogéneno, en cuanto a su relación con la naturaleza, dejando de lado la variedad de situaciones provenientes de la diversidad de paisajes, estados, formas organizativas, estrategias de sometimiento, etc. Y con ello cercenando el camino reivindicatorio de las particularidades.

\footnotetext{
${ }^{53}$ Estos trabajos, entre otros, han dado lugar a la corriente denominada género, medioambiente y desarrollo (GMAD), la cual propone identificar las responsabilidades de mujeres y hombres en relación a determinados recursos, así como las instituciones y relaciones de propiedad que rigen el acceso a éstos en contextos socio-ambientales específicos (Leach et al 1995, Rocheleau et al 1996, Rico 1997; Schminck, 1999, Meléndez y Workman 2000)
} 
Las generalizaciones de Shiva omiten la edificación de diferencias desde conceptos no necesariamente capitalistas, ya que a la diferencia de clases, que tampoco toma Shiva, se podría agregar las jerarquizaciones por castas, razas, etnias, sitios ecológicos, por nombrar algunos de los aspectos que Bina Agarwal menciona como debilidades de "abrazar la vida".

En estas revisiones hay similitudes con las críticas que Christine Delphy (1977) y Heidi Hartmann (1975) realizan revisando las posiciones de la ortodoxia marxista. Porque también estas autoras objetan que se privilegie el análisis de desigualdades desde los procesos capitalistas a un nivel tal que permite eclipsar otras formas de opresión que, como reconoce Agarwal, pueden vincularse a la dimensión material más inmediata que es bastante más compleja que la estructura de dominio general que Shiva presenta en su obra.

Pero no sólo la base material del vínculo sociedad - naturaleza permite poner en tela de juicio la cercanía atemporal de la mujer y la naturaleza, que Shiva presenta bajo la idea de Shakti. La propia idea de sensibilidad de la mujer, por el rol social que le toca cumplir, es un punto inestable como para tomar de piedra fundamental en relación al potencial de cambio.

Esto no implica que la experiencia femenina no sea fuente de conocimiento y generación de vías alternativas de desarrollo, por el contrario, las revisiones que toman este punto llaman la atención hacia profundizar y contextualizar en cada caso un nivel de experiencias que, al generalizarse o idealizarse, corren el riesgo de perder su potencial. La confianza en la voz del/la oprimido/a como un sitio privilegiado de revisión debe mediarse con los obstáculos de reconocimiento que incorpora la misma lógica de dominio que sitúa a los/as oprimidos/as en ese lugar. La comprensión de la situación, y en esta línea, la posibilidad de interpretación de las voces silenciadas deben considerarse a la luz de las dinámicas relacionales (Mellor 1997). No se trata de cambiar un sitio privilegiado por otro, asumiendo que el otro es menos problemático, sino de reparar en los vínculos de ocultamiento que involucran a todas las partes. Ya Pierre Bourdieu (1999) hace referencia a trabas en la toma de conciencia de las situaciones de desigualdad, cuando, a través de la violencia simbólica, se instalan interpretaciones legitimadoras del estatus quo. En esta línea cobran relevancia las propuestas pragmáticas de Iris Young (1997) y Nancy Fraser (1997), donde se destaca la necesidad 
de establecer un diálogo consciente de las tensiones, con voces moduladas de tal forma que ninguna de las partes se atribuya la verdad.

Para ilustrar este punto bien vale un ejemplo que cruza elementos de emancipación femeninos en las sociedades occidentales y toma de conciencia ambiental a partir de una de las figuras femeninas más paradigmáticas de los reclamos ecologistas: Rachel Carson.

Esta bióloga norteamericana, en 1960, avanzó sobre sus conocimientos científicos para arribar, en su texto La primavera silenciosa, a un reclamo en torno a una ética de la responsabilidad, ausente en las prácticas que tomó como base de sus consideraciones. Ella entendió que sin este nivel de ética no había salida para el nivel de degradación ambiental que denominó "biocidio".

María José Guerra Palmero (2004), desde una perspectiva -como ella misma definematerialista y social, analiza el trabajo de Carson revisando la incidencia de su condición femenina en el trabajo desarrollado. Al respecto concluye que Carson fue "una exiliada, al menos parcial, del destino de mujer- nunca se casó, vivió con su madre a la que cuidó y tuvo, también, que adoptar un sobrino.”(Guerra Palmero 2004, 124). Guerra entiende que fue, precisamente, esta posición excéntrica o diferente a la de la mayoría de las mujeres, la que facilitó a Carson estudiar, desarrollar una profesión plenamente ligada a sus intereses y escribir permitiéndose, incluso, desafiar a los importantes intereses económicas de las industrias agroquímicas. En este sentido Guerra no encuentra condicionamientos de género en la redacción de la obra, aunque sí encuentra una clara referencia en este sentido en la recepción social del texto, donde la autoría femenina es presentada como argumento para desacreditar las conclusiones de la obra. Conclusiones que apelaron al reconocimiento de la interdependencia entre todos los seres vivos y a la necesidad de incorporar una necesaria dimensión ética explícita en la propia metodología de investigación.

Este ejemplo pone de manifiesto la necesidad de revisar la variedad de situaciones de opresión: da cuenta de una trayectoria que pudo desarrollarse como tal precisamente porque no cumplió con los mandatos clásicos sobre la labor femenina. Aunque, frente a la exposición pública y al revisar intereses económicos, se explicite la situación de desigualdad de las mujeres en esta sociedad, al tomarse como desacreditación de la 
investigación la condición femenina de la autora, y más aún la de ser una mujer que no asume su rol como tal.

Los condicionamientos y trabas sociales tienen múltiples aristas que deben recorrerse en cada escenario. Donde es posible, incluso, que las formas más sutiles (y profundas) de desigualdad sean reconocidas cuando las/os oprimidas/os se presentan en un escenario que, sin estar explícitamente vedado, se percibe como ajeno desde la lógica social general. Este puede ser el caso de Rachel Carson, quien pudo desempeñar su labor sin mayores dificultades desde su condición femenina, hasta que decide trascender con sus reflexiones hacia un plano diferente. También podría ser el caso de Simone de Beauvoir, quien no reconoce su situación de desigualdad en sus prácticas cotidianas hasta que se dedica a reflexionar explícitamente sobre este punto (Beauvoir 2005).

Esta variedad de situaciones, que en la misma observación de la pluralidad genera una mayor comprensión de la situación de dominio en general, es la que lleva a pensar en que la homogeneización que se desprende del trabajo de Shiva es su punto de mayor debilidad. Tal es así que en el mismo prólogo del texto Abrazar la Vida Rajni Kothari señala ser consciente que Shiva no distingue lo suficiente entre mujeres urbanizadas y rurales. E incuso señala que esta falta de distinción es funcional a la argumentación de Shiva, porque le permite situar los problemas de la mujer (como un todo) dentro de perspectivas ecológicas (cuyas particularidades tampoco se problematizan).

Debo señalar que, aún cuando Kothari reconoce este problema, no lo toma como una fuente de confusión sino que aprecia la vocación de unificación que se presenta en la obra de Shiva, así señala

"El movimiento feminista sólo tendrá futuro si logra llevar las perspectivas y luchas relativas a género, ecología, etnicidad, clase y derechos humanos hasta ahora dispares a una concepción común para reestructurar la empresa humana. Y no de otro modo" (Kothari 1988, 17).

La unidad se asocia a la idea de activismo, y desde aquí se justifica la omisión. El avance en la reivindicación se presenta como argumento contra la compresión de la heterogeneidad, y esto, a mi entender, limita la efectiva capacidad para reestructurar la empresa humana. 
Otro punto que no termina de resolverse en la obra de Shiva es que, aún aceptando las críticas hacia las sociedades occidentales, resulta difícil asumir la fortaleza, justicia y sustentabilidad de las sociedades que se presentan idealizadas. Estos grupos nooccidentales se presentan sin desigualdades, con vínculos armónicos de los individuos entre sí y con su entorno. Desde esta visión, la pobreza en el sentido de falta material efectiva de bienes de subsistencia, se presenta estrictamente como resultado del despojo que se fundamenta exclusivamente en la modernización capitalista, que en los espacios periféricos se presentó bajo la forma del colonialismo. Lejos de discutir las diferencias intrínsecas del sistema capitalista, cuyas contradicciones impregnan el actual proceso de globalización, las mismas deben considerarse a la luz de las contradicciones surgidas de procesos no capitalistas, que aún alejados de las leyes del mercado han generado diferencias sociales y utilizaciones desgastantes del entorno.

En otras palabras, las problemáticas específicas de las sociedades capitalistas, las desigualdades sociales que se toman como naturales, la explotación indiscriminada del entorno no son argumentos suficientes como para asumir que otras formas de organización están exentas de estas contradicciones. Y este punto es fundamental para revisar la compleja relación entre sociedades-entorno, porque las formas efectivas en que se realiza la interacción está mediada, en parte, por el proceso de globalización, pero en otra, por los condicionantes culturales e históricos que pesan de forma decisiva en las formas locales de apropiación y vinculación.

Tampoco resulta obvio que las propuestas sobre los desarrollos posibles deban reducirse a dos opciones: la aceptación indiscutible del modo de uso capitalista -como suele argumentarse, por ejemplo, cuando se indica que la crítica a la situación del medioambiente no va de la mano con una disminución de la utilización de automóviles-, el abandono y negación de los cambios acontecidos en los últimos quinientos años -como se reclama en las propuestas que presentan como salida el retorno a un pasado ideal. Ambos caminos son falaces, por un lado las agriculturas de subsistencia, como señalaba previamente en base a los argumentos de Cochrane (2006), no aseguran la cobertura alimenticia de la actual población mundial y no permiten pensar en formas de emancipación eficientes. Por otro lado, la densidad de la población mundial actual, sumado a la cultura de consumo que no termina de revisarse 
(Riechmann 2004), está llevando a un proceso de desgaste que desde hace más de treinta años se presenta como insostenible.

Las discusiones sobre la mirada espiritual de Shiva cobran una forma diferente a la luz de la propuesta de Holland Cunz (1996), quien explora el valor del espiritualismo, como movilización, y en esta línea plantea una vinculación entre la teoría y la acción, buscando evitar el arribo hacia las visiones dicotómicas que suelen estar vinculadas a estas propuestas. Para ello toma diversas formas desde las cuales se pueden organizar las teorías feministas, que son el marco de los ecofeminismos.

Uno de los puntos de partida más destacados para repensar la vinculación entre la teoría y la práctica es el que se encuentra en el trabajo de Myra Ferrere y Beth Hess (1985). Si bien estas autoras no reparan exactamente en el vínculo teoría-práctica, permiten explorar distintas estrategias de la práctica que, posteriormente, servirán de base para ligar la acción hacia los modos de elaborar teoría.

Ferrere y Hess (1985) dividen al movimiento feminista en colectivistas y burocráticas. Desde esta división exploran la relación entre lo que denominan activistas y moderadas. Estas autoras señalan que el compromiso de quienes se autodefinen como "revolucionarias", con un activismo rupturista permanente, se acopla a la sensibilidad de quienes adoptan una postura reformadora y es la conjunción la que ayuda a mantener un equilibrio "entre vaivenes de valores activos y reactivos". En relación a la tensión entre estos valores aclaran

“... en todo movimiento social, las y los extremistas tienen, además, la importante función de justificar las luchas y las reivindicaciones de los moderados... sin embargo, los extremistas mismos gozan de poca credibilidad y legitimidad. Sin la simpatía y el apoyo de los grupos más bien moderados y respetados, los que abogan por transformaciones radicales pueden verse calificados de sospechosos o peligrosos, y sometidos impunemente a represión, por ello que las y los extremistas necesiten de los moderados a modo de protección" (Ferrere y Hess 1985, 173-174)

Barbara Holland Cunz (1996) rescata de este análisis la posibilidad de presentar al movimiento feminista, que a la luz de la mutua solidaridad necesaria entre las partes pierde su carácter monolítico sin caer en un conglomerado de acciones y discursos dispersos y desconectados. Asimismo va planteando una solución de continuidad desde 
el activismo hacia la elaboración de teoría y la riqueza de ir considerando de forma permanente estas vinculaciones.

Dado el cambio que se plantea como necesario desde el feminismo en general, y el ecofeminismo en particular, no sorprende que sea desde estas teorías desde donde se rescate la importancia efectiva de no perder de vista la relación entre teoría y práctica. Como mencionaba, las reivindicaciones fundamentales que comparten las ecofeministas son: -el reconocimiento de importantes puntos en común entre la represión de la naturaleza y la represión de la mujer; -la necesidad de entender el carácter de esta relación para toda la comprensión cabal de la representación de la naturaleza y la representación de la mujer; -que la teoría y la práctica del feminismo tiene que incluir una perspectiva ecológica; - y que las soluciones a los problemas ecológicos deben incluir una perspectiva feminista (Holland Cunz 1996).

Siguiendo a la autora alemana, acompaño su estrategia por revisar el estado de los debates sobre los que va construyendo una mirada alternativa, buscando problematizar la relación con la naturaleza, un punto que Holland Cunz entendía como una de las deudas de los ecofeminismos. Paralelamente, los enfoques ecológicos tampoco terminan de incorporar el problema de la relación entre los sexos, de allí que la deuda es compartida.

Holland Cunz rescata que el punto de vista (eco)feminista representa respecto de la relación social hacia la naturaleza y la relación entre los sexos una corrección necesaria de las concepciones teórico-naturales androcéntricas, señalando que "la corriente ecofeminista ... representa hoy el enfoque que intenta una comunicación socio-teórica entre la relación hacia la naturaleza y la relación entre los sexos" (Holland Cunz 1996, 30). Desde esta perspectiva Holland Cunz va a explorar, entre otros temas, el desafío del esencialismo como motor de activismos y como riesgos de dualismos.

El paso inicial de la filósofa alemana es organizar el marco de ideas feministas y, a partir de ello, caracterizar el sitio que ocupan los ecofeminismos. Para ello elabora un cuadro que, aún sin ser completo, resulta ordenador

\section{Cuadro 1: las ideas feministas}




\begin{tabular}{|c|c|c|}
\hline Feminismo radical & $\begin{array}{l}\text { 1)Orientación política de } \\
\text { comienzos del nuevo } \\
\text { movimiento de liberación e la } \\
\text { mujer (Europa occidental - } \\
\text { norteamérica) } \\
\text { anarcofeministas }\end{array}$ & $\begin{array}{l}\text { 2)Clásicas del ecofeminsimo } \\
\text {-corrientes espiritualistas } \\
\text { (europea occidental, } \\
\text { norteamericana) } \\
\text {-feminismo cultural }\end{array}$ \\
\hline Feminismo liberal & $\begin{array}{l}\text { 3)políticas feministas actuales } \\
\text { e institucionales } \\
\text {-políticas laborales } \\
\text {-múltiples grupos de presión }\end{array}$ & $\begin{array}{l}\text { 4)feminismo neoconservador } \\
\text { hasta llegar a nuevas políticas } \\
\text { para la familia }\end{array}$ \\
\hline Feminismo socialista & $\begin{array}{l}\text { 5)ideas de emancipación } \\
\text { socialistas y en parte también } \\
\text { socialdemócratas clásicas } \\
\text { - mujeres críticas con la teoría } \\
\text { socialista }\end{array}$ & $\begin{array}{l}\text { 6) nuevas posturas } \\
\text { ecofeministas } \\
\text { - mujeres críticas para con la } \\
\text { teoría socialista }\end{array}$ \\
\hline
\end{tabular}

(Holland Cunz, 47)

En este esquema la autora reconoce la falta de las propuestas posmodernas, que no se encuentran por la misma ambigüedad de estas posturas. En este sentido se puede tomar la propuesta de Linda Nicholson (1990), quien analiza la relación entre feminismo y posmodernismo proponiendo se consideren tres posturas feministas: el feminismo racionalista (también conocido como humanista o moderno), el feminismo anti racionalista y el feminismo postracionalista.

Esta propuesta, que surge a partir de aportes de los últimos años ha llevado a revisar las autocategorizaciones históricas, que son las que se presentan en el cuadro. En el mismo las propuestas 1,3 y 5 corresponderían al feminismo racionalista, mientras que las posturas 2, 4 y 6 se encontrarían entre el feminismo antiracionalista y el postracionalista, aún cuando no diferencien en detalle sobre el mismo. 
Desde esta diversidad se presentan diferentes estrategias para responder a uno de los grandes desafíos que asumen los ecofeminismos: la revisión de la relación sociedadnaturaleza. Debo señalar que a esta altura considero necesario llamar la atención sobre los dos tipos de dualidades presentes en el foco de las tensiones del discurso de la modernidad, una aporética que opone sociedad a naturaleza y otra de concurrencia que asocia naturaleza a mujer.

En función de las mismas se encuentran dos líneas complementarias desde las que se puede pensar en desmontar este aparato simbólico, la mirada desde la naturaleza y la mirada desde la humanidad. Ambas perspectivas permiten reconocer problemas específicos del vínculo a la vez que plantean estrategias diferentes desde las cuales repensar los vínculos.

\section{Las relaciones sociedad-naturaleza, con el acento en la naturaleza}

La observación desde la naturaleza no-humana ha sido criticada por apelar a fundamentos esencialistas. En este sentido las éticas naturalistas que se referencian en determinaciones inmateriales, como la mutualidad, sociedad o espiritualidad, se presentan como contrapuestas a aquellas que reparan en consideraciones materiales.

Considero, siguiendo a Holland Cunz (1996), que estas miradas no son mutuamente excluyentes. La filósofa alemana indagó especialmente en la posible vinculación de estas perspectivas; ambas resultan problemáticas, pero a su vez, desde estas dos tradiciones que reconocen los problemas de la actual situación de desarrollo, se han elaborado iniciativas que no necesariamente resultan opuestas. Existe un punto particularmente sensible en las discusiones que se llevan adelante entre las posturas "materialistas" y las "espiritualistas o esencialistas"; se trata del tema de la libertad.

Las argumentaciones que apelan a la resacralización de la naturaleza, reclaman una solidaridad hacia el heterogéneo grupo humano existente, para desde allí proyectar el cuidado y el reconocimiento hacia todas la especies. Esto trae aspectos a revisar respecto del tema de la libertad, porque, como señala Mechtild Oechsle (1988), puede ser un intento de explicar la sociedad a través de determinadas leyes naturales, dando lugar al peligro de justificar la violencia y el dominio desde las mismas 
argumentaciones que se presentan como superadoras del orden actualmente establecido. Estas posturas, que se han denominado como "ecologías de derecha" legitiman procesos restrictivos de libertad, de acción y de reflexión en función del bien común del planeta (Jahn y Wehling 1991).

Ahora bien, sería discutible que las/os pensadoras/es que reconocen el valor espiritual de las argumentaciones ecológicas o feministas adhieren a estos supuestos naturalistas, que en definitiva llevan a posturas totalitarias. Janet Biehl (1991), Murray Bookchin (1985), Peter Kropotkin (1989) o Vandana Shiva (1988), entre otros autores que han provocado gran impacto sobre el tema, toman como una preocupación central el arribar a una de propuesta de democracia entre todo lo vivo, y con esta perspectiva teórica de liberación garantizan los límites a procesos autoritarios. ${ }^{54}$

Bárbara Holland Cunz ha explorado el marcado rechazo que comparten teorías que denomina del dominio (en general con referencias a concepciones liberales) y contrarias al dominio (en general con referencias marxistas) respecto de las simbolizaciones románticas o espirituales de la naturaleza. La filósofa alemana encuentra notables límites para la aplicación de las visiones de naturaleza clásica fuera del contexto teórico eurocéntrico. Así señala que las críticas de esencialismos reduccionistas a las visiones espirituales de la naturaleza dejan a la luz "lo extraño que resulta la formulación dentro de la propia cultura de una relación no mecanicista con la naturaleza" (Holland Cunz, 184).

A fin de mostrar su hipótesis, que las dimensiones inmateriales de mutualidad, sociedad y espiritualidad pueden ser interpretadas como eslabones hacia una determinación sentida y con sentido, hacia una concepción que trascienda los aspectos materiales de la naturaleza extrahumana, recorre perspectivas anarquistas, neo anarquistas y espirituales.

Entre los textos que toma, destaco la revisión de la postura de Peter Kropotkin, quien, desde sus reflexiones sobre biología, puede vincular con varias de las argumentaciones expuestas en el primer capítulo.

\footnotetext{
${ }^{54}$ El tema de la libertad, y las salvedades que se realizan al respecto, no suele ser revisado a la hora de plantear las críticas, por ejemplo Regina Cochrane (2006) pone en duda la cercanía entre Vandana Shiva y los fundamentalismos de derecha de la india, a los que entiende apoyados por las propuestas teóricas de la pensadora india.
} 
Este pensador anarquista, fiel representante de las concepciones del siglo XIX, más allá de todas las dificultades que encontraba nunca dudó de la capacidad libertadora de la ciencia y la técnica. Kropotkin marca un retorno a principios naturalistas al sostener que el progreso social debe regirse por los principios naturales, ahora bien, lejos de reconocer estos principios en la competencia o la predación, los explora desde una de las interacciones menos reconocidas en los estudios entre los organismos: el mutualismo.

Es, precisamente, el mutualismo de la naturaleza, el aspecto que Kropotkin reconoce como maestro de ética. La ciencia, como la actividad humana para conocer la naturaleza, y las interacciones naturales (entendidas como mutualismos) como guía de las postulaciones éticas humanas, se conjugan en Kropotkin como un camino hacia un desarrollo justo. Esto no significa una visión sesgada del pensador ruso en relación a la naturaleza no humana, porque más allá de los mutualismos también reconoce otras interacciones signadas por la violencia, sino que reconoce en las vinculaciones mutualistas las formas potenciales de guía natural. Con esta opción sortea la crítica que entiende a las visiones naturalistas como necesariamente ligadas a la legitimación de la violencia, asimismo permite una revisión sobre la construcción de la desigualdad social desde nuevas perspectivas.

Kropotkin (1989) entiende que el trabajo humano ha llevado a la generación de una enorme riqueza de las entrañas de la naturaleza (una naturaleza animista). Ahora bien, esta riqueza que fue producida de generación en generación, por el esfuerzo colectivo, no pertenece a una comunidad general sino que está en manos de pocos privados, asociando de este modo la miseria de la mayoría a la riqueza de los menos. Desde aquí Kropotkin reclama la colectivización de lo que colectivamente se creó, entendiendo que el reparto de acuerdo a las necesidades, y no en base al rendimiento, es la base adecuada de la organización social.

Desde esta mirada la naturaleza no sólo es el ámbito de apropiación del trabajo (como se infiere de las propuestas marxistas), también es inspiración, maestra de ética y de vida en libertad. La falta de reconocimiento del rol inspirador de la naturaleza afecta, a decir de Kropotkin, al conjunto del conocimiento, porque las reflexiones de economía política han privilegiado el análisis de la producción antes que el del consumo y las necesidades individuales. Desde el saber reconocido como legítimo, las teorías sobre las 
que se fundamentan las acciones públicas, la riqueza de los productores se prioriza por sobre los requerimientos de la población en general (Kropotkin 1976,1920). En este sentido el anarquista ruso critica el saber científico abstracto y dominante, porque desde este lugar se pierde el conocimiento sobre las tareas que desarrollan el espíritu de la comunidad y con ello se eclipsan las capacidades creativas.

La vigencia de estas críticas me llevan a reconocer, con Holland Cunz, la importancia de revisar estas ideas, donde se critica la industrialización acelerada porque lleva a un proceso que deja de estar orientado desde la red social. Kropotkin resulta particularmente interesante por destacar que los procesos de dominio se cuelan, precisamente, por los quiebres que logran introducirse en la red social. Yendo a los términos específicos del autor anarquista:

"No desagrada esto a los vulgarizadores de Darwin, ignorando en él todo lo que no había sacado de Malthus; el sentimiento de solidaridad es el rasgo predominante de la existencia de todos los animales que viven en sociedad. El águila devora al gorrión; el lobo, a las marmotas; pero las águilas y los lobos se ayudan entre sí para cazar; y los gorriones y las marmotas se prestan solidaridad también contra los animales de presa, pues sólo los poco diestros se dejan expoliar. En toda agrupación animal la solidaridad es una ley (un hecho general) de la naturaleza, infinitamente más importante que esa lucha por la existencia, cuya virtud nos cantan los burgueses en todos los tonos, a fin de mejor embrutecernos". (Kropotkin 2002, 11)

Desde estos argumentos se aleja de la idea hobbsiana de la sociedad como resultante de la lucha del hombre contra el hombre. En contraposición señala que la lucha por la supervivencia no es una lucha de individuos sino de sociedades, con lo cual resulta de interés tanto el proceso de ataque y defensa como el de cohesión. Vale recordar en este punto las menciones del primer capítulo, donde se expone que desde fines del siglo $\mathrm{XIX}$, y prácticamente hasta fines del siglo XX, las nociones mutualistas tampoco tuvieron mayor lugar en la reflexión ecológica, debido a que la noción de competencia, intra e interespecífica, fue la interacción que se tomó como determinante de la pluralidad de relaciones que podían establecerse entre los organismos y sus ambientes, y este reconocimiento, guió la mayor parte de los estudios.

Volviendo al análisis de las sociedades humanas, en contra de los conceptos de Kropotkin la historia de la naturaleza se alejó de la historia de la humanidad, aunque en 
ambos casos primó el estudio de la competencia por sobre el de los mutualismos. Esta adopción, asociada a la aceptación de un cierto modo de desarrollo y legitimando formas específicas de dominio, se puede vincular al crecimiento del modelo capitalista. Sin embargo el romanticismo de las ideas de Korpotkin no debe llevarnos a desconocer que la obra de este pensador está atravesada por una tensión que no termina de resolver.

La idea de naturaleza que presenta el pensador anarquista fluctúa entre una imagen idílica e ingenua donde las especies se ayudan entre sí, y por otro el rostro violento de un espacio inhóspito y agresivo. El problema fundamental, que se reconoce sobre todo en Mutual Aid, es que la ayuda se presenta sobre todo en relación a la propia especie, perdiéndose de este modo la fuerza para discutir la apropiación indiscriminada de la actividad humana respecto de hábitat de otras especies (Holland Cunz 1996), en este sentido queda sin respuesta la vinculación de las sociedades con su entorno. Así, aun cuando la visión de Kropotkin traiga indicios sólidos en cuanto a la revisión de la concepción de naturaleza y las vinculaciones teórico-prácticas que se establecen, el pensador ruso no pudo revisar la dualidad que resulta intrínseca a la propuesta de la ciencia en la que tanto confiaba.

En esta visión puede destacarse, sin embargo, la impresión de un carácter trascendente de la naturaleza respecto de la materialidad productiva. Un lugar teórico que resulta fecundo para repensar la relación sociedad-naturaleza. La concepción de la naturaleza como animada permite incorporar una dimensión espiritual al estricto reconocimiento material -que es el que opera en la actualidad-, y a partir de esta dimensión espiritual se facilita la integración teórica que sortea la dualidad sociedad/naturaleza.

En este contexto la ética que se plantea desde la propuesta de la pensadora alemana, debe ser relacional antes que racional. El eje en las actitudes hacia lo natural debe, entonces, sostenerse desde valores históricamente omitidos en las elaboraciones teóricas, como los valores de confianza, amistad, cariño, erotismo, entre otros (Fox Keller 1991). La racionalidad, como el precepto que ha guiado la producción del conocimiento, debe resituarse a fin de permitir valorar la inteligencia, tanto racional como emocional (Segales 2006).

Esto implica un cambio en el modo de concebir el conocimiento, porque al asumir los cambios en la visión de la razón, y la resignificación de la naturaleza como animada, 
lleva a imaginar una epistemología radicalmente diferente a la que ampara los actuales desarrollos del método científico. En una línea similar a la planteada desde los análisis de Horkheimer y Adorno (1997), se trataría de pensar como posible una reflexión diametralmente opuesta a un modo de conocer que ha negado cualquier reconocimiento del otro no-humano con caracteres espirituales.

El estricto conocimiento material que se propone desde la ciencia nos lleva a las trampas del dominio. Porque sitúa una jerarquía en el modo de conocer que es base de legitimación del uso al que se reduce el entorno. Esto nos lleva hacia un problema, porque no es para nada obvio el modo en que la ciencia, en su actual modo de desarrollo, pueda plantearse el conocimiento de un mundo investido espiritualmente.

Este camino implica repensar el mismo concepto de conocimiento, porque los condicionantes de la modernidad han presentado al intelecto como vencedor de la superstición, y por lo tanto amo de la naturaleza desencantada. En este camino, como marcan Horkheimer y Adorno, la razón se tornó técnica, razón instrumental; y la naturaleza deja de ser cualidad para ser sustrato de la dominación.

Aquí se plantea un desafío ¿cómo conocer de otra forma? Creo que un punto de partida sería asumir que ello es posible, reconociendo las capacidades y limitantes de las formas clásicas de conocimiento, y revisando las prácticas como espacios fundamentales para edificar los compromisos desde los cuales se plantea el conocimiento, tal vez buscando una vinculación con el ámbito de movilización que la ciencia percibe como ajeno y reconociendo en general el plano de interacción que Ferrere y Hess (1985) reclaman para el feminismo. ${ }^{55}$

A partir de asumir como posible este re-conocimiento, la búsqueda del saber puede pensarse como dinámica, asociada incluso a cada contexto cultural. Esto no implica abandonar un lenguaje de intercambio sino considerar, como parte fundamental de la instancia de investigación, el contexto material en que el conocimiento producido deviene en prácticas.

Podemos pensar, como señala Segales (2006) que se tratará de una epistemología holística que incluya la perspectiva de los "otros", humanos y no-humanos.

\footnotetext{
${ }^{55}$ Estos puntos se van a explorar de forma ampliada en el capítulo cinco.
} 
Permitiendo, junto a las formas clásicas de justificación, la introducción de la afectividad y el erotismo.

Ahora bien, si bien efectivamente la epistemología debe pensarse como herramienta para conocer un mundo más allá de las dualidades instaladas desde la modernidad, el intento espiritual por sortear la dualidad, que ha generado un importante debate entre los ecofeminismos, debe observarse desde dos facetas. Una como imagen del diálogo a partir del reconocimiento de una naturaleza animada, con las cuales se pueden concebir relaciones que trascienden lo material. Un potencial que no debe eclipsar el riesgo de la otra faceta, aquella que al extremar la valoración espiritual abren las puertas a nociones jerárquicas y rituales.

El interrogante que se plantea desde estas opciones es si esta crítica a la espiritualidad extrema, a la concepción animista de la naturaleza, es suficiente para impugnar la espiritualidad en sus diversas formas como sitio para repensar la naturaleza.

En contra de las argumentaciones que condenan el ejercicio de remistificación de la naturaleza, por entenderlo como indisolublemente ligado a compromisos totalitarios, adhiero a la visión de Holland Cunz que reconoce en la espiritualidad un sitio privilegiado para realizar críticas a los conceptos y políticas occidentales, que precisamente asumieron una naturaleza exenta de magia y reducida a una cosificación que justificó el uso indiscriminado que se realizó. La dimensión histórica de la naturaleza, al igual que la dimensión espiritual que se presenta como un sitio especialmente fértil de revisión, resultan problemáticas cuando se toman como razón última. Sobre todo porque es desde esta razón última desde la cual se elaboran las visiones jerárquicas.

A fin de sortear el peligro de asumir razones últimas, que justifiquen jerarquías y oculten las diversidades, Holland Cunz propone "situar [la espiritualidad] sobre el nivel menos altamente simbolizado de la dimensión sociedad la aproximación conceptual y temática a la lógica propia de la naturaleza" (Holland Cunz, 249). Así sugiere rescatar de la dimensión espiritual la imagen de diálogo posible, porque es desde la asunción de esta espiritualidad donde se funda la posibilidad de la relación. Asumiendo en esta adopción la necesidad de re-conocer un mundo que se llena de nuevas cualidades, donde 
las propias relaciones (el punto de partida de los estudios ecológicos), se presentan con dinamismos inaccesibles desde las formas usuales de conocimiento.

Para dimensionar el desafío que propone Holland Cunz, resulta útil retomar las reflexiones de C.S. (Buzz) Holling (1998) o Kevin de Laplante (2004), quienes abogan por una concepción integral de la ecología que contenga la dimensión humana. Estos autores reflexionan en torno a las dificultades, aún vigentes, por incorporar análisis vinculados a la ecología de la mente, la psicología ecológica o la ecología social, como parte de la disciplina fundada en la biología, señalando la necesidad de revisión antes que formas concretas como para efectivizar la incorporación. ${ }^{56}$ Donde se destaca que no se trata de discutir a la ecología clásica (el estudio de los organismos-no humanos y sus sistemas), sino e incorporar nuevas áreas de estudio, que involucren factores sociales y permitan enriquecer el área de debates de la ecología como conjunto.

Es decir, aún resulta difícil incorporar perspectivas que no proponen la impugnación de valores sobre los que se constituyó la ciencia. Por ello no resulta extraño que el acercamiento de propuestas que implican cambios en la cosmovisión que sustentan las prácticas de investigación, genere rechazos antes que adopciones. Sin embargo la consideración de tomar a la humanidad (desde toda su variabilidad), como parte del mundo, es una obligación a la que nos enfrentan los problemas ambientales. El punto a destacar es la dimensión de los supuestos a desmontar, porque se trata de reconocer a los objetos asumidos como ajenos o extraños en términos de pares o similares. No para homologarlos a las características humanas sino para avanzar en la idea que la

\footnotetext{
56 "Ecología de la mente" es el término acuñado por Gregory Bateson (1999) para tomar como objeto de estudio a la mente como sistema; un sistema compuesto por los comportamientos reglados y entendidos como un lenguaje. Lo mental para Bateson no ocurre sólo dentro del cerebro, sino que es un proceso interaccional y relacional. La mente es relación, es el cerebro en interacción con el entorno. Ampliando la noción clínica de mente, Bateson contribuyó a establecer en el campo psiquiátrico la idea de que los trastornos "mentales" son trastornos de la comunicación. Para él la comprensión emerge de la interacción, el sujeto negocia continuamente con la naturaleza y con los otros y crea una experiencia recurrente.

"Psicología ecológica" es un enfoque conocido también como "ecología del desarrollo humano" que comprende el estudio científico de la progresiva acomodación mutua entre un ser humano activo, en desarrollo, y las propiedades cambiantes de los entornos inmediatos en los que vive la persona en desarrollo, en cuanto este proceso se ve afectado por las relaciones que se establecen entre estos entornos y por los contextos más grandes en los que están incluidos los entornos. (Bronfenbrenner 1987)

"Ecología social" finalemente hace referencia a una escuela ambientalista y anarquista que afirma existe una relación holística entre los seres naturales, incluídos los seres humanos, que lleva a afirmar a los ecólogos sociales de que el orden natural no necesita autoridades ni mando centralizado, sino que es descentralizado y en redes. Eso significa que la naturaleza se autorregula y de igual forma pueden organizarse los humanos, que producen los problemas ambientales sólo cuando introducen procesos autoritarios en sus sociedades
} 
diferencia no es sinónimo de inferioridad o de la imposibilidad de establecer vínculos no-instrumentales.

Desde una perspectiva que puede comprenderse como complementaria, vale una mención a las reflexiones que parten de considerar la condición humana como base de la búsqueda de alternativas, porque revisan las tensiones con un ángulo que facilita el avance en la búsqueda de alternativas.

\section{Las relaciones sociedad-naturaleza, con el acento en la humanidad}

Una de las pensadoras que se ha detenido especialmente en el desafío de las relaciones que se establecen con los otros naturales es la filósofa australiana Val Plumwood. Como se anticipó en el capítulo dos, la estudiosa discute que la superación de las dicotomías pueda reducirse a la negación de las mismas. Ahora bien, en este desafío por repensar los modos e implicancias de los vínculos que existen y los que se desean, la filósofa australiana plantea que la naturaleza, en el sentido de mundo no-humano, debe reconocerse desde una perspectiva diferente a la establecida por la tradición occidental. Pero esto no sólo significa repensar la naturaleza sino, en forma asociada, reflexionar sobre las dimensiones de lo social e incluso de redefinir lo humano.

En el apartado previo se plantea que, una posibilidad para establecer relaciones con la naturaleza, es investirla de caracteres animistas, que no se tomen como determinantes, por correr el riesgo de llegar a nuevos dualismos y jerarquizaciones, pero que formen parte de la visión de la naturaleza. Lejos de este tema Plumwood (1996) repara en las cualidades humanas, señalando como estrategia para salvar el dualismo humanidad/naturaleza, el reconocimiento de las cualidades históricamente excluidas, interpretadas como ajenas o propias de los "seres inferiores" de la humanidad, como las mujeres, los pueblos originarios, las "razas no arias".

Asumir como enteramente humanas, e incluso como característico de lo humano a factores como la sensibilidad, la sensualidad, la reproductividad, la emocionalidad puede ser clave para edificar una continuidad que permita el reconocimiento del mundo natural. Plumwood postula la revisión desde una perspectiva que se edifique desde la 
particularidad humana, que desde esta perspectiva deja de circunscribirse a capacidades como el pensamiento o el cálculo abstracto.

La pensadora australiana abandona la descripción del mundo natural y reclama la reconceptualización del yo-humano, en función del cual, entiende, se puede reconstruir el vínculo de continuidad con esa naturaleza que la modernidad presentó como ajena.

El trabajo de Plumwood (1996) expone la relación entre la visión de una naturaleza escindida de lo humano y las formas de dominio legitimadas. El vínculo que une estos conceptos, y se sostiene desde la discontinuidad es, a decir de esta autora, el instrumentalismo.

La visión instrumentalista de la naturaleza, acotada a una esfera diferente a la humana, es la base justificativa de la explotación. Ahora bien, sería falaz postular que este instrumentalismo se proyecta exclusivamente sobre el entorno no-humano, el "yo instrumental" o "autointeresado" (Plumwood 1996, Chodorow 1979,1985), porque esta concepción del humano permite el uso, tanto de los otros humanos como del mundo para su satisfacción. En el proceso de responder a sus propios intereses, la referencia a los otros se hace explícita en la medida que se vincule con su beneficio. Como indica la pensadora:

"Los otros como medios son intercambiables se producen satisfacciones equivalentes... Los intereses de un individuo tal como el de la teoría de mercado... se define como esencialmente independiente o desvinculado de los de otra gente, y sus (de él o de ella) transacciones con el mundo consisten fundamentalmente de muchos intentos de obtener satisfacción de esos intereses privados predeterminados" (Plumwood 1996, 54)

Es decir, los límites para poder repensar la relación con la naturaleza desde este esquema estriba en que no se tienen herramientas siquiera para pensar en una vinculación con los otros-pares, más allá de la instrumentalidad.

Como se ha reclamado desde múltiples perspectivas, se trata de objetar esta visión que no ofrece una imagen adecuada del yo-humano, que es un yo fundamentalmente social (un punto que trae resonancia de la propuesta de Kropotkin y sus referencias hacia el mutualismo)..$^{57}$

\footnotetext{
${ }^{57}$ Desde las revisiones de la teoría política se han presentado impugnaciones desde perspectivas como la feminista, la crítica al liberalismo, la filosofía medioambiental. Entre los autores que pueden revisarse se cuentan Plumwood 1996, Benhabib 1987, Benjamín 1985, Chodorov 1985, Gilligan 1987, Poole 1990
} 
Desde el privilegio del egoísmo instrumental se pierden o empobrecen importantes dimensiones de nos constituyen como efectivamente humanos, que son, precisamente, las relaciones que establecemos con los otros, humanos o no humanos (Warren, 1990). La filósofa australiana considera que la presencia de relaciones no implica que las intenciones y particularidades de unos sean absorbidos por los otros, por el contrario, hay superposición que no implica indistinguibilidad. A fin de exponer esta pluralidad de sentidos e intenciones superpuestas Plumwood (1996) propone el reconocimiento de un yo-en-relación que dé lugar a la exposición de interdependencias sin diluir la visión de los unos en otros.

Ahora bien, este yo-en-relación, que es un modo posible de concebir a la humanidad, no es la forma en que necesariamente se la comprende. Porque, como señala Plumwood (1996) ciertas corrientes de la modernidad, desde los preceptos egoístas e instrumentales sobre los que ha sostenido las visiones que han interpretado y organizado la sociedad, han ignorado esta posibilidad.

A fin de salvar los límites que nos ha impuesto la modernidad hegemónica, que reiteradamente nos atrapa en estructuras conceptuales dualistas, debemos revisar las limitaciones que encontramos en el análisis de los mismos procesos de predación. La importancia de este aspecto queda al desnudo cuando la pensadora australiana introduce uno de los problemas más sensibles a nuestro propio reconocimiento, porque los seres humanos (sobre todo los pertenecientes a las sociedades occidentales) hemos investido nuestra propia vida con una santidad que nos impide reconocernos a nosotros mismos como parte de la cadena alimenticia (Plumwood 2004).

Cuando Arthur Tansley, en 1935, entendía a la humanidad fuera de los ecosistemas lo justificaba por la capacidad de intervenir en los ambientes, demostrada sobre todo por las sociedades modernas. Sin embargo las reflexiones de Val Plumwood (2004) nos llevan hacia un sitio diferente donde resulta más clara la separación. Porque la distinción entre humanidad y naturaleza, que nos omite como parte de los ecosistemas, se encuentra en que no concebimos el ser conceptualizados como comestibles, como parte del sistema en igual sitio que el resto de los organismos. Como indica Plumwood "Este concepto de identidad humana nos coloca fuera y por encima de la cadena de

entre otros. 
alimentos, no como parte del banquete en una cadena de reciprocidad, sino como amos y manipuladores externos" (Plumwood 2004, 69).

Esto nos lleva a otros problemas al buscar formas de proyectar los preceptos morales y los derechos hacia animales no-humanos, tal como se desprende de reflexiones como las de Tom Reagan (1980, 1998); Peter Singer (1998) o Teresa López de la Vieja (2005). Porque la sacralidad con que se inviste la vida humana se proyecta hacia los seres a los que consideramos similares, que consecuentemente se evalúan como fuera de nuestra cadena alimentaria, incorporando formas de ruptura antes que de vinculación entre los organismos. ${ }^{58}$ Estas reflexiones tienen, entre otras conclusiones, una reivindicación del vegetarianismo así como una condena a la producción de animales comestibles. Sobre este punto podría argumentarse que la única defensa al cultivo de plantas sobre la cría de ganado es que el ganado tiene mayores similitudes a lo humano que las plantas, un punto que nos remite al problema de las jerarquías de dominio que se establecen al tomarnos, en tanto humanos, como medida de todas las cosas siguiendo el denominado "giro antropocéntrico" cuyo origen se remonta a Protágoras en el siglo V a.C. "El hombre es la medida de todas las cosas: de las que son porque son, de las que no son porque no son"

El problema de pertenecer o no a la cadena alimentaria. O más aún, si intervenir o no en el desarrollo de esta cadena se desprende de estas argumentaciones. Sobre todo por referirse a un tema que enfrenta a los defensores de los derechos de los animales a paradojas, cuando se plantea, por ejemplo, la situación de un lobo comiéndose una oveja, que permite abrir interrogantes en relación a impedir o no la acción para cuidar los derechos a la vida de las ovejas, o si dejar continuar la cacería para cuidar los derechos a alimentarse (que es también un derecho a la vida) del lobo.

Tom Reagan (1986) trató de evitar esta paradoja al señalar que ni el lobo ni la oveja son agentes morales, por lo tanto no son susceptibles de recibir auxilio o condena. Pero a la luz de la pueblada chubutense que se organizó para cazar al puma que había matado al niño, podemos preguntarnos, como hace Val Plumwood (1996) ¿qué pasaría si el lobo atacara un bebé humano? ¿Hasta dónde llega esta confianza en la evaluación del lobo

\footnotetext{
${ }^{58}$ Como vimos en el capítulo tres, no terminan de escapar a las consideraciones jerárquicas sobre las cuales se ha erguido la concepción de los animales en la modernidad. Es decir, no terminan de salvar los presupuestos sobre los cuales se fundaron las acciones que hoy se evalúan como explotación y crimen.
} 
como un ser no moral? O más cerca de nuestra cotidianeidad ¿Cómo tratar el problema de los perros mordedores?

Val Plumwood (1996) señala que uno de los problemas que atraviesa este tema es el imperio de la razón que ha signado la reflexión ética en las sociedades occidentales. Desde allí se ha establecido una tradición que entiende el progreso moral como la creciente adhesión a ciertas reglas morales. En este proceso se ha considerado al mundo natural (esto es, no humano) como ajeno a las reglas morales. Porque la naturaleza se ha entendido como habitada por seres sin caracteres morales (motivo por el cual, por ejemplo, no se condenan los ejercicios de predación). La paradoja que plantea Plumwood (1996) es que desde esta tradición se pretende extender el ejercicio de las reglas morales abstractas hacia la naturaleza misma, y desde aquí plantea

"Los derechos parecen haber adquirido una exagerada importancia como parte del prestigio de la esfera pública y de lo masculino, en énfasis sobre la separación y autonomía, sobre la razón y la abstracción. Un abordaje más prometedor para una ética de la naturaleza, y también mucho más alineado con las direcciones corrientes en el feminismo, sería desplazar los derechos del centro del escenario de la ética y poner más atención a otros conceptos morales menos dualistas tales como respeto, comprensión, cuidado, interés, compasión, gratitud, amistad y responsabilidad” (Plumwood 1996, 41-42).

La propuesta de Plumwood, al igual que la de Holland Cunz (aunque desarrollen sus teorías desde lugares diferentes), es que en las evaluaciones no se puede perder la consideración del dinamismo relacional. Se parte de asumir que no hay preceptos fijos ni razones absolutas.

Las características humanas no se reducen a lo racional (que además se asocia a lo masculino y occidental). Asimismo el privilegio exclusivo de la razón instrumental nos lleva, como vimos, al uso indiscriminado de los otros, sean o no humanos. Nuestra humanidad-en-relación debe sostenerse sobre caracteres que trasciendan los valores sobre los que se constituyeron las sociedades occidentales y sus prácticas. Y este problema no es ajeno a la producción misma de conocimiento.

Sabemos que la noción de naturaleza también debe acomodarse a esta nueva visión, retomando un carácter animista, que no la determine pero que la habilite a presentarse, 
desde los seres que la habitan y los paisajes que la integran como una pluralidad de “otros" vinculados a la propia edificación de la forma particular de humanidad que se adopte.

Desde la literatura, las historias de vida, el arte en general, este vínculo no se perdió. Queda por ver cómo avanzar con una ciencia que se origina en la negación de la relación o similitud animista. Sobre todo si se plantea la edificación de una arena de diálogo entre iguales, donde ninguna de las partes se perciba con potestad sobre la verdad o la Razón última.

En este ejercicio de diálogo e intercambio se ponen a la luz muchos aspectos que movilizan la sensibilidad que hemos construido, como el aceptarnos -en tanto especiecomo posible comida de otras especies. Así como la modificación de las formas aceptadas de la cotidianeidad occidental apuntando, por ejemplo, a implementar limitaciones en el consumo. O impugnaciones que discuten la estructura económica, debatiendo, por ejemplo, la necesidad de revisar el proceso de centralización de riquezas buscando alternativas redistributivas socialmente más justas y ambientalmente más sustentables. Estas modificaciones apuntan a modificar el sentido común en un sentido amplio, a "re-educar el deseo".

\section{Consideraciones finales del capítulo}

Podemos pensar que el ecofeminismo es una corriente que postula que el estudio de las interrelaciones entre las lógicas de dominación de las mujeres y el resto de "otros" del discurso social dominante y la Naturaleza por parte del hombre, puede arrojar luz sobre su origen y sus consecuencias, así como sobre los modos para luchar contra ellas. Afirman así que las formas que adopten las luchas contra el deterioro ambiental y el patriarcado deberán tener en cuenta este debate. No se trata de que la opresión de género sea más importante que otras formas de opresión, sino de que el género sea la categoría analítica fundamental a partir de la cual se acometa el estudio de todos los sistemas de dominación establecidos para el control social de estos “otros”(Warren 2000).

La adopción del ecofeminista no implica el sostener la idea de una esencia femenina que vincula a las mujeres con su entorno, sino reconocer que el sometimiento sufrido por los 
sectores sociales menos privilegiados, que contienen tanto hombres como mujeres en diferentes niveles etáreos, ha llevado a desarrollado estrategias de supervivencia que permiten presentarlos como agentes especialmente sensibles para reconocer tensiones e idear estrategias alternativas (con las salvedades ya mencionadas en el texto).

El recorrido por los ecofeminismos llevó a distinguir las alternativas al modo occidental de vinculación sociedad-naturaleza en dos grandes ramas: -aquellas que reclaman un cambio en la forma de concebir la naturaleza y -aquellas que reclaman un cambio en el carácter de humanidad.

Desde ambas perspectivas se concluye en la necesidad de abandonar la Razón clásica como fundamento último del conocimiento, postulando la necesidad de incorporar dimensiones relacionales. Como la propuesta de Holland Cunz, quien argumenta a favor de reinvestir a la naturaleza de espiritualidad; o el análisis de Plumwood en torno a la importancia por reconocernos, en tanto humanos, como parte de la cadena alimenticia de otros, con los cuales se plantea una relación que no implica la subsumción de los caracteres de unos en otros o la difusión completa de las particularidades.

Desde todos los puntos de vista se destaca una perspectiva optimista que entiende el cambio como posible, aunque no por optimista resulta ingenua, ya que se desarrolla en detalle la vasta dimensión de desafíos que se asumen con este cambio, teniendo particular reparo en las dificultades que existen para incorporar formas alternativas en el desarrollo de conocimiento, que implican la remoción de buena parte de los valores sobre los que se ha edificado el saber occidental, asumiendo, por ejemplo, a la ciencia como uno más de los relatos posibles.

El ejercicio cotidiano de las sociedades occidentales se pone en entredicho en conjunto y esto no es independiente del proceso mismo de conocer, que partiendo del caso de la biología ecológica, nos trajo hasta este punto. El desafío en esta línea sería comprender al conocimiento científico como uno más de los relatos, ligado a una cierta práctica de poder, y plantear una arena de intercambio "inter-tran-pluri disciplinaria", que permita el diálogo como pares entre el saber legitimado y la experiencia vivida. Donde el conocimiento técnico no sea argumento para desmerecer perspectivas diferentes y la razón pueda redefinirse en un modo tal que no implique una naturaleza privada de espiritualidad. 
Desde este desafío la Razón clásica como guía y fundamento, deja de ser un tema aislado, porque se vincula a un conjunto de prácticas asociadas y se cruza con las propuestas institucionales estructurantes de las relaciones sociales, que desde su propio dinamismo reproducen, no tanto la Razón, sino el reconocimiento particular con que ha sido coronada en la visión occidental.

Queda, entonces, la pregunta por la posibilidad de acción, en el sentido de cambio en la relación y modo de conocimiento. Existe un cierto nivel de experiencias que permiten pensar en esta posibilidad, como son las experiencias de sociedades no occidentales o los propios grupos sociales afectados por las mayores desigualdades, que en muchos casos han desarrollado acciones alternativas como estrategias de supervivencia, pero esto no evita la pregunta ¿qué pasa con aquellos otros que no están impelidos por estos condicionantes? Esto es, los grupos más privilegiados. Específicamente, ¿cuál es la posibilidad de acción de cambio de un científico? O retornando al título que contiene estas reflexiones ¿cuáles son los vínculos, que a la luz de estas reflexiones, pueden establecerse entre ecología y praxis ambiental? 


\section{Tercera sección: El terreno de las prácticas}

Capítulo 5:

Praxis ambiental, el desafio pendiente 


\section{Introducción}

En los capítulos precedentes he explorado la producción de conocimiento ecológico en un contexto de crisis ambiental. He indagado, por una parte, el tipo de interrogantes que se inauguran tanto en el plano de las ciencias como de los ambientalismos. Desde este punto he revisado las distancias entre estudios y reclamos. Este análisis me llevó a reparar en dos de las más importantes trabas de acciones y reflexiones, esto es, en dos de los pilares de la lógica de dominio, que subyace: 1- el supuesto de un mundo jerárquico, organizado a medida del hombre y 2- la dualidad sociedad/naturaleza que atraviesa las consideraciones organizativas y el diseño de modos de intervención. El carácter artificial que se reconoce en ambos pilares no alcanza, sin embargo, para desmontarlos. En el presente capítulo completo la reflexión a partir de indagar en el campo de las prácticas.

La producción científica, enfrentada a las demandas actuales, pone en evidencia un soporte de prejuicios diferenciadores que signan el diseño de protocolos de investigación. Esta base de supuestos, que podemos entender como las formas simbólicas de apropiación, se articula con estrategias materiales de intervención en el espacio. Este capítulo se propone recorrer, precisamente, las prácticas específicas, diseñadas en función de determinadas intenciones, con objetivos explícitos.

A fin de dar cuenta de la complejidad que adquiere este nivel de acciones materiales tomaré la noción de praxis para recorrer las formas de elaboración de saberes y toma de decisiones conciente de los modos de intervención. Desde este reconocimiento, y con el objeto de distinguir el cambio en cuanto a las iniciativas de vinculación con el entorno, presentaré el concepto de praxis ambiental para exponer el tipo de actividades que reconozco como fundamentales en el escenario vigente. Para realizar esta exposición revisaré, en primer lugar el concepto general de praxis para, desde el mismo, acuñar una nueva acepción que tome en consideración la dimensión ambiental involucrada en las acciones efectuadas, con la problematización correspondiente en cuanto al vínculo que se plantea con y hacia el entorno en que se despliegan las actividades.

Así voy a tomar en consideración: 1) El origen del vocablo praxis; 2) la noción marxista de praxis y 3) algunas de las variantes que fue adoptando el término, que en general apelan o se refieren a la propuesta de Marx, incorporando variaciones para adecuar el 
término hacia los aspectos que se buscaba explorar desde esta noción. En esta línea una de las revisiones más útiles al tema que nos ocupa será la lectura de la praxis que se elabora desde la antropología, por tomar el concepto para indagar en las vinculaciones que se establecen en sociedades no occidentales. En general las acepciones de la palabra praxis que se tomarán como referencia serán aquellas que han buscado dar cuenta de la acción reflexionada proyectada hacia su entorno.

\section{Primeras aproximaciones teóricas}

El origen griego de la palabra praxis refiere a lo práctico, pero no reducido a una conducta. Un ejemplo que ayuda a diferenciar es el de la araña tejiendo su tela, que remite a una conducta a diferencia de la praxis de los trabajadores de un telar. Una frontera sutil, que se desdibuja cuando, por ejemplo, se reconoce el carácter automático de una rutina. Por ello la diferenciación entre conducta y praxis debe ser discutida en cada caso. En general se supone que la praxis es el resultado de anamórfosis de conductas previas, lo que implica que será preciso contar con configuraciones culturales, sociales e históricas. La idea de praxis, entendida de este modo, se corresponde muy de cerca con el significado, en español, de la expresión hacer humano. La revisión desde la praxis implica necesariamente un reconocimiento de los límites entre lo humano y lo no-humano así como los criterios y las formas que han permitido establecer esos propios límites.

A grandes trazos podemos pensar que el concepto de praxis incorpora a ideas como práctica o conducta, una dimensión explícita de conciencia e intención, que buscan diferenciar estas actividades intencionadas de las acciones vinculadas a ejercicios rutinarios. La praxis presupone la conducta y la acción, pero no se reduce a las mismas, justamente por la intencionalidad o reflexión implícita. En este sentido podemos pensar que la noción de praxis ha sido tomada como el hacer humano conciente $e$ intencionado, diferentes y distinguible de otros haceres (humanos o no).

Abro un paréntesis en relación a la idea de intención y sobre todo a la valoración moral de la misma. En este punto voy a seguir la lectura que José María Torralba (2005) realiza respecto del trabajo de G.E.M. Anscombe. El trabajo de la filósofa británica permite reconocer que la valoración moral de una acción depende de cómo sea esta 
descripta. Un punto fundamental para evaluar la legitimación social de la misma. En el libro de Anscombe Intention, el tema de la descripción de acciones es fundamental, así menciona que todas las acciones pueden ser descriptas de variadas formas, pero será reconocida como acción en tanto se describa en término de intenciones. La acción intencional, que se acerca mucho a la consideración de praxis, es para Anscombe la base para la adscripción de responsabilidad. Intenciones propias y juicios sociales emergen en la valoración de las acciones intencionadas. Siguiendo esta línea de reflexiones, debe indicarse que las razones desde las cuales se describe a las acciones se contienen, a su vez, en dos conjuntos:1- las creencias y 2-los deseos que para la autora permiten se consideran desde principios morales absolutos. En síntesis

“... la propuesta de Anscombe, consiste en el desarrollo de una teoría de la virtud -de corte aristotélico- , a la vez que mantiene el sentido de los absolutos morales -tal y como aparecen en la ley moral. Lo que Anscombe rechaza es que el término 'moral' añada -por sí mismo- algo de la noción de 'lo debido', porque la acción humana posee, ya de entrada, carácter moral. La 'obligatoriedad' de realizar -o no- una determinada acción no es un añadido a la acción, sino que se descubre en el mismo momento de tomar la decisión de actuar y forma parte del contenido de lo que se hace. La originalidad del planteamiento reside en que recupera el carácter normativo de las virtudes, según el cual la bondad o maldad de una acción procede de su mayor o menor conformidad con los fines de la virtud." (Torralba, 73-74)

No es objetivo del presente trabajo discutir esta noción de valores morales absolutos, sino rescatar de esta idea de intención, que forma parte necesaria de la definición de praxis, el camino hacia el punto del reconocimiento y valoración social de las acciones. Porque el suponer que las actividades intencionadas pueden agruparse, tiene como corolario el reconocimiento de otro conjunto de actividades no-intencionadas. De hecho podemos inferir la existencia de una distinción clara y unívoca entre praxis de aquello que no es praxis, es decir, las actividades no-humanas o no-concientes. Indagar en la praxis lleva a observar tanto los recortes como el ejercicio de diferenciaciones.

Esto nos lleva a un punto de tensión en relación con las referencias exploradas en los capítulos previos, porque la praxis ambiental, desde su carácter de ambiental pone al menos en entredicho la posibilidad de realizar una separación tajante entre lo humano y lo no-humano tanto a nivel simbólico como material. La posibilidad de interacción, el reconocimiento de una agencia extendida, e incluso la ética y la epistemología 
relacional, abren interrogantes sobre la posibilidad de trazar límites tajantes entre lo humano y la naturaleza. Lo humano se reconoce en-relación-con, abandonando la idea de carácter humano per se.

Desde esta visión, la praxis como actividad que distingue lo humano debe, al menos, tomar como marco de referencia los supuestos de separación y vinculación que se edifican desde ciertos marcos culturales. En este sentido me alejo de uno de los supuestos más importantes de Anscombe. Considero que las intenciones, desde las evaluaciones sociales desde las cuales son valoradas, deben distanciarse de su interpretación como distintivo humano a ser considerado desde un marco absoluto y pasar a revisarse desde las estrategias de legitimación y aplicaciones materiales donde cobran forma en el mundo.

Prefiero en este camino acercarme a la propuesta de Judith Butler (1999) sobre el deseo. Para la teórica norteamericana sólo desde el deseo es posible avanzar y entender el eje fundamental de la vida humana. No se trata ya de un recorte en oposición a, sino desde un lugar fundamentalmente ligado a acciones productoras de cambio. Butler se opone a la idea de deseo reducida a la falta de un objeto (precisamente lo que desea), porque allí se pierde de vista la dimensión productiva del deseo (Casale 2006). Desde esta consideración del deseo humano Butler retorna a su noción de sujeto, que cobra una doble dimensión, *como sujeto-sujetado pasivo frente a los determinantes que lo contienen, y *como agencia productora que se define performativamente (Casale 2006). Desde esta perspectiva las acciones sociales, el universo de praxis que busco explorar, no se acotan ni a una voluntad ciega ni a un determinismo absoluto, sino que resultan de las complejas combinaciones de estos extremos.

No es motivo de la presente tesis evaluar si esta capacidad de hacer, fundada en el deseo, es exclusivamente humana. Carezco de los elementos como para tener una posición al respecto. Por el contrario, el eje sobre el que trato de avanzar es que esta capacidad de acción no debe implicar la subordinación jerárquica de lo que es culturalmente evaluado como diferente. Es decir, que los vínculos pueden establecerse desde el respeto y reconocimiento de las diversidades. A partir de estas referencias indagaré en praxis específicas, en las distancias que pueden encontrarse entre el plano de compromisos propuestos y ciertas actividades de producción de conocimiento o de cuidado ambiental. 


\section{El concepto de praxis}

La noción de praxis como eje de las actividades humanas, ha sido tomada desde diversas perspectivas. La incorporación de éste término en un escrito puede interpretarse como una denominación que da cuenta de las intenciones y objetivos concientes de las acciones. Desde esta línea no parecería haber mayores conflictos para agregar cualidades a la noción de praxis, que den cuenta de ciertas intenciones, como podrían ser praxis ambiental o praxis ecológica en el tema que nos ocupa.

Sin embargo, entiendo que la noción de praxis involucra dimensiones más profundas de las acciones, que se exponen a la luz de la interpretación del término propuesta por los autores que han incorporado un cierto sentido a su uso. Volviendo los ojos a la historia es posible distinguir dos grandes interpretaciones sobre la noción de praxis, que desde ciertos aspectos podrían interpretarse como contrapuestas (González, 1997). La primera, que podría denominarse aristotélica, se encuentra desarrollada en la Etica Nicomaquea del estarigita. En esta obra el filósofo introduce el término prâxis para designar actividades cuyo fin está en ellas mismas. Esta visión separa la noción de praxis de otras actividades productivas, (poiesis), que tendrían su fin en aquello que ellas crean. La praxis haría referencia a aquellas actividades que tienen fin que no es medio para ningún otro fin, por lo cual la theoría o contemplación resulta en la forma suprema de praxis.

Desde una perspectiva que puede evaluarse como opuesta, las filosofías que han avanzado sobre el pensamiento de Carlos Marx entienden praxis como aquella proyección de los seres humanos sobre su mundo circundante, con el objeto de transformarlo. La diferencia más notable respecto de la postura previa es que desde los escritos marxistas la producción está necesariamente incluida en la noción de praxis.

Marx en 1841, en su tesis doctoral titulada Las diferencias entre la filosofía de la naturaleza Democrito y Epicuro, introduce una nueva forma de considerar a la praxis. Marx, acuerda con Epicuro que el conocimiento se arraiga en la autoconciencia, y la misma es inseparable de la subjetividad concreta en que está arraigada. Desde aquí considera que la actividad teórica se encuentra determinada por las condiciones prácticas, materiales y sociales, en las que se desarrolla la vida social del ser humano. 
El pensador renano se mostraba crítico a la filosofía previa, que evaluaba como especulativa, teórica y desvinculada de la realidad. A fin de diferenciarse Marx reivindicó la importancia de considerar el horizonte de cambios que se deseaban en el mundo, porque para este autor, al igual que para Epicuro, el mundo era un ámbito susceptible de recibir modificaciones.

Lejos de estar determinada por condicionamientos trascendentes, la situación cotidiana resultaba de los modos de hacer humanos, y los mismos eran modificables. Desde este reconocimiento Marx otorga a la idea de praxis un nuevo sentido: la praxis es presentada como la acción que introduce cambios en el mundo. Desde esta nueva interpretación las actividades productivas están necesariamente incluidas en el concepto.

De razón especulativa a principio revolucionario, la idea de praxis continúa, sin embargo, ligada al hacer humano. Esto nos plantea un desafío porque, como vimos en los capítulos previos, la separación entre sociedad y naturaleza, lejos de ser un recorte absoluto responde a un constructo cultural. La actividad humana, entendida como la única intencionada, diferente al del resto de los seres vivos, lleva inexorablemente hacia la diferenciación, que en las sociedades occidentales ha tomado de forma de dualidad antagónica.

Esto nos pone de frente a una paradoja, si se asume la noción de praxis como definición fija, desde cualquiera de las dos consideraciones expuestas, se encuentra que contiene en sí a la síntesis de las diferencias que se han establecido y naturalizado respecto del entorno. Por ello es discutible que desde esta noción puedan surgir vías para revisar intervenciones humanas en relación a las actividades no humanas.

Este problema se resuelve, sin embargo, si abandonamos la idea de praxis como definición fija y la pensamos como las actividades que se reconocen como humanas en contextos culturales espacio-temporalmente determinados. Desde esta perspectiva el modo de reconocer o de comprender la praxis daría cuenta de la pluralidad de relaciones que se busca problematizar, sería la acción humana en-relación-con. Esto es, aquellas que ligan los modos de conocer a las formas de apropiación y simbolización del entorno.

Tomando como centro a las líneas interpretativas que se han establecido desde las formas occidentales de comprender el mundo, vale señalar que tanto la perspectiva 
aristotélica como la marxista de praxis apuntan a dar cuenta de las acciones humanas concientes. Ambas perspectivas -aunque de diverso modo- comparten la aceptación de la escisión entre "humanidad" y "naturaleza". Las dos interpretaciones nos ponen de frente a la concepción de ser humano que subyace en el conjunto de reflexiones sobre las que se han erigido los modos de conocer de la sociedad occidental y, ligados a los mismos, las formas de apropiación que en la actualidad se denuncian como insostenibles.

Aquí se introduce otro punto interesante, porque si bien ambas ideas de praxis suponen el hacer humano, en la definición que otorgan incorporan referencias que dan cuenta que el grupo humano capaz de comprometerse con la concreción de esa praxis tiene restricciones. Es decir, praxis en ninguno de los casos pretende dar cuenta del hacer humano universal, pero es la referencia que da cuenta de esas acciones humanas que distinguen, en consecuencia, las actividades de los no-humanos.

Puede interpretarse que en Aristóteles, lo humano en sentido estricto se refiere a un grupo específico integrado por ciudadanos, porque la racionalidad se reconoce como potestad de ese sector (Femenías 1996). En Aristóteles, el reconocimiento del hombre como tal se sostiene desde la facultad peculiar de razonar. Guthrie (1981) señala que el estarigita entiende que la vida se comparte con las plantas, la sensación con los animales. Sólo el logos, la capacidad de razonar, es exclusivamente humano. De modo que la función propia como ser humano es

"una actividad de la psychē de acuerdo con el logos, o que no puede darse sin el logos. Unido al logos como lo distintivamente humano se encuentra el sentido con conciencia moral de lo justo y lo injusto, el bien para el hombre se convierte en una actividad de la psychē de acuerdo con la virtud" (Guthrie 1981, 354).

En Aristóteles, las prácticas y rutinas desligadas de esta particular concepción de razón son acciones que permanecen fuera de la idea de praxis. Así, por ejemplo, esclavos, mujeres y "otros" con fundamentos que no se aten a esta razón occidental, quedarían fuera de la humanidad que elije, desea y acciona, por carecer de la posibilidad de ejercer una praxis. Las actividades de estos humanos sin-praxis quedarían acotadas al plano de sensaciones. En la incapacidad de ejercer una praxis se filtra la idea de límites en la razón, y con ello en la conciencia moral. Podría pensarse que el propio ejercicio de la libertad está limitado desde estas consideraciones, en todas las personas que no se 
reconozcan como responsables de sí y hacia los otros. La praxis, desde esta perspectiva, es una capacidad de pocos.

Los seres humanos que ejercen todas sus capacidades, son reconocidos como tales en la medida que se asimilen o adecuen al modelo desde el que se mide el potencial para concretar esas mismas capacidades. La distancia y separación que de esta visión se plantea frente a la naturaleza, no sólo da cuenta de la diferenciación de los hombres respecto de otros organismos, también resulta en un ejercicio de quiebre hacia el interior de la humanidad.

Marx, en 1841, se aleja de esta concepción. Su reflexión se aboca a reparar en las diferencias entre teoría y práctica a partir de revisar los giros práctico y crítico de la filosofía en distintos períodos históricos. La diferencia que plantea se funda en la importancia que el pensador renano reconoce en las actividades productivas. Entiende que la filosofía, al desestimar la producción como una actividad de menor importancia que la especulación, perdió de vista el objetivo fundamental del pensar: la necesidad de cambiar el mundo.

A fin de avanzar en la idea de humanidad que se presenta en la propuesta de Marx, indagaremos en los detalles de su lectura sobre Epicuro y la propuesta que edifica desde esta lectura. Las líneas argumentativas de la tesis doctoral recorren dos conceptos que resultan fundamentales en el pensamiento general de Marx: praxis y crítica. El concepto de praxis es introducido con el propósito principal de la tesis: revisar la historiografía filosófica a los efectos de rehabilitar el tipo de filosofía práctica y antisistemática que Epicuro encarna. En forma complementaria el concepto de Crítica se toma a fin de comprender - a partir de la experiencia antigua- la crisis histórica y política de comienzos del siglo diecinueve (Gonzalez 1997). La teoría crítica propuesta por Marx trascendía el mero ejercicio intelectivo y se reconsideraba desde la praxis porque praxis y razón se tomaban como los dos polos de la Teoría Crítica. La dialéctica descripta operaba en la interacción y tensión entre ellos, aunque la primacía de la razón nunca estuvo en duda (Jay 1974)

Una de las lecturas que avanzan sobre la idea de Marx es la de Herbert Marcuse (1968), quien señala que el trabajo es la praxis específica de la existencia humana en el mundo. El filósofo alemán indica que el hombre se transforma en lo que es, desarrollando la 
forma de su existencia al mismo tiempo que transforma el mundo en su mundo. Desde esta visión podemos plantear que hay tensión entre la naturaleza y la sociedad tecnológica que interactúa con ella, porque el mundo tecnológico es un mundo con la naturaleza escindida. ${ }^{59}$

Ernst Bloch, asume en la misma línea la idea del trabajo como categoría mediadora de la relación sujeto-objeto; en la novedad marciana de la relación teoría-praxis (Gimberant 1993). En estas reflexiones resulta de interés la crítica de Donna Haraway (1999), para quien tanto el produccionismo como su corolario, el humanismo, se reducen al argumento en el que «el hombre lo hace todo, incluido a sí mismo, a partir del mundo, que sólo puede ser recurso y potencia para este proyecto y agencia activa». Este produccionismo se refiere al hombre fabricante y usuario de herramientas, al trabajador cuya producción técnica más brillante es él mismo; que retorna, según entiende la autora, al argumento del falogocentrismo.

La sobre valoración del trabajo implica la naturalización de un dominio sobre el mundo que fue discutido desde los propios lectores de Marx. Así, entre las diferenciaciones que plantea Horkheimer respecto de las lecturas ortodoxas, se encuentra que para Marx el progreso de la humanidad implica el dominio de la naturaleza y el crecimiento ilimitado de la fuerza productiva, del cual son parte integrante la ciencia y la técnica. Como contrapartida, para el filósofo frankfurtoniano, el dominio continuo sobre la naturaleza implica un incremento de la ciencia y la técnica que redundan en un dominio creciente sobre el hombre (Abagnano 1993).

Antonio Gramci (1975), quien entiende a la praxis como la relación entre la voluntad humana (superestructura) y la estructura económica, sostiene en su La inmanencia y la filosofía de la praxis que la filosofía de la praxis continúa a la filosofía de la inmanencia, pero la depura de todo su aparato metafísico y la guía sobre el terreno concreto de la historia. Theodor Shanin (1988) y Kaye Harvey y Keith McClellend (1980) continúan la propuesta del filósofo italiano, asumiendo el marxismo como praxis en el sentido de concebirlo como un conjunto de relaciones dentro de las cuales se mueven y actúan personas reales, en sus contradicciones sociales. Esta lectura de la praxis ligada a tensiones y posibilidades de cambio permanentes es mediada por Shanin, Harvey y McClellend, desde las trabas efectivas que operan, sobre todo desde el ${ }^{59}$ Este no es el único problema que puede encontrarse en la propuesta de Marcuse. Como indica Alicia Puleo (1992) este autor asocia a la mujer con el inconsciente y "el ello". 
entramado institucional, dirigido a generar consensos, que observados en profundidad resultan la base del dominio y la reproducción de intereses del grupo hegemónico.

El mérito de Marx se refuerza desde sus lectores posteriores, ya que no sólo redescubre la filosofía práctica de Epicuro oponiéndola a las tendencias especulativas que le precedieron, sino que, volviéndose al ocaso de la civilización griega, tematiza su propio presente histórico, sosteniendo el fin de la filosofía especulativa. El particular contexto posaristotélico llevó a Marx a reflexionar sobre la pluralidad de reflexiones que acontecieron en un período histórico determinado. Más allá de la trascendencia lograda desde la perspectiva estoica sobre los escritos de Platón y Aristóteles, que imprimieron un sesgo fundamental en el pensamiento occidental, y fortalecen la idea de principios universales y ajenos a los contextos.

La tradición que discute Marx es la que sostiene que el conocimiento se fundamenta desde un marco real, aunque como ajeno a la humanidad, que ya desde Platón se plantea como inaccesible en el mundo sensible. Una noción que fundamenta una línea de reflexión denominada escéptica, que discutió, no sólo al saber del mundo sensible, sino a la misma especulación filosófica. Desde esta perspectiva se presenta casi una paradoja, porque "apenas dos siglos después de Tales de Mileto, algunos griegos llegaron a confesar que el esfuerzo no valía la pena, y a exigir la prohibición de pensar." (Segura Cortés 1980)

Frente a estas posturas Epicuro recupera la antigua tradición jónica defendiendo la posibilidad de conocer un mundo en el que la humanidad no debe considerarse ajena. En grandes líneas podemos plantear que, según Epicuro la sensación es la base de todo el conocimiento y se produce cuando las imágenes que desprenden los cuerpos llegan hasta nuestros sentidos. Ante cada sensación el ser humano reacciona con placer o con dolor, dando lugar a los sentimientos, que son la base de la moral. Cuando las sensaciones se repiten numerosas veces se graban en la memoria y forman así lo que Epicuro denomina las ideas generales.

Epicuro rechaza la Idea platónica y el Universal aristotélico argumentando que nada resiste al conocimiento. Debe rescatarse que para el filósofo de Samos tanto conocimiento como pensamiento se concretan a partir de las experiencias sensibles, que son reproducciones en nuestra conciencia emitidas por las cosas y recogidas por 
nuestros órganos. Desde esta línea sostiene que si el conocimiento es posible, la calidad del mismo se explica por la cantidad de experiencias y sensaciones que se viven. ${ }^{60}$

El avance en el conocimiento se da, entonces, desde la vinculación con la naturaleza misma. Epicuro planteaba que el subsistir de los efectos de la sensación era testimonio suficiente para fundamentar la veracidad de las sensaciones. El pensador de Samos no ignoraba que muchas veces las sensaciones no corresponden con el mundo, pero lejos de tomar esto como un problema explicita la parte de subjetividad que contienen las sensaciones. A partir de tomar esta subjetividad como punto de partida entiende que el problema de las confusiones se resuelve, precisamente, incrementando el número de experiencias.

Marx toma estas discusiones y repiensa tanto la actividad humana como en el carácter que constituyen al ser humano en sí. Recupera en Epicuro la idea de subjetividad práctica, de la filosofía como sabiduría existencial y no como sistema. Sobre ello agrega, en función de su propia formación, la exigencia de criticar al mundo y denunciar la futilidad de todo pensamiento desvinculado de su situación histórica.

La praxis, desde esta crítica, es la acción que tiende al cambio. Una actividad vinculada al trabajo material y a su incidencia en el mundo. El punto que debería revisarse en Marx, desde la perspectiva que presentamos en este capítulo, es que junto a la capacidad de transformación del mundo, la praxis marxista asume una idea de dominio de la humanidad sobre la naturaleza, de una forma tal que arrastra muchas de las contradicciones sobre las que se asienta la explotación moderna del mundo. La sobrevaloración del trabajo como posibilidad de cambio del mundo lleva a perder de vista otros modos de intervenciones, tal vez más sutiles, tal vez con menos impacto paisajístico, pero no por ello menos intencional o reflexivo.

En la acción transformadora de la naturaleza material, base de la praxis marxista, se filtra de este modo una concepción de naturaleza escindida de la humanidad. A partir de ello se entiende que la capacidad de transformación descansa en el conocimiento científico de la naturaleza. Es decir, no se trata de cualquier tipo de conocimiento, sino

\footnotetext{
${ }^{60}$ Epicuro recupera las ideas de Demócrito, quien había indicado que el contenido por la combinación de átomos físicos, que difieren en forma, peso y magnitud y cuentan en común una cantidad infinita de combinaciones. Los átomos y el lugar de su combinación son suficientes para el planteo de las explicaciones, pues los átomos y el lugar reúnen una combinación simple y un poder de explicación infinito.
} 
de un saber que se supone fundado en leyes que rigen el recorte no-humano del mundo. Las acciones humanas para Marx son aquellas ligadas a una vinculación instrumental, y que se supone como determinantes respecto de otro tipo de relaciones, como podría ser la afectiva. La praxis social propuesta desde el marxismo supone el dominio de la naturaleza a través del conocimiento y utilización de sus leyes mediante técnicas adecuadas. Desde este lugar la propuesta marxista, aún con los cambios que propone, no termina de desmontar las formas de apropiación y dominio elaboradas en las sociedades occidentales.

A esto se suma que la forma en que la noción de praxis propuesta por Marx cobra sentido tanto a partir de sus escritos como de las sucesivas lecturas de sus seguidores. Por ello las referencias a las que alude el término deben contemplar tanto la propuesta del pensador renano, como la forma que fue cobrando a partir de sus lectores. ${ }^{61}$

No es objeto de esta tesis el dar cuenta de la pluralidad de aristas que la noción de praxis tomó a través del tiempo. Pero resulta importante señalar que la centralización de las reflexiones sobre la estructura económica lleva a plantear praxis fundamentalmente como trabajo transformador. Praxis supone la transformación de la cosa y la toma de conciencia de si mismo (Revueltas 1986). En otros términos, desde esta línea se plantea que el concepto de praxis estudia y demuestra que el hombre ha transformado la naturaleza mediante su praxis productiva y en consonancia con ella, ha transformado también sus propias relaciones sociales.

Pero este planteo, donde la actividad humana implica un cambio en el mundo, restringe la idea de cambio a un trabajo sobre una naturaleza considerada ajena. Esto implica un compromiso subyacente con una cierta concepción de humanidad y de formas relacionales desde el cual, por ejemplo, se podría argumentar que los pueblos que no impactan materialmente sobre su entorno quedan fuera de este recorte de praxis. Es decir se vuelve a medir tomando como norma las sociedades occidentales. Desde el marxismo, con el peso colocado en el trabajo y la prioridad de relaciones focalizadas en el ámbito de la producción, se pierden de vista problemas relacionales que se proyectan fuera de este recorte, como resulta de la problemática ambiental.

${ }^{61}$ A modo de ejemplo I. V. Blauberg, P. V. Kopnin e I. K. Pantin (1975), mencionan en su Diccionario Filosófico Marxista, el carácter contingente de la praxis marxista, indicando que en cada etapa de la historia, la práctica es limitada y cambiante, por ello el criterio de la práctica no es absoluto, en cada caso determinado. 
Hay una consecuencia en términos de género que vale la pena mencionar. En el proceso de reconocer las actividades femeninas suelen restringirse las mismas a las experiencias biológicas. Ya se revisó en el capítulo 4 la profunda vinculación entre naturaleza y mujer que se sostiene desde múltiples metáforas modernas. Esto lleva a relativizar (o directamente omitir) las acciones femeninas en términos de cambio, porque no se distinguen de otras de animales que también traen al mundo hijos y cuidan de ellos. Así, la noción de actividad humana se circunscribe preferentemente a las actividades masculinas. Celia Amorós (2008) señala que los propios feminismos socialistas han tenido trabas para la problematización de la situación femenina, precisamente porque sobrevaloraron la categoría de trabajador.

El aporte marxista, sin embargo, inaugura un reconocimiento al plano de las experiencias y actividades concretas, que permiten dar cuenta de una "humanidad" más amplia que la que se desprende de la perspectiva aristotélica, aunque no sea tan claro que sea a toda la humanidad, porque como señalamos las relaciones que se priorizan como praxis se circunscriben a formas productivas culturalmente específicas, aquellas que provocan un cambio tangible en el mundo que los rodea. La conciencia se despliega en la actividad productiva, es decir, sólo en uno de los múltiples vínculos que se pueden desplegar. De hecho la actividad productiva es en sí problemática, porque desde la forma que adopta en las sociedades modernas, reducen los vínculos existentes a la forma instrumental de los mismos (Plumwood 1996).

Asumir un parámetro - la razón occidental- o un vínculo -el trabajo sobre el mundocomo privilegiados para definir la acción humana, imprime un recorte en la humanidad. Es decir, acota los parámetros de reconocimiento que inciden incluso en limitaciones para decidir sobre sus las actividades y vinculaciones que se evalúan como propios. Por otra parte, si la praxis da cuenta de la actividad humana (aún asumiendo que esta generalidad es posible), aquello que no es praxis resulta en lo distintivo de las actividades no-humanas. Los otros surgen tanto en Aristóteles como en Marx como un homogéneo cuya principal característica es una falencia.

Otro problema que emerge de la exploración de la noción de praxis es que choca con las formas intuitivas que usualmente se reconocen en el término. Porque las referencias de la praxis vinculadas a una intención, antes que a una forma de razonar o a una intervención material, no pueden acotarse necesariamente a la humanidad, porque tanto 
intención como capacidad de aprendizaje o transmisión de la memoria, distan de ser exclusivos de las poblaciones humanas, tal como se ha expuesto desde la Etología, la Sociobiología o la Psicología Comparada. En forma circular esto nos retorna a los debates aún abiertos en torno a los derechos de los animales.

Con las limitaciones mencionadas, el debate sobre el concepto de praxis no deja de ser relevante. La lectura de Marx sobre la disputa de ideas en la antigüedad clásica nos coloca frente a la posibilidad de cambio como resultado de abandonar la idea de razón como autónoma de la experiencia. Asumir la dimensión de subjetividad implícita en la experiencia lleva a discutir el sitio de condescendencia al que se arribaba desde las posturas estoicas o, incluso, escépticas. Desde Epicuro, Marx fortalece el abandono a la idea de destino. Porque renuncia tanto al ideal regente heredado de Platón como al determinismo que el atomismo conllevaba en su forma original. El filósofo de Samos introduce un elemento de azar en el movimiento de los átomos, una desviación de la cadena de las causas y efectos con lo que la libertad queda asegurada para las cosas, y entre las cosas, para la humanidad como totalidad.

En Marx, quebrar con la idea de praxis aristotélica, implicó el abandono de la aceptación sobre ese modo de reconocer el mundo y asumir la perspectiva de cambio como una dimensión fundamental del conocimiento. En una línea similar, adscribir a la necesidad de incorporar la dimensión ambiental asociada a la noción de praxis, implica abandonar que la praxis se acota a las actividades circunscritas a formas de producción. Porque hay una enorme dimensión de la vinculación con el entorno - donde se cuenta la presencia de humanos y no-humanos- que demandan formas alternativas de pensar esta actividad que nos distingue como humanos.

\section{EI desafío de la praxis ambiental}

La praxis ambiental deberá definirse a partir de desmantelar los compromisos ligados a diferenciaciones tajantes y atemporales entre lo humano y lo no-humano. En este sentido me opongo a la visión intuitiva donde praxis ambiental se asume como prácticas 
concientes ligadas a la preservación del entorno (p.e. Avellaneda 2002; Gonzaga 2007), porque ni praxis ni ambiente son términos unívocamente definidos.

Entiendo que la praxis ambiental tiene un importante peso coyuntural. Es una praxis que se define en un contexto, que se reconoce y describe a partir de formas locales de organización, con una trayectoria histórica particular. Una praxis con minúscula pero con una incidencia directa en los procesos en los cuales se trabaja para explicitarla.

Marx fundamentó su discusión sobre la praxis en las voces silenciadas de los debates; partió de uno de los filósofos caracterizado como socrático menor, en el sentido de haberse reconocido con una trascendencia menos destacada que las figuras clásicas. En una línea equiparable en este punto, Bárbara Holland Cunz (1981) toma en su reflexión sobre los ecofeminismos esta idea de minorías silenciadas, de formas de comprensión alternativas que, precisamente por situarse fuera de las reflexiones que sustentan los modos oficiales de conocimiento, permiten una problematización más sutil $\mathrm{y}$ confrontativa.

Para el caso que me ocupa transito por varias de estas "minorías silenciadas", pero en el tema específico de la praxis debo apelar no sólo a las voces minoritarias sino a las disciplinas que han afrontado el problema de las prácticas humanas en su máxima diversidad, donde la antropología se destaca por el recorte de actividades que asume como de interés.

\section{El aporte antropológico}

La complejidad de constitución de las teorías antropológicas es un tema que escapa a los objetivos de esta tesis, pero resulta de interés el modo en que la noción marxista de praxis fue incorporada en esta disciplina (Levi-Strauss 1997, Godelier 1978). A grandes trazos debo señalar que esta idea se tomó limitando el compromiso de cambio revolucionario introducido por su autor original, más bien se tomó para fortalecer vías de estudios que priorizan la indagación de la estructura relacional y el contexto histórico.

En antropología se toma la praxis como un término que permite recorrer los fundamentos de las costumbres que se observan. Un punto diametralmente opuesto a la 
perspectiva aristotélica. Sin embargo podríamos pensar que el alejamiento del compromiso de cambio vuelve a recuperar, en alguna medida, la visión de una praxis donde la teoría subordina a la práctica.

Esto no significa que la opción de reparar en la praxis marxista no-revolucionaria sea un aporte menor. Vale mencionar, por ejemplo, en las reflexiones de Claude Levi-Strauss (1997), quien sostiene que los antropólogos no deben acotarse al estudio las prácticas, sino rescatar los esquemas conceptuales dentro de una teoría de las superestructuras. Esta idea se vincula con la propuesta de Maurice Godelier (1978), quien argumentó sobre la importancia de reparar en las fuerzas productivas, es decir, las constricciones que imponen y las posibilidades que ofrecen a cada sociedad para extraer de la naturaleza sus condiciones materiales de existencia, antes que los procesos concretos de producción.

Camilo Quintero (2006), señala que uno de los más importantes aportes de la mirada antropológica fue poner en reconocimiento la presencia de saberes locales, un concepto posteriormente revisado desde las críticas hacia la epistemología establecida (Haraway 1988). En los años ochenta Clifford Geertz ya había argumentado que los etnógrafos no pueden percibir el mundo como sus objetos de estudio lo perciben. En este sentido el antropólogo señaló que la labor del etnógrafo es interpretar estos saberes locales en términos occidentales, y entender que el mundo occidental no es más que un caso dentro de muchos (Geertz 1983). Desde esta perspectiva se impugnó la noción de saberes establecidos y estáticos. La historicidad y dinamismo del conocimiento en la pluralidad de sociedades humanas llevaron a reconocer estructuras de saber en cambio permanente en los más diversos contextos (Clifford 1997).

En el diálogo que se plantea entre el saber (occidental) del antropólogo y la cultura local, queda claro que en cada situación, por el propio dinamismo del saber, tanto el conocimiento local como el saber occidental se modifican (Arnold 1993, Prakash 1999).

En relación al tema que nos ocupa, encontramos un aporte más específico en Philipp Descola (1996), quien determina un caso etnográfico sobre el cual analizar las relaciones entre una sociedad determinada y su medio ambiente, bajo el aspecto de las interacciones dinámicas entre las técnicas de socialización en la naturaleza y los sistemas simbólicos que las organizan. Y en esta línea la idea de praxis cobra una arista 
particular que lo distingue de las formas más ortodoxas del marxismo. Como indica el antropólogo francés

"El empirismo materialista considera las representaciones de la vida material como elaboraciones secundarias, como meros reflejos ideológicos de los modos de apropiación y socialización de la naturaleza. Tal perspectiva parece inaceptable, pues nada permite atribuir a lo material una preeminencia causal o analítica sobre lo mental. Toda acción, todo proceso de trabajo se constituye a partir de una representación de las condiciones y de las modalidades de su ejecución” (Descola 1996, 19)

Desde esta perspectiva la praxis, en tanto actividad humana, se reconoce en las prácticas productivas y en las representaciones sociales de prácticas y condiciones.

"Una praxis es así una totalidad orgánica en la que se mezclan estrechamente los aspectos materiales y los aspectos mentales, si no es posible reducir los segundos a los efectos deformados de los primeros, en cambio tal vez no es imposible evaluar la parte respectiva de unos y otros en la estructuración de las prácticas” (Descola 1996, 19)

En Descola la praxis cobra sentido desde las pautas culturales específicas. Se trata de un punto de partida que permite incorporar formas comprensivas desde las cuales revisar el complejo lazo que une a la producción de conocimiento de los organismos vivos, con las formas de apropiación del espacio. Este reconocimiento se cruza con otro debate fundamentado en gran medida en las observaciones antropológicas, si el saber occidental era intrínsecamente superior o debía tomarse como un saber local más (Quintero 2006). Porque no se trata sólo de la teoría, sino de las actividades que desde ella de despliegan que, en tanto se fundamenten en un reconocimiento mayor, difícilmente se encuentren en planos de intercambio que efectivamente permitan la revisión de la lógica de jerarquías.

A partir de indagar la noción de praxis, este hacer necesariamente humano cobra sentidos variados que dependen de contextos. Así se encuentra una dimensión de constructo en la relación entre teoría y práctica, que se vincula a la propia edificación de la idea (más o menos amplia) de humanidad, y desde allí a la relación entre modos de conocer y vinculaciones que se establecen con la naturaleza, que puede o no observarse como ajena. 
Desde esta perspectiva, la edificación de una praxis ambiental en nuestra sociedad occidental inaugura desafíos porque la posibilidad de una praxis que tome en consideración a los otros: humanos en su diversidad, no-humanos, organismos vivos o paisajes; expone y enfrenta los recortes y las limitaciones edificadas desde la praxis occidental, sustentada en las diferenciaciones y dualismos presentados en los capítulos precedentes.

\section{La definición}

A partir de los debates precedentes, en una primera aproximación, entiendo por praxis ambiental a la acciones concientes sobre las cuales edificamos formas de vinculación específicas. Acuerdo con Descola en reconocer la convergencia de aspectos materiales y mentales, pero recupero de la propuesta original de Marx la idea que la praxis nos debe llevar necesariamente al compromiso con un cambio.

No se trata ya de un cambio asumiendo como única o prioritaria la relación de producción, sino a partir de reconocer la vastedad de las formas relacionales, donde el afecto y la estética no son aspectos que se subsuman o se eclipsen por la productividad. Es la praxis del yo-en-relación (Plumwood 1998) muy conciente de la particularidad y con una actividad que repara en las formas de vínculo que se establecen. Es una praxis que se preocupa por abandonar las formas de dominio establecidas, es indudablemente un desafío a construir.

La noción de praxis ambiental, por ejemplo, no necesariamente contiene a la práctica científica, porque implica compromisos activos en cuanto a la revisión de los vínculos hacia los "otros" desde su pluralidad. Ello ligado a una revisión crítica de las propias formas productivas que sustentan material y simbólicamente la praxis que se desarrolla.

La noción de praxis ambiental que propongo toma de la propuesta original la idea de dar cuenta de un hacer humano conciente e intencionado, asumiendo que ese carácter humano se cimienta desde el conjunto de relaciones e intervenciones materiales que se evalúan como válidas. Es conciencia de problemas y compromiso de cambio.

La noción de praxis ambiental también recupera que el ejercicio de reflexión tiene implícito un compromiso con la acción, una intervención efectiva en determinados 
procesos. Aunque debo resaltar una diferencia, porque esta intervención no radica en una actitud de denuncia, reclamo o revolución, sino a partir de edificar formas relacionales alternativas sobre las prácticas constituidas. En este sentido recupero el compromiso que Donna Haraway reclama a lo largo de su obra. Esta filósofa tiene su punto de vista puesto en los sujetos emergentes de la presente era de la globalización, sujetos con aspiraciones y problemas que permiten poner en debate las clásicas dualidades, de exponer las posibilidades epistemológicas donde las/os “inapropiables/ inapropiados" actuales puedan ser pensados, reconocidos y considerados.

Vale aclarar que la noción de praxis ambiental propuesta no es equivalente a las reivindicaciones ambientales, que proponen el cuidado del entorno desde actividades que focalizan mayormente la denuncia. De hecho las actividades que podríamos denominar de militancia ambiental no necesariamente reparan en las formas relacionales que se proyectan sobre una pluralidad de planos. En general, el foco de los discursos ambientales (o ambientalistas) tiende a la descripción de problemas y a la demanda de tomar en consideración a los mismos desde las esferas de toma de decisión.

Pero antes que en los discursos o las actividades de denuncia, es en las esferas que toman las decisiones donde deseo situar mi atención. Porque la noción de praxis ambiental propuesta busca incidir en estos ámbitos. $\mathrm{O}$ en otros términos, desde la noción de praxis ambiental se puede revisar el sentido y la interpretación que detentan las praxis en los espacios institucionales que en una sociedad orientan la vinculación de sus habitantes con el entorno. La praxis ambiental precisa del reconocimiento del problema ambiental, por eso supone la previa toma de conciencia. Sin embargo, desde esa toma de consciencia no necesariamente se llega a una praxis ambiental en el sentido de modificar las relaciones sobre las que se asientan las problemáticas: formas paternalistas, que suponen sociedades jerarquizadas y naturalizan lazos de dominio.

A fin de explorar esta aseveración revisaré las acciones tendientes a presentar y resolver temas ambientales desde experiencias concretas, así indagaré las reflexiones desde ilustraciones que nos pongan de frente a las situaciones materiales que se desprenden de los supuestos. A partir de las situaciones presentadas argumentaré que, aún reconociendo el problema, no necesariamente se edifica una praxis ambiental. Porque no se concibe la revisión de relaciones como parte del problema. 
Los ejemplos que tomo apuntan, en primer lugar a revisar el proceso de toma de decisiones en los ámbitos institucionales, esto es, los espacios políticos desde los cuales se diseñan y reglamentan las intervenciones sobre el entorno. Dado que los justificativos sobre las tomas de decisión descansan mayormente en una cierta jerarquía reconocida al conocimiento científico, el segundo grupo ilustrativo apunta a revisar características específicas de la producción del saber ecológico, analizando si en la propia lógica de producción de conocimiento se insertan aspectos que redundan en la problemática visualizada desde el primer conjunto de casos.

\section{La praxis ambiental y las instituciones}

Las dependencias gubernamentales no pueden considerarse como ámbitos homogéneos, en los cuales el problema ambiental se reconoce desde grados diferentes. Existen, sin embargo, cada vez más delegaciones específicas que aluden a la revisión de la situación del medioambiente y cada vez más se declama desde las esferas legales el derecho a una vida sana en un ambiente propicio. Para iniciar la revisión sobre el proceso de toma de decisiones definidas desde estas esferas, voy a partir de un ejemplo puntual. Desde la descripción de una situación específica reconoceré líneas de tensión que operan como trabas a la praxis ambiental propuesta. Se trata del manejo del vertedero municipal de San Carlos de Bariloche, donde los desafíos ambientales se cruzan con las tensiones sociales de la población.

El vertedero de San Carlos de Bariloche, situado en uno de los puntos límites entre la localidad y el Parque Nacional Nahuel Huapi, sobre la ruta 40, en un predio que linda con barrios de sectores populares, provoca importantes problemas ambientales. Se trata de un depósito a cielo abierto, donde los camiones recolectores depositan los residuos sin mayores tratamientos. En este proceso el depósito cobra una dimensión cada vez mayor. A este problema se agrega la cercanía de barrios de sectores populares, cuyos habitantes, cada vez que la seguridad del predio disminuye, ingresan a buscar residuos o simplemente a jugar. En estas ocasiones no es extraño que se produzcan incendios, que afectan a todo el entorno poblado. En este horizonte de problemas existe un grupo que trabaja para recuperar metales, plásticos y cartones en el predio, la Asociación de Recicladores Bariloche (en adelante ARB). En el modo en que el municipio se vincula a 
este grupo se explicitan los supuestos desde los que esta esfera gubernamental asume la vinculación con el entorno. ${ }^{62}$

La ARB se formó en uno de las peores situaciones de opresión económica y ausencia de instituciones estatales vividas en esta localidad, la crisis política, social y económica del año 2001. La mayor parte de las/os integrantes de la ARB, pertenece a un conjunto de habitantes caracterizado por el mayor porcentaje de población infantil y las condiciones sociales más desfavorables de la ciudad, ya sea en cobertura social, nivel de instrucción, asistencia escolar, desocupación, hacinamiento y necesidades básicas insatisfechas (Sánchez, Sassone y Matossian 2007).

Las memorias de quienes integran este grupo dan cuenta de la búsqueda infructuosa de soluciones en las esferas oficiales e históricas. La falta de documentación sobre esta experiencia se cubre con las voces directas de las/os protagonistas. Por ejemplo, Zulema Morales, una de las principales referentes del grupo, acerca un recuerdo que se repite en caso todos/as los/as integrantes. Al evocar el modo en el que llega al vertedero relata una experiencia que se repite

"Mi marido hace 8 años, más o menos, se quedó sin trabajo. Primero insistí en conseguir un plan social y después me la rebusqué así, en lugares por ahí donde daban comida. Cosa que nunca había llegado ni en mi infancia ni tampoco en los primeros años de mi matrimonio. Y bueno, después empezaron a venir mucha gente al basural, algunas de mis amigas, compañeras de barrio me decían 'vamos que allá se puede hacer algo, que se yo, juntar metales', y así empecé a venir”.

Los motivos que justifican su iniciativa pueden leerse desde un punto de vista generizado, y en este sentido nos retrotraen a los debates presentados en el cuarto capítulo. Sobre todo porque estamos frente a un caso formado por una mayoría de mujeres y cuyo desarrollo también descansó en manos femeninas. En relación a los motivos que la llevaron a acercarse al vertedero indica

“...cuando mi marido trabajaba bien ganaba bien y podíamos mantener los chicos bien, bien comidos, bien calzados, todo. Y bueno, la idea mía fue seguir el mismo ritmo de vida, en los años, el uno o dos años que nosotros estuvimos más que nada con el plan,

\footnotetext{
${ }^{62}$ Otra institución fundamental en la relación de esta sociedad local con el entorno es la Administración de Parques Nacionales, cuyos supuestos fueron revisados en el segundo capítulo.
} 
nos faltaba todo, quería cocinar y que te faltaba una papa, te faltaba una cebolla... y eso yo no lo quería para mi”.

La organización se consolidó en torno a un problema particularmente emotivo para quienes se juntaban en el predio, que llevó a reclamar a quienes ocupaban los cargos de gobierno en la dependencia municipal. Se trataba del tema de lo menores que vivían de la basura.

"Había chicos que vivían directamente en el basural a los cuales nosotros no conocíamos los padres ni nada. Un abandono total de muchos chicos, eso me conmovió porque yo también soy madre y yo trataba de hacer todo para que a mis hijos no tuvieran necesidad ni andar de esa manera como andaban los pibes".

El problema de los niños era percibido por todas las personas que buscaban alternativas en el basurero, "José Miguel dice ser un experto en hambre: conozco todos los tipos de hambre", afirma. "la más dura es esta, yo tengo hambre, pero los chiquitos esos también, miralos pobrecitos que desesperados están. Por eso ésta duele más”. (Fuentes $2007,160)$.

Este problema, y la necesidad de desarrollar alternativas a la precaria situación económica, donde las formas clásicas de contención se habían diluido, fueron la base de las actividades que se generaron desde la ARB. Las reflexiones en general dan cuenta del crecimiento de la autoestima y autonomía asociada a esta iniciativa. En este sentido es una experiencia similar a la reconocida por Kate Young (1995), quien encuentra en las formas locales de apropiación del desarrollo esta población adquiere "control sobre sus propias vidas para sentar sus propias agendas, organizarse para ayudarse unas a otras y elevar demandas de apoyo al Estado y de cambio a la sociedad" (Young 1995, 158-159).

En la actualidad, las razones que dentro del grupo fundamentan la actividad son, por una parte económicas, porque quienes forman parte de esta organización han logrado un ingreso que asegura la satisfacción de sus necesidades básicas. Pero por otro lado también dan fundamentos afectivos. Las/os integrantes de la ARB, en su discurso incorporan de forma permanente referencias a la contención social de las/os más vulnerables entre las/os vulnerables, como las madres solteras muy jóvenes y los adultos mayores. 
Este auto-reconocimiento, sin embargo, choca con el modo en que muchos de los funcionarios municipales interpretan este proceso. En esta dependencia gubernamental se expresan impugnaciones que limitan el reconocimiento de la experiencia y dan cuenta de un plano valorativo diferente para analizar la actividad. No es extraño que un desarrollo sostenido mayormente por mujeres de sectores populares carezca de reconocimiento oficial. Ya Ester Boserup, en 1970, daba cuenta de la escasa consideración de las particulares situaciones de las mujeres en los programas de desarrollo. En la actualidad la ARB enfrenta el desafío de la falta de reconocimiento, porque a pesar del éxito obtenido en el proceso organizativo, las visiones estatales entienden como prescindible la experiencia de estas personas.

Los fundamentos para desconocer o desvalorizar esta experiencia se proyectan sobre tres ejes, todos vinculados con aspectos biológicos. El primero es la jerarquía reconocida a la ciencia como diferente a la experiencia cotidiana. La forma en que se constituye el saber establecido no es independiente a la invisibilización de procesos alternativos a la perspectiva de desarrollo que se plantea. Hoy, el discurso de los/as funcionarios/as del municipio sostiene que el diseño de manejo del vertedero debe realizarse en términos biológicos, que no tienen que ver con la problemática social y menos aún con el particular desarrollo de la ARB. La biología se comprende como ajena a lo humano, las decisiones sobre el manejo de un espacio pasa a descansar en evaluaciones técnicas que omiten las reflexiones de la población directamente involucrada y afectada.

Podemos pensar que durante la crisis del 2001, por la ausencia del Estado, los márgenes de la posibilidad de acción se ensancharon lo suficiente como para dar lugar a una experiencia como la ARB. Sin embargo, con el paso del tiempo, la recomposición de las estructuras estatales y la proyección de políticas públicas que han naturalizado las desigualdades, la estrechez de los márgenes de libertad empiezan a ser cada vez más notables. La precarización del reconocimiento se erige como una amenaza a la experiencia vivida y los prejuicios se filtran de forma cada vez más tangible en los discursos-acciones llevadas adelante por los funcionarios municipales. ${ }^{63}$

Desde la Municipalidad se contemplan exclusivamente aspectos técnicos de los procesos de reciclado en sistemas que se entienden como asépticos a las tensiones ${ }^{63}$ Para un desarrollo sobre el modo en que la política pública oficial ha naturalizado las desigualdades estructurales de la población puede consultarse a Fuentes, R. y Núñez, P. (ed) (2007). 
sociales. Así se traba el reconocimiento de quienes se erigieron como sujetos activos en la resolución de una emergencia social y una problemática ambiental. Esta perspectiva no considera como parte fundamental del análisis la única experiencia exitosa de recuperación de basura, porque no fue hecha por expertos sino por personas que desarrollaron prácticas en función de la necesidad y la urgencia. Este camino de ensayo y error no es considerado conocimiento, porque el conocimiento parece restringirse a propuestas académicas que buscan reproducir lógicas que aparecen como exitosas en otros espacios del mundo.

Los profesionales del municipio asumen que la única argumentación válida debe provenir del mismo ámbito de conocimiento -académico- desde el cual ellos/as razonan. En este argumento incorporan prejuicios de diferente carácter, aunque entre ellos, los prejuicios de género son los más sutiles pero, creo, los más profundos. La ARB fundamentan su éxito en valores que usualmente no cotizan en mercado: la maternidad, la solidaridad, la contención social. Aspectos que usualmente se reconocen desde dependencias de acción social, pero que difícilmente se toman en cuenta en las oficinas de planificación urbana. El problema que enfrentan las estructuras estatales es que, en base a estos fundamentos, se ha llevado adelante una iniciativa económicamente exitosa y se ha dado inicio a la más importante campaña de educación ambiental.

Ahora bien, el éxito económico no suele referirse a procesos alejados de la razón económica científica/instrumental problematizada en los capítulos precedentes. El ejemplo de la ARB no termina de adecuarse a los cánones de evaluación clásicos, y entonces se termina evaluando como un proceso casual o con menos importancia de la que podría tener un emprendimiento privado. En este sentido las limitantes de la situación presentada se enraízan más en las limitantes de la visión de unos/as que en los condicionamientos materiales, las trabas a las acciones se introducen por la percepción del proceso de la ARB como casual, ligada a aspectos afectivos y no económicos.

Esta falta de reconocimiento, que acarrea limitaciones en las posibilidades de incidir en la toma de decisiones, tiene aristas trágicas que se proyectan sobre un segundo plano de invisibilización: la salud personal. La presencia de un vertedero a cielo abierto ha impactado en la salud de los habitantes de los barrios aledaños, tanto por la proliferación de alimañas como por el humo que recurrentemente sale del vertedero a causa de los incendios. Como los barrios que rodean al vertedero pertenecen a los 
sectores marginales de Bariloche, el reclamo por esta situación suele desconocerse en las esferas oficiales. Sin embargo, a partir de estrategias de irrupción en actos públicos, en el último tiempo la voz de estos vecinos comenzó a incrementarse. Siendo uno de los pedidos más recurrentes un estudio de la situación de la salud de la población directamente afectada.

En contra de los supuestos que indicaban que los vecinos y los integrantes de la ARB compartían esta preocupación, las/os integrantes de la ARB pidieron que los estudios de salud que se reclaman sobre las poblaciones aledañas no los tome en cuenta. El argumento surge de la conciencia sobre los problemas de salud que les acarrea la actividad a la que se dedican y las condiciones precarias de trabajo, pero sobre esta situación las/os integrantes de la ARB privilegian su derecho a mantener la fuente de ingresos que edificaron. Los argumentos sobre la salud resultan perjudiciales a sus intereses, porque pueden convertirse en un instrumento que beneficie la introducción de intereses privados que buscan lucrar con el manejo de la basura. Así, desde la perspectiva de la ARB, los argumentos sobre la salud no llevan al diseño de modos alternativos de trabajo, sino a la destrucción de la iniciativa. El derecho al trabajo de este grupo se presenta como contrario al derecho a la salud. El ejercicio de una ciudadanía incompleta continúa permaneciendo desde la opción de derechos que deben realizar.

Existen antecedentes históricos en relación a la medicina como control social, desde los cuales esta desconfianza expresada por las/os integrantes de la ARB cobra mayor relevancia. Warwic Anderson (1996), por ejemplo, ha mostrado cómo, en las primeras décadas del siglo XX, la medicina fue un instrumento fundamental para avanzar sobre el control en los espacios que Estados Unidos comenzaba a controlar. A modo de ejemplo, para el caso de Filipinas, y a partir de la nueva microbiología de la época, los filipinos pasaron a ser vistos como portadores de enfermedades en el imaginario estadounidense. Desde esta perspectiva se fomentaron numerosos programas sanitarios para asegurar la salud tanto de los estadounidenses que iniciaban actividades en la región, como de filipinos. Anderson muestra cómo estos programas trajeron consigo no sólo una reforma completa de la conducta íntima de las personas, sino que otorgaron a los estadounidenses el poder modificar la vida privada de la región, dando fundamentos para reconocer el espacio de Filipinas como colonia de Estados Unidos (Quintero 2006). 
Esta experiencia, donde las enfermedades son argumento de control y de expulsión, nos recuerda Michel Foucault (1997) y sus referencias al biopoder. La definición de enfermedad, salud, y los argumentos en torno a la seguridad social vinculados a estos conceptos resultan en herramientas fundamentales para la invisibilización de ciertos derechos y el acallamiento de las voces. Las/os integrantes de la ARB reconocen estos problemas desde su cotidianeidad no-académica, asumiendo que la única defensa hacia los intereses que declaman como propio, es el ocultamiento de los problemas de salud.

El tercer plano de invisibilidad proviene del rol biológico que se asume como propio de las mujeres y que se reproduce desde instituciones como centros de salud o escuelas. Uno de los ejemplos más pintorescos de estas limitantes y prejuicios proviene del jardín de infantes. Cuando pregunté a distintas integrantes por las dificultades para actuar como trabajadoras, dirigentes y difusoras de la experiencia, mencionaron que lo más difícil de sobrellevar fueron las horas lejos de sus hijos menores, que las reclamaban mucho más que sus hijos mayores, y sobre esto agregan "el reclamo también ha sido desde la escuela, más que nada del jardín que hacen muchas reuniones y uno no puede estar en todas". Las maestras, guiadas por una clara concepción maternal clásica, no reconocían en la enorme tarea que estaban enfrentando un justificativo para no ir a las reuniones. Pareciera que ellas, mujeres de sectores populares, debían cumplir las tareas clásicas de madre-esposa ligada a lo doméstico.

En este punto es interesante la reflexión de Nancy Amstrong (1991) quien, siguiendo una perspectiva foucultiana, sostiene que el deseo se disciplina. La teórica elabora una genealogía de lo que reconoce como ideal de la feminidad normativa, que explora en las novelas y libros de conducta del siglo XVIII. Así muestra que, en contra de la idea femenina del antiguo régimen -donde las mujeres de la aristocracia entregaban sus hijos a nodrizas-, en la modernidad fue emergiendo un nuevo ideal de vida privada.

Para el caso de las mujeres en las sociedades occidentales, este disciplinamiento ha llevado a la configuración de la idea de mujer como mujer doméstica, que es claramente el imaginario de las docentes que reclaman esa presencia de la madre en el jardín de infantes. Porque dan por sentado que es ella quien tiene el deber de ocuparse de los tiempos que las instituciones definan sobre sus hijos. Estas formas opresivas, naturalizadas en las instituciones, permiten retomar la idea de dominio elaborada por Horkheimer y Adorno en relación con las capacidades y potencias de la sociedad civil, 
descripta desde Gramci. A la luz de estos conceptos, cobra una nueva arista la no discusión de la demanda institucional. El consenso está en la base discursiva de las propias actoras de la ARB, sólo justifican su imposibilidad por cumplir con la imagen de mujer-madre-esposa que se les reclama, pero no reconocen el aparato opresivo que opera tras los discursos hegemónicos.

Vale una mención personal sobre lo que entiendo, es el sitio de las instituciones en estos procesos. Como refería en el párrafo previo, las instituciones son los sitios normalizadores por excelencia, pero esto no significa demonizarlas. Comparto con Celia Amorós (2008) que la instalación de sinergias también pasa por las instituciones. El punto que reduce las instituciones a espacios de reproducción de formas opresivas es su distanciamiento de los movimientos de cambio, como señala la filósofa española, "sin la permanente presión de los movimientos, las instituciones se esclerotizarían" (Amorós 2008, 114). Pero sin la referencia de las instituciones los movimientos correrían el riesgo de dispersarse o de no poder plasmar de forma efectiva sus objetivos. En el caso desde el cual estoy recorriendo las contradicciones de la apropiación de una comunidad de su ambiente, lo que se enfrenta es una enorme distancia que presenta a las instituciones como ajenas (Fuentes y Núñez 2007). El punto que se descubre es que la distancia se sostiene sobre valoraciones de tipo biológico.

El silencio sobre formas alternativas de plantear iniciativas de desarrollo, puede comprenderse desde tres ejes relacionados: 1- la jerarquía de la ciencia biológica sobre la experiencia social, que involucra al reconocimiento ligado exclusivamente a la valoración de la formación académica; 2- la salud como argumento condicionante de las posibilidades de iniciativas, que nuevamente privilegian la formación técnica sobre la percepción compleja y cotidiana de la actividad, y 3- los supuestos institucionales, donde la visión de las mujeres continúa ligada al espacio doméstico.

En esta combinación de supuestos subyace el de reconocimiento a la formación académica como condición necesaria para el ejercicio de iniciativas alternativas. Los argumentos se fundan en preceptos biológicos de: la naturaleza escindida de lo social, la salud independiente del acceso al trabajo, la mujer con un rol reproductor (pasivo). Sobre la permanencia de supuestos de jerarquía se mantienen prejuicios que naturalizan las desigualdades. El reconocimiento institucional de los problemas ambientales descansa en visiones parciales que invisibilizan las formas jerárquicas preestablecidas. 
La consecuencia de este desconocimiento es la imposibilidad de edificar una praxis ambiental desde las esferas gubernamentales, sea en dependencias de gobierno, de salud o de educación. La praxis ambiental involucra un nivel de reconocimiento de todos los actores que no sólo descansa en el reconocimiento a la problemática biológica-nohumana, sino que abarca una revisión de las relaciones. Ahora bien, queda claro que en las principales esferas de toma de decisión, la sobre valoración de la teoría sobre la práctica impide el reconocimiento de actores directamente implicados en el problema. Lo que no resulta tan obvio es si esta falta de reconocimiento está vinculada con la producción de saberes en sí.

En este punto me resulta iluminadora la visión de Lyotard (1984) sobre la ciencia, al sostener que el saber científico modifica su estatuto al mismo tiempo que cambian las sociedades. Entendiendo que en los últimos años, en el marco de lo que define como “era postindustrial”, el saber científico está legitimado por el lenguaje, por los discursos construidos a su alrededor, por las informaciones y los medios que informan, por las teorías de la comunicación y la informática, entre otras. Lyotard entiende que la ciencia en general es una nueva producción que se vende y consume.

Esto me lleva a volver sobre el conocimiento biológico del entorno, donde la ecología se ha erigido como la ciencia de las relaciones entre los organismos y sus ambientes. La indagación sobre esta disciplina, no ya desde las teorías, sino desde el modo en que se construye el conocimiento, cobra interés no sólo por las particularidades de su desarrollo teórico, sino (y sobre todo) por el sentido social que asume. Un sentido que puede o no estar vinculado a la tendencia a la atomización del saber (Lortie et al 2004, Davis et al 2005) y el reclamo por preguntas que apelan a situaciones donde lo social y natural están irremediablemente mezclado (Holling 1998, de Lapante 2004).

\section{Praxis ambiental y ecología}

En este marco de teorías y prácticas desencontradas ¿Es posible elaborar conocimiento ecológico desde la noción propuesta de praxis ambiental? Y si ello es posible ¿existen vías para repensar las praxis institucionales? En este punto vale la pena retornar a la reflexión desde la perspectiva de género. La reflexión sobre el patriarcado pone en evidencia que la ciencia ha sido un instrumento que ha endurecido las condiciones de opresión (Segales Kirzner 2006). La ciencia asume supuestos de dominio, jerarquías 
diferenciadas y los proyecta y resignifica en la elaboración de conocimiento. De aquí se desprende que, en tanto no se repare en ese plano de supuestos que atraviesa a la producción de conocimiento, es difícil que las decisiones que apelan a los saberes científicos discutan las formas jerárquicas y reconozcan las voces de los sectores más vulnerables del esquema social.

En este proceso deja de lado formas alternativas de conocimiento como la afectiva y la espiritual, y en especial aquellas que se relacionan con la experiencia directa de las personas en el mundo y las de colaboración con la naturaleza, excluyendo, de este modo, gran parte de las prácticas cotidianas.

Los saberes legitimados por las ciencias son instancias fundamentales mediante las cuales se han moldeado nuestras relaciones con los demás seres vivos del planeta. En este sentido el conocimiento que se produce no puede pensarse ajeno o independiente de las prácticas que se diseñan a partir del mismo. No se puede omitir la fuerza de los supuestos que subyacen en el diseño de un determinado modo de producción de conocimiento. Volviendo los ojos hacia el espacio que tomo como ejemplo, Pedro Navarro Floria (2007a) explora el modo en que los relatos elaborados desde la geografía descriptiva sirvieron, en el siglo XIX, para fomentar la apropiación de la región patagónica en términos de "progreso nacional". La dimensión simbólica de la producción de conocimiento resultó por demás relevante en el avance del Estado Nacional sobre este espacio. Tal es así que el saber producido desde las instituciones argentinas no acentuaba el uso de los dispositivos técnicos modernos, sino que se dirigía a resaltar la percepción de este espacio en términos de condiciones de posibilidad para la tarea de modernización que el Estado proponía (Navarro Floria 2007b).

El proceso que presentamos en Patagonia a fines del siglo XIX, está enmarcado en una tendencia mucho más general. Porque en la edificación de los imperios europeos durante los siglos XVIII y XIX (Hobsbawm 1998, 2001, 2002), el control territorial de las potencias, no sólo se proyectaba sobre los espacios donde ejercía dominio político directo. En esto resultaron fundamentales los trabajos de los naturalistas, que no sólo favorecieron el reconocimiento de elementos que desde los países europeos se valoraban como recursos (MacLeod 2001, Drayton 2000, Nieto 2002), sino que en las incipientes organizaciones políticas de los países no-europeos, fomentaron la 
estructuración de instituciones académicas que consolidaron la mirada desde la ciencia (y los intereses occidentales) en los territorios a incorporar (Quintero 2006).

En esta dialéctica, tanto el imperio como las instituciones y científicos locales resultaron favorecidos. Los beneficios para los países centrales redundan en el conocimiento y diseño de utilización de los recursos. El beneficio para las instituciones y científicos locales redunda en el reconocimiento de las actividades locales. ${ }^{64}$

Esta incidencia específica de la producción del conocimiento, que signó una cierta forma de apropiación del espacio, no abandonaba la idea de la ciencia como pretensión de neutralidad, objetividad o reflejo de la realidad. El modo en que el Estado Nacional avanzó sobre el espacio patagónico, por ejemplo, se justificó, legitimó y naturalizó desde la presentación científica de la región.

La visualización de las lógicas de control y apropiación, que se legitiman desde ciertas formas de conocimiento, es una dimensión ineludible de la praxis ambiental que se plantea. En este sentido la serie de compromisos subyacentes en los ejercicios de producción de conocimiento debería explicitarse desde las primeras instancias de la elaboración del conocimiento. Ahora bien, esta explicitación no se realiza, en parte porque no se considera como parte del Método a seguir, y en parte porque la misma estructura institucional académica funciona como sombra de ocultamiento de estas tensiones. Esto nos vuelve a traer a los estudios de caso, porque es en los ejemplos concretos donde las contradicciones cobran formas y los ocultamientos se reconocen en las instancias más simples de lo cotidiano.

Así, al revisar la producción de conocimiento con detalles que recuerdan a la etnografía de laboratorio, por un lado, asumo uno de los fundamentos de la epistemología denominada naturalismo cientifico, que sostiene la tesis que la ciencia debe ser estudiada como cualquier otro fenómeno empírico. ${ }^{65}$ Por otro lado, entiendo que los fenómenos empíricos no se encuentran aislados del marco de tensiones sociales que rodea la situación en que se concretan. En esta línea considero que deben contemplarse

${ }^{64}$ Pablo Kreimer (1997a, 1997b, 1998) observa el desarrollo científico de la biología molecular, en el siglo XX en argentina y señala desde una perspectiva kuhniana, que la forma en que los laboratorios nuestro país se vinculan a los laboratorios más relevantes, tiene un carácter hipernormal, esto es, avanzan en los detalles más puntuales de los temas que se investigan pero no inciden en el diseño de las preguntas o los protocolos de investigación.

${ }^{65}$ Para tener referencias sobre esta línea de reflexión se puede consultar las obras de Ronald Giere (1988, 1999) Philip Kitcher (1992, 1993), David Hull (1988), Larry Laudan (1981), entre otras. 
dos niveles en el mapa de tensiones en que está inscripta la ciencia, por un lado la vinculación de las prácticas científicas con las instancias de legitimación propias de la disciplina, y por otro la articulación del conocimiento con las sociedades específicas en que el mismo cobra sentido.

\section{Praxis ambiental y producción de conocimiento}

La revisión en torno a la elaboración específica del conocimiento ecológico seguirá otro ejemplo situado en el espacio patagónico: se trata de las investigaciones desarrolladas en uno de los espacios con mayor reconocimiento académico en Argentina: el laboratorio Ecotono, dependiente de la Universidad Nacional del Comahue, Centro Regional Universitario Bariloche.

Este laboratorio, inaugurado en 1989, tiene la particularidad de haber sido edificado gracias a las gestiones de uno de los primeros ecólogos argentinos, Eduardo Rapoport, quien logró un importante reconocimiento por sus aportes a la biología ecológica. Por ello la edificación del laboratorio no sólo se enmarca en decisiones específicas tomadas en a década del ochenta, sino que se explica desde la historia misma de la disciplina en la Argentina.

La historia de este laboratorio se relata con un sesgo que pone en evidencia un supuesto de distancia entre la producción teórica y los factores económicos y políticos. Hasta el momento en que los investigadores comienzan a trabajar el relato de la edificación tiene claras referencias a tensiones económicas y políticas. Las referencias sobre el modo en que se desarrolla la ecología se cruza con los efectos de las interrupciones de la vida institucional democrática y las sucesivas crisis económicas que asolaron nuestro país desde los años sesenta hasta los ochenta. Los cierres de laboratorios, los exilios, los experimentos suspendidos por la irrupción de fuerzas armadas y la hiperinflación son algunas de las referencias que se mencionan. (Núñez 2005)

Sin embargo, cuando los relatos históricos superan esta instancia de fundación, las tensiones políticas parecen perderse. Las menciones se centran en aspectos materiales y traen a primer plano los reconocimientos provenientes de la comunidad científica en general, esto es: publicaciones y menciones a los trabajos. Los tiempos del laboratorio 
pasan a referirse al reconocimiento académico proveniente de pautas internacionales y al establecimiento efectivo de una práctica que Diana Crane (1972) describió como colegios invisibles.

El desarrollo teórico se concibe como ajeno a las tensiones económicas y políticas. La preeminencia de referencias internacionales en el reconocimiento se infiere desde la selección del idioma de publicación -inglés- hasta los modos en que se desarrollan redes de intercambio, donde los principales anclajes se realizan con ámbitos de investigación extranjeros. Los protocolos de investigación responden a líneas diseñadas en laboratorios de Estados Unidos, ámbito donde se generan las líneas de investigación que se siguen en el mundo (Deléage 1993). En contraposición las publicaciones en revistas argentinas resultan prácticamente inexistentes. Los interlocutores de los científicos de Ecotono son otros científicos. En todas las menciones sobre la difusión de los trabajos no se hizo alusión a estrategias que trasciendan el ámbito académico.

Existe, sin embargo, una diferencia cualitativa reconocida en la elaboración de conocimiento en Argentina que la diferencia de los estudios realizados sobre otros espacios. En nuestro país, y sobre todo en el espacio patagónico, existe una falencia en cuanto al conocimiento de los ecosistemas locales, esto es la historia natural local. Al mismo tiempo que se presenta la necesidad de adecuar las preguntas a las líneas de trabajo definidas por laboratorios situados en espacios muy estudiados, con siglos de historia natural, como son Europa y Estados Unidos.

Esta situación debe indagarse desde el contexto que descubre la historia de la biología, porque las múltiples reflexiones que reparan en la misma indican que en el siglo XX la biología cambió de carácter: de los naturalistas que recolectaban muestras en el siglo XIX se pasó a privilegiar el trabajo en los laboratorios. El laboratorio de Ecotono parece estar tensionado por el deber responder a esa historia y el necesitar conocer en detalle el entorno. Una situación que enfrentan múltiples ámbitos de estudio de gran reconocimiento internacional. Acuerdo con Quintero (2006), quien indica que la política de la ciencia estadounidense permite revisar la aseveración previa en relación el cambio que se reconoce en la biología. Porque a lo largo del siglo XX existen numerosas actividades tendientes a revisar la historia natural (Windsor 1991), y la ecología es una de las disciplinas que asume con mayor ímpetu este desafío. Los aires de control y dominio de la ciencia del siglo XIX reaparecen en esta área de estudios. Los científicos 
locales se asumen enmarcados en una rama de conocimiento "débil" que, en alguna medida, los coloca en una situación diferenciada. ${ }^{66}$ Este carácter dependiente puede favorecer el que se privilege las vías de reconocimiento disciplinar e internacional sobre las estrategias de integración local. Podemos pensar, junto a Ranajit Guha (1988), que las metodologías científicas hegemónicas y sus categorías, no son simplemente incapaces de revelar la subjetividad de los dependientes, sino que producen ellas mismas la condición de subordinación que se suman a la forma de fragmentación social.

Otra explicación que podría ensayarse sobre el modo en que se desarrollan los estudios ecológicos en este laboratorio se vincula a las circunstancias de creación. La ecología, como área de investigación, surgió a fines del siglo XIX en Europa y Estados Unidos, por los límites que empezaba a encontrar, sobre todo, en la explotación agraria. Pero en Argentina, y específicamente en Bariloche, la ecología no surge de problemas vinculados a la producción o al desarrollo económico. Es un área de estudios que se desarrolla en el marco de la universidad y tomando como referencia a una comunidad científica internacional establecida y sólida, con un ejercicio sistemático de diferenciación del ambientalismo (Holling 1998), asumiendo entonces un carácter diferenciado respecto del resto de las actividades sociales.

Retomando los aportes de Lapante (2004) y Holling (1998), en la actualidad la ecología parece comprenderse desde dos perspectivas contrapuestas. La analítica u ortodoxa y la expansionista o integradora. Desde la primera se concibe a la ecología como disciplina natural, desligada de los factores sociales, con un sitio limitado para la incertidumbre y adscribiendo a las normas establecidas por la epistemología clásica o concepción heredada (Menna 2004). La segunda, en cambio, entiende a la ecología como ciencia interdisciplinar que da cabida a especializaciones provenientes de las ciencias sociales. La incertidumbre en este segundo caso es intrínseca al estudio de cualquier sistema y la humanidad un factor que debe incorporarse a partir de asumir presupuestos valorativos en torno a la preservación ambiental.

Estos debates no surgen, sin embargo, en el trabajo del laboratorio. El modo en que se desarrolla la práctica no puede desprenderse del modo en que se concibe la disciplina, que en este caso responde a los supuestos de ciencia clásica que prevalecían en la disciplina en la década del setenta y hoy pueden interpretarse como formas que traban el

\footnotetext{
${ }^{66}$ Esta perspectiva reproduce, sin citarla, la idealización de las ciencias naturales asumiendo a la física como modelo de ciencia (Núñez 2008).
} 
diálogo transdisciplinar. A modo de ejemplo de las reflexiones epistemológicas realizadas en el laboratorio puede mencionarse el trabajo de Fanji Brener (2003) quien revisa en distintas publicaciones la vinculación lógica entre las hipótesis y las observaciones supuestas en el método hipotético deductivo. Este autor señala que en la mayor parte de los trabajos publicados en ecología no se encuentra la aplicación de este método. Además la mayor parte que lo utiliza, lo aplica en forma incompleta o errónea. Este uso parcial e incluso erróneo del método hipotético deductivo lo lleva a concluir que "Finalmente, la mejor de las situaciones sería poner a prueba dos o más hipótesis sobre el sistema en estudio que generen predicciones antagónicas, permitiéndonos discriminar nuestros supuestos entre sí. De este modo, eliminando las ideas menos plausibles, el uso correcto del método hipotético deductivo nos ayudará a comprender el mejor funcionamiento de la naturaleza" (Fanji Brener 2003,26). Este ecólogo reproduce en su escrito las reflexiones epistemológicas presentes en el laboratorio: el método Hipotético Deductivo, que asume a las tensiones sociales como ajenas e independientes de los razonamientos, es un ideal difícil de alcanzar pero igualmente deseable.

Desde esta visión clásica del conocimiento científico, se asume una jerarquía diferenciada respecto del saber no científico. Este supuesto, que en el caso de las instituciones operaba de forma tal que desconocía las experiencias de los sectores más frágiles de la sociedad, en el laboratorio opera de forma tal que resulte discutible el sumar interlocutores fuera del ámbito académico.

Este ejercicio, que elude las tensiones sociales que lo atraviesan y naturaliza la diferenciación entre la producción de conocimiento científico y otros modos de saber, no es independiente de los modos sociales en que se aplica el conocimiento biológico. En contra de las reflexiones de Peter Sloep (1993), quien señala que las reflexiones sobre los supuestos filosóficos solo introducen ruido y confusión en ecología, creo que la ecología visualiza nuevos desafías, debido a que la impronta humana en los ecosistemas del planeta es cada vez más evidente. Si bien esta disciplina fue la base de programas de conservación e investigación que suponen una naturaleza en equilibrio, desligada del contexto socio-cultural.

Por ello resulta cada vez más clara la necesidad por orientar la ciencia y conservación a todo el ámbito del paisaje, incorporando explícitamente el contexto cultural en que se desarrolla la indagación científica (Armesto et al. 2004). Ahora bien, la incorporación 
de este contexto no puede reducirse a la descripción sobre el uso de los recursos, porque ello implica asumir a la vinculación instrumental como la privilegiada. En este punto la idea de saberes locales, que la antropología introduce y Donna Haraway (1998) recupera, cobra nueva relevancia.

Haraway (1988) sostiene la posibilidad de un saber situado como práctica de la objetividad subalterna. Un ejercicio para incidir de forma ineludible en los modelos precedentes y modificarlos. La pensadora norteamericana busca superar el riesgo de un enfoque romántico de los saberes de las minorías, al explicitar que éstas, lejos de detentar un saber puro, desnudo, o independiente, poseen conocimientos atravesados por representaciones y visiones. El ver desde cualquiera de las posiciones, necesita de un aprender a ver con el otro sin pretender ver en su lugar. Se trata, entonces, de lograr un desplazamiento de los debates epistemológicos sobre la objetividad hacia una genealogía política de los saberes, a través de la noción de saber situado. Esta reflexión nos trae nuevamente a la dimensión de las prácticas concretas, porque a partir de este reconocimiento se trata, como indica Haraway, de inventar políticas relacionales, estrategias de interseccionalidad política que desafíen los espacios de cruce de opresiones. La política de los saberes situados puede así ser pensada como una política de saberes que conecta diferencias, que establece alianzas en la discontinuidad, una política hecha de redes de posicionamientos diferenciales. Para ello resulta fundamental el abandono del supuesto de jerarquía diferenciada del conocimiento científico, asumiendo que la posibilidad de otros modos de relación con el entorno pueda descansar en formas alternativas de conocimiento.

La praxis ambiental, en el sentido postulado, resulta ajena a la elaboración de conocimiento científico tal como está establecido, pero no tanto por limitaciones teóricas, sino por las prácticas específicas ligadas a modos de reconocimiento específicos. Entiendo, en acuerdo con Imannuel Wallerstein (1997), que una disciplina científica y sus manifestaciones en la práctica deben dar cuenta de tres planos diferentes: intelectualmente como disciplina; organizacionalmente como estructura corporativa, y culturalmente como comunidades de académicos que comparten ciertas premisas elementales. En el caso del laboratorio de Ecotono encontramos cómo, en cada uno de estos planos, subyace un supuesto de ciencia con una jerarquía diferenciada que la aleja de los modos de apropiación espacial específica de la sociedad que los contiene, 
y en esto se consolidan como una instancia más de legitimación sobre las relaciones que se establecen.

La praxis ambiental, en oposición a los valores que se desprenden de estas prácticas, reconoce en el investigador un observador contextuado que, al igual que el testigo modesto, propuesto por Haraway (2000) se opone al investigador presentado por Hobbes, que defendía un saber único y trascendente, independiente de las comunidades de las cuales procede. "Ser testigo, es ver, atestiguar, volverse públicamente responsable de, y físicamente vulnerable a, sus propias visiones y representaciones." (Haraway, 2000, 155). Ver siempre con otro pero jamás en su lugar

\section{Vínculos posibles, quiebres heredados}

Revisando la vinculación entre ecología y praxis ambiental encontramos que las formas organizativas desde las que se elabora el conocimiento reconocido traban la edificación de los vínculos con la sociedad inmediata. A esto se agrega que las instituciones limitan el reconocimiento de la experiencia de los grupos sociales más afectados por los problemas ambientales, bajo el supuesto de un reconocimiento diferenciado en relación a la formación académica, y con el fundamento de discursos biológicos que retrotraen la argumentación a una visión dual, profundamente instalada en la organización social en general.

En este sentido, ni desde la producción de conocimiento, ni desde las instituciones, se lleva adelante una praxis ambiental en el sentido propuesto. Y esto es así aún cuando traten sobre problemas ambientales específicos, como es el caso del manejo del vertedero.

La biología, desde una visión que escinde sociedad y naturaleza, continúa siendo la fuente de argumentaciones para las intervenciones sesgadas, pero el punto básico de distancia se encuentra, sobre todo, en la falta de reconocimiento a la experiencia cotidiana como espacio generador de saber. Es decir, todas las prácticas que se diseñen y desarrollen fuera de los parámetros académicos establecidos se consideran con un estatus menor, y en esta diferencia de jerarquía se introduce la dinámica de invisibilización que atraviesa el conjunto de instituciones. 
Existe un nivel de experiencias que no se toma en consideración, aquel donde precisamente confluyen factores sociales y naturales. Este nivel de experiencias no se toma en consideración, por asumir la visión dual desde las diversas esferas de gobierno, de educación, de producción de saberes; es decir desde las esferas de poder.

Estas reflexiones nos enfrentan al desafío del planteo de la praxis ambiental: la experiencia existe, la crisis ambiental se reconoce, pero las iniciativas socialmente reconocidas como válidas no tienen incorporada como necesaria la referencia al problema. De hecho, la visión dual prevalece y la naturalización de las jerarquías se filtra en la mayor parte de las evaluaciones ambientales (Arocena 1995, Funtowicz Y Ravetz 1993, Lins Ribeiro 2005, Poggiese 2001, Redín y Morroni 2002).

\section{Repensar la praxis desde la experiencia}

Ahora bien, ¿cómo se logra tomar en cuenta el nivel de experiencias, cuya omisión es la prueba de la invisibilización? Tal vez retrotrayéndonos a las reflexiones previas a la consolidación de la ciencia moderna. Esto es, a las reflexiones sobre las que se cimentó el interés sobre lo empírico. Porque, a partir de compartir el reconocimiento a las necesidades empíricas como fundamento de reflexiones y acciones, nuestras observaciones en torno a las tensiones que operan en relación a la problemática ambiental nos llevan a revisar qué se considera como evidencia para tomar decisiones.

Vale, entonces, retrotraernos a las reflexiones de uno de los más importantes teóricos de la perspectiva empírica, David Hume. ${ }^{67}$ El filósofo escocés que afianzó la idea del conocimiento basado en la experiencia, sostuvo que el fundamento de todos nuestros razonamientos es la experiencia. Esto es, la aplicación de nuestra sensibilidad sobre el mundo y la recepción de las impresiones provenientes desde ese intercambio.

Hume señaló que los argumentos que se fundan en la experiencia están basados en la semejanza y que sólo después de una larga cadena de experiencias uniformes de un tipo, alcanzamos seguridad y confianza firme con respecto a un acontecimiento particular. Sin intentar introducir una discusión atemporal sobre los condicionamientos subjetivos

\footnotetext{
${ }^{67}$ El texto de Hume consultado es la edición de 1994 de su texto Investigación sobre el conocimiento humano, presentado por primera vez en el año 1748. Editorial Altaya. Barcelona. Traducción Jaime de Salas Ortueta.
} 
de las observaciones, el punto que me gustaría señalar es que en estos primeros ejercicios por revindicar las observaciones tangibles sobre las elucubraciones teóricas, Hume toma como referencia uno de los planos sobre los que se intenta llamar la atención, aquel donde se presenta la complejidad cotidiana más heterogénea: el plano de las costumbres sociales.

Hume reconoce que "la costumbre es la gran guía de la vida humana. Tan sólo este principio hace que nuestra experiencia nos sea útil y nos obliga a esperar en el futuro una serie de acontecimientos similares a los que han aparecido en el pasado" (Hume 1994, 68). En los ejemplos previos, donde la ciencia se presenta con una jerarquía particular, desligada de metodologías de observación y análisis, el plano cotidiano de las costumbres se escapa como referencia de conclusiones y se eclipsa como parte del proceso de edificación legítimo del saber el reconocimiento social de que está investido.

Y esto no se presenta sólo en las investigaciones académicas, con la excepción de estudios específicos, en general aislados. La separación de las ciencias, que se instala en las praxis institucionales que ocultan los saberes subalternos que reclama Haraway.

Al suponer la existencia de un orden explicativo, donde lo biológico subordina a lo social, y también al asumir un estatus superior de un cierto tipo de conocimiento, nos encerramos en una falacia largamente descripta desde el siglo XVIII, la de confundir causas con efectos. Un punto desde el que se nos escurre la posibilidad de aplicar la noción de praxis ambiental tanto a la producción de conocimiento como a la incidencia que implica en las acciones.

Ahora bien, los ámbitos donde se diseñan los protocolos de investigación no contemplan formas para dar cuenta de las problemáticas que vinculan sociedad y naturaleza. Sin embargo el retorno hacia un reclamo empírico tampoco resolvería de forma satisfactoria el desafío, porque las estructuras del saber operan escindiendo los temas de investigación entre sociales y naturales, de forma tal que permanece el circuito de invisibilización.

El quiebre de este círculo, que recurrentemente nos retorna a visiones duales, nos pone de frente a la necesidad de profundizar la edificación de genealogías en el sentido que Michel Foucault (2000) le dio al término. Esto es el acoplamiento de los conocimientos eruditos y las memorias locales "acoplamiento que permite la construcción de un saber 
histórico de las luchas y la utilización de ese saber en las prácticas actuales" (Foucault $2000,22)$.

El filósofo francés entiende que desde principios de los ochenta los discursos globalizadores se enfrentaron, cada vez más, a críticas locales, que llamaron la atención sobre las formas específicas que toman los procesos generales. En este sentido se recuperaron muchos saberes sometidos, entendiendo por ello a los saberes no reconocidos como saberes conceptuales, jerárquicamente inferiores de aquellos saberes académicos o eruditos, denominados por Foucault (2000) como el saber de la gente. La genealogía sería, entonces la arena de edificación de discursos compartidos y el espacio de reconocimiento de los saberes que, desde este nuevo lugar, dejarían de tener este carácter de sometidos.

Ahora bien, si desde los años ochenta se reconoce la necesidad de elaborar reflexiones y ejercicios que dan espacio a este nivel de experiencia, resulta difícil comprender cómo los problemas ambientales nos vuelven a situar en las dificultades para reconocer el valor de estos conocimientos locales, en la permanencia del carácter de sometimiento. Tal vez el reconocimiento histórico de las luchas se ha desarrollado de forma fragmentada, o tal vez la jerarquización de las experiencias se realiza desde una línea argumentativa que, tal como se presenta en el capítulo cuatro, se puede calificar como minorías silenciadas.

Volviendo los ojos a la discusión ecológica actual, el carácter atomizador que se reconoce en el proceso de elaboración de conocimientos (Lortie et al. 2004), así como la permanencia de principios de edificación de teorías reduccionistas, que asumen los factores físico químicos con una jerarquía explicativa que prevalece sobre el resto de las teorías (Brown 1999), pone de frente la envergadura de los supuestos jerárquicos a desmontar. Porque resulta casi quimérico plantear que la edificación de saberes se realizará desde una arena con lugar para los saberes de la gente, si la propia actividad científica se encuentra en un contexto de debates fragmentados y atravesada por reconocimientos desiguales.

La parcialidad de la mirada se cristaliza en estas formas de producción de conocimiento, y en esta cristalización se pierde la posibilidad de edificar genealogías en las que converjan perspectivas de análisis eruditas y cotidianas. Tal vez una de las trabas es que 
en un tema como el que se trata, donde se plantea la necesidad de una mirada integral, existe una necesaria referencia a tomar entre las variables a las consideraciones morales en juego. En lo personal considero que este reconocimiento no se debe acotar a la descripción de diversidades, sino a consolidar las vías en que desde las diversidades se acuerden modos de desarrollo e intervención compartidos.

Pensar que este problema es ajeno a las ciencias naturales tiene entre sus corolarios que desde la ecología (o desde la ciencia en general) no se diseñen alternativas a las trabas que históricamente se han instalado en los temas ambientales. En este sentido acuerdo con la deep ecology en que en el fondo el tema del problema ambiental es un problema de consideración moral, aunque no comparto que la respuesta es la dilución de diferencias. Pero vale la pena no perder de vista que en estas reflexiones existe un sustrato donde se filtra la idea de justicia, de lo que es justo. Del reconocimiento del valor de la diversidad de voces como objetivo válido.

Por eso, en el problema por la introducción de valores, de las voces silenciadas y de las dificultades de reconocimiento, resultan ineludibles las reflexiones feministas, no porque se trate de una cuestión exclusivamente de pertenencia sexual, sino porque los escritos feministas son los que han explorado con mayor profundad las formas de invisibilización de los sectores silenciados.

Amelia Valcarcel (2007), al reflexionar sobre la situación de las mujeres en España, llama la atención sobre la importancia de tener en cuenta el problema de la construcción del respeto. Ella hace mención sobre todo a las mujeres insertas en espacios académicos o de toma de decisiones, pero sus reflexiones toman en cuenta un aspecto fundamental del reconocimiento que es el problema del respeto. La filósofa española señala que el respeto es el incontable más fuerte, porque aún pensando en una sociedad que ha logrado repartir sus bienes básicos podría suceder que el reparto de este incontable no estuviera hecho o no pudiera hacerse.

La fragilidad de los logros materiales se miden en función de este incontable, según las indicaciones de la española, aún obteniendo la paridad, la mitad de todo, o incluso si se tuviera todo, si no se tiene respeto eso que se tiene es muy frágil. La obtención de la autoridad es el desafío, para las mujeres, para los sectores populares, para todas/os quienes quedan recortados de los márgenes de reconocimiento que se establecieron en 
nuestra sociedad jerárquica. Amelia Valcarcel (2007), retomando la reflexión del derecho romano, señala que la principal dificultad para las mujeres (y todos los otros invisibles), es que el respeto depende del auctoritas, y los invisibles no tienen auctoritas. En este punto Valcarcel distingue, como los romanos, entre auctoritas y potestas. Donde potestas es el poder explícito, fuerza y cohesión concretas, y auctoritas resulta ese nivel de reconocimiento que produce en el que ha de ser ordenado el deseo de obedecer. Ese es el punto donde aún queda mucho por hacer, en el reconocimiento, el establecimiento de una auctoritas que sean base de un ejercicio de reconocimiento que atraviese el conjunto de instituciones. Para ello Valcarcel observa que el punto de partida de esta edificación es el propio reconocimiento, el trabajo sobre el auto-respeto. Volviendo al plano de la tesis, a la valoración de la propia experiencia como espacio legítimo de conocimiento que debe ser incorporada entre los aspectos a considerar en los ámbitos donde se toman decisiones.

En este sentido el feminismo, como señala Françoise Collin (2006) no se reduce a mera pretensión de reparar una injusticia sino que apunta a la necesidad de una reconsideración de la comunidad. La pregunta por las estrategias para traducir las reflexiones sobre el silencio y la desigualdad, hacia la reparación de problemas que se reiteran y se agravan, nos lleva a tomar en cuenta esta idea de reconsiderar la comunidad no sólo como teoría, sino desde la dimensión práctica de las interpelaciones, demandas y reivindicaciones.

Desde este punto retornamos a la noción de praxis ambiental, a la luz de una estructura de conocimiento que consolida el imaginario de sociedad jerárquica pero que, dentro de sus propias reflexiones, genera ámbitos de estudio -como algunas de las vertientes de estudio de la ecología, antropología, historia, filosofía, entre otras- que aún cuando adolecen de las herramientas para diseñar y concretar intervenciones específicas, nos llaman la atención sobre el problema.

\section{Consideraciones finales del capítulo}

A la luz de lo expuesto entiendo que el límite en la consolidación de una praxis ambiental no se encuentra en la propuesta teórica o el reconocimiento de los valores implicados, ni siquiera en el diseño de una posible metodología de investigación, sino 
en la jerarquía y reconocimiento que se asume al tomar una cierta forma de producción de conocimiento como única o legítima, ajena a las tensiones sociales.

Las instituciones asumen y fortalecen la praxis no-ambiental, en el sentido que desde argumentaciones burocráticas que fijan lógicas de dominio que silencian actores y consolidan niveles de reconocimiento diferenciados. Aún cuando se planteen argumentos que compartan en los discursos la importancia por la preservación ambiental, o el bienestar ambiental de la población, las formas de intervención reproducen supuestos de jerarquía, no basados en elecciones concientes sino como parte de la costumbre.

En este sentido la praxis ambiental, al tener como referencia el problema del reconocimiento y al asumir un compromiso con el cambio de la situación, recupera el compromiso con la acción que Marx reivindicó en su propuesta de praxis. Esta acción, sin embargo, no necesariamente es una acción revolucionaria, porque puede ser una acción que se despliegue dentro de las vías institucionales establecidas, buscando modificar tanto la presentación de las teorías como la reflexión sobre la intervención, como parte de la propia edificación del saber. No se trata de retomar propuestas de estudio que han sido trazas, sino de llamar la atención en las referencias al cambio en el plano de reconocimientos que debe asumirse desde los espacios generadores del saber legítimo. Se trata de comprender que el problema ambiental nos lleva a reconocer la importancia del diálogo permanente con las actividades que se diseñen.

Retornando desde este concepto de praxis ambiental hacia las reflexiones previas, podemos encontrar en este ejercicio propuesto el desafío de los límites que en la actualidad se encuentran en la ciencia ecológica, revisando el mapa de demandas actualmente existentes desde un ejercicio de diálogo que atraviese el profundo entramado de la producción científica, para retornar desde este diálogo modificado a los desafíos que se enfrentan en este horizonte de crisis ambiental

La mera reivindicación de valores ambientales no termina de constituirse en práctica social, porque los supuestos jerárquicos operan como instancias de ocultamiento. Los supuestos jerárquicos atraviesan nuestras percepciones, en tanto individuos pertenecientes a la cultura occidental. A través de estos supuestos jerárquicos se filtran formas de desigualdad que se asumen como naturales y nos sitúa en una percepción 
dual que no termina de perderse, a pesar del enorme número de escritos, las actividades de militancia ambiental o los propios límites que estallan en los condicionamientos ambientales a los que están sometidos los segmentos más vulnerables de nuestra sociedad.

La vastedad de los aspectos a desmontar en relación a la remoción de la dualidad sociedad/naturaleza nos enfrenta a repensar la naturaleza desde el reconocimiento de una investidura espiritual, como propone Bárbara Holland Cunz, y a reconsiderar, a la luz de los desafíos que se inauguran, nuestra propia característica como seres humanos (Plumwood 1996, 2004). Estos aspectos nos enfrentan a nuevos modos de conocer, no tanto en el sentido de diseñar metodologías de toma de datos, sino en las perspectivas que se reconocen como válidas para dar sentido al conjunto de información.

La práctica y la intervención, si se consideran como parte del horizonte de referencias de las investigaciones provocarían cambios en el modo de reflexionar sobre las teorías, así como en la conciencia que la no consideración de estas dimensiones fomenta la forma de intervención instrumental, que nos ha llevado a esta situación de desgaste.

La noción de praxis ambiental no resulta fácil de imaginar en los contextos actuales en gran medida por la pervivencia de supuestos que han configurado la praxis clásica, donde aún quedan rasgos aristotélicos en la subordinación de teoría hacia la práctica, o tal vez, como indica Susan Bordo (1986), se trata de la herencia cartesiana que, al distinguir la razón del marco material (reducido a confusiones), imprime una tendencia masculina en la elaboración de conocimiento. Y en este sentido el abandono de estos lazos resulta concebible en un contexto en el que se asuma el compromiso de la reflexión asociado a la idea de cambio.

Para esto hay que negociar el control y la jerarquía, no la metodología, no la tecnología, pero sí la escala de reconocimientos que se han constituido con esta ciencia y esta tecnología. No se trata de un retorno al pasado, sino de la toma de conciencia de cada productor de conocimiento, compromiso de avanzar hacia estos espacios, de edificar proyectos de visibilidad desde los centros establecidos del saber. Este es el punto de partida de la praxis ambiental y la posibilidad de articulación de la misma con la ecología. 
Cuarta sección: Consideraciones finales

Capítulo 6:

Recapitulación y conclusiones 
Tal como se anticipara en la introducción, la presente tesis recorre un camino que escruta distintas perspectivas de un tema intrínsecamente complejo, el que vincula a las sociedades occidentales actuales con su entorno. La llegada hacia este problema no fue directa, se originó en la historia y desafíos epistemológicos de una disciplina científica enmarcada en las ciencias naturales: la ecología. Desde este lugar indagué en el carácter de las preguntas que no se responden y las tensiones que permanecen. Procuré, en definitiva, poner de manifiesto la existencia de "puntos ciegos" en la revisión de los problemas recurrentes, constituidos desde preconceptos aproblematizados, tal como se desprende de las páginas precedentes.

Desde la exposición de estos "puntos ciegos" llevé a cabo una indagación sobre los supuestos y fundamentos que traban la tematización de los mismos. Así como la revisión de los elementos sobre los que descansa la permanencia de preguntas recurrentes. La reflexión sobre las ideas me guió ineludiblemente hacia el plano de las prácticas, pero no en un sentido interno sino en uno más amplio, la investigación científica a la luz de las demandas y ejercicios de apropiación sociales.

A fin de organizar la lectura de estas consideraciones finales he diferenciado la sección de las conclusiones en dos partes: la recapitulación, en donde recorro los objetivos y las principales observaciones de cada capítulo, y las conclusiones, donde presento una revisión integral de los problemas que emergen como temas comunes desde las diversas formas de aproximación elegidas. Así desarrollo los problemas a retomar y ampliar, profundizando especialmente en las tensiones que se reconocen a partir de problematizar el concepto fundamental que atraviesa la presente reflexión: la naturaleza.

Desde una propuesta donde convergen tanto las consideraciones elaboradas a lo largo de estas páginas como utopías personales, a modo de cierre planteo posibles vías alternativas que ayuden a escapar de las condenas a las que parecen someternos las miradas que acometen sobre el mundo sin detenerse a inspeccionar los supuestos en que fundan sus acciones.

\section{Recapitulación:}

En el primer capítulo exploré la pregunta científica por la naturaleza, su conocimiento y el vínculo que se elabora a partir de indagar en las ciencias naturales, no sólo por su 
capacidad en el establecimiento de definiciones y diseños de manejo del entorno sino porque la propia denominación ecología, como actividad y problema emerge de esta área de estudios. Se trata de indagar en las particularidades disciplinares de esta ciencia natural que, a pesar de su definición, no puede evitar un sitio limítrofe entre las actividades humanas y las de otros organismos. Por ello contiene muchas de las contradicciones que se desprenden de la aceptación acrítica de la dualidad excluyente entre sociedad y naturaleza.

Entre las consideraciones del primer capítulo se expone que uno de los escollos que debe sortearse es que dentro de la propia edificación de teorías científicas, se han consolidado trabas que limitan, por un lado el propio ejercicio autoreflexivo (Haila y Taylor 2001) y por otro las posibilidades de elaboración de respuestas para una disciplina enfrentada a las más variadas presiones sociales (Núñez 2008, sin editar; Holling 1998).

En este capítulo muestro cómo, bajo supuestos de neutralidad y objetividad, se eclipsa que la ciencia es una actividad productiva influida por el resto de las instituciones sociales (Lewontin 1992), y en este ocultamiento se pierden herramientas para reparar en el recorte del mundo asumido por la ecología.

A partir de un rastreo histórico se revela que la ecología es una disciplina cercana a los problemas ambientales, a situaciones concretas, con debates abiertos que no impiden crecimiento disciplinar y con múltiples perspectivas que, en la actualidad, no terminan de articularse. En esta revisión se pone de manifiesto el carácter lábil de los compromisos sobre los que se sostiene la disciplina, que en un primer período respondía a nociones descriptivas, en un segundo priorizó la experimentación y la matematización, y en un tercero avanza más sobre dudas que sobre certezas.

Puede pensarse a la ecología (parafraseando a Bourdieu) como la ciencia dominada del conocimiento dominante. Fuente de definiciones fundamentales para el manejo del mundo orgánico, pero sometida a trabas que llegan a limitar incluso la capacidad de revisión interna. El recorte de las preguntas dentro de la ecología, sobre todo desde mediados del siglo XX, estuvo acotado a la visión de "ciencia modelo" que guió las prácticas. Aún cuando el origen mismo de la disciplina se liga al problema de la 
producción humana y a la relación de las sociedades con sus entornos, existió una omisión explícita respecto de los factores sociales.

El desarrollo de esta disciplina, que apuntó a la búsqueda de patrones, tuvo sin embargo un clivaje fundamental a fines del siglo XX. La interacción que se suponía fundamental para la estructuración de comunidades -la competencia- fue puesta en duda, y desde la imposibilidad de sostener el supuesto privilegiado con datos concretos, se dio inicio a una serie de interrogantes que permitieron pensar nuevos dinamismos en torno al funcionamiento del mundo vivo.

Esta situación, de cambios teóricos internos y contextos de emergencia, se constituirá en uno de los puntos fundamentales de tensión disciplinar, porque en la actualidad los problemas que se presentan ante la ecología no provienen tanto del desarrollo teórico sino que surgen en escenarios ajenos a la disciplina, a problemas que exponen seres humanos y no-humanos interactuando entre sí, con presencia de factores abióticos y con urgencias cuyas soluciones dependen de una profunda comprensión del complejo sistema en general.

En este plano de respuestas inconclusas se fue constituyendo un campo de debates en el cual el sentido del propio término "ecología" está en disputa. Este será el punto de partida del segundo capítulo.

En este segundo apartado se evidencia que, en el siglo XIX, la respuesta de los gobiernos (comprometidos con la forma de producción capitalista), frente a los límites que empezaban a reconocerse en la naturaleza, fue la producción de conocimiento científico. Entre los múltiples desarrollos iniciados en el período he destacado la producción de conocimiento ecológico, porque la apertura de este nuevo campo de estudios fue el ámbito por excelencia para encontrar respuestas.

En contra de una historia fundacional aséptica, reviso cómo en este proceso se filtraron nociones precedentes que sustentaban la ciencia moderna, tales como las discriminaciones de género (Merchant 1983) o la escisión excluyente sociedad/naturaleza (Descola y Palsson 2001). Es interesante el modo en que estos preceptos se filtran hacia prácticas de conservación, donde los Parques Nacionales se erigen como ejemplo de lo que se debe cuidar y diferenciar. Un ejercicio distintivo 
hacia el resto del espacio que, por omisión, queda relegado a un no-cuidado. No se asume como posible el cuidar por el hecho de estar habitado por humanos.

En un período acorde al del surgimiento de la ecología, y a partir del reconocimiento de problemas similares, los teóricos socialistas intentaron problematizar el vínculo sociedad/naturaleza, dando varias pistas en torno a los problemas y riesgos de las prácticas capitalistas, pero sin quebrar con los preceptos teleológicos ni abandonando la confianza en la mirada científica. Así, ni el debate científico, ni el debate político, terminaron de instituirse como alternativas.

Por ello no resulta extraño que desde lógicas diferentes se comenzaran a elaborar discursos y prácticas tendientes a llamar la atención hacia el problema ambiental. La dificultad que se encuentra en estos reclamos es, por un lado, su diversidad, que hace discutible el reconocimiento de una reivindicación común. Y por otro, la pervivencia de ciertos obstáculos que tampoco han facilitado reflexiones tendientes a cambios definitivos en las sociedades actuales.

Como contracara emerge un reconocimiento cada vez más profundo del problema ambiental, cuya denuncia no termina de desmontar las trabas del sistema productivo capitalista globalizado, a fin de favorecer la constitución de alternativas. Resulta claro que el mero conocimiento no produce los cambios y, de hecho, muchas de las reflexiones exponen un esquema de opresión tan vasto, que hace discutible la posible implementación de alternativas.

La desigualdad creciente, asociada al desarrollo del capitalismo en este período de globalización, impacta en la crisis y el desgaste en los sectores más frágiles de la sociedad (pueblos del tercer mundo, mujeres, ancianos, etc.). De allí que se planteen horizontes apocalípticos, donde la destrucción aparece más cercana que la posibilidad de cambio, en contra de la intuición de Fourier y Engels. Esta noción se fortalece si se tiene en cuenta que los mismos movimientos ambientales han resultado mucho más eficientes en términos de denuncia que de búsqueda de alternativas.

Sin embargo, en contra de esta visión que puede llevar a posturas inmovilizantes, sigo una línea de reflexión que abandona los procesos generales de las sociedades occidentales e indaga en debates de espacios históricamente no reconocidos, los que se desplegaron en ámbitos privados. 
Se trata de repensar la cotidianeidad como sitio al cual debe llegar el cambio, la nueva sociedad, pero ya no como resultante final de una estructura de control y dominio, sino como fuente eficiente y efectiva de cambio en si misma.

Por ello me alejé de las preguntas para avanzar en la revisión de dos de los ejes sobre los que se sostiene la diferencia y el dominio: la concepción jerárquica del mundo, que se explora en el tercer capítulo y la dualidad sociedad / naturaleza, asociada a la metáfora de la tierra viva como femenina, cuyas particularidades y consecuencias se indagan en el cuarto capítulo.

Uno de los principales resultados del tercer capítulo es el reconocimiento que los cimientos de una sociedad desigual se edificaron desde presupuestos biológicos, concordantes en sus inicios a ideas religiosas y sociales. Resulta interesante el modo en que se edificaron estos supuestos, cuyos orígenes se rastrean en la antigüedad clásica, pero donde la articulación con la disciplina actual se encuentra en el siglo XVII, en los debates que dieron origen a la disciplina moderna.

Las diferencias biológicas fueron el justificativo del dominio. El ser humano, asumido como la entidad viva más desarrollada, se entendió con el derecho de utilizar al resto de los seres y de las cosas para su propio beneficio. El enorme cambio conceptual del siglo XIX, asociado a la teoría darwiniana, sumado a la consolidación multidisciplinar de las diferentes áreas de investigación que se profesionalizan en el siglo XX, fue conformando una visión de los organismos que permitió eclipsar el discurso biológico precedente.

En la actualidad la desigualdad edificada en el siglo XVII se sigue reproduciendo desde el discurso elaborado a partir de la práctica científica. Los científicas/os, al no reconocerse como agentes de la desigualdad estructural elaborada desde la biología, continúan reproduciendo inequidad desde los presupuestos aproblematizados de sus prácticas.

La historia de la consolidación del manejo jerárquico y dominante del mundo, en el sentido de relaciones hacia la sociedad o el entorno, expone los fundamentos biológicos que sostuvieron la idea de dominio, en un contexto donde esta misma idea era debatida, por ejemplo, desde las teorías socialistas. 
La teoría de la evolución permitió la remoción del supuesto fijista que había atravesado la reflexión sobre los distintos organismos. Pero el debate por la jerarquía, antes que resolverse se deslizó hacia otras áreas temáticas. Un ejemplo de ello fue la antropología física y la justificación de las diferencias humanas a partir de caracteres antrópicos (tamaño del cráneo, color de la piel, entre otros). La jerarquía, sobre todo desde una perspectiva que naturalizaba el derecho al dominio, no volvió a ser tema de la biología, porque quedó atrapada en consideraciones sociales que se consideraban fuera del ámbito de las ciencias naturales.

Volviendo a la biología puede postularse que, en la creciente especialización que se consolidaba a finales del siglo XIX, se perdieron de vista los compromisos fundacionales. La parcialización de los debates científicos ayudó a perder de vista el fundamento del dominio como parte de la estructura teórica de esta área de estudios en sus orígenes. Apelando a una metáfora organicista, puede pensarse que las raíces de la jerarquía, sobre la que crecen las desigualdades, se plantan en el territorio de la biología para crecer en el ámbito extra científico de las prácticas sociales.

El velo de ocultamiento que traba el reconocimiento de este tema parece repetir herramientas y estrategias: homogeneización, universalización, reduccionismo son algunas de los más recurrentes. Las estructuras que operan como invisibilizadoras del carácter artificial de las jerarquías están en sí mismas edificadas con esta lógica desigual. El desafío que se abre desde este examen es el modo de remoción de estas estructuras, tanto porque legitiman determinados usos de una naturaleza condenada a la idea de recurso, como porque acotan las formas de evaluar las situaciones.

Para ello se adopta una línea de estudios particularmente sensible a la revisión de las jerarquías naturalizadas, me refiero a la que se inauguró a fin de avanzar en la revisión de la situación varón/mujer. Adhiero a la teoría de género en que esta vinculación desigual ha dado lugar a la indagación general sobre el conjunto de situaciones opresivas. Desde allí argumento a favor de tomar los ecofeminismos para explorar la dualidad sociedad/naturaleza, tomando en cuenta el conjunto general de desigualdades vinculadas a la pervivencia de este antagonismo.

El cuarto capítulo indaga sobre este punto. La dualidad sociedad/ naturaleza se revisa desde una metáfora que, casi de modo paradójico, permite una oposición antagónica y 
desigual a partir de llenar el espacio limítrofe con seres que no terminan de reconocerse ni en un lado ni en el otro, como las mujeres o algunos de los pueblos no-occidentales. Esta dualidad, que se supone excluyente aún cuando involucra intersecciones no vacías, se ha presentado en la literatura asociada a una metáfora que equipara mujer a naturaleza o mujer a tierra. Así en este cuarto capítulo exploro la forma en que esta equiparación permitió el ejercicio de dominio desde la humanidad (acotada a los varones occidentales), sobre la naturaleza-mujer-“otro" no occidental.

De la mano de las novelas e imágenes literarias, la naturaleza emerge como mujer joven e indómita, a la que se debe someter para que cumpla su destino de dominio, donde a pesar de sus límites se acerca a un mundo establecido por la razón occidental. El reconocimiento del carácter construido de la noción de naturaleza permite un debate asociado al conocimiento y a las prácticas de dominio, porque los recortes que se asumen operan como norma de lo que debe-ser. A fin de ilustrar el límite abierto entre la humanidad y la naturaleza, remito un pintoresco ejemplo de un paraje cordillerano, donde las circunstancias y los intereses dan como resultado un relato de origen, donde los recientemente llegados inmigrantes europeos, reconocen a un caballo como héroe, y sitúan a los pobladores originarios entre los peligros de una naturaleza impetuosa.

Desde este sitio, que recorre metáforas y mitos, retorno a las propuestas ecofeministas. Asumo que las formas que adopten las luchas contra el deterioro ambiental y el patriarcado deben tener en cuenta este debate. No se trata de que la opresión de género sea más importante que otras formas de opresión, sino de que el género sea la categoría analítica fundamental a partir de la cual se avance en el estudio de los sistemas de dominación establecidos.

La adopción del ecofeminismo no implica sostener la idea de una esencia femenina que vincula a las mujeres con su entorno, sino reconocer que el sometimiento sufrido por los sectores sociales menos privilegiados, que contienen tanto hombres como mujeres en diferentes niveles etáreos, ha llevado a desarrollar estrategias de supervivencia que permiten presentarlos como agentes especialmente sensibles para reconocer tensiones e idear estrategias alternativas (con las salvedades ya mencionadas en el texto).

Este recorrido me llevó a distinguir las alternativas al modo occidental de vinculación sociedad-naturaleza en dos grandes ramas: -aquellas que reclaman un cambio en la 
forma de concebir la naturaleza y -aquellas que reclaman un cambio en el carácter de humanidad. Desde ambas perspectivas se concluye en la necesidad de abandonar la Razón clásica como fundamento último del conocimiento, postulando la necesidad de incorporar dimensiones relacionales. En este sentido refiero a la propuesta de Holland Cunz, filósofa que argumenta a favor de reinvestir a la naturaleza de espiritualidad; y al análisis de Plumwood en torno a la importancia por reconocernos, en tanto humanos, como parte de la cadena alimenticia de otros, con los cuales se plantea una relación que no implica la subordinación de los caracteres de unos en otros o la difusión completa de las particularidades.

Desde estos puntos de vista se destaca una perspectiva optimista que entiende el cambio como posible. Aunque no por optimista resulta ingenua, ya que se desarrolla en detalle la vasta dimensión de desafíos que se asumen con este cambio, teniendo particular reparo en las dificultades presentes en la incorporación de formas alternativas en el desarrollo de conocimiento, pues implican la remoción de buena parte de los valores sobre los que se ha edificado el saber occidental, asumiendo, por ejemplo, a la ciencia como uno más de los relatos posibles.

El ejercicio cotidiano de las sociedades occidentales se pone en entredicho en conjunto y esto no es independiente del proceso mismo de conocer, que partiendo del caso de la biología ecológica, abrió el camino hasta este punto. El desafío en esta línea sería comprender al conocimiento científico como uno más de los relatos, ligado a una cierta práctica de poder, y plantear una arena de intercambio "inter-tran-pluri disciplinaria", que permita el diálogo como pares entre el saber legitimado y la experiencia vivida. De esta forma el conocimiento técnico no será argumento para desmerecer perspectivas diferentes y la razón podrá redefinirse en un modo tal que no implique una naturaleza privada de espiritualidad.

Desde este desafío la Razón clásica como guía y fundamento, deja de ser un tema aislado, porque se vincula a un conjunto de prácticas asociadas y se cruza con las propuestas institucionales estructurantes de las relaciones sociales, que desde su propio dinamismo reproducen, no tanto la Razón, sino el reconocimiento particular con que ha sido coronada en la visión occidental. 
Queda, entonces, la pregunta por la posibilidad de acción, en el sentido de cambio en la relación y modo de conocimiento. Existe un cierto nivel de experiencias que permiten pensar en esta posibilidad, como son las experiencias de sociedades no occidentales o los propios grupos sociales afectados por las mayores desigualdades, que en muchos casos han desarrollado acciones alternativas como estrategias de supervivencia, pero esto no evita la pregunta ¿qué pasa con aquellos otros que no están impelidos por estos condicionantes? Esto es, los grupos más privilegiados. Específicamente, ¿cuál es la posibilidad de acción de cambio de un científico? O retornando al título que contiene estas reflexiones ¿cuáles son los vínculos, que a la luz de estas reflexiones, pueden establecerse entre ecología y praxis ambiental?

Este es el desafío indago en el quinto capítulo. Reviso la noción de praxis desde una doble mirada, la propuesta por Aristóteles y la retomada por Marx, con la consecuente complejidad adoptada en las sucesivas lecturas de las propuestas de estos pensadores. La praxis es un ejercicio humano, el conjunto de acciones que presupone el particular recorte de naturaleza que se asume en la constitución de la sociedad en la que se llevan adelante esas acciones. Sobre los límites y las potencialidades de la noción de praxis, avanzo hacia la idea de una praxis ambiental. Cuya principal diferencia es que reconoce como problema la edificación de idea de naturaleza que se ha aceptado de forma acrítica en las propuestas precedentes.

Entiendo que el límite en la consolidación de una praxis ambiental no se encuentra en la propuesta teórica o en el diseño de una posible metodología de investigación, sino en la jerarquía y reconocimiento que se asume sobre el mundo.

Las instituciones internalizan praxis no-ambiental, en el sentido que desde argumentaciones burocráticas fijan lógicas de dominio que silencian actores $\mathrm{y}$ consolidan niveles diferenciados de reconocimiento. Aún cuando se planteen argumentos que compartan en los discursos la importancia por la preservación ambiental, o el bienestar ambiental de la población, las formas de intervención reproducen supuestos de jerarquía que implican discriminación, no basados en elecciones concientes sino establecidas como parte de la costumbre.

En este sentido la praxis ambiental, al tener como referencia el problema del reconocimiento y al asumir un compromiso con el cambio, recupera la acción que Marx 
reivindicó en su propuesta de praxis. Esta acción en el sentido propuesto no necesariamente es una acción revolucionaria, porque puede ser una acción que se despliegue dentro de las vías institucionales establecidas. No se trata de retomar propuestas de estudio que han sido trazadas, sino de llamar la atención en las referencias al cambio en el plano de reconocimientos que debe asumirse desde los espacios generadores del saber legítimo y desde la institucionalización de prácticas. Se trata de comprender que el problema ambiental nos lleva a reconocer la importancia del diálogo permanente con las actividades que se diseñen y los actores que se involucren.

Retornando desde este concepto de praxis ambiental hacia las reflexiones previas, podemos encontrar en este ejercicio propuesto el desafío de los límites que en la actualidad se encuentran en la ciencia ecológica, revisando el mapa de demandas actualmente existentes desde un ejercicio de dialogo que atraviese el profundo entramado de la producción científica, para retornar desde este diálogo modificado a los desafíos que se enfrentan en este horizonte de crisis ambiental

La mera reivindicación de valores ambientales no termina de constituirse en práctica social, porque los supuestos jerárquicos continúan operando como instancias de ocultamiento. Los supuestos jerárquicos atraviesan nuestras percepciones, en tanto individuos pertenecientes a la cultura occidental. A través de estos supuestos jerárquicos se filtran formas de desigualdad que se asumen como naturales y que conducen a una percepción dual que no llega a desmontarse ni desde los escritos, las actividades de militancia ambiental o los propios límites de un planeta en crisis ambiental.

La vastedad de aspectos a deshacer, en relación a la remoción de la dualidad sociedad/naturaleza, ha sido asumida a partir de repensar la naturaleza desde el reconocimiento de una investidura espiritual, como propone Holland Cunz, y a reconsiderar nuestra propia característica como seres humanos (Plumwood 1996, 2004). Ambas perspectivas implican nuevos modos de conocer, no tanto en el sentido de diseñar metodologías de toma de datos, sino en las perspectivas que se admiten como válidas para dar sentido al conjunto de información.

La práctica y la intervención, si se consideran como parte del horizonte de referencias de las investigaciones provocarían cambios tanto en el modo de reflexionar sobre las teorías, como en la conciencia de remoción de la intervención instrumental. 
La noción de praxis ambiental no resulta fácil de imaginar en los contextos actuales en gran medida por la pervivencia de supuestos que han configurado la praxis clásica, donde aún pueden percibirse rasgos aristotélicos en la aceptación de la subordinación de teoría hacia la práctica, o tal vez, como indica Susan Bordo (1986), se trata de la herencia cartesiana que, al distinguir la razón del marco material (reducido a confusiones), imprime una tendencia masculina en la elaboración de conocimiento. Es por ello que el abandono de estos lazos resulta concebible en un contexto en el que se asuma el compromiso de la reflexión asociado a la idea de cambio.

Para esto hay que admitir la incapacidad de mantener el control absoluto de un mundo que no necesariamente debe comprenderse en términos estrictos de jerarquía. No se trata de impugnar o demonizar la metodología o la tecnología, sino de revisar la escala de reconocimientos que se han constituido con esta ciencia y esta tecnología. No se trata de un retorno al pasado, sino de la toma de conciencia de cada productor de conocimiento, en el compromiso a avanzar hacia estos espacios, a edificar proyectos de visibilidad desde los centros establecidos del saber. Este es el punto de partida de la praxis ambiental y la posibilidad de articulación de la misma con la ecología.

\section{Conclusiones: temas pendientes y vías de reflexión}

\section{I- El reconocimiento del marco desde el cual se elabora la reflexión: $L a$ globalización}

Las preguntas que se presentan como ineludibles y las estrategias propuestas no parten tanto de una reflexión analítico-conceptual, sino de un contexto donde ciertas dificultades estallan frente a los ojos, entre cerrados y atónitos, de instituciones que no contienen elementos desde los cuales otorgar respuestas definitivas o siquiera promesas de esas posibles respuestas.

El marco fundamental es el de la globalización. Este mundo que Castells (1999)

entiende como inmerso en la era de la información. La globalización, como mencionaba en la introducción, ha sido presentada como un proceso centralmente económico, de concentración y acumulación de capital sin parangones. Se ha iniciado un desarrollo histórico variable, contradictorio y multifacético, que inaugura formas 
relacionales y prácticas que invaden ciudades, naciones, y continentes. Formas de trabajo y de vida, modos de ser y de pensar, producciones culturales y modos de imaginar (Ianni 1992), a la vez que conlleva el surgimiento de regiones supranacionales, las cuales buscan constituirse en nuevos polos de poder económico y político integrándose en un mercado de escala mundial.

Las instituciones modernas quedan relegadas, los Estados Nacionales se enfrentan a un proceso que limita sus propias autonomías, percibidas en si mismas como límites para la circulación de este capital. La globalización, además, fuerza al reconocimiento de la problemática ambiental; el cambio climático, el deshielo de los polos, el incremento de tormentas, entre otras tragedias, se presenta afectando a la humanidad (como a los seres que habitan este planeta) en forma general. Resulta imposible omitir en este análisis el factor de incidencia de la sociedad occidental y su modo de explotar los recursos, que se reconoce cada vez más ligada al desencadenamiento de las catástrofes, que por la propia dinámica informativa, resultan cada vez menos conmocionantes para una sociedad que, a fuerza de repeticiones, parece sumergir esta crítica cotidiana bajo el manto de la apatía.

La dimensión del problema es de tal envergadura que, antes que acciones, parece generar inmovilizaciones. Y esto lleva a otra de las características de la globalización, la impresión que en este proceso arrollador se pierden las diferencias y particularidades. La humanidad, en los discursos que se multiplican tras el reconocimiento de este proceso, parece homogeneizarse al ser expuesta como afectada por los mismos procesos.

El presente escrito se sostiene desde un lugar que asume el problema y la situación, pero se opone a las consecuencias que impone una visión catastrófica e ineludible. Busca escapar de la trampa construida, no sólo desde procesos generales, sino de discursos que impiden clarificar la emergencia de otros, con tradiciones propias, estrategias alternativas. Inicio mi reflexión desde el deseo de alejarme de lo que Mario Margulis reconoce como

“... las modalidades discursivas que forman parte de un dispositivo massmediático que contribuye a deshistorizar los acontecimientos mundiales, proponiéndonos un mundo global cuyas asimetrías, contradicciones y desigualdades aparecen naturalizados ante la 
velocidad de la información y la presunta racionalidad de los mercados..." (Margulis 1998, 39).

El proceso de globalización avanza en el ocultamiento de particularidades al impedir su problematización desde sus preconceptos homogeneizantes. Muchas de las reivindicaciones logradas en contextos previos empiezan a desdibujarse o tornarse frágiles e inestables. Celia Amorós (2008) se refiere a este proceso como una sensación de retorno en el tiempo, no tanto por desconocer los derechos que vuelven a ponerse en juego, sino por el destino inapelable que se desprende de los discursos globalizantes.

Para escapar de esta visión sigo el camino propuesto por Donna Haraway quien reclama por el reconocimiento de lo que denomina los otros inapropiables/inapropiados (Haraway 1999), esto es, los sujetos que no se corresponden con la organización taxonómica de los discursos hegemónicos. Porque, y esto es fundamental en mi trabajo, las taxonomías hegemónicas no contienen todas las categorías posibles o siquiera existentes. En general estas taxonomías siempre han contenido recortes que ocultaron el derecho a ser del otro. El punto que se revisa, en este contexto de globalización, es la dimensión de ocultamiento que se logra. Y aquí vale una aclaración, el ser inapropiable no significa estar en un sitio de reserva especial, un reducto de lo auténtico e intocable. Por el contrario, significa

“... estar en una relación crítica y reconstructiva, una (racio)nalidad difractaria más que refractaria, como formas de establecer conexiones potentes que excedan la dominación.” (Haraway 1999, 126).

El desafío es abrir espacios donde esos otros (que no se reducen a los humanos), puedan ser pensados. Una epistemología que los contenga, porque desde esa capacidad de contener y comprender resulta posible establecer los puentes que no terminan de edificarse entre lo que entiendo como ecología y praxis ambiental.

En medio de este vínculo, sin circunscribirse a ninguna de las dos categorías, se encuentran los movimientos ambientalistas, como tantas otros espacios desde los cuales se interpela a las instituciones -nacionales, internacionales, científicas, etc.- en parte por respuestas, en parte por el derecho a establecer respuestas desde un nuevo sitio de reconocimiento. 
En este sentido, la explícita revisión del vínculo con la naturaleza, no trata de retornar a un pasado concebido como ideal, sino de revisar las tensiones que también se edificaron históricamente, a fin de presentar alternativas que permitan abrir espacios de diálogos en los que se pueda incidir sobre ciertos procesos. Aquí no puedo evitar una referencia a la visión de Marx y su compromiso con el cambio, aunque en este caso no se trate de un cambio que se plantee desde el concepto de trabajo, sino por la capacidad de elegir las relaciones que se desean.

Las herramientas de análisis escapan del marxismo y avanzan hacia aquellas perspectivas desde las cuales el problema del reconocimiento se tome como foco y referencia permanente. Desde este compromiso adopto herramientas provenientes de la teoría de género. Acuerdo con Celia Amorós (2008) en que el feminismo tiene mucho que aportar al "movimiento" de los movimientos sociales. Porque se trata de teorías, prácticas y estrategias de supervivencia propias de un sujeto que ha empezado su recorrido político en condiciones de extrema debilidad, pero al mismo tiempo se ha revelado capaz de transformar, reclamar y, sobre todo, revisarse permanentemente a si mismo.

Las teorías adoptadas como fundamento del análisis del presente escrito, merecen una aclaración desde la cual leer las conclusiones. A diferencia del "feminismo radical" devenido en "feminismo cultural" (Amorós, 2008), el presente trabajo no apunta a demonizar una posición. Se trata, por el contrario, de analizar el establecimiento de jerarquías, de reconocer el carácter artefactual de nociones naturalizadas, de normas y desigualdades. El objetivo es debilitar el sitio "natural" del patriarcado por el mero hecho de mostrarlo como un constructo que, entonces, resulta susceptible de ser modificado e incluso abandonado. En definitiva es tomar una opción teórica según la cual el cambio es posible y el optimismo forma parte del horizonte de utopías.

\section{II- Los temas pendientes}

\section{II - 1- La situación de la ciencia}

Uno de los primeros tópicos que se tocaron es la situación de la ciencia. Para ello indagué en una disciplina particularmente problemática: la ecología. Esta rama de la 
biología se presenta como parte de las ciencias naturales, aunque no logra distanciarse lo suficiente de las demandas sociales. Una presión que se incrementa al estar en juego la vinculación de las sociedades occidentales con su medioambiente.

Es, en este sentido, una disciplina situada en medio de la dualidad humanidad/naturaleza, y desde este sitio limítrofe sus tensiones y preguntas resultan iluminadoras tanto para visualizar las estrategias que han permitido sostener esta dualidad, como de las paradojas a las que lleva la pervivencia de la misma.

La ecología, en el contexto vigente, se enfrenta a un concierto de preguntas ineludibles sin respuesta posible, en tanto no considere su producción a la luz del esquema de valores sobre los cuales funda su práctica. La distancia consciente entre la práctica científica y los movimientos ambientales es una de las consecuencias más notables. Desde la constitución de la ecología como disciplina se fue abriendo un abismo de significados hacia el propio término ecología que deja ver cómo, a lo largo del siglo $\mathrm{XX}$, el conocimiento científico irremediablemente dejó de ser sinónimo de cuidado, protección o preservación.

Las diferencias entre ambas posturas se constituyen, por un lado, en los supuestos sesgados sobre los que se edificó la práctica científica, y por otro en la pluralidad de intereses e intenciones sobre los que se sostienen las variadas reivindicaciones ambientales.

Entre las contradicciones sobre las que se constituyó la investigación ecológica se cuenta la fundamentación biológica desde la cual se fue constituyendo un mundo ordenado, susceptible de ser conocido en forma completa con las herramientas científicas, que en la cima del orden y el derecho del dominio estaba el hombre. Un mundo regido por la razón, aún en los espacios que parecen escapar inexorablemente a los intentos comprensivos. Un mundo donde el fin último siguió siendo el varón blanco occidental ya naturalizado en su sitio regente. Con una noción de humanidad ligada a su opuesto, la naturaleza, en una diferenciación antagónica, excluyente y exclusiva.

Ahora bien, desde este reconocimiento la pregunta por la práctica científica y la elaboración de conocimiento tiene una relevancia ineludible. En el rol vigente, escindido de referencias a la aplicación y a la responsabilidad implícita en el propio acto de conocer e informar sobre ello, lleva a perder de vista que las teorías que se elaboran y 
reconocen tienen sentido en ciertos procesos históricos. El no problematizarlo es un modo de reproducir el proceso hegemónico, sea cual sea el tema que se trate.

Siguiendo a Haraway $(1988,1997)$ entiendo que la producción de conocimiento debe tener como horizonte de referencia un compromiso político con las necesidades epistemológicas de los sujetos emergentes inapropiables. En esta línea deben abandonarse formas y compromisos asociados a concepciones heredadas del empirismo lógico. El círculo vicioso de fondo es que se trata de discutir, desde la propia práctica, el sitio de privilegio que en gran medida, es el fundamento de la posibilidad de esa propia práctica.

Las objetividades subalternas explotan en los límites de las respuestas instituidas. La pluralidad de sujetos que emergen como agentes, esto es como constructores activos de objetos científicos naturales abren ventanas hacia el desafío de una construcción ontológica adecuada. No sólo se trata de humanos en sus más diversas organizaciones sociales y culturas, sino también de máquinas y seres vivos o materiales. Sujetos que son parte de una construcción discursiva, o como Haraway (1999) los denomina actores semiótico-materiales que no terminan de tener lugar en el discurso científico instituido.

La ciencia enfrenta el desafío de un desplazamiento de los debates epistemológicos sobre la objetividad hacia una genealogía política de los saberes, a través de la noción de saber situado (Preciado 2005), según el cual se trata de escribir para

“... sostener las políticas y las epistemologías vinculadas a un lugar, a un posicionamiento, a una colocación, donde la parcialidad es la condición para que nuestras proposiciones de saber racional sean entendidas" (Haraway 1988)

Se trata de construir saberes que permitan una política de conexión de las diferencias, donde la propia descripción facilite la edificación de alianzas desde la discontinuidad antes que el consenso. Donde los posicionamientos diferenciales no impliquen grados de reconocimiento jerárquicos (Sandoval 2000, Preciado 2005). Como indica Amorós (2008), el desafío es oponer una "república de la tecnociencia" a la "industria de la bioética" que hoy se enfrenta.

La oposición parece establecerse entre una ciencia adecuada para la globalización y una ciencia adecuada para el cambio, donde las visiones sobre la vida ocupan un sitio 
fundamental, porque desde las mismas descansan las decisiones en cuanto a quién vive y quién muere, qué se cuida y qué se pierde de vista. El punto que aún queda abierto es la edificación de herramientas para ver e incidir en los problemas que se consideren como tales. Como se ha mostrado a lo largo de estas páginas, la ciencia adecuada para la globalización no ve los problemas en danza sobre las cuestiones ambientales y sociales. Aún es una deuda el cómo dar continuidad a los logros del conocimiento moderno sin perder de vista el nuevo carácter de los desafíos.

En esta línea la revisión de los límites podría ser un punto de partida. Tomo en esto las referencias intradisciplinares ya mencionadas, relativas a la incorporación de modificaciones en el recorte temático de la ecología. Siguiendo a Holling (1998) y de Laplante (2004), los límites provenientes de la visión ortodoxa sobre la disciplina dejan fuera muchos de los ámbitos desde los cuales se podrá avanzar en el ejercicio de reconocimiento de los inapropiables. O cuanto menos en asumir el carácter inapropiable de muchos de los seres a los que se refieren los estudios biológicos.

Actualmente la visión ortodoxa se incrementa en contra de estas impugnaciones, mayormente, por el profundo proceso de especialización, que cercena encuentros dentro de la propia disciplina, que impide el diálogo entre las diversas escalas de observación (Lortie et al. 2004, Davis et al. 2005). Esta naturalización de la atomización del saber difícilmente facilite formas de encuentro entre voces diferentes. Más bien parece adecuarse a la tradición sobre la cual se edificó el estudio de la naturaleza "sin hombres". Una mirada de jerarquías instituidas donde la propia ecología tiene trabas para presentar sus particularidades (Haila y Taylor 1992), pero desde la cual se reconoce en un sitio de preeminencia y privilegio como el resto de los saberes científicos, sobre todo de las ciencias naturales. Así, la legitimidad aparece sostenida desde el reconocimiento desigual antes que en la capacidad de respuesta a los problemas.

El desafío que aún se adeuda es vasto y profundo. Se trata de responder a problemas que se originaron en una visión de jerarquías y dominio, que las propias disciplinas contienen desde la conformación de sus conceptos y prácticas. Se trata de asumir el desafío ilustrado de dar cuenta del mundo aceptando la complejidad del mismo, valorando la experiencia pero abandonando las estrategias que reproduzcan desigualdades. Un ejercicio introspectivo inaccesible en tanto no se edifique junto, y en 
relación con la valoración del mundo que se pretende conocer. Es decir, en tanto no se abandone la pretensión de jerarquía diferenciada en el acto de investigar.

\section{II- 2- La permanencia del dominio}

La revisión de la ecología desde sus reflexiones internas, o incluso a partir de las impugnaciones que se le han realizado, no permite mayor avance hacia formas efectivas de cambio. En la base de las prácticas científicas y relaciones de vinculación persiste la legitimidad de una situación de dominio, que se convalida en la desigualdad aproblematizada, y que cristaliza la condena hacia la imposibilidad del cambio.

Vale mencionar que, en parte, la falta de perspectivas hacia el cambio descansa en el escaso reconocimiento que han tenido las referencias que buscaron reflexionar sobre el desarrollo social a partir de problematizar el vínculo con la naturaleza. Retomo en este punto las reflexiones elaboradas en el capítulo dos, que toman como referencia la aseveración de Holland Cunz sobre la escasa incidencia de la revisión sobre el vínculo con la naturaleza en la teoría política. Pero a pesar de esa tendencia, existieron teorías que tomaron el tema de la naturaleza desde propuestas políticas, por considerar en el problema de la naturaleza elementos autónomos, que aún estando incluidos en las determinaciones sociales no se presentaban como reductibles a las mismas (Beer 1990). Parte de la escasa audibilidad de estas propuestas descansa en el nivel de cambios que implican, porque como Holland Cunz destaca, constituyeron desde mediados del siglo XIX, "la estructura interna de teorías de liberación antiburguesas, anticapitalista y antipatriarcales" (Hollanz Cunz 1996, 81).

Revisar el dominio es avanzar sobre caminos ya recorridos por variados/as autores/as hurgando en los espacios de resistencia intensamente vividos y escasamente reconocidos (Fuentes 2007). En esta línea empezaré a recorrer una de las referencias más recurrentes en la reflexión sobre la vinculación desigual: la dialéctica hegeliana del amo y el esclavo que revisaré mayormente desde la lectura que Alexandre Kojeve (1987) realiza sobre el tema, y no tanto desde un interés exegético de la fuente hegeliana. 


\section{II- 2.1- La dialéctica hegeliana del amo y el esclavo}

En el capítulo tres presenté una visión general de la dialéctica del amo y el esclavo, y al modo en que desde la misma se considera al dominio. Los aspectos que resultan relevantes son, por una parte, la organización fundamentalmente desigual como estructura intrínseca de las sociedades humanas, y por otra parte, que aún cuando se llevara adelante una reorganización, la misma convergerá necesariamente a una nueva forma que igualmente resultará jerárquica. Si se asume esta dialéctica como ineludible, el actual debate sobre el privilegio del lenguaje científico y el intento de remoción de las sombras que tiene asociada, sólo puede leerse como una estrategia para desmontar un orden a fin de edificar otro igualmente jerárquico.

Ahora bien, esta visión organizativa jerárquica toma como punto de partida el proceso de autorreconocimiento. El punto de partida del mismo es el deseo, siguiendo la lectura de Alexandre Kojeve (1987) sobre la dialéctica del amo y el esclavo, el deseo es fundamental para la constitución del yo. Este filósofo asume que el hombre que observa es absorbido por eso que observa y sólo retorna hacia sí a través del deseo, como por ejemplo, el de comer. Es el deseo el que lo lleva a decir Yo. Ahora bien, Koyeve hace referencia al hombre que observa, no queda claro que pasa con el resto de los seres vivos, puede pensarse en una similitud respecto de los mamíferos, pero es menos claro que efectivamente podamos pensar en la constitución del Yo de una medusa, un coral, una planta o un virus, aún cuando en todos exista, al menos, el deseo de alimentarse.

Esta reflexión que incorpora a otros-no-humanos no sólo se debe al motivo de la tesis, sino que en la presentación de la propia dialéctica hay un esfuerzo particular en la separación de los seres humanos respecto del resto de los seres vivos. Esta separación también tiene que ver con el deseo. Volviendo a Kojeve encontramos que el mismo ser del hombre implica y presupone al deseo, porque la realidad humana no puede constituirse y mantenerse más que al interior de una realidad biológica. Este deseo por el alimento es un deseo animal. Sobre él se va a constituir la autoconciencia humana.

En la mirada hegeliana, el Yo creado por la satisfacción se asume con la misma naturaleza que las cosas a las que lleva ese deseo, un "Yo 'cosificado', Yo solamente viviente, un Yo animal” (Koyeve 1987), que se revela a los otros a través del sentimiento: este es el sitio de los seres vivientes no humanos. Porque desde este 
análisis, para constituirnos en "hombres", para superar el deseo-natural, el deseo debe fijarse sobre un objeto no-natural, debe dirigirse hacia otros deseos.

Desde esta reflexión empieza a levantarse un límite que asume naturaleza y sociedad como separadas. Para que el deseo humano exista como tal, es decir, dirigido hacia otros deseos y no sólo hacia cosas, es fundamental que existan otros deseos, que conduzcan o puedan ser conducidos por los deseos del resto de los miembros de la sociedad.

Pero esto aún no es condición suficiente para constituirnos como hombres, la humanidad se edifica cuando el deseo del hombre prevalece efectivamente sobre el deseo animal, y esto, según Koyeve, acontece cuando se supera el deseo de conservación, cuando se arriesga la vida en función de los deseos humanos. "El deseo humano, antropogéneo, generador de la Autoconciencia, de la realidad humana, se ejerce en función del deseo de "reconocimiento"' (Koyeve 1987).

Desde este planteo, que realiza un recorte dentro de la humanidad, retorno a la pregunta del cuarto capítulo sobre la escisión entre la humanidad y la naturaleza. Siguiendo la dialéctica hegeliana el humano es el que se arriesga. El esclavo, aquel que no puede superar el miedo a la muerte, tiene un deseo humano sin fuerza suficiente como para superar el deseo animal, por ello desde esta mirada puede desprenderse que no queda constituido como hombre en sentido completo.

Múltiples preguntas se abren en torno a la consideración de culturas desde las cuales el constituirse en seres humanos implica el constituirse esporádicamente en otros animales (me remito en este caso al ejemplo de los achuar citado en el cuarto capítulo). La humanidad desde los preconceptos es una humanidad sesgada, se diferencia de la naturaleza con un carácter que tiene sesgos varoniles, de riesgo y aventura. La humanidad, ya desde la constitución hegeliana, emerge particularmente apegada a la tradición occidental de la cual el filósofo de Stuttgart es heredero.

Se asume una lucha por el prestigio, sin la cual se entiende que no habría seres humanos sobre la tierra. Una competencia fundamental y fundacional. Se trata de lograr el reconocimiento a través de imponerme al otro en un contexto de lucha a muerte. El escenario de la vida se edifica con los ladrillos de la destrucción. Para evitar la destrucción material de uno de los adversarios, se resuelve el dinamismo de interacción 
con el establecimiento de otro comportamiento, de un hombre que no arriesga su vida por el reconocimiento, un hombre menos humano si consideramos las referencias previas, un ser que admite como deseo humano el deseo del amo.

No hay mayores referencias a los motivos que llevan a deponer el propio deseo de reconocimiento, se lo considera natural porque de no ser así la humanidad desaparecería por la destrucción implícita en la lucha. En el tercer capítulo he presentado que Simone de Beauvoir (2005) puso de manifiesto que en nuestra sociedad la dialéctica amoesclavo se resuelve en la relación varón-mujer, y no tanto por los temores de la segunda como por las condiciones estructurales de socialización donde sus deseos no tienen cabida en la medida que no estén mediados por los deseos del primero.

Hay muchos otros cuyos deseos estructuralmente no se reconocen, no tanto por sus temores como porque su diferencia se valoriza en términos peyorativos. Los inapropiados/inapropiables de Haraway, en el subconjunto humano de los seres asumidos con esta categoría por la norteamericana.

En la diferenciación y vinculación que se presenta desde la dialéctica hegeliana hay al menos dos puntos que resultan problemáticos desde los capítulos precedentes. El primero es asumir a la humanidad reconociéndose como tal en oposición a la naturaleza. El segundo es asumir a la competencia a muerte como forma estructurante primigenia.

En relación al primer aspecto, esta dialéctica admite la escisión jerárquica, antagónica y excluyente. Donde la cercanía al sitio "natural" es el de aquel que, por temor, no se arriesga. El humano natural debe delegar necesariamente sus deseos, forma parte de su naturaleza. Los deseos de la naturaleza ni siquiera se consideran como tales o en relación al reconocimiento o autorreconocimiento humano.

La dialéctica hegeliana nos coloca frente a una de las principales síntesis de la ontología y dinamismo de la tradición occidental. Una reflexión, que por su profundidad y riqueza, permite indagar en los preconceptos de las formas relacionales que se trata de problematizar. En la dialéctica amo-esclavo, se asume, junto a la escisión humanidad/naturaleza, a la competencia-a-muerte como relación fundamental en la estructuración de vínculos. 
En relación al segundo aspecto podemos argumentar que la competencia, que en el caso humano Hegel presenta como la lucha a muerte por el prestigio, antes que relación fundamental trascendente, puede ser pensada como el vínculo privilegiado desde la tradición occidental moderna. Desde la misma se fue edificando la comprensión del mundo vivo (desde la teoría darwiniana hasta la moderna ecología), a pesar que en la toma de datos recurrentemente surjan impugnaciones de un mundo que no se adapta pasivamente a las formas comprensivas que se busca imponer desde el saber humano. ${ }^{68}$ En el primer capítulo hacía referencia al debate establecido por Daniel Simberloff a partir de constatar que lejos de ser el vínculo estructurante fundamental, la competencia en su capacidad explicativa medida en términos de probabilidades, no superó en muchos casos una estructuración explicada en términos exclusivos de azar.

Esto nos lleva a uno de los problemas recurrentes en las reflexiones que apelan o se sustentan sobre presupuestos biológicos: la confianza en la realidad material de las descripciones científicas. Es decir, el determinismo que se desprende del uso de una forma específica de lenguaje. ${ }^{69}$ Este punto resulta fundamental para interpretar el debate ecológico sobre la competencia, porque el compromiso realista no sólo se despliega en los ámbitos extra científicos, dentro de esta área de estudios gran parte de las contraargumentaciones apelaban a rebatir el derecho a indagar por fuera de los patrones descriptivos admitidos como legítimos, la propia validez de indagar desde presupuestos filosóficos que trascienden lo exclusivamente disciplinar fue uno de los puntos de debate (Sloep 1993).

Retornando a Hegel desde el mundo vivo, si la competencia no se sostiene desde las comunidades orgánicas ¿por qué debe asumirse sin dudas para las sociedades humanas? Considero que la falacia de fondo es que desde la explicación sobre el dinamismo de una jerarquía reconocida se desliza la aceptación acrítica del derecho al ejercicio de dominio implícito. Este es el punto que liga la dialéctica hegeliana con los debates de la ecología. Contra estas visiones entiendo que dominio y orden teórico no tienen mayor asociación que la intención por unirlos. Pero ello no debe hacer perder de vista que, históricamente, la argamasa fundamental para legitimar el vínculo entre ambos

\footnotetext{
${ }^{68}$ La biología no es la vida, sino un relato sobre la vida señala Haraway (1999).

${ }^{69}$ De hecho un modo de establecer una lectura reduccionista parte de suponer que, como nada queda fuera del lenguaje y de su capacidad descriptiva, todo queda determinado por las reglas de este mismo lenguaje. En contra de esta visión adopto la mirada de Haraway (2003), quien señala que el lenguaje se sitúa en un universo que de algún modo lo trasciende, en el producto de otras formas de agencia diferentes que interactúan con él
} 
conceptos, ha sido la aceptación de la competencia como interacción fundamental en todos los órdenes.

En este punto cobran sentido las reflexiones de Kropotkin presentadas en el cuarto capítulo, donde privilegiaba análisis tomados de ideas como simbiosis y mutualismos, esto es, las interacciones positivas como base de sus teorías políticas. Ahora bien, si se reconoce que la competencia no es necesariamente el fundamento de nuestra constitución como seres humanos -aunque sí es fundamental para la constituir al "serhumano-occidental-moderno"- puede pensarse que el reconocimiento, que efectivamente es el problema fundamental que se repite en todos los puntos de análisis, puede establecerse desde nociones en acuerdo con. El yo-en-relación que Plumwood presenta (ver capítulo cuatro), que se opone al yo "instrumental" o "autointeresado" edificado a partir de las relaciones planteadas exclusivamente en términos de interacciones negativas.

A la luz del carácter construido de interacciones que se presentan como naturales, donde la misma idea de Naturaleza es un horizonte socialmente edificado, resulta muy discutible la idea de los deseos dirigidos por otros deseos. Esa dirección antes que acompañar oculta, silencia e incluso ignora las formas emancipatorias de los esclavos que no son tales.

La pregunta por las interacciones horizontales es uno de los aspectos a revisar en la dialéctica hegeliana, tal como Amorós (2008) recuerda respecto de la afirmación de Jean Paul Sarte, que señala que un sistema de dominación no se entiende sólo como una relación amo-esclavo, según el cual el esclavo es depositario del secreto del amo y viceversa. Sino que sólo es comprensible si se tiene en cuenta la relación de los amos entre sí, así como la de los esclavos. A partir de reconocer que la jerarquía se asienta en estas confianzas, que en definitiva son edificadas, permite suponer que si se reflexiona desde un sitio alternativo, como son por ejemplo las interacciones positivas, puede salvarse la reducción de la diferencia al sometimiento. Abandonar el dominio como destino de unos pocos y avanzar en un ejercicio de reconocimiento con sitio para vinculaciones no-racionales en la exclusión instrumental.

En este punto vale retornar a las propuestas de Holland Cunz y Plumwood mencionadas en el cuarto capítulo, porque desde ambas se desprende la posibilidad de vínculo. 
Siguiendo a la pensadora alemana se establece al investir al otro con algo similar a lo que entendemos como propio. Aquello según lo cual nos constituimos como humanos, el espíritu al que hace referencia Holland Cunz. No tanto para subsumir a unos a la medida de otros, sino para asegurar el derecho a ser reconocidos desde su particularidad y no desde la norma. El ejemplo ya citado del caballo de Trevelin, que no deja de ser caballo para constituirse en héroe, puede ser visto desde esta línea.

Plumwood, por su parte, repara en una condición de vínculo complementaria, para poder relacionarnos con otros diferentes debemos valorar aquello del otro que contenemos en nosotros. Recuperar el valor de la "animalidad" sin por ello perder la particularidad. Su reflexión en torno a la cadena alimenticia es particularmente ilustrativa en cuanto al desafío que se abre en la búsqueda de nuevas relaciones. Revisar nuestra cultura extractiva occidental a partir de entender que no se trata sólo de extraer recursos, que el vínculo se establece en la posibilidad de retornos, que serán imposibles en la medida en que se sobre-valore la Razón ilustrada.

Desde ambas autoras vuelvo a un punto fundamental de la dialéctica hegeliana del amo y el esclavo, porque en el hacernos humanos, aún cuando se lo plantee desde la edificación de interacciones positivas, el tema fundamental sigue siendo el reconocimiento. Aunque me alejo del planteo original al postular la jerarquía y el dominio como la única forma posible de vincularnos entre humanos y hacia el resto de los seres.

\section{II- 2.2- Humanidad y naturaleza iintereses contrapuestos?}

En el mundo globalizado parece imposible superar este antagonismo entre humanidad y naturaleza, dejando sitio a las consecuencias más amenazantes. Marta Tafalla (2005) advierte que, si desde una postura extrema, los intereses de la biosfera se aceptan por encima de la humanidad, la acción que debería llevarse adelante sería la inmediata disminución de la población humana que está sobredimensionada respecto del resto de las especies. En este sentido el riesgo de una teoría holística tan vasta es su acercamiento al totalitarismo (Light y Rolston, 2003), sobre todo porque la descripción de los intereses de las partes, asumidas como antagónicas, no buscan describirse desde consideraciones alternativas. 
En este punto vuelven a ser válidas las consideraciones de Plumwood y Holland Cunz, los intereses no resultarán contrapuestos en tanto el reconocimiento esté basado en una arena de similitudes y no sólo de diferencias. La sobredimensión de lo distintivo es lo problemático, y esto no apunta a negar la existencia de la diferencia, sino a discutir que sea lo fundamentalmente estructurante. Nos constituimos desde particularidades y similitudes, tal vez la propia concepción de humanidad deba investirse de ese carácter laxo que cubre a las nociones reconocidas como constructos. Tal vez las similitudes entre las pluralidades humanas no puedan acotarse a una concepción específica de reconocimiento.

Tornar en diferente es un modo de someter. Haraway (1999), a propósito de Tanzania y la colonia de chimpancés estudiados por la Dra. Jane Goodall, repara en el modo en que los espacios "colonizados" suelen ocultar este carácter al ser presentados como "refugios" de un Eden original. Una noción que lejos de construirse atemporalmente es posible sólo a partir de las imágenes construidas desde la tecnología. Desnaturalizar la naturaleza para edificar una relación de pares aparece en tensión con la organización establecida por este mundo globalizado.

El riesgo de una salida ambiental que justifique el incremento de las formas opresivas es un horizonte cercano. En contra del mismo, confío en un supuesto que no tiene más fundamento que mi propia intuición y deseo: un mundo que cuide y respete la vida y la diversidad ambiental, es un mundo socialmente más justo.

Es posible que un mundo que considere el cuidado del entorno como parte ineludible de su cotidianeidad esté sostenido desde formas organizativas aún más autoritarias que las vigentes. Un mundo totalitario, donde el derecho a condenar se fundamente es ser la única forma de cuidar la vida del planeta y la de todos. Una sociedad que retorne a la idea aristotélica en que el derecho a mandar de una de las partes beneficia al conjunto. Donde la consciencia del todo descanse en ese gobierno-padre que señala al conjunto de la población que acata cómo comportarse. El biopoder aproblematizado y aceptado en su grado máximo, como salida a la crisis, es un argumento que se encuentra como desenlace de muchas argumentaciones ambientales. 
Desde las presentes conclusiones queda debilitada la idea de la jerarquía como única opción relacional. Lo que falta por revisar es el entramado de lugares y prácticas que edifican estas visiones específicas de normalidad, con su teleología desigual implícita.

\section{II- 3- La naturaleza y la edificación de lo normal}

Lo normal es edificado, ello no acerca mayores novedades. Ahora bien, los sitios desde los cuales se construye la norma sí resultan de interés. En parte porque la ciencia no resulta ajena o independiente, y en parte porque en el fondo de la norma emerge una particular visión de naturaleza que cobra sustancia en las acciones sociales. El horizonte referencial reconocido por Haraway para fundar lo cotidiano. El recorte que desde la cultura occidental se cimentó en términos de oposición y diferencia. El justificativo profundo del dominio que se establece.

Naturaleza y norma son dos conceptos fuertemente ligados, cuya vinculación puede remontarse a Aristóteles. Como señalaba en el cuarto capítulo, Naturaleza es para el estarigita materia y potencia. El filósofo griego toma como presupuesto el orden fundamentalmente jerárquico del mundo, donde la potencia ordena lo material de acuerdo a dominios y finalidades preestablecidas. Lo natural es el respeto al orden establecido, el orden establecido es la norma. Lo antinatural es antagónicamente no deseable, va en prejuicio del conjunto. La naturaleza tiene para Aristóteles un carácter normativo, cuyo fundamento es el preconcepto no revisado de mundo jerárquico.

El modo en que esta norma cobra forma socialmente no es ajeno a la propia norma. Tampoco es independiente de los espacios de edificación del reconocimiento. En este punto vale mencionar el peso de la norma a través del deseo. No se trata ya del deseo como motor de cambios (aunque sea una referencia permanente), sino en los deseos que se presentan en determinados contextos espacio-temporales. Específicamente de los deseos y normas de la modernidad.

Nancy Amstrong (1991) avanza hacia la noción de deseo disciplinado a partir de indagar en la situación femenina. La teórica se preocupó por revisar novelas, y concluye que el sujeto moderno empieza con la escritura acerca de y hecha por mujeres. La mujer doméstica- reina del hogar- no constituyó simplemente un modelo de feminidad, sino 
que acabó convirtiéndose en el modelo de subjetividad para el individuo moderno, producto de la cultura burguesa en formación, basada sobre unos valores que implicaban el desplazamiento socio político a favor de las relaciones aparentemente universales y subjetivas (emocionales y sexuales) entre varones y mujeres individuales.

Las referencias hacia los escritos le permiten aseverar que el ascenso de la novela giró en torno al esfuerzo por decir que es lo que hace deseable a una mujer que puso en juego una dimensión mucho más vasta. En la adecuación del deseo al nuevo contexto se dio un paso decisivo a la hora de producir el género densamente entretejido de sentido común y sentimentalidad, que fundamentó lo que la autora denomina "la ubicuidad del poder de la clase media". ${ }^{70}$ Una socialización, que más allá de los privilegios sectoriales, se asume en relación a una naturaleza permanentemente ajena, reducida a la idea de recurso.

En el modo de descubrir el disciplinamiento del deseo, Amstrong utiliza elementos similares a algunas de las referencias tomadas en el presente trabajo. Me refiero a las novelas, a las imágenes y normas que se presentan de imágenes que en el relato se plantean como naturalizadas.

Se trata de relatos que, más allá de un planteo de ficción, se instalan como historias ejemplares. Mitos modernos de un mundo que se reconstruye en sus deseos, relaciones y formas sociales. Mircea Elíade (1992), reflexionaba que en las sociedades arcaicas los mitos están aún vivos y fundamentan y justifican todo el comportamiento y la actividad de los habitantes de esas sociedades. No hay gran diferencia entre estas sociedades y las modernas en relación a la existencia de relatos vivos que se toman como referencia de comportamientos. En este punto resulta provocativa la idea de Haraway (1999) de la Naturaleza como lugar retórico. La referencia que permite habitar lugares comunes, el fundamento de la edificación de lo cotidiano, la base del sentido común. No debe sorprender, entonces, que junto a los relatos de mujer doméstica se encuentren otros tantos con referencias metafóricas entre mujer y naturaleza. Si a esto se agrega el clivaje del siglo XIX, con nuevas formas de interpretar y explotar una

\footnotetext{
${ }^{70}$ Desde esta relación, deseo disciplinado e intereses económicos sectoriales, Celia Amorós (2008) repara en el salario familiar como ideal normativo, que permite configurar una fantasía masculina de horizontalización en la clase obrera. El salario familiar niega la dependencia de los empleados respecto de los patrones, pero encubre otra posición de subordinación, la doméstica.
} 
naturaleza reducida a recursos o santuarios, los relatos de los grandes naturalistas pueden releerse como fundamento de los mitos modernos.

En este proceso de edificación simbólica, la norma, lo natural, no se reprodujo sólo en los escritos. Las prácticas se llenaron de sustancia en las instituciones que se constituyeron. Antonio Diegues (2005) argumenta que el mito de la naturaleza intocada se edificó en la modernidad a través de la constitución de los Parques Nacionales. Desde estas dependencias se cristalizó la noción de una naturaleza escindida de lo social, dejándose como consecuencia la condena del espacio vivido. Desde esta perspectiva la humanidad sólo tiene acceso a lo natural en condición de turista. El sitio propio que Arthur Tansley (1935) reclamó para la humanidad cuando acuñó el término ecosistema, se constituyó como el sitio fuera, y los Parques Naciones fueron (y son), el principal representante institucional de esta escisión.

Siguiendo las referencias del segundo capítulo, Norberto Fortunato (2005) llamó la atención sobre el cuerpo de preconceptos que se establecieron bajo la denominación de Parque Nacional. Desde la propia adjetivación, nacional, el autor revisa qué se cuida en un Parque. Allí explora la tradición que se preserva en la idea del Parque Nacional, la de los pionners que en su avance civilizatorio tuvieron contacto directo con la naturaleza y desde allí edificaron su espíritu nacionalista. Es esto lo que se cuida, por eso son Parques Nacionales antes que Parques de Vida o Parques Salvajes.

Pero estas no son las únicas instituciones que reproducen los mitos regulativos, porque las instituciones de los Estados modernos contienen un importante rol reproductor y disciplinador que ha sido largamente explorado. ${ }^{71}$ Celia Amorós (2008) señala que sin movimientos sociales que enfrenten a las instituciones a las propias reproducciones que dicen desmontar, las instituciones se esclerotizarían. En el capítulo cinco se muestran, tanto en las instituciones científicas como en las escolares, algunos ejemplos de reproducciones que repiten en formas opresivas naturalizadas. ${ }^{72}$ En contra de la

\footnotetext{
${ }^{71}$ En este punto resulta ineludible una referencia a la obra de Michel Foucault. Al trabajo ya mencionado Defender la sociedad vale la incorporación de la lectura de la obra Vigilar y castigar en relación a la teoría del panóptico elaborada por el filósofo francés.

${ }^{72} \mathrm{He}$ trabajado en profundidad las instancias reproductivas de la construcción de conocimiento ecológico en Núñez, P. (2008) "Entre la Ciencia "ideal" y la "real" El problema de la producción de conocimiento en el laboratorio de Ecología Ecotono. Tesis de Maestría en Filosofía e Historia de las ciencias. Universidad Nacional del Comahue. Inédita. No es objeto del presente trabajo redundar en reflexiones o ejemplos previamente trabajados, pero a modo de síntesis vale señalar que los ruidos epistemológicos provenientes de un mundo que no termina de adecuarse a los patrones de estudio establecidos por la ciencia, se resuelven al interior del laboratorio en un incremento del criterio de autoridad basado en la
} 
aceptación pasiva de estas instancias normalizadoras, este trabajo pretende exponer el carácter artificial de estas normas, no tanto por reparar en el modo en que se normativiza o naturaliza desde cada ámbito, sino por desmontar las confianzas establecidas sobre la idea de Naturaleza.

Lejos de discutir la existencia de las instituciones con referencias que remonten hacia propuestas anarquistas, concluyo que las tensiones no parten de las formas institucionales sino de la aceptación acrítica de situaciones de desigualdad. No se trata de negar las diferencias desde una postura holística que ignore las jerarquías a partir de invisibilizar diferencias (al estilo de las falacias expuestas en el segundo capítulo en la deep ecology). Se busca asumir las prácticas jerárquicas, pero con un determinismo debilitado que dé lugar a la permanente revisión de las desigualdades estructurales que se edifican en torno a esta jerarquía.

El carácter construido de la noción de naturaleza es un punto de partida facilitador en este sentido. En la medida en que se lo acepte como tal, obliga a revisar desde vínculos hasta recortes temáticos disciplinares. No se trata siquiera de imponer revisiones, de ello se encarga la permanente frustración de un mundo que no se adecua ni a las taxonomías ni a los dinamismos preestablecidos, se trata más bien de reconocer al interior de cada ámbito los debates que apuntan a las contradicciones que emergen en los límites de lo instituido para fortalecerlos.

Yendo a las reflexiones elaboradas en el quinto capítulo, las instituciones en este contexto de globalización, y desde su rol de reproductoras de compromisos modernos desde el cual han sido conformadas, asumen y fortalecen la praxis no-ambiental. Desde argumentaciones burocráticas, apelaciones a principios que se asumen como universales, preconceptos situados más en el plano de las acciones que en el de las reflexiones, constituyen a los otros en esos inapropiables harawaianos. En definitiva instituyen niveles de reconocimiento y consolidan diferencias.

Cabe destacar las permanentes trabas por avanzar desde el nivel reclamativo hacia el nivel de prácticas. Podría pensarse que la costumbre atenta contra el cambio. Aún cuando se comparta y explicite la importancia del cuidado por el entorno, o el bienestar

trayectoria. 
ambiental de la población, las formas de intervención reproducen supuestos de jerarquía.

No se trata con esto de demonizar a las instituciones u olvidar el nivel de potencialidad de las mismas para incorporar cambios valorativos reclamados por movimientos de reivindicación social. ${ }^{73}$ Entiendo a las instituciones como susceptibles de incorporar progresivamente cambios, pero en la medida que las personas que las forman admitan como parte fundamental de sus tareas, la revisión y modificación de los problemas de reconocimiento de los otros ajenos como pares a respetar y con los cuales establecer vínculos que trasciendan lo instrumental.

Aquí retomo la escueta reflexión del segundo capítulo en torno a dominio o hegemonía, en el sentido de asumir como sobre determinantes las esferas de poder hegemónico, en oposición a reparar en los actores que desde su cotidianeidad edifican instancias de resistencia. Actores que, como recuerda García Canclini (1984) en torno a las lecturas clásicas, se han presentado como pertenecientes a esferas sociales susceptibles de ser diferenciadas en términos de clase. En mi búsqueda de salida de las dualidades y oposiciones considero que la revisión de los modos de establecer dominio está lejos de ocultar la permanente emergencia de agentes de resistencia y cambio en todas las clases y actividades. A veces ni siquiera como parte de actitudes contestatarias, tan sólo por permitirse reflexiones que desde los límites de lo permitido habiliten el diálogo con factores que se suponen intrínsecamente ajenos.

En este contexto de globalización el carácter de esos otros ajenos es un tema en sí mismo. Donna Haraway llama la atención sobre estos nuevos inapropiables, proponiendo un nuevo conocimiento científico tecnológico que tome como referencia las necesidades políticas de estos nuevos sujetos. "De esta manera implementa lo que entiende por conocimiento adecuado, es decir, situado en forma responsable en orden al autoesclarecimiento de estas subjetividades emergentes" (Amorós 2008, 90). Este trabajo ha avanzado en una línea similar.

Puede pensarse que las dificultades para incorporar a los agentes de Haraway es que se establecen en las interfaces de las categorías reconocidas como excluyentes por la tradición occidental. Interfaces que involucran a la tecnología, porque las máquinas ya

\footnotetext{
${ }^{73}$ Un punto que rescata Celia Amorós (2008)
} 
no se pueden considerar trabajo muerto como las representaba Marx, en la medida en que son parte de las relaciones sociales (Latour 1990). Ahora bien, acuerdo con la crítica hacia Bruno Latour en que ese colectivo desde el cual se edifican las relaciones no puede restringirse a los cientificos y sus maquinas (Haraway 1999, Strum 1987). Haraway (1999) hace particular referencia a que lo colectivo es siempre un artefacto, y en este colectivo involucra su noción de naturaleza. Siguiendo a la norteamericana entiendo que estos colectivos son siempre sociales, no en un sentido que retorna a un reduccionismo antropocéntrico, sino en la medida en que están formados por agentes humanos y no humanos, donde las máquinas y los animales son referentes ineludibles. Pero no se trata sólo de seres individuales susceptibles de ser encerrados en una categoría fija, sino que debe tenerse en consideración las interfaces entre los mismos, los vínculos que se establecen en tanto relaciones también deben ser considerados. ${ }^{74}$ En este punto se constituye un conjunto de seres que habitan el mundo que, desde posturas complementarias, reclamaban Holland Cunz y Plumwood. Un lugar donde los animalesno-humanos (o los otros humanos diferentes) pierdan su estatus de objeto, esto es, la reducción a cosa a los que los ha sometido la filosofía y la práctica occidental, o como Barbara Noske plantea "mundos, cuya alteridad no debe ser desencantada ni disminuida a nuestra magnitud sino respetada" (Noske 1989, XI).

A lo largo de las páginas precedentes, he buscado indagar en las trabas de reconocimiento, no sólo en cuanto a los agentes involucrados sino, y sobre todo, a la luz de una disciplina que contiene herramientas desde las cuales percibe la complejidad involucrada pero que, por los recortes asumidos en la edificación del conocimiento científico, lo asume como ajeno a su horizonte de temas, a pesar de ser atravesada permanentemente por ese mundo extracientifico que ni se reduce ni se escinde de lo reconocido como humano.

Para este recorrido he tomado una disciplina en particular: la ecología, un área de estudios que a pesar de sus notables particularidades, no contiene problemas epistemológicos diferentes a los del resto de las ciencias naturales (Núñez 2008 sin editar). El punto que la constituye como substancialmente relevante para la presente

\footnotetext{
${ }^{74}$ Haraway ha utilizado la idea de coyote, y de los mitos asociados a este animal, como imagen del enredador que obliga a reconocer que las relaciones humanas con la naturaleza deben considerarse como genuinamente sociales y activamente relacionales. (Haraway 2007). Seres que no habitan ni en la naturaleza ni en la cultura, precisamente porque a partir de reconocerlo se pierde la dualidad excluyente entre estos extremos.
} 
reflexión es el lugar y el recorte de problemas que adopta. Como área de conocimiento se encuentra situada en una tensión ineludible, acorralada por las relaciones de los variados inapropiables, que no tienen lugar en las definiciones de la ciencia tal cual está, pero que impactan necesariamente en los dinamismos de estudios de los que pretende dar cuenta.

Es decir, las particularidades de la ecología, e incluso sus desafíos epistemológicos, no resultan tan claros desde una revisión introspectiva, sino que cobran densidad a partir de reparar en las relaciones que, intencionalmente o no, se establecen hacia un mundo que la visión clásica asume como extracientífico. Las actividades de los científicos vuelven a quedar acotadas al contexto de justificación reichenbaciano que tantas críticas ha recibido desde la filosofía de la ciencia. Avanzar sobre las dualidades implica avanzar sobre recortes temáticos, sobre las miradas epistemológicas, ensuciándolas con las demandas políticas de los otros diversos, como señala Haraway.

La permanente referencia a la ecología puso en evidencia el impacto de la desigualdad en el reconocimiento dentro de las producciones científicas. Una desigualdad que opera entonces como invisibilizadora de los otros inapropiables harawaianos o los otros diferentes a secas, de las particularidades disciplinares de la ecología y, en definitiva, de la profunda imbricación entre sociedad y naturaleza, en contra de los presupuestos modernos.

A la luz de estas reflexiones concluyo retomando la reflexión nacida de mis utopías personales, un mundo que valore la vida de los no-humanos naturales (animales, paisajes, etc.) es un mundo socialmente más justo, con racionalidades que no se restrinjan a lo instrumental y avancen hacia lo estético y sensible.

Este puede ser el principio de una alternativa para escapar del fundamento de un mundo jerárquico de dominios y controles, sostenido desde la aceptación acrítica de las vinculaciones negativas como fundamentales en la estructuración de todas las comunidades de organismos vivos, sean o no humanos. Se puede avanzar en esta línea pensando que no existe algo así como una esencia humana, el constituirnos en tanto humanos puede pensarse como el acuerdo social primero sobre el cual se edifica la sociabilidad. El Yo emerge del particular recorte del Nosotros que se constituya en un determinado espacio geográfico-temporal. Un Nosotros que lejos de definirse en 
oposición, resulta susceptible de constituirse en relación, con lugar a un diferente no por ello ajeno. ${ }^{75}$

La cristalización de las desigualdades en esta propuesta se diluye en la medida en que se asienten formas de reconocimiento no peyorativas del otro. La fuerza del determinismo del dominio se pierde al dejar de pensarse como único destino inevitable. De la mano de pensadoras como Plumwood y Holland Cunz abandono la idea de una esencia humana, y mucho más de una esencia humana violenta y dominante. Este es el permiso fundamental para avanzar en la idea de nuevas vinculaciones.

Se trata de diseñar prácticas que permitan alejarnos de las diferencias desde las cuales se ha edificado la idea restringida de lo-humano a partir de consolidar diálogos entre diferentes sectores, es un mundo sin jerarquías asumidas como naturales, determinantes o trascendentes. En este contexto ideal, se trata de conformar la elaboración del conocimiento en modos que contemplen las vinculaciones en términos de respeto y reconocimiento. Es decir que dejen de asumirse como parte exclusiva de un sector privilegiado, sino que sea permeable a la incorporación de las experiencias, al ejercicio de observación y reflexión proveniente desde las más variadas perspectivas.

Recuerdo en este punto un debate anclado en los modos de plantear la estadística en ecología. Esta disciplina, tan ligada a la búsqueda de patrones y a la matematización de los términos, fue el marco en el cual desde diversas miradas estadísticas se comenzó a discutir el concepto de evidencia por un problema irresuelto: la estadística clásica (frecuentista) no permitía hacer proyecciones a futuros sobre el comportamiento de sistemas complejos (Taper y Lele 2004). Entre las alternativas propuestas se encontraban reflexiones surgidas de la estadística bayesiana. ${ }^{76}$ Desde las mismas se incorpora la medición de las creencias previas o los saberes expertos no científicos desde los cuales se pueden organizar las observaciones y realizar las previsiones sin

\footnotetext{
${ }^{75}$ Carolyn Merchant llamó la atención sobre el modo de considerar la actividad minera. En tanto la tierra estuvo ligada a la noción de tierra-madre la minería se establecía con límites, para no herir. En la medida que la metáfora se fue permutando a la de tierra-mujer-a-dominar las minas se profundizaron y el desbaste ambiental de la actividad fue tomado como marca del progreso. Este es un ejemplo de tomar o no como ajeno a un contexto.

${ }^{76} \mathrm{La}$ estadística bayesiana se diferencia de la frecuentista, fundamentalmente, en que no considera que las vinculaciones entre variables puedan deducirse de la observación puntual de cada variable, porque en medio existen vinculaciones ineludibles que no pueden asumirse a propio como inexistentes. Desde el bayesianismo se propone que se observa al mundo desde un sistema de creencias y, a partir de lo observado, se modifica ese sistema de creencias. En este sentido avanza en la idea de ponderar las creencias previas, para incluirlas en las ecuaciones que llevaran a elaborar las predicciones que se le demandan.
} 
quebrar necesariamente con las metodologías previstas al interior de la propia disciplina. ${ }^{77}$ Con esta digresión busco llamar la atención sobre herramientas presentes que pueden, en la medida en que se considere pertinente, facilitar el reconocimiento de una complejidad, inaccesible desde las taxonomías vigentes. Las permanentes referencias hacia lo empírico tuvieron este sentido, se trata de mostrar que existen bases materiales para pensar la utopía, no sólo a partir de reconocer los híbridos de Haraway, sino a partir de retomar el nivel de las experiencias para repensar la praxis.

Es en esta línea desde la cual la noción de praxis ambiental propuesta cobra sentido, sobre todo por el compromiso con el cambio que lleva implícita. Se trata de tener en el horizonte de las prácticas el tema del reconocimiento y, sobre todo, de admitir la importancia de renovar el espacio vivido en una vía diferente a las modificaciones que se ha establecido desde la tradición occidental. No es un reclamo a movilizaciones, revoluciones o destrucciones institucionales, sino a llamar la atención sobre la importancia por incorporar el compromiso de la intervención, desde la edificación del saber, por una parte, y desde la edificación de relaciones sociales por otra. Se trata de buscar, desde las especificidades locales, las formas posibles de incorporación de los otros. Una incorporación que posiblemente no descanse exclusivamente en el reconocimiento de las particularidades sino en el diseño de estrategias que permitan a ese actual otro incidir activamente en la construcción del conocimiento que pretende dar cuenta de él.

Acuerdo con Plumwood en que los propios vínculos humanos deben ser indagados si se busca avanzar en una nueva relación con la naturaleza. Desde las reflexiones de la filósofa australiana los permisos para investir lo humano con un carácter más lábil y contextual parecen abrirse. El instrumentalismo proyectado sobre la propia especie, con sus raíces paternalistas y sus desigualdades cristalizadas, es fundamento de gran parte de las formas opresivas que se ha revisado en este trabajo. Vuelvo a la idea que un mundo que valore la vida de los no-humanos naturales (animales, paisajes, etc.) en términos de respeto a la diferencia es un mundo socialmente más justo, con lugar ineludible para la propia diversidad de aquello que se reconozca como humano. Donde las jerarquías que habiliten opresiones puedan ser revisadas y desmontadas sin necesidad de luchas, heridas y víctimas.

\footnotetext{
${ }^{77}$ Debo indicar que, aún cuando esta metodología se considera legítima, es escasamente utilizada.
} 
No se trata de asumir un orden (o desorden) como favorable a cierta tendencia, sino de retornar a la complejidad de lo local, al espacio donde las prácticas se llenan de sentido social y desde esta revisión atomizada, empezar a construir los puentes entre lo que he denominado Ecología y Praxis Ambiental. 
Bibliografia Temática 


\section{Biología: Evolución y Ecología}

Abril, A. (2004). "Microbiología y ecología: una integración todavía pendiente" En Bender, B. Estivariz, C. Scoon, C. y Theiler, M (org) La ecología en tiempos de cambio. Segunda reunión binacional de Ecología. Mendoza. 31 de octubre al 5 de noviembre del 2004.

Andrewartha, H. G. y Birch L.C. (1954). The Distribution and Abundance of Animals. The University of Chicago Press, Chicago, Illinois.

Barbour, M.G., Burk, J.H., Pitts, W.D., Gilliam, F.S. y Schwartz, M.W. (1999). Terrestrial plant ecology. Benjamin/Cummings, Menlo Park. Canadá.

Bazzaz, F.A. (1996). Plants in changing environments: linking physiological, population, and community ecology. Cambridg. Cambridge University Press.

Begon, M., Harper, J.L., Townsend, C.R. (1990). Ecology: Individuals, Populations, and Communities, 2nd Edition, Cambridge University Press, New York.

Bertness, M.D. y Callaway, R. (1994). "Positive interactions in communities". Trends Ecol. Evol. 9. pp. $191-193$.

Blackburn, T.M. y Gaston, K.J. (2002). "Macroecology is distinct from biogeography". Nature 418. pp. 723

Bookchin, Murray (1985). Die Ökologie der freiheit. Wir brauchen keine Hierarchien. Beltz. einheim/Basilea.

Brown, J.H. (1991). "Methodological Advances. New Appoaches and Methods in Ecology” Real, L; Brown, J (eds) Foundations of Ecology. Classic Papers with Commentaries. University of Chicago Press. Chicago

Brown, J.H. (1999). “Macroecology: progress and prospect”. Oikos 87. pp. 3-14.

Brown, J.H. y Maurer, B.A. (1989). "Macroecology: the division of food and space among continents". Science 243. pp. 1145-1150.

Brown, J.H., Gillooly J.F., West, G.B. y Savage, V.M. (2003). "The next step in macroecology: from general empirical patterns to universal ecological laws". En: Blackburn, T.M. and Gaston, K.J. (eds.), Macroecology: Concepts and Consequences: The 43rd Symposium of the British Ecological Society, Held at the University of Birmingham, Published by the British Ecological Society. 
Brown, J.H., Gillooly, J.F., Allen, A.P., Savage, V.M. y West, G.B. (2004a). “Toward a metabolic theory of ecology". Ecology 85. pp. 1771-1789.

Brown, J.H., Gillooly, J.F., Allen, A.P., Savage, V.M., y West, G.B. (2004b). "Response to forum commentary on "Toward a metabolic theory of ecology". Ecology 85. pp. 1818-1821.

Bruno J.F., Stachowicz J.J. y Bertness M.D. (2003). "Inclusion of facilitation into ecological theory". Trends in Ecology and Evolution 18. pp.119-125

Clements, F. T. (1905). Research Methods in Ecology. Lincoln. Estados Unidos.

Clements, F.E. (1916). Plant Succession. Washington.

Clements, F.E. (1936). "Nature and structure of the climax". The journal of ecology 24. pp. $252-284$

Clements, F.E. y Shelford, V.E. (1939). Bio-ecology. John Wiley \& Sons, New York

Connor, EF y Simberloff, D. (1979). "The assembly of species communities: chance or competition?”. Ecology 60(6). Pp.1132-1140.

Cowles, H.C. (1899). "The ecological relations of the vegetation on the sand dunes of Lake Michigan”, Botanical Gazette 27. Chicago

Crick, F. (1966). Of Molecules and Men. University of Washington Press. Seattle.

Cushing, R. (1977). Marine ecology and fisheries. Cambride University Perss. Cambridge.

Drake, J.A., Zimmermann, C.R; Purucker, T, y Rojo C. (1999). "On the Nature of the Assembly Trajectory", en E. Wieher and P.Keddy (eds), Ecological Assembly Rules, Cambridge University Press, Cambridge.

Elton, C. (1946). "Competition and the structure of ecological communities". Journal of Animal Ecology 15. pp. 54-68.

Elton, C.S. (1927). Animal Ecology. Sidgwick and Jackson, London

Elton. C.S. (1958). Ecology of Invasions by Animals and Plants. Univ of Chicago Press. Chicago.

Forbes S.A. (1887). "The lake as microcosm". Bull. of the Scientific Association (Peoria, IL). Pp. 77-87 
Forel F.A. (1892). Le Léman. Monographie Limnologique. F. Rouge Lausanne.

Gause, G. F. (1935). Vérifications expérimentales de la thérie mathématique de la lutte pour la vie. Hermann. París.

Gleason, H.A. (1926). The individualistic Concept of the Plan Association. Bulletin of the Torrey Botanical Club 53. pp.7-26

Gotelli, N. Y Graves, G. (1996). Null models in ecology. Smithsonian Institution Press. USA

Gotelli, N.; Buckley, N. y Wiens, J. (1997). "Co-occurrence of Australian land birds: Diamond's assembly rules revisited". Oikos 80. pp. 311-324

Grant, P.R. y Abbot, I (1982). "Interespecific competition, island biogeography and null hipotheses". Evolution 34. pp. $332-341$

Grinnell, J. (1917). "The niche relationship of the California thrasher". Auk 34. pp. $427-433$

Hacker, S.D. y Gaines, S.D. (1997). "Some implications of direct positive interactions for community species diversity". Ecology 78. pp. 1990 - 2003

Hanski, I. (1999). Metapopulation ecology. Oxford University Press, Oxford, UK.

Hanski, I. y Gilpin, M. E. (1997). Metapopulation biology. Ecology, genetics and evolution. Academic Press, San Diego (California), USA.

Holling, C.S. (1959). "The components of Predation as Revealed by Study of Small Mammal Predation on the European Pine Sawfly". The canadian etnomologist 91. pp. $293-320$.

Hutchinson, G.E. (1957). “Concluding Remarks”. Quant. Biol. 22. pp. 415 - 427

Hutchinson, G.E. (1959). "Homage to Santa Rosalía; or, Why Are There So Many Kinds of Animals?". The American Naturalist 93. pp.145-159

Jokela, J. y Haukioja, E.(2000). "Evolution of Strategies to Stay in the Game", Biology \& Philosophy 15. pp. 177-196.

Krebs, C.J. (2001). Ecology: The Experimental Analysis of Distribution and Abundance, 5th Ed., Benjamin Cummings, San Francisco. 
Levins, R. (1968). Evolution in Changing Environments, Princeton University Press, Princeton.

Lindeman, R.L. (1942). “The trophic-dynamic aspect of ecology”. Ecology 23. pp. 399-418.

MacArthur R.H y Wilson E.O. (1967). The Theory of Island Biogeography. Princeton UP, Princeton.

MacArthur, R.H. (1971). Geographical Ecology: Patterns in the Distribution of Species. Princeton University press. Princeton

MacArthur,R.H. (1958). "Population Ecology of some Warblers of Northeastern Coniferous Forests". Ecology 39. pp. 599-619.

Margalef, R. (1977). Ecología. Omega. Barcelona.

Marquet, P.A. (2002). "The search for general principles in ecology". Nature 418. pp. 723.

Marquet, P.A., Labra, F.A. y Maurer, B.A. (2004). "Metabolic ecology: linking individuals to ecosystems". Ecology 85. pp. 1794-1796.

Marshall J.A. (1960). "Annual periodicity in the migration and reproduction of birds". Quant Biol. 25. pp. 499-505.

Maurer, B. A. (2000). "Macroecology and consilience". Global Ecology and Biogeography 9. pp. 275-280.

Maurer, B.A. (1999). Untangling ecological complexity. The macroscopic perspective. The University of Chicago Press, Chicago.

McNaughton, S.J. y Wolf, L.L (1984). Ecología General. Ed. Omega. Barcelona

Mobius, K. (1892). "Morphologie der haarartigen Organe bei den Algen”. Biologisches Zentralblatt 12. pp. 71-87.

Odum, E.P. (1975). Ecology. Holt Rinehart and Winston. New York.

Paine, R.T. (1966). "Food web complexity and species diversity". The American Naturalist 100. pp. 65-75.

Rapoport, E. (1975). Aerografia. Estrategias Geográficas de las Especies, Fondo de Cultura Económica, México. 
Richardson, D.M. (2000). "Plant invasions - The role of mutualisms". Biol. Rev. 75. pp. $65-93$.

Simberloff, D y Van Holle, B. (1999). "Positive interactions of nonindigenous species: invasional meltdown?”. Biol. Inv. 1. pp. 21-32

Simberloff, D. (1970). “Taxonomic diversity of island biotas”. Evolution 24(1). Pp. $24-47$

Simberloff, D. (1978). "Using Island Biogeographic Distributions to Determine If Colonization Is Stochastic”. American Naturalist 112. pp.713-726.

Simberloff, D. (1982). "Replay". en Saarinen,E. (Ed) Conceptual issues in ecology. D. Reidel Publishing Company, Dordrecht, Holland.

Simberloff, D. y Boecklen, W. (1981). "Santa Rosalía reconsidered: siza, ratios and competition". Evolucion 35. pp. 1206 - 1228.

Von Liebig, J., (1840-44). Traité de Chimie organique, 3 vols., Fortin, Paris

Whittaker, R.H. (1953). "A consideration of climax theory: the climax as a population and pattern". Ecol. Monogr. 23.pp. 41-78

Whittaker, R.H. (1960). "Vegetation of the Siskiyou Mountains, Oregon and California”. Ecol. Monogr. 30. pp. 279-338.

Wiens, J.A. (1989). The ecology of bird communities. Cambridge Univ. Press.

Williams, C.B. (1947). "The Generic Relations of Species in Small Ecological Communities”. Journal of Animal Ecology 16. pp. 11-18

Williams, C.B. (1964). Patterns in the balance of nature: and related problems in quantitative ecology. London: Academic Press.London

\section{Filosofía e historia de la biología}

Alberti, S.J.M.M. (2001) "Amateurs and Professionals in One County: Biology and Natural History in Late Victorian Yorkshire”. Journal of the History of Biology 34. pp. $115-147$.

Anderson, W. (1996). "Immunities of Empire: Race, Disease, and the New Tropical Medicine, 1900-1920" en Bulletin of the history of medicine. Vol $70 \mathrm{~N}^{\circ} 1$. pp. 94-118 
Armesto, J.J.; Troncoso, A.; Díaz, M.F.; Carmona, M. (2004). "Ciencia fuera de la academia: Biodiversidad, conservación y la interfase investigación - acción”. En Bender, B. Estivariz, C. Scoon, C. y Theiler, M (org) La ecología en tiempos de cambio. Segunda reunión binacional de Ecología. Mendoza. 31 de octubre al 5 de noviembre del 2004.

Caponi, G. (2004). "El reduccionismo en la biología contemporánea" Signos Filosóficos vol VI No 12 . pp 33-62

Casares Serrano, A. (2005). "De la ecología a la geofísica. Imágenes y metáforas de una naturaleza cambiante". A parte Rei. Revista de Filosofía 38. Publicación electrónica. http://serbal.pntic.mec.es/AParteRei/.

Cecchi, M.C., Guerrero-Bosagna, C. y Mpodozis, J. (2001). "El ¿delito? de Aristóteles” Revista Chilena de Historia Natural 74. pp. 507-514.

Cupani, G. (2006). "Retorno a Limoges. La adaptación en Lamark". Asclepio. Revista de Historia de la medicina y la biología. Vol LVIII. No 1. pp. 7-42

Davis, M; Perglb, J.; Truscott, A.; Kollmann, J, BAkker, J.; Domenech, R.; Prach, K.; Prieur - Richard, A.; Veeneklaas, A.; Pysek, P.; del Moral, R; Hobbs, R.; Collins, S.; Picket, S.; Reich, P. (2005). "Vegetation change: a reunifying concept in plant ecology". Perspectives in Plant Ecology, Evolution and Systematics 7. pp. 69-76

de Laplante, K. (2004). "Toward a more expansive conception of ecological science" Biology and Philosophy 19 No2. pp. $263-281$

Dear, P. (1995). Discipline \& Experience. The Mathematical Way in the Scientific Revolution. The University of Chicago Press. Chicago.

Deléage, J. (1993). Historia de la ecología. Nordan Comunidad. Uruguay

Descola, P. y Palsson, G (coord.) (2001). Naturaleza y Sociedad. Perspectivas antropológicas. Siglo XXI. México

Diamond, J.M. (1975). “Assembly of species communities”. en Cody, M. y Diamond, J. (eds) (1975): Ecology and evolution of communities. Harvard University Press. Cambridge. 
Drayton, Richard (2000). Government Science, Imperial Britain and the Improvement of the world. Yale University Press. New Haven.

Farji-Brenner, A. (2003). "Uso correcto, parcial e incorrecto de los términos "hipótesis" y "predicciones" en ecología". Ecología Austral 13. pp. 223-227

Frezzatti, W.A. (2003). "Haeckel e Nietzsche: aspectos da crítica ao mecanicismo no século XIX”. Scientelae Studia Vol.1. N4. pp. 435 - 461.

Gallopin, G. (1981a). "Planning methods and the human environment”. Socioeconomics studies 4.

Gallopin, G. (1981b). “The abstract concept of environment”. Int. J. General System 7.

Gallopin, G. (1982). Tecnología y sistemas ecológicos. UCORED-CIFCA. Argentina

Gallopin, G. (1983). La ecología y sus relaciones con otras disciplinas. CIFCA. México

Goodman, D. (2004). "Taking the Prior Seriously: Bayesian Analysis without Subyective probability" en Taper, M; Lele, S. The nature of scientific evidence. Statistical, philosophical, and empirical considerations. The University of Chicago Press. USA

Gotelli, N. (2001). "Research frontiers in null model analysis". Global Ecology \& Biogeography 10. pp. 337-343

Graham, M.H. y Dayton, P.K. (2002). "On the evolution of ecological ideas: paradigms and scientific progress". Ecology 83.pp. 1481 - 1489

Guevara-Chumacero, L.; López-Wilchis, R. y Sánchez-Cordero, V. (2001). “105 años de investigación mastozoológica en México (1890 - 1995): una revisión de sus enfoques y tendencias". Acta Zool. Mexicana (n.s.) 83. pp. 35-72.

Gutiérrez, D. (2002). "Metapoblaciones: un pilar básico en biología de conservación”. Ecosistemas 2002/3

Guyénot, E. (1956). Las ciencias de la vida en los siglos XVII y XVIII. El concepto de evolución. Unión tipográfica Editorial Hispano Americana. México.

Hagen, J.B. (1989). "Research perspectives and the anomalous status of modern ecology”. Biology and Philosophy 4. pp. 433-455.

Haila, Y. y Levins, R.(1992). Humanity and Nature. Ecology, Science and Society, Pluto Press, London. 
Haila, Y. y Taylor, P. (2001). The Philosophical Dullness of Classical Ecology, and a Levinsian Alternative. Biology and Philosophy 16. pp. 93 - 102

Hengeveld, R. (1992). "Right and wrong in ecological explanation". Journal of Biogeography 19. pp. $345-347$.

Holling, C.S. (1998). “Two Cultures of Ecology" Conservation Ecology [on line] 2(2):4. pág. Disponible en URL: http://www.conecol.org/vol2/iss2/art4.

Hutchinson, G.E. (1979). El teatro ecológico y el drama evolutivo. Blume. España Jaksic, F. (2001). Ecología de comunidades, Universidad Católica de Chile, Santiago.

Keller, D.R. y Golley, F.B. (eds) (2000). The Philosophy of Ecology: form Science to Synthesis. Georgia University Press. USA.

Kingsland, S.E. (1991). "Defining Ecology as a Science”. En Real, L y Brown, J (eds) Foundations of Ecology. Classic Papers with Commentaries. University of Chicago Press. Chicago

Kingsolver, J.G. y Paine R. (1991). “Theses, Antitheses, and Syntheses Conversational Biology and Ecological Debate" En Real, L y Brown, J (eds) Foundations of Ecology. Classic Papers with Commentaries. University of Chicago Press. Chicago.

Kreimer, P (1997 a). L'universel et le contexte dans la recherche scientifique. Etude comparative des laboratoires en biologie moléculaire. CNAM-STS. París

Lamark, Jean Baptiste de Monet (1986). filosofía zoológica alfa fulla. Barcelona. Trad. Jaime Serrasolsas.

Leibold, M. y Gedes, P. (2005). "El concepto de nicho en las metacomunidades" Ecología Austral 15. pp. 117-129

Lele, S. (2004). "Elicit Data, Not Prior: On Using Expert Opinion in Ecological Studies" en Taper, M; Lele, S. The nature of scientific evidence. Statistical, philosophical, and empirical considerations. The University of Chicago Press. USA

Levins, R y Lewontin R. (1982). "Dialectics and reductionism in ecology". Pp 107 138 en Saarinen,E. (Ed) Conceptual issues in ecology. D. Reidel Publishing Company, Dordrecht, Holland. 
Levins, R. (1973). “The Limits of Complexity”, en H. Pattee (ed.), Hierarchy Theory. The Challenge of Complex Systems, George Braziller, New York.

Lewontin R. C. (1992). Biology as ideology. The doctrine of DNA. HarperPerennial. EEUU.

Lortie, C.J ; Brooker, R.W.; Choler, P.; Kikvidze, Z.; Michalet, R.; Pugnaire, F.y Callaway, R. (2004). "Rethinking plant community theory". Oikos 107 (2). pp. $433-438$

MacLeod, Roy (ed) (2001). Nature and Empire Science and the colonial Enterprise. University of Chicago Press. Chicago.

Mahner, M.y Bunge, M. (1997). Foundations of Biophilosophy. Springer. Nueva York.

Makinistan, A.A. (2004). Desarrollo de las ideas y teorías evolucionistas. Prensa Universitaria de Zaragoza. España.

Margalef, R. (1980). La biosfera, entre la termodinámica y el juego. Omega. Barcelona.

Marone L y González del Solar, R (2000). "Homenaje a Mario Bunge, o por qué las preguntas en Ecología deberían comenzar con por qué”. en Denegri GM y Martínez G (eds.) Tópicos actuales en Filosofía de la ciencia: Homenaje a Mario Bunge en su 80 aniversario. Ed. Martín. Mar del Plata

Marone L, Milesi F, González del Solar R, Mezquida ET, Lopez de Casenave J; V. Cueto (2002). "La teoría de evolución por selección natural como premisa de la investigación ecológica”, Interciencia 27. pp. 137-142

Mayor, J (1958). "Plant Ecology as a Branch of Botany”. Ecology 39 (2). Pp. 352 - 363

Mayr, E. (1961). “Cause and effect in biology”, Science, vol. 134, pp. 1501-1506.

Mayr, E.(1988). Toward a new philosophy of biology. Observations of an evolucionist, Harvard, Estados Unidos.

McIntosh, R.P. (1982). "The background and some current problems of theoretical ecology”. Pp.1 - 61. En Saarinen, E. (Ed) Concetual issues in ecology. D. Reídle Publishing Company, Dordrecht, Holanda.

Monod, J. (1974). Chance and Necessity: an essay on the natural philosophy of modern biology. Wainhouse. Londres. 
Nieto, M. (2002). Remedios para el Imperio, historia natural y la apropiación del nuevo mundo. ICANH. Bogotá

Núñez, O. (1990). “Lamark: fundador de la teoría de la evolución” Ciencia Hoy Nº vol.2 pp. 54-57

Núñez, P. (2005). “¿qué significa descubrir en ecología? Una reflexión a partir de lecturas de Peirce" en Faas, H., Saal, A., Velasco, M. (eds.) Epistemología e Historia de la Ciencia. Selección de trabajos de la XV Jornadas. Universidad Nacional de Córdoba. Argentina

Núñez, P. (2005). “Historia de la ecología. Surgimiento y Desarrollo”. Mesa Temática $\mathrm{N}^{\mathrm{o}}$ 30: "Instituciones, saberes y práctica científico-tecnológica en sus contextos histórico-culturales, Europa y América Latina, siglos XVIII y XX" X Jornadas Interescuelas - Departamentos de Historia. Rosario, 20 al 23 de septiembre.

Núñez, P. (2007). "La ecología. Entre la ciencia ideal y la práctica concreta” en Pablo Lorenzano y Hernán Miguel (eds.) Filosofía e Historia de la Ciencia en el Cono Sur, Volumen II. Buenos Aires: Prometeo Libros-AFHIC.

Núñez, P. (2008). "Entre la Ciencia “ideal” y la "real” El problema de la producción de conocimiento en el laboratorio de Ecología Ecotono. Tesis de Maestría en Filosofía e Historia de las ciencias. Universidad Nacional del Comahue. Inédito.

Núñez, P. y Núñez, C. (2006). "El concepto de sucesión vegetal”. en VIII Coloquio Internacional Bariloche de Filosofía. 22 al 24 de septiembre. San Carlos de Bariloche. Inédito

Núñez, P. y Núñez, M. (2007). "The importance of controversies in the epistemic progress of ecology" Interciencia vol. $32 \mathrm{~N}^{\mathrm{o}} 12$. pp. 804-811

Odum, E.P. (1953). Fundamentals of ecology. Saunders, Philadelphia

Odum, E.P. (1969). “The Strategy of Ecosystem Development”. Science 164. pp. $262-70$

Osorio, C.G. (2007). "Sobre agentes infecciosos, zoofitos, animálculos e infusorios”. Revista Chilena de Infectología 24 (2). Pp. 171-174

Peters, R.H. (1991). A critic for ecology. Cambridge, MA. Cambridge University Press

Rostand, J. (1985). Introducción a la historia de la biología. Barcelona, Planeta. 
Roughgarden, J. R. M. May, y Levin S.A. (Eds.) (1980). Perspectives in Ecological Theory, Princeton University Press. Princeton.

Ruse, M. (1990). La filosofía de la biología. Alianza Universidad. Madrid

Sagoff, M. (1999). "What's wrong with exotic species?" Philosophy \& Public Policy. 19(4). Pp. 16-23

Sagoff, M. (2003). "The plaza and the pendulum: Two concepts of ecological science". Biology and Philosophy 18. pp. 529-552.

Senet, J. (1971). “Introducción” en Lamark Filosofía zoológica. Mateu. Madrid.

Simberloff, D. (1980). "A succession of paradigms in ecology: esentialism to materialism and probabilism". Synthèse 42. pp. 3-39.

Sloep, P. (1993). “Methodology Revitalized?”. The British Journal for the Philosophy of Science. Vol 44. No2. pp. 231 - 249

Tansley, A.G. (1935). "The Use and Abuse of Vegetal Concepts and Terms". Ecology 16. pp. $284-307$

Taper, M; Lele, S. (2004). The nature of scientific evidence. Statistical, philosophical, and empirical considerations. The University of Chicago Press. USA

Taylor, P. (2000). "Socio-Ecological Webs and Sites of Sociality: Levins' Strategy of Model-Building Revisited”, Biology \& Philosophy 15, pp. 197-210.

Turchin, P. (2001). “Does population ecology have general laws?” Oikos 94. pp.17-26.

Wilson, J.B. Agnew, A.D. y Sykes, M.T. (2004). "Ecology or mythology? Are Whittaker's "gradient analysis" curves reliable evidence of continuity in vegetation?". Preslia, Praha, 76. pp. 245-253

Winsor, M. (1991). Reading the Shape of Nature:Comparative Zoology at the Agassiz Museum. University of Chicago Press. Chicago

\section{Filosofía e historia de las ciencias}

Albornoz, M., Kreimer, P. y Glavich, E. (comps), (1996). Ciencia y sociedad en América Latina, Universidad Nacional de Quilmes, Buenos Aires.

Barnes, B. (1957). Sobre Ciencia, Madrid, Labor.

Bloor, David (1976). Conocimiento e imaginario social, Barcelona, Gedisa. 
Castells, M. (1999). La era de la información, economía, sociedad y cultura Fin de milenio. Alianza, Marid.

Crane D. (1972). Invisible Colleges. Diffusion of knowledge in scientific communities. The Chicago University Press. Chicago

Funtowicz, S. Y Ravetz, J. (1993). Epistemología política, ciencia con la gente. Centro Editor de América Latina, Argentina.

Giere, R. (1988). Explaning Science. A Cognitive Aprroach, Chicago, University of Chicago Press.

Giere, R. (1999). Science Without Laws, Chicago, University of Chicago press

Hanson, N (1958). Patterns of Discovery. Cambridge University Press. Cambridge.

Hayles, N.K. (1990). Choas Bound: Orderly Disorder in Contemporary Literature and Science. líhaca, Cornelí University Press, Pp. 265-295.

Hull, D. (1988). Science as a Process, Chicago, University of Chicago Press.

Kitcher, P. (1992): “The Naturalists Return”, Philosophical Review 101. pp. 53-114.

Kitcher, P. (1993). The Advancement of Science. Science without Legend, Objectivity without Illusions, Oxford, Oxford University Press.

Kitcher, P. (2001). Science, truth and democracy. Oxford University Press, New York.

Kreimer, P. (1997 b). "Scientific Migrations and Scientific Community in Argentina: Migration of Scientists and Scientific Community in Argentina". Science, Techhnology and Society $\mathrm{N}^{\mathrm{o}}$ 2, vol 2.

Kreimer, P. (1998). “¿Una modernidad periférica? La investigación científica entre el universalismo y el contexto" Documento de trabajo. Grupo Redes. Instituto de Estudios Sociales de la Ciencia y la Tecnología. Universidad Nacional de Quilmes. Buenos Aires.

Kreimer, P. (2000). Ciencia y Periferia: una lectura sociológica, en Monserrat, M. (comp.): La ciencia en la Argentina entre siglos. Textos, contextos e instituciones. Cuadernos Argentinos Manantial. Bs. As.

Kreimer, P. (2001). ¿Una modernidad periférica?. La investigación científica, entre el universalismo y el contexto, en Obregón, D. (ed.): Culturas científicas y saberes locales. CES/ U.N. de Colombia, Bogotá. 
Kuhn, T. (1999). [1962]. La estructura de las revoluciones cientificas, México: FCE.

Lakatos, I. (1993). La metodología de los Programas de investigación científica.

Alianza. Madrid.

Latour, B. (2004). Politics of nature. How to bring the sciences into democracy. Harvard -University Press. Londres

Latour, B. (1990). "Postmodern? No simply Amodern! Steps toward an Antropology of science”. Studies in the History of Philosophy and Science. 21(1). Pp. 145-171.

Latour, B. y Woolgar, S. (1995). La vida en el laboratorio. La construcción de los hechos cientificos. Alianza. Madrid.

Laudan, L. (1981). “A Confutation of Convergent Realism”, Philosophy of Science 48. pp. 19-48.

Longino, H. (1990). Science as Social Knowledge. Value and Objectivity in Scientific Inquiry, Princeton University Press, Princeton, N.J.

Menna, S. (2004). La nueva metodología de la ciencia. N.R. Hanson y la lógica de la plausibilidad. Universitas. Editoria Científica Universitaria de Córdoba. Argentina

Navarro Floria, P. (comp.) (2004). Patagonia. Ciencia y Conquista. La mirada de la primera comunidad cientifica argentina. Universidad Nacional del Comahue. Argentina.

Nudler, O (1999). "Filosofía de la ciencia: ¿empresa descriptiva o prescriptiva?” en Sota, E; L.Urtubey (ed.) Epistemología e Historia de la Ciencia. Selección de trabajos de las IX Jornadas. Vol.5 N5

Núñez, M y Núñez, P. (2005). “Controversias en ecología: la competencia, de la certeza a la pregunta" Ecol. Austral 15. pp. 229-238

Núñez, P. (2007). 'Relaciones entre 'metodologías ideales' y 'prácticas concretas'. Un estudio de caso" en Lorenzano P. y Miguel, H. Filosofía e Historia de la Ciencia en el Cono Sur, Vol. II. Prometeo Libros - AFHIC. Argentina.

Peset, J.L. (1983). Ciencia y Marginación. Negros, Locos y Criminales. Crítica. Barcelona.

Popper, K. (1963). Conjetures and refutations. Routledge. Londres. 
Quintero Toro, C. (2006). ¿en qué anda la historia de la ciencia y el imperialismo? Saberes locales, dinámicas coloniales y el papel de Estados Unidos en el siglo XX. Historia Crítica. Bogotá. Pp. 151-172

Reichenbach, H. (1938). Experience and prediction. University of Chicago Press, Chicago.

Strum, S. (1987). Almost Home: A Journey into the Wold of Baboons. Random House. Nueva York.

Wallerstein E. (1997). Differentiation and reconstruction in the Social Sciences [en línea]. Disponible en: http://fbc.binghamton.edu/papers.htm

\section{Teoría ambiental}

Acerbi, M. y Barrenechea, J. (1999). “Análisis de las estrategias frente al derrame de petróleo en Magdalena (Provincia de Buenos Aires, Argentina)". En V Congreso Internacional sobre Desastres. Palacio de las Convenciones. La Habana. Cuba. 7 - 10 de septiembre.

Alimonda, H. (2002). "Introducción: política, utopía, naturaleza" en Héctor Alimonda (Compilador) Ecología política naturaleza, sociedad y utopía. CLACSO. Buenos Aires.

Altvater E. (2006). “¿Existe un Marxismo Ecológico?” en Atilio A. Boron, Javier Amadeo y Sabrina González (compiladores) La Teoría Marxista hoy. Problemas y perspectivas. CLACSO, Buenos Aires.

Altvater, E. (1993). The Future of the Market. An Essay on the Regulation of Money and Nature after the Collapse of 'Actually Existing Socialism' (London/New York: Verso).

Arocena J. (1995). El Desarrollo Local, un desafio contemporáneo. CLAEH Universidad Católica el Uruguay. Ed. Nueva Sociedad. Uruguay.

Arribas Herguedas, F. (2006). "Del valor intrínseco de la Naturaleza". Isegoría 34, pp. 261-275

Attfield, R. (1997). "El ámbito de la moralidad", en José Ma García Gómez-Heras, (coord.): Ética del medio ambiente: problema, perspectivas, historia. Tecnos. Madrid. 
Avellaneda Cusaria, A. (2002). Gestión Ambiental Y Planificación del Desarrollo. El Reloj Verde. Entropía. Globalización. Democracia. Cultura. ECOE Ediciones. Colección Textos Universitarios. Bogotá.

Callicott J.B. (1989). In defense of the Land Ethic: Essays in Evironmental Philosophy. Sunny Press. EEUU.

Callicott, B. (1998). "En busca de una ética ambiental”. En Kwiatkowska, T. Issa, J. (comp.) Los caminos de la ética ambiental. Una antología de textos contemporáneos. Plaza y Valdés. México.

Campillo, A. (2000). "Filosofía y ecología. Documento del curso de actualización científica”. En Moya, E. (coord.) Ciencia, tecnología y sociedad. Sociedad de Filosofía de la Región de Murcia. Departamento de Filosofía, Universidad de Murcia.

Carson, R (1962). Silent Spring. Houghton Mifflin. USA

Casares Serrano, A. (2005). De la ecología a la geofísica. Imágenes y metáforas de una naturaleza cambiante. A parte Rei. Revista de Filosofia 38.

de Laplante, K. (2004). "Toward a more expansive conception of ecological science" Biology and Philosophy 19 N 2.pp. 263 - 281

Descola, P, (2005). Par-delà nature et culture. Gallimard. Paris

Descola, P. y Palsson, G (coord.) (2001) Naturaleza y Sociedad. Perspectivas antropológicas. Siglo XXI. México

Diegues, C.A. (2005). El mito moderno de la naturaleza intocada. Center for Research on Human Population and Wetlands. Brasil

Fox, W. (1984). “Deep Ecology: a New philosophy of our time?” The ecologist 14. pp. 194-200

Funtowicz, S. y Ravetz, J. (1993). Epistemología política, ciencia con la gente, Centro Editor de América Latina. Buenos Aires.

Gonzaga Valencia Hernandez, J. (2007). “Conflictos ambiéntales: Praxis, participación, resistencias ciudadanas y pensamiento ambiental". La laguna 24. pp. 1-7 
Kaul, I.; Conceição, P. Le Goulven, K. y R. Mendoza (2003). Providing Global Public Goods. Managing globalization. UNDP/Oxford University Press. Oxford/New York.

Kwiatkowska, T. Issa, J. (comp.) (1998). Los caminos de la ética ambiental. Una antología de textos contemporáneos. Plaza y Valdés. México.

Latour, B. (2004). Politics of nature. How to bring the sciences into democracy. Harvard -University Press. Londres

Leff, E (1998). Saber Ambiental: Sustentabilidad, racionalidad, complejidad, poder Siglo XXI. México.

Leff, E. (1998). Ecología y capital. Racionalidad ambiental, democracia participativa y desarrollo sustentable. DF/Madrid: Siglo XXI. México.

Leff, E. (2001). Epistemología Ambiental, Cortez Editora, Sao Paulo.

Leopold, A. (1987). [1948]. A Sand County Almanac, and Sketches Here and There, Oxford University Press, New York.

Light,A. y Rolston, H.(eds.) (2003). Environmental. Ethics. An Anthology, Blackwell, Oxford.

Lins Ribeiro, G. (2005). "Poder, redes e ideología en el campo del desarrollo" serie antropología 383.Brasília.

López de la Vieja, T. (2005). "Derechos de los animales, deberes de los humanos" Isegoría 32. pp. 157-174

Malpartida, A. y Lavanderos, L. (1995). Aproximación a la unidad Sociedad_ Naturaleza. Rev. Chilena de Hist. Nat. 68. pp. 419 - 427.

Malpartida, A. y Lavanderos, L. (1998). "Relación sociedad-naturaleza. El ecotomo como unidad". INTERSCIENTIA vol $3 \mathrm{n}^{\mathrm{o}} 1$. Disponible en http://www.uottawa.ca/publications/interscientia/inter.4/ecotmo/ecotoesp.html

Martinez-Alier, J. (1987). Ecological Economics. Energy, Environment and Society Basil Blackwell Publishers. Oxford.

Morello, J. (1984). "La ecología y el medio ambiente. Nociones para políticos y juristas". Ambiente y recursos naturales. Revista de Derecho, Política y Administración vol $1 N^{\circ} 1$. pp. 23-32 
Naess, A. (1986). "El movimiento de ecología profunda: algunos aspectos filosóficos". En Kwiatkwoska e Issa (comp.) Los caminos de la ética ambiental. Una antología de textos contemporáneos. pp.19-40. Plaza y Valdés. México

O’Connor, J. (1988). “Capitalism, Nature, Socialism: A Theoretical Introduction” en Capitalism, Nature, Socialism. A Journal of Socialist Ecology, № 1, Fall.

O’Connor, J. (1989). "Socialism and ecology”. Capitalism nature socialism. num 2. pp. $5-11$

Poggiese, H. (2001). “Alianzas transversales, reconfiguración de la política y desarrollo urbano: escenarios del presente y del futuro", en Ana Clara Torres Ribeiro, (comp.) Repensando la experiencia urbana de América Latina: cuestiones, conceptos y valores. Grupo de Trabajo Desarrollo Urbano de CLACSO.

Reagan, T. (1981). "The Nature and Possibility of an Environmental Ethics". Envirnomental Ethics 3. pp 19-34.

Reagan, T. (1986). The case for animal rights. University of California Press. Berkeley.

Reagan, T. (1998). "Derechos animales e injusticias humanas" en Kwiatkowska, T. e Issa, J. (comp.) Los caminos de la ética ambiental. Una antología de textos contemporáneos. Plaza y Valdés. México.

Reagan, T. (ed.) (1980). Matters of life and death. McGraw-Hill. New York

Redín M.E. y Morroni W. (2002). “Aportes metodológicos para la ampliación democrática de la toma de decisiones y la participación social en la gestión sociourbana" en su Gestao Democratica das Cidades, metodologías de participación, redes y movimientos sociales. Brasil.

Riechmann, J. (2004). "Hacia una agroética. Considerciones sobre ética, ecología y actividad agropecuaria" en Riechmann, Jorge (coord.) Etica Ecológica. Propuestas para una reorientación. Nordan comunidad. Uruguay

Sapontzis, S. (1987). Morals, Reasons and Animals. Temple University Press Philadelphia.

Sierra Alvarez, J. (1984). "De las utopías socialistas a las utopías patronales: para una genealogía de las disciplinas industriales paternalistas." Reis 26. pp. 29-44 
Singer, P. (1980). "Matters of life and death" en Reagan, T. (ed.) (1980) Animals and the value of life. New Cork.

Singer, P. (1998). "Los animales y el valor de la vida" en Kwiatkowska, T. e Issa, J. (comp.) Los caminos de la ética ambiental. Una antología de textos contemporáneos. Plaza y Valdés. México.

Singer, P. (1999). Liberación animal. Trotta. Madrid.

Taylor, P. (1986). Respect for nature, Princeton University Press. EEUU

Valdés, M (comp.) (2004). Naturaleza y valor.Una aproximación a la ética ambiental, México D.F., UNAM-FCE.

Vila Valenti, J. (1984). Las distintas visiones geográficas de las relaciones entre Naturaleza y Hombre. Revista de Geografia, vol. XVIII. Pp. 5-17

\section{Teoría de género}

Agarwal, B. (1998). "El género y el debate medioambiental: lecciones desde la india" en Agra Romero, María Xosé (comp.) Ecología y Feminismo. Ecorama. Granada-España. Pp.179-226

Agarwal, B. (2002). Are We Not Peasants Too? Land Rights and Women's Claims in India. The Population Council, New York

Agarwal, B. (2003 a). "Gender and land rights revisited: exploring new prospects via the state, family and market". Journal of Agrarian Change 3 (1-2). Pp. 184-224.

Agarwal, B. (2003 b). "Gender inequality, cooperation and environmental sustainability” en Jean-Marie Baland, Samuel Bowles y Pranab Bardhan (eds.) Inequality, Collective Action and Environmental Sustainability. Russell Sage, New York

Agra Romero, M.X. (comp.) (1998). Ecología y Feminismo. Ecorama. España.

Amorós, C. (1994). Historia de la teoría feminista. Univ. Complutense de Madrid. España.

Amorós, C. (1996). "Prólogo" en Femeninas, María Luisa (1996) Inferioridad y Exclusión. Un modelo para desarmar. Nuevo hacer. Argentina

Amorós, C. (2000). Feminismo y Filosofía. Síntesis, Madrid. 
Amorós, C. (2008). Mujeres e imaginarios de la globalización. Reflexiones para una agenda teórica global del feminismo. Homosapiens. Argentina.

Amorós, C. (Dir.) (1992). Actas del Seminario Permanente "Feminismo e Ilustración. 1988-1992”. Instituto de Investigaciones Feministas de la Universidad Complutense. Madrid

Amstrong, N. (1991). Deseo y ficción doméstica. Ed. Cátedra. Madrid

Barros Freitas, L. (2004). Discriminación sexista y otras formas de violencia estructural e institucional contra la mujer. Tesis doctoral. Universidad Carlos III de Madrid Instituto de Derechos Humanos Bartolomé de las Casas Doctorado en Derecho Programa Derechos Fundamentales

Beauvoir, S. (2005). [1949] El Segundo Sexo. Cátedra. Madrid.

Beer, U. (1990). Geschlecht, Struktur, Geschichte. Soziale Konstituierung des Geschlechterverhältnisses. Campus. Frankfurt.

Benhabib, S. (1987). “The generalized and the concrete other”. En Kittay, E. y Meyers, D. (eds) Women and moral theory. Rowman y Allenheld. Totowa N.J.

Benjamín, J. (1985). "The bonds of love: racional violence and erotic domination" en Einsenstein, H. y Jardine, A. (eds) The future of difference. Rutgers University Press. New Brunswick

Biehl, J. (1991). Rethinking Ecofeministy Politics. South End Press. Boston.

Blum, L.A. (1980). Friendship, altruism and morality. Routledge \& Kegan Paul. Boston and London

Bordo, S. (1986). “The Cartesian Masculinization of Thought” Signs, Vol. 11 No. 3. pp. $439-456$

Boserup, E. (1970). Women's Role in Economic Development. George Allen \& Unwin. Londres.

Braidotti, R. (1994). Women, the environment and sustainable Development: towards a Theoretical sintesis. Ed. Zed Books. Londres.

Braidotti, R. (2000). Sujetos nomádicos. Paidos. Buenos Aires. 
Butler (1990). Gender Trouble: Feminism and the Subversion of Identity. Routledge. USA. (Edición española (2001) El género en disputa. El feminismo y la subversión de la identidad. Paidós. México).

Butler J. (1998). "Sexo y género en El segundo sexo de Simone de Bauvoir". Revista MORA N 4 (1986) versión original "Sex and Gender in Simone de Beauvoir's Second Sex." Yale French Studies No 72. Pp. 35-49

Butler, J. (1997). “Sujetos de sexo/ género / deseo". Feminaria año X, N 19. pp 1-20

Butler, J. (1999). Subjects of desire. Hegelian Reflections in Twentieth-Century France. Columbia University Press. New York.

Casale, R. (2006). "Deseo y producción de agencia en Judith Butler” en Femenías, M.L. (comp.) (2006) Feminismos de Paris a La Plata. Catálogos. Argentina.

Cavana, M.L; Puleo, A.y Segura C. (2004). Mujeres y Ecología. Historia, Pensamiento, Sociedad, ed. Almudayna, Madrid.

Cochrane, Regina (2006). "No son realmente pobres": en Ecofeminismo, justicia global y pobreza "culturalmente percibida" Taller Otro mundo es necesario: Justicia, desarrollo sustentable y soberanía Center for Global Justice 19 al 26 de Julio de 2006

Collin, F. (2006). Praxis de la diferencia. Liberación y libertad. Ed Icaria. Barcelona.

Chodorow, N. (1979). The reproduction of mothering. University of California Press. Bekerley

Chodorow, N. (1985). "Gender, relation and difference in psychoanalyst perspective" en Einsenstein, H. y Jardine, A. (eds) The future of difference. Rutgers University Press. New Brunswick.

Del Valle, T. (1997). Andamios para una nueva ciudad. Lecturas desde la antropología. Cátedra. Madrid

Delphy, C. (1977). The Main Enemy: A Materialist Analysis of Women's Opresión.: WRRC Publication London.

Femenías, M.L. (1996). Inferioridad y Exclusión. Un modelo para desarmar. Nuevo hacer. Argentina. 
Femenías, M.L. (2007). El género del multiculturalismo. Universidad Nacional de Quilmes. Buenos Aires.

Femenías, M.L. (comp.) (2006). Feminismos de Paris a La Plata. Catálogos. Argentina.

Ferrere, M. y Hess, B. (1985). Controversy and Coalition: The new Feminist Movement. G.K. Hall. Boston

Fox Keller, E. (1991). Reflexiones sobre género y ciencia, Alfonso el Magnànim, Valencia.

Fraser, N (1997). Justice Interruptus: Critical Reflections on the "Postsocialist" Condition. Routledge. New Cork.

Fraser, N. (1989). "Usos y abusos de las teorías francesas del discurso para la política feminista" en: Hypatia, Buenos Aires.

Galster, I. (1997). "Entre Hagiografía y Matricido. La recepción actual de la Obra de Simone de Beauvoir". Utopía y praxis latinoamericana Año 2 №3. pp 71-76.

García Alonso, R. (2007). "Feminismo, espacio público, ciudadanía y democracia deliberativa". Revista de ciencias jurídicas y sociales SOCIUS №3. http://www.socius.es/numeros/numero_3/feminismo.pdf

García Escribano, J.J. y L. Frutos Balibrea (1999). "Mujeres, hombres y participación política. Buscando las diferencias”. Reis 86. pp. 307-329

García Gómez Heras, J.M. (2005). “Ética y medioambiente. La descomposición y reconposición de la razón práctica" Isegoría 32. pp. 63-94

Gilligan, C. (1982). In a different voice. Hardvard Univertçsiy press. Cambridge

Gilligan, C. (1987). “Moral orientation and moral development” En Kittay, E. y

Meyers, D. (eds) Women and moral theory. Rowman y Allenheld. Totowa N.J.

Guerra Palmero, M.J. (2004). “¿un vínculo privilegiado mujer-naturaleza? Rachel Carson y el tránsito de la sensibilidad naturalista y la conciencia ecológica" en Cavana, María Luisa; Puleo, Alicia; Segura, Cristina (coords) Mujeres y Ecología: historia, pensamiento y sociedad. Al-Mudayna. Madrid.

Guerra Palmero, M.J. (2006). “Algunas notas sobre feminismo global. Mujeres, cultura e igualdad"en Femenías, M.L. (comp.) (2006) Feminismos de Paris a La Plata. Catálogos. Argentina. 
Guerra y Aranzazu Hernández, M.J. (2005). "Mujeres, desarrollo y medio ambiente: hacia una teoría ecofeminista de la justicia”. Isegoiria 32. pp. 185-200

Haraway, D. (1988). "Situated Knowledge: The Science Question in Feminism as a Site of Discourse on the Privilege of Partial Perspective". Feminist Studies, 14 (3), pp. 575-99

Haraway, D. (2004). Testigo modest@del Segundo Milenio.

HombreHembra®_Conoce Oncoratón ${ }^{\circledR}$. Feminismo y tecnociencia. UOB. Barcelona.

Haraway, D. (1999). "La promesa de los monstruos: una política regeneradora para otros inapropiados/bles”. Política y Sociedad 30. Pp. 121-163.

Haraway, D. (2000). How a Leaf, An Interview With Thyrza Nichols Goodeve, Routledge, New York

Haraway, D. (2003). The Companion Species Manifesto. Prickly Press Paradigm. Chicago.

Haraway, D. (2007). Ciencia, cyborgs y mujeres: La reinvención de la naturaleza. Universitat de València. Valencia. Traducción Manuel Talens

Hartmann, H. (1975). “Un matrimonio mal avenido: hacia una unión más progresiva entre feminismo y marxismo". Zona abierta 24. pp. 85-114

Holland Cunz, B. (1996). Ecofeminismos. Cátedra. Madrid.

Immler, H. y Schmied, W. (1984). Marx und die Naturfrage Ein Wissenschaftsstreit. VSA. Hamburgo.

Irigaray, L. (1978). [1974]. Speculum del otro que es mujer. Saltés. Madrid.

Jaggar, A. (1983). Feminist Politics and Human Nature, Rowan \& Allanheld. New Jersey.

Jahn, T. y Wehling, P. (1991). Ökologie von rechts. Nationalismus und Umweltschutz bei der Neuen Rechten un den "Republikanern". Campus. Frankfurt.

Joekes, S. Green, C. Y Leach, M. (2004) ."La integración del género en la investigación y las políticas ambientales" en Vazquez García, V. Y Velazquez Gutierrez, M. (comp.) Miradas al futuro. Hacia la construcción de sociedades sustentables con equidad de género. UNAM. México. 
Kothari, R. (1988). "Prólogo" en Shiva, V. Abrazar la vida. Mujeres, ecología y supervivencia. Horas y horas. España.

Lagarde, M. (1993). Los cautiverios de las mujeres. Madresposas, monjas, putas, presas y locas. UNAM. México

Le Doeuff, M. (1993). El estudio y la rueca. Cátedra. Madrid.

Mayer Tasch, P. (1985). "Die Politische Ökologie als Leitwissenschaft der Postmoderne" en Aus dem Wörterbuch del Politischen Öekologie. Pp 9-29.

Mellor, M. (1997). "Women and Nature: A privileged Standpoint?" in Mellor,M. Feminism and ecology. New York University Press. New York.

Merchant, C. (1980). The death of nature: Women, Ecology and the Scientific Revolution. Harper \& Row. Nueva York.

Mies, M. (1989). Patriarchy and Accumulation on a World Scale. Women in the International Division of Labour. Zed Books Ltd. Londres.

Mies, M. (1998). "Nuevas tecnologías de reproducción: sus implicaciones sexistas y racistas" en Mies, Marta y Shiva, Vandana La praxis del ecofeminismo. Icaria. España

Mies, M. y Shiva, V. (1998). La praxis del ecofeminismo. Biotecnología, consumo, reproducción. Icaria. Madrid

Millet, K. (1975). La política sexual. Aguilar. México.

Nicholson, L. (1990). Feminism/Posmodernism. Routledge. New York.

Oechsle, M. (1988). Der ökologische Naturalismus. Zum Verhältnis von Natur und Gesellschaft im ökologischen Diskurs. Campus. Frankfurt.

Okin, S. (1995). "Politics and the Complex Inequalities of Gender" en D. Miller y M. Waltzer, Pluralism, justice and Equality, Oxford University Press. Oxford

Pateman, C. (1988). The Sexual Contract: the end of the story?. Stanford University Press. Stanford.

Perez Naser, E. (1999). El proceso de emponderamiento de las mujeres indígenas organizadas desde una perspectiva de género. Tesis de maestría en desarrollo social. UAM Xochimilco. México 
Phillips, A. (1996). “¿Deben las feministas abandonar la democracia liberal?” En Castells, C. (comp.) Perspectivas feministas en teoría política. Paidos. Barcelona-Buenos aires.

Plumwood, v (1998). "Naturaleza, yo, y género: feminismo, filosofía medioambiental y crítica del racionalismo" en Agra Romero, M.J. (comp) Ecología y feminismo. Ecorama. España.

Plumwood, V. (1996). "Naturaleza, yo y género: feminismo, filosofía del medioambiente y crítica del racionalismo". Mora Revista del área Interdisciplinaria de Estudios de la Mujer. №2. Noviembre. Pp. 35-59

Plumwood, V. (2004). “Feminismo y Ecología ¿Artemisa versus Gaia?” en Cavana M.L., Puleo, A. Segura, C. (coords) Mujeres y ecología: Historia, pensamiento y sociedad. Asociación Cultural Al-Mudayna. Madrid.

Poole, R. (1990). "Modernity, rationality and "the masculine"”. En Threadgold, T. y Cranny, F. (eds) Feminity/Masculinity and representation. George Allen and Unwin. Sidney.

Portolés, A.O. (2005). "las teorías de las mujeres como clase social: Chistine Delphy y Lidia Falcon" en Amorós, C. y A de Miguel (comps) teoría feminista: de la ilustración a la globalización. Minerva. Madrid

Preciado, B. (2005). “Savoirs_Vampires@War”, Multitudes, $\quad \mathrm{n}^{\mathrm{o}} 20$. http://multitudes.samizdat.net/spip.php?article2576

Puleo, A. (1992). Dialéctica de la sexualidad. Género y sexo en la Filosofía Contemporánea, Cátedra, Madrid.

Puleo, A. (2000). "Hacia una redefinición filosófico-política de "Naturaleza" y "ser humano", en Amorós, Cèlia (dir.), Filosofía y género, ed. Síntesis, Madrid. Pp.165-190.

Puleo, A. (2005). "Del ecofeminismo clásico al deconstructivismo: principales corrientes de un pensamiento poco conocido" en Celia Amorós y Ana de Miguel (Ed) Teoría feminista. De la ilustración a la globalización, vol.3. Ed. Minerva. Madrid. Pp: 121-154

Puleo, A. (2006). "Ideas que mueven el mundo: el contrato sexual" Diario El País 4 de noviembre de 2006 
Rocheleau, D. (1995). "Gender and biodiversity: A Feminist Political Ecology Perspective" en International Development Studies Bulletin 26 (1). pp: 9 a 16.

Rosenthal, A. (1973). “Feminism Without Contradictions”. Monist 57. pp. 28-42.

Sandoval, Chela (2000). Methodology of the oppressed. University of Minnesota Press. Minneapolis.

Santa Cruz, I. (1992). "Sobre el concepto de igualdad: algunas observaciones". Isegoría $\mathrm{N}^{\mathrm{o}} 6 . \mathrm{pp} 145-152$

Segales Kirzner, M. (2006). “Ciencia (económica), Naturaleza y Género”. X Jornadas de Economía Crítica “_alternativas al capitalismo?” Barcelona 23-35 de marzo de 2006.

Shiva, V. (1995). [1988]. Abrazar la vida, mujer, ecología y supervivencia. Horas y horas. Madrid

Stage, M. (1997). Woman the hunter. Beacon. Boston

Tafalla, M. (2005). "Por una estética de la naturaleza: la belleza natural como argumento ecologista”. Isegoría 32: 215-226

Valcarcel, A. (2007). "Conferencia mesa redonda: Nuestros Logros en el Poder, Nuestros Logros en el Saber" Instituto de la Mujer. España. http://www.soyempresaria.com/aplicacion/AF.php? accion $=$ pag_blanca\&clave_f $=$ palcong\&id_pagBla $=10$

Vazquez García, V. (2007). "Genero y pesca en el México indígena. Implicaciones para la política ambiental" Territorios 16-17.pp 90-106

Vianello, M. y Camarazza, E. (2002). Género, espacio y poder, Cátedra, Valencia.

Warren, K. (1987). "Feminism and Ecology: Making Connections". Environmenthal Ethics 12 (2). Pp. 121-146

Warren, K. (2000). Ecofeminist philosophy: a western perspectiva on what it is and why it matters, Rowman and Littlefield, Lanham

Warren, K. (1990). "The power and promise of ecological feminism" Environmenthal Ethics 12 (2). Pp. 121-146 
Young, I.M. (2005). "Structural injustice and the politics of difference" en Young, I y Fraser, N. (ed) (2005): Les dones I les transformacions de la justicia. CUIMPB. Barcelona.

Young, I.M. (1997). Intersecting Voices: Dilemmas of Gender, Political Philosophy, and Policy. Princeton University Press. EEUU

Young, K. (1995). Planning Development with women. McMillan, Londres.

\section{Obras de consulta en filosofía y lingüística}

Abbagnano, N (1993). Storia della Filosofia vol settimo. La filosofia contemporanea 1. di Giovanni Fornero. TEA. Milan.

Adorno, T. (1994). Actualidad de la Filosofia. Planeta-Agostini. Barcelona.

Aristóteles (1999). Politica. Biblioteca Virtual Miguel de Cervantes. Alicante. Traducción Patricio de Azcárate

Aristóteles (1990). Historia de los animales. Akal. Madrid

Aristóteles (1987). Tratados breves de historia natural. Ed. Gredos. Madrid.

Aristóteles (1978). Metafísica. Sudamericana. Buenos Aires. Traducción Hernán Zucchi.

Attfield, R. (2005). Generaciones futuras: considerando todas las partes afectadas. Isegoría $32: 35-46$

Benjamin, W. (1987). Obras Escolhidas Vol. 1. Brasiliense. São Paulo.

Blauberg-P. Kopnin-Pantin. (1975). Diccionario de Filosofia Marxista. Venezuela. Ediciones Armadillo. Caracas.

Bloch, E. (1983). Sujeto objeto. En el pensamiento de Hegel. Fondo de Cultura Económico. México

Bourdieu, P. (1999). Meditaciones pascalianas. Anagrama. Barcelona.

Butler, J. (1999). Subjects of desire. Hegelian Reflections in Twentieth-Century France. Columbia University Press. New York.

Collingwood, R.G. (1981). Idea de la Historia. FCE. Buenos Aires

de Bustos, E. (2000). La metáfora. Ensayos Transdiciplinares. FCE. Buenos Aires. 
Eliade, M. (1972). El mito del eterno retorno. Alianza. Madrid.

Eliade, M. (1992). Mito y realidad. Labor. Barcelona.

Engels, F. (1875). "Introducción $a$ La Dialéctica de la Naturaleza" en C. Marx y F. Engels, (1974) Obras escogidas, en tres tomos, Editorial Progreso, Moscú.

Foucault, M. (2000). Defender la sociedad. Fondo de Cultura Económica. Buenos Aires

Foucault, M. (1976). Vigilar y Castigar. Nacimiento de la prisión. Siglo Veintiuno Editores. Madrid.

Fourier, C. (1972).[1808]. La armonía pasional del nuevo mundo. Taurus. España.

García Canclini, N. (1984). “Gramsci con Bourdieu. Hegemonía, consumo y nuevas formas de organización popular" Nueva Sociedad 71. Pp. 69-78

Gilson, D. (1980). De Aristóteles a Darwin (y vuelta). Universidad de Navarra. Pamplona

Gilson, E. (1988). De Aristóteles a Darwin (y vuelta). Eunsa, Pamplona.

Gimbernat O. J.A (1993). "La filosofía de la historia de Ernst Bloch". Anthropos: Boletín de información y documentación, $\mathrm{N}^{\circ}$ 146-147. pp. 98-101

González, A. (1997). Estructuras de la praxis. Ensayo de una filosofía primera. Trotta Madrid.

Gramci, A. (1972). Introducción a la Filosofía de la praxis. Ediciones Península, Barcelona

Grene, M.(1985). Descartes. The Harvester Press. Brighton. Sussex.

Guthrie, W.K.C. (1981). Historia de la Filosofía Griega. VI Introducción a Aristóteles. Gredos. Madrid

Hartmann, N. (1960). La Filosofía del Idealismo Alemán, Tomo I, Editorial Sudamericana, Biblioteca de Filosofía, Buenos Aires.

Horkheimer, M. y Adorno, T. (1997). Dialéctica de la ilustración. Fragmentos filosóficos. Trotta. Madrid. Trad. Juan José Sanchez

Hume, D. (1994). [1748]. Investigación sobre el conocimiento humano. Altaya. Barcelona. Traducción Jaime de Salas Ortueta. 
Kant, I. (2007). [1790]. Crítica del Juicio, edición de Juan José García Norro y Rogelio Rovira, Editorial Tecnos. Madrid. Traducción de Manuel García Morente.

Kant, I. (1969). [1755]. Historia general de la naturaleza y teoría del cielo. Juárez Editor. Buenos Aires.

Kittay, E.F. (1987). Metaphor: Its Cognitive Force and Linguistic Structure. Clarendon Press. Oxford.

Kojeve, A. (1987). La dialéctica del amo y del esclavo en Hegel. La pléyade. Argentina. Trad. Juan José Sebreli.

Kropotkin, P. (2002). La moral anarquista. Los libros de la Catarata. Madrid.

Kropotkin, Peter (1902). Mutual Aid. Heinemann. Londres.

Kropotkin, Peter (1976). Landwirtschaft, Industrie und Handwerk. Kramer. Berlin.

Kropotkin, Peter (1989). Die Eroberung des brotes. Wolfgang Haug. Berna.

Larizza, M. (1970). Presupuestos del anarquismo de Charles Fourier. Zero. España

Lins Ribeiro, G. (2006). "Poder, redes e ideología en el campo del desarrollo" serie antropología 383. Brasília

Locke, J. (1984). Ensayo sobre el entendimiento humano. Sarpe. Madrid. Trad. Luis Rodriguez Aranda.

Lyotard, J. (1984). la condición posmoderna. Cátedra. Madrid.

Lloyd, G. (1983). “Public Reason and Private passion”. Metaphilosophy 14. pp. 308-26

Lloyd, G.E.R (1977). de Tales a Aristóteles. Eudeba. Buenos Aires

Marcuse, H. (1968). El hombre unidimensional. Seix Barral. Barcelona.

Ochman, M. (2004). "Sociedad civil y participación ciudadana”, Revista Venezolana de Gerencia (RVG) Año 9. № 27. pp. 473-489

Revueltas, J. (1986). Dialéctica de la conciencia. Ed. Era, Vol. 20 (Obras completas), México.

Segura Cortés, E. (1980). "El jardín de Epicureo". Revista de Comunicación Volumen 1, Año 4, No 4. 
Torralba, J.M. (2005a). Acción, intensión y razonamiento práctico según G.E.M. Anscombe. Ediciones Universidad de Navarra. Pamplona.

Yarza, I. (2008). "Sobre la praxis aristotélica". Universidad de Navarra. http://hdl.handle.net/10171/2252

\section{Obras de consulta en Historia y Antropología}

Anderson. P. (1989). El Estado absolutista. Siglo XXI. Madrid

Anderson. P. (1993). Transiciones de la antiguedad al feudalismo. Siglo XXI. Madrid

Bateson, G. (1999). Pasos hacia una ecología de la mente. Ed. Lohlé-Lumen. Buenos Aires.

Bronfenbrenner, U. (1987). La ecología del desarrollo humano. Paidós. Madrid.

Clifford, J. (1997). Routes: travel and translations in the late twenty century. Harvard University Press. Cambridge.

Descola, P. (1996). La selva culta: Simbolismo y praxis en la ecología de los achuar. Abya Yala. Ecuador

Fontana, J. (2006). "El agotamiento del modelo académico tradicional (1918-1939)" en su La Historia de los hombres: el siglo XX. Editorial Crítica. España

Fontana, J. (1992). La Historia después del fin de la Historia.Crítica. Barcelona.

Fortunato, N. (2005). "El territorio y sus representaciones como fuente de recursos turísticos. Valores fundacionales del concepto de "parque nacional". Estudios y Perspectivas en Turismo, Volumen 14, Número 4. pp. 314-348.

Fuentes, D. (2007). "La historia oral: apuntes teóricos y metodológicos" en Fuentes, R. y Núñez, P. Sectores populares, identidad cultural e historia en Bariloche. Núcleo Patagónico. Argentina.

Fuentes, R. (2004). "Fragmentación social e identidad barrial. Los Barrios Pilar 1 y 2 de Abril de San Carlos de Bariloche (1995-1999)". Tesis de Licenciatura en Historia. Universidad Nacional del Comahue. Inédito.

Fuentes, R. y Núñez, P. (ed.) (2007). Sectores populares, identidad cultural e historia en Bariloche. Núcleo Patagónico. Argentina. 
Fuentes, R. y Núñez, P. (ed.) (2008). Robles - Pilar 1: identidad y lucha por la tierra en San Carlos de Bariloche. Núcleo Patagónico. Argentina

Geertz, C. (1983). local knowledge: Further Essays in interpretive anthropology. Basic Books. New York.

Godelier, M. (1978). Economía, fetichismo y religión en las sociedades primitivas. Siglo Veintiuno Editores. México.

Guha, R. (1988). "Subaltern Studies: Deconstructing Historiography", in Selected Subaltern Studies, Oxford U Press,

Hall, E.T. (1973). La dimensión oculta: enfoque antropológico del uso del espacio, Instituto Nacional de la Administración Pública, Madrid.

Halperin Dongui, T. (1992). Una Nación para el desierto argentino. CEAL. Argentina

Hammer, D. y Widavsky, A. (1990). "Entrevista semiestructurada de final abierto", en: Historia y Fuente Oral N ${ }^{\circ}$. Barcelona.

Harvey, K. y McClellend,K. (1980). Perspectivas críticas y conceptos fundamentales del marxismo. Alfons el Magnánim. Valencia.

Hobsbawm, E. (1998). La era del capital: 1848- 1875. Labor. España

Hobsbawm, E. (2001). La era del imperio: 1875-1914. Crítica. España

Hobsbawm, E. (2002). La era de las revoluciones: 1789-1848. Crítica. España

Hosne, R. (1998). Barridos por el viento. Historia de la patagonia desconocida. Planeta. Argentina

Ianni, O. (1992). A sociedade global. Civilizaçao Brasileira. Río de Janeiro.

Jay, M. (1974). La imaginación dialéctica. Taurus. Madrid.

Levi-Strauss, C. (1996). Mitológicas. FCE. México.

Levi-Strauss, C. (1997). El pensamiento salvaje. Fondo de Cultura Económica. México.

Marglin, S. (1988). "Losin touch: The cutural conditions of worker Accommodation and resistente" en Frederique Marglin y Stephen Marglin Knowledge and Power. Oxford University Press. Oxford. 
Margulis, M. (1988). "Cultura y discriminación social en la época de la globalización”, en: Bayardo, R., y Lacarrieu, M. (comp.). Globalización e identidad cultural. Editorial Ciccus. Buenos Aires.

Marinas, J.M. y Santamarina, C. (comp.) (1993). La Historia oral: Métodos y experiencias. Debate. Madrid.

Mendez, L e Iwanow, V. (2001). Bariloche: las caras del pasado. Novedades Educativas. Argentina.

Mignolo, W. (2003). Historias locales/diseños globales: Ensayos sobre los legados coloniales, los conocimientos subalternos y el pensamiento de frontera, Akal, Madrid.

Moyano, A. (2007). Crónicas de la resistencia Mapuche. Adrián Moyano. Buenos Aires.

Navarro Floria, P. (2007a). "Paisajes de un progreso incierto. La norpatagonia en las revistas científicas argentinas (1876-1909)" en su Paisajes del progreso. La resignificación de la Patagonia Norte. 1880 - 1916. Universidad Nacional del Comahue. Argentina

Navarro Floria, P. (coord) (2007b). Paisajes del progreso. La resignificación de la Patagonia Norte. 1880 - 1916. Universidad Nacional del Comahue. Argentina

Nelson J.G., Needham R.D., y Mann D.L. (eds.) (1978). International experience with National Parks and Related Reserves. Publication Series No. 12 University of Waterloo. Waterloo, Ontario.

Noske, B. (1989). Humans and Others Animals, Beyond the Boundaries of Antropology. Pluto Press. Londres.

Núñez, P. (2007). "La dinámica de una localidad desde la articulación de sus instituciones. El municipio de San Carlos de Bariloche, el Club Andino y Parques Nacionales (1931 - 1955)" En Iuorno, G. y Crespo E. Nuevos espacios, nuevos problemas. Universidad Nacional del Comahue. Argentina.

Núñez, C. Fuentes, R. y Núñez, P. (2008). "Paisajes invisibles y voces silenciadas" en Fuentes, R. y Núñez, P. (ed) Robles - Pilar 1: identidad y lucha por la tierra en San Carlos de Bariloche. Núcleo Patagónico. Argentina 
Oelschlaeger, M. (1991). The Idea of Wilderness: From Prehistory to the Age of Ecology. New Haven. Yale University Press.

Fraser, R. (1990). "La formación de un entrevistador", en: Historia y Fuente oral N³. Barcelona.

Sánchez D., Sassone S. y Matossian B. (2007). "Barrios y áreas sociales de San Carlos de Bariloche: Análisis geográfico de una ciudad fragmentada”. Sesión 16 Aspectos sociodemográficos de la Región Patagonia, IX Jornadas Argentinas de Estudios de Población, Asociación de Estudios de Población de la Argentina. Córdoba.

Schwarzstein, D. (comp.)(1991). La historia oral. CEAL. Buenos Aires.

Segato, R. (2007). La nación y sus otros. Raza, etnicidad y diversidad religiosa en tiempos de políticas de la Identidad. Prometeo. Argentina

Shanin, T. (1988). El Marx tardío y la vía rusa. Revolución. Madrid.

Storey, J. (1993). An introductory Guide to cultural Theory \& Popular culture. Harvester Harvester Wheatsheaf. Nueva York y Londres.

Tevoedjre, A. (1980). Poverty: Wealth of Mankind. Pergamon Press. Oxford.

Thompson, E.P. (1988). La voz del Pasado. Historia Oral. Edicions Alfons. Valencia.

Vallmitjana, R. (1993). 90 años de turismo en Bariloche. Bariloche.

\section{Fuentes documentales y literarias}

Anasagati, H.; Windhausen, A. Hosseus, C. Frey, E. (1926). "El Parque Nacional del sud. Rasgos de la geografía física, de la historia y del porvenir de la región del lago Nahuel Huapi” en: GAEA Anales de Estudios geográficos. T.II N2 Buenos Aires.

Bustillo E. (1971). El despertar de Bariloche Buenos Aires, Casa Pardo.

Cambaceres, E. (1887). En la sangre. Imprenta de Sud América. Buenos Aires

Evans, Clery (1994). Una historia entre Gales y la Colonia 16 de octubre. John Daniel Evans "el molinero". Clery Evans. Trevelin-Chubut.

Hudson, W. (1997). Días de ocio en la Patagonia. El Elefante Blanco. Buenos Aires. 
Rapoport, E. (2006). "Entrevista" realizada por Núñez, P. en el marco de la recopilación de datos para la realización de la tesis "Entre la Ciencia "ideal" y la "real" El problema de la producción de conocimiento en el laboratorio de Ecología Ecotono. Redactada en para la Maestría en Filosofía e Historia de las ciencias. Universidad Nacional del Comahue. Inédita.

Willis, B. (1988) El norte de la Patagonia. Eudeba. Argentina. 